\title{
Eksponencijalne atomske bazne funkcije : razvoj i primjena
}

\section{Brajčić Kurbaša, Nives}

Doctoral thesis / Disertacija

2016

Degree Grantor / Ustanova koja je dodijelila akademski / stručni stupanj:

University of Split, Faculty of Civil Engineering, Architecture and Geodesy / Sveučilište u Splitu, Fakultet građevinarstva, arhitekture i geodezije

https://doi.org/10.31534/DocT.041.BraN

Permanent link / Trajna poveznica: https://urn.nsk.hr/urn:nbn:hr:123:911031

Rights / Prava: In copyright/Zaštićeno autorskim pravom.

Download date / Datum preuzimanja: 2023-04-26

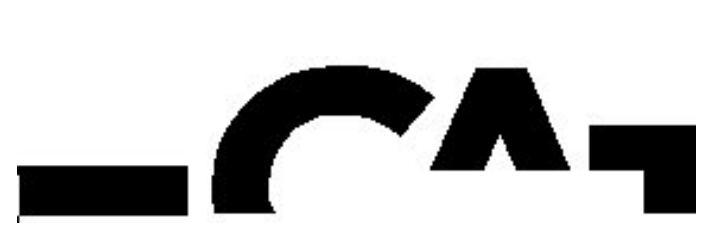

Repository / Repozitorij:

FCEAG Repository - Repository of the Faculty of Civil Engineering, Architecture and Geodesy, University of Split

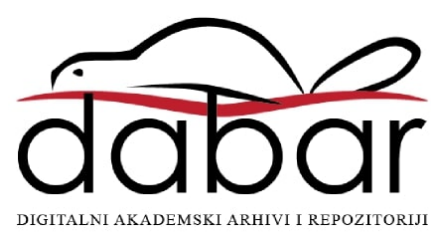




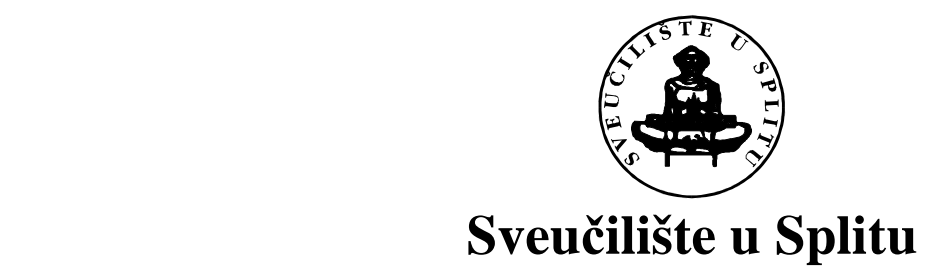

FAKULTET GRAĐEVINARSTVA, ARHITEKTURE I GEODEZIJE

Nives Brajčić Kurbaša, dipl. ing. građ.

\title{
EKSPONENCIJALNE ATOMSKE BAZNE FUNKCIJE: RAZVOJ I PRIMJENA
}

\author{
Disertacija
}

Split, 2016. 
Nives Brajčić Kurbaša, dipl. ing. građ.

Redni broj: 041

Ova disertacija predana je na ocjenu Fakultetu građevinarstva, arhitekture i geodezije Sveučilišta u Splitu u svrhu stjecanja akademskog stupnja doktora tehničkih znanosti u znanstvenom polju građevinarstvo.

Mentor:

Komentor:
Prof. dr. sc. Blaž Gotovac, dipl. ing. građ.

Prof. dr. sc. Vedrana Kozulić, dipl. ing. građ.

Povjerenstvo za ocjenu: Prof. dr. sc. Vedrana Kozulić, dipl. ing. građ.

Prof. dr. sc. Blaž Gotovac, dipl. ing. građ.

Prof. emer. dr.sc.Josip Dvornik, dipl. ing. građ. 


\section{Povjerenstvo za obranu:}

Prof. dr. sc. Vedrana Kozulić, dipl. ing. građ.

Prof. dr. sc. Blaž Gotovac, dipl. ing. građ.

Prof. emer. dr. sc. Josip Dvornik, dipl. ing. građ.

Rad je obranjen dana: 22. travnja, 2016.

Tajnica:

Saša Delić, dipl.iur. 
Rad sadrži:

188 stranica teksta

105 crteža

10 tablica

46 citiranih referenci 
Mom Josipu... 
Na jednom ormariću u našem uredu piše:

Tko ne zna, a ne zna da ne zna,

Opasan je, izbjegavajte ga.

Tko ne zna, a zna da ne zna

Dijete je, naučite ga.

Tko zna, a ne zna da zna

Spava, probudite ga.

Tko zna i zna da zna

Mudar je, slijedite ga.

Konfucije

Posebnu zahvalnost dugujem mom mudrom mentoru, prof.dr.sc Blažu Gotovcu, na nesebičnoj pomoći, posvećenom vremenu i trudu, vodstvu i konstruktivnim kritikama svih ovih godina, vitaminima, strpljenju prema jednom temperamentnom emotivcu...

Veliko hvala i mojoj komentorici prof.dr.sc. Vedrani Kozulić na pomoći i prijateljskoj potpori.

Mojoj dragoj obitelji dugujem najveću zahvalnost. Bilo je puno lakše uz vašu bezuvjetnu podršku, ljubav, strpljenje, razumijevanje, vjeru... Nije sa mnom uvijek bilo lako... Josipe, Roza, mama, tata, Dajo, teta Mare, barba Ante, ...

Hvala vam... 
Nives Brajčić Kurbaša, dipl.ing.građ.

\section{EKSPONENCIJALNE ATOMSKE BAZNE FUNKCIJE: \\ RAZVOJ I PRIMJENA}

\section{Sažetak}

U ovom radu su sistematizirana osnovna svojstva algebarskih $\underline{\text { Atomskih }}$ Baznih $\underline{\text { Funkcija }}$ $(\mathrm{ABF})$ te su, koristeći analogan pristup, razvijene $\mathrm{ABF}$ eksponencijalnog tipa, do sada poznate samo na osnovnoj razini. Po prvi put su svojstva eksponencijalnih ABF detaljno istražena te su izvedeni izrazi za izračunavanje vrijednosti funkcije i svih potrebnih derivacija u proizvoljnoj točki područja kao i neke posebnosti potrebne za njihovu praktičnu primjenu u obliku pogodnom za numeričku analizu.

U sklopu rada izrađen je i programski modul za izračunavanje svih potrebnih veličina eksponencijalnih $\mathrm{ABF}$ čime je njihova primjena svedena na razinu korištenja korisničke ili kompajlerske funkcije uključujući i vlastitu grafičku podršku.

Prikazani verifikacijski 1D primjeri aproksimacije zadane funkcije te primjeri rješavanja diferencijalnih jednadžbi ilustriraju i potvrđuju praktičnu prednost ABF eksponencijalnog tipa u odnosu na do sada uglavnom korištene algebarske funkcije, naročito za opisivanje izraženih frontova i/ili valova sadržanih u numeričkom rješenju različitih tehničkih zadaća.

Ključne riječi: $A B F$ eksponencijalnog tipa, konvolucija, Fourierova transformacija, kompaktni nosač, frekvencija, frontovi 
Nives Brajčić Kurbaša, M.Sc.Civ.Eng.

\section{EXPONENTIAL ATOMIC BASIS FUNCTIONS: DEVELOPMENT AND APPLICATION}

\section{Summary}

In this work basic properties of algebraic Atomic Basis Functions (ABF) are systematized and, using analogous approach, $\mathrm{ABF}$ of exponential type, so far known only at the basic level, are developed. For the first time the properties of exponential ABFs are thoroughly investigated and expressions for calculating the values and all the necessary derivatives of the functions in an arbitrary points of the domain are developed as well as some special features required for their practical application in a form suitable for numerical analysis.

A software module for calculating all necessary values of the exponential ABFs, including its own graphics support, is created within this work. Thus, the exponential ABF is prepared to use as users or compiler function.

The presented 1D verification examples of the function approximation and the examples of solving differential equations illustrate and confirm the practical advantage of the ABFs of the exponential type in relation to the, so far mostly used, algebraic functions, especially for describing expressed fronts and/or waves contained in the numerical solutions of various technical tasks.

Keywords: ABF of exponential type, convolution, Fourier transform, compact support, frequency, fronts 


\section{SADRŽAJ}

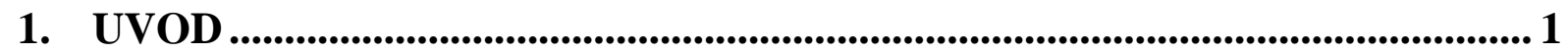

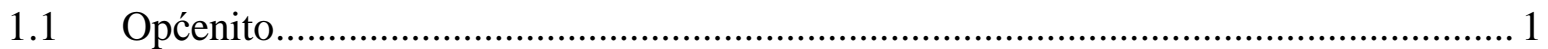

1.2 Pregled dosadašnjih istraživanja o ABF ........................................................... 2

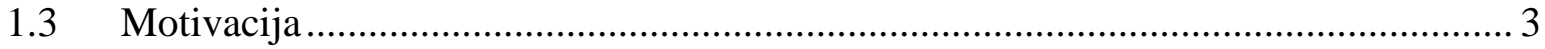

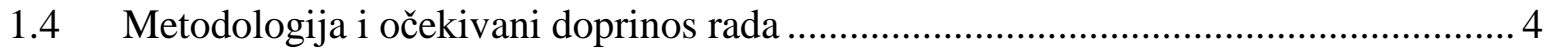

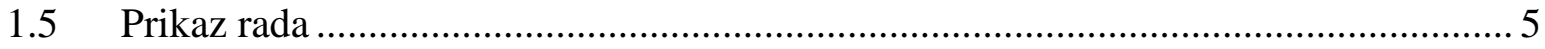

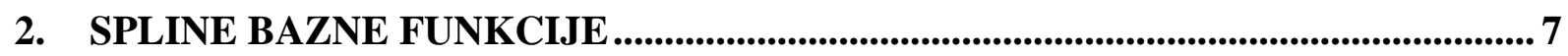

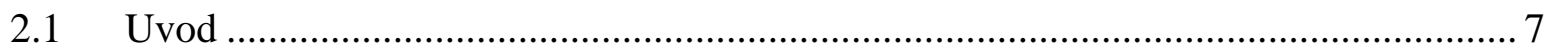

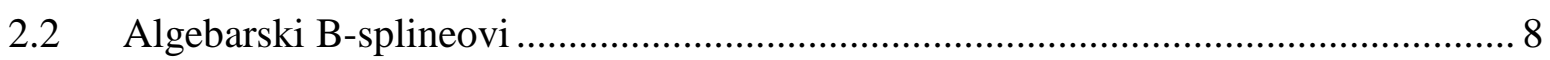

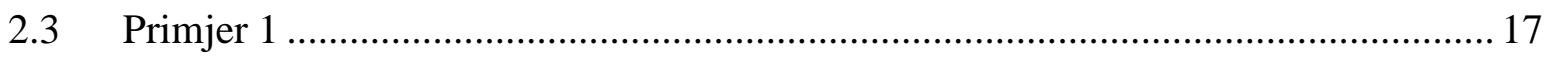

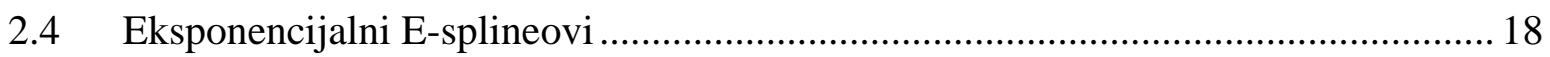

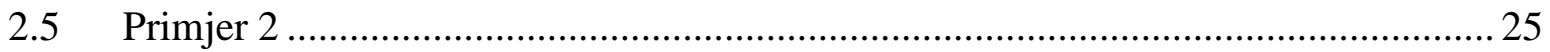

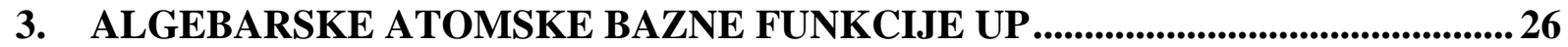

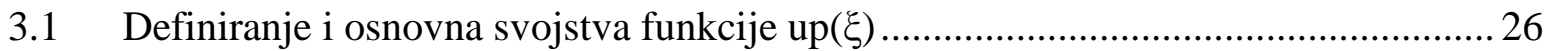

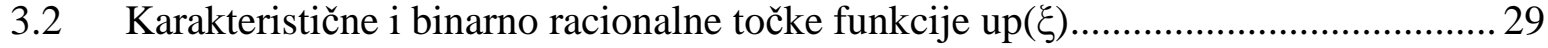

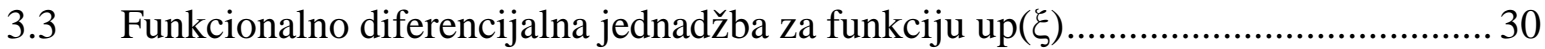




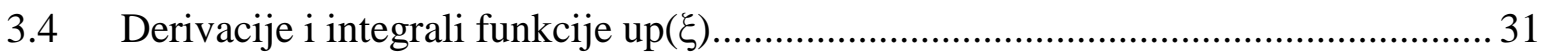

3.5 Momenti funkcije up $(\xi)$. Skalarni produkt polinoma i funkcije up $(\xi)$..................... 34

3.6 Vrijednost funkcije up $(\xi)$ u binarno racionalnoj točki........................................ 37

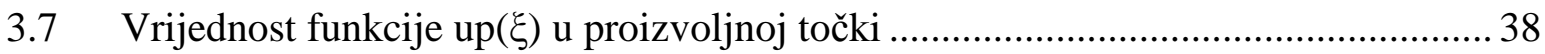

3.8 Polinom kao linearna kombinacija pomaknutih up $(\xi)$ funkcija.............................. 41

3.9 Skalarni produkt međusobno pomaknutih funkcija up $(\xi)$.................................. 45

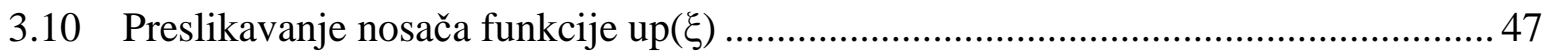

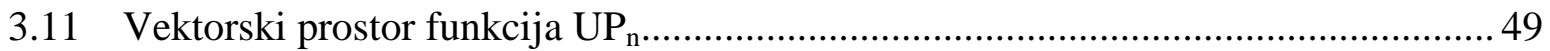

3.12 Aproksimacija zadane funkcije u obliku algebarskog polinoma........................... 49

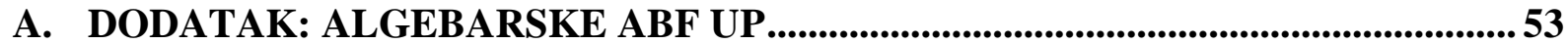

A.1. Izravno računanje vrijednosti funkcije up $(\xi)$ u točkama tipa $\xi_{\mathrm{n}}=-1+\mathrm{k} / 2^{\mathrm{n}} \ldots \ldots \ldots \ldots . .53$

4. ALGEBARSKE ATOMSKE BAZNE FUNKCIJE FUP

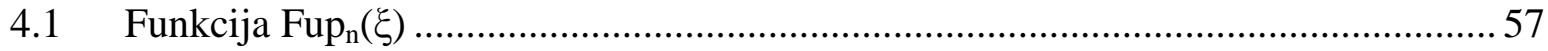

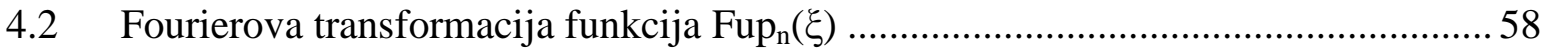

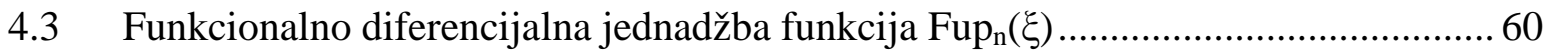

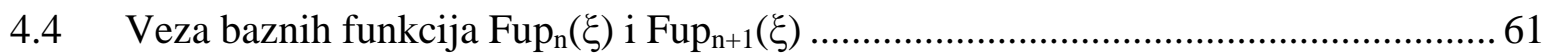

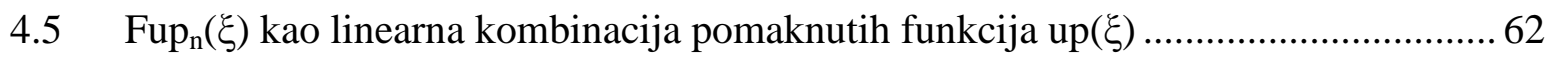

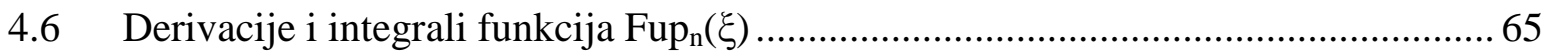

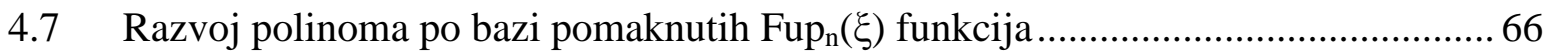

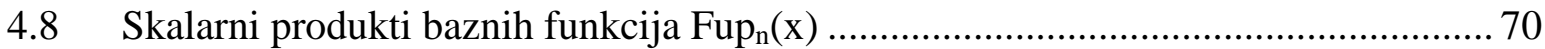

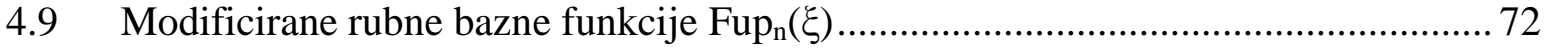

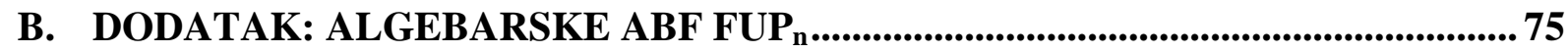

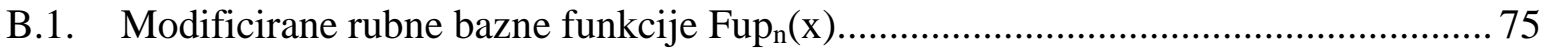

B.2. Skalarni produkt polinoma $\mathrm{x}^{\mathrm{m}}$ i funkcije Fup $\mathrm{n}(\mathrm{x})$ na karakterističnom odsječku $\Delta \mathrm{x}_{\mathrm{n}} 76$

B.3. Skalarni produkti međusobno pomaknutih baznih funkcija $\mathrm{Fup}_{2}(\mathrm{x})$ na

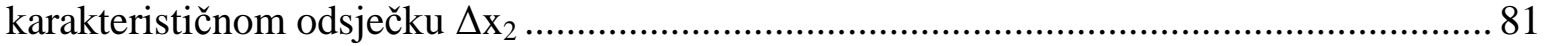


5. EKSPONENCIJALNE ATOMSKE BAZNE FUNKCIJE EUP 88

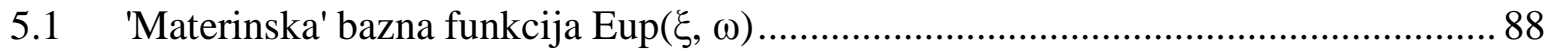

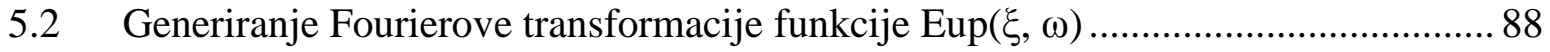

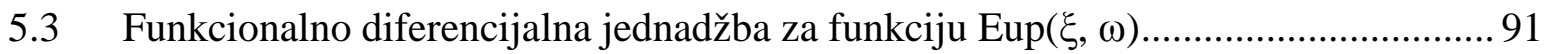

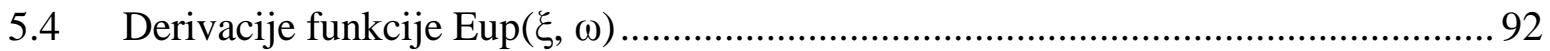

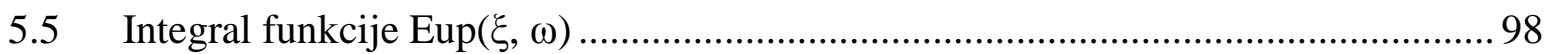

5.6 Veza baznih funkcija $\operatorname{Eup}(\xi, \omega)$ i eksponencijalnih polinoma $\mathrm{e}^{2 \mathrm{~m} \omega \xi} \ldots \ldots \ldots \ldots \ldots \ldots \ldots . . . . . . . . . . .99$

5.6.1 Primjer aproksimacije funkcije eksponencijalnog polinoma .............................. 105

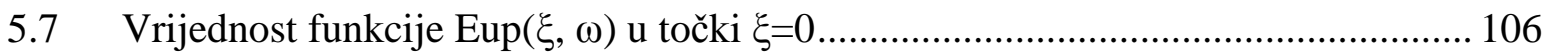

5.8 Vrijednost funkcije $\operatorname{Eup}(\xi, \omega)$ u binarno racionalnim točkama $\xi \mathrm{br} \ldots \ldots \ldots \ldots \ldots \ldots \ldots . . . . . . . . . . .108$

5.9 Vrijednost funkcije $\operatorname{Eup}(\xi, \omega)$ u proizvoljnoj točki ........................................... 110

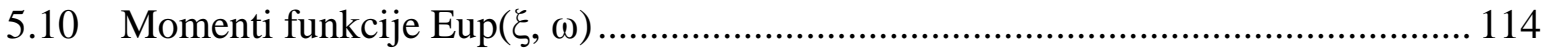

5.11 Derivacije funkcije $\operatorname{Eup}(\xi, \omega)$ u karakterističnim točkama po parametru $\omega \ldots \ldots \ldots \ldots . . .117$

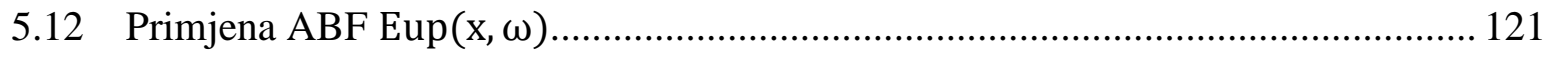

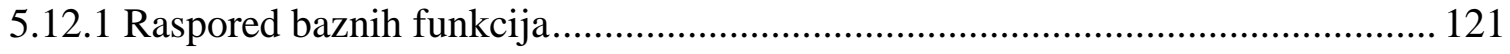

5.12.2 Aproksimacija zadane eksponencijalne funkcije e $\omega x$..................................... 122

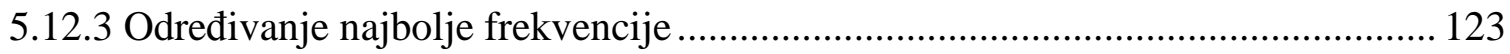

5.12.4 Aproksimacija na jednolikom (uniformnom) gridu ....................................... 125

5.12.5 Aproksimacija po nivoima (MultiLevel aproksimacija) .................................. 127

6. EKSPONENCIJALNE ATOMSKE BAZNE FUNKCIJE EFUP n $_{\text {..................... } 130}$

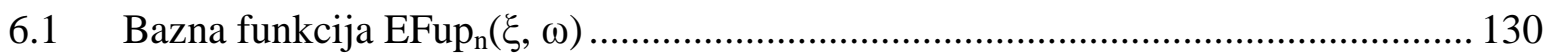

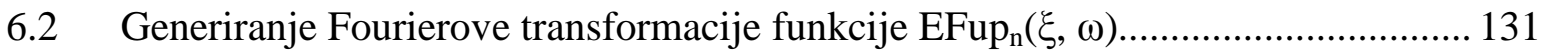

6.3 Izvod funkcionalno diferencijalne jednadžbe funkcije $\operatorname{EFup}_{n}(\xi, \omega) \ldots \ldots \ldots \ldots \ldots \ldots \ldots \ldots . . . . .136$

6.4 Vrijednosti funkcija $\operatorname{EFup}_{\mathrm{n}}(\xi, \omega)$ u karakterističnim točkama............................... 138

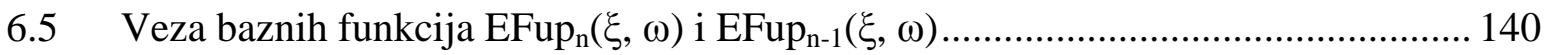

6.6 $\operatorname{EFup}_{n}(\xi)$ kao linearna kombinacija pomaknutih funkcija $\operatorname{Eup}(\xi, \omega) \ldots \ldots \ldots \ldots \ldots \ldots \ldots . . . . . . .142$ 


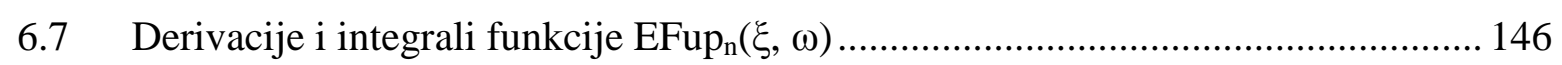

6.8 Veza funkcije $\operatorname{EFup}_{\mathrm{n}}(\xi, \omega)$ i eksponencijalnih polinoma................................... 150

6.9 Praktično korištenje eksponencijalnih ABF ..................................................... 154

7. PRIMJENA EKSPONENCIJALNIH ATOMSKIH BAZNIH FUNKCIJA ............ 156

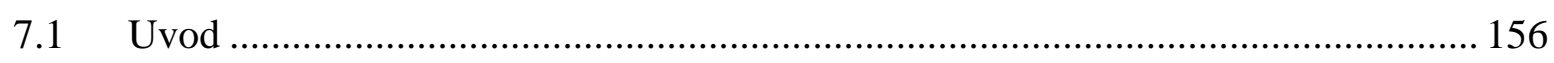

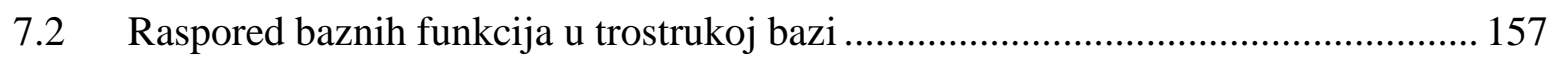

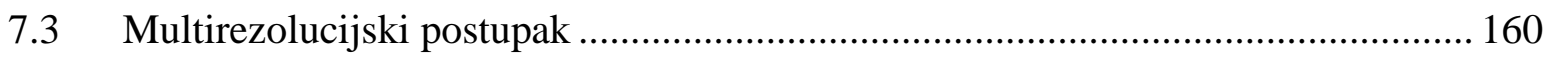

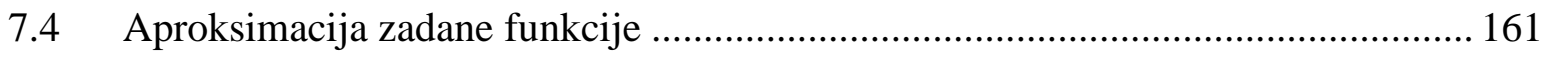

7.5 Funkcija opisana diferencijalnom jednadžbom i rubnim uvjetima ....................... 171

8. ZAKLJUČCI I PRA VCI DALJNJIH ISTRAŽIVANJA ......................................... 181

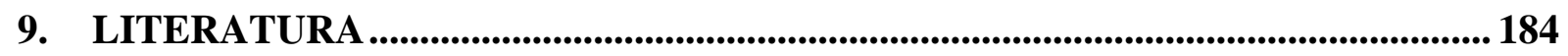




\section{UVOD}

\subsection{Općenito}

Pojava i brzi razvoj sve moćnijih elektroničkih računala dovela je do mogućnosti sve preciznije interpretacije fizikalnih procesa bilo koje vrste koji nas svakodnevno okružuju. To se najčešće postiže širokom paletom raznih numeričkih metoda.

Poseban zadatak u svim numeričkim metodama je izbor baznih funkcija.

Algebarski i trigonometrijski polinomi, kao klasične bazne funkcije, imaju veoma dobra svojstva, kao na primjer svojstvo univerzalnosti, svestrano su izučeni kriteriji konvergencije i ocjene točnosti traženih približnih rješenja. Istovremeno $s$ inženjerskog aspekta imaju i niz nedostataka. Osnovno ograničenje je nefinitnost, što ima za posljedicu punu matricu sustava jednadžbi. Te matrice su često slabo uvjetovane, a to dovodi do numeričke nestabilnosti postupka, slabe preciznosti rezultata, te veoma neekonomične procedure gledano $\mathrm{s}$ numeričkog aspekta, [6].

Zbog toga je došlo do razvoja novih baznih funkcija, npr. spline i wavelet baznih funkcija, koje posjeduju važno svojstvo finitnosti ali $\mathrm{s}$ druge strane ne posjeduju svojstvo univerzalnosti vektorskog prostora te su ograničene glatkosti što dovodi u pitanje kakvoću aproksimacije jer najčešće neprekinutost derivacija približnih rješenja, tj. flukseva predstavlja fizikalno značajniji rezultat nego sama osnovna varijabla koja se promatra.

U tom smislu, nameće se potreba za daljnjim razvojem baznih funkcija i istraživanjem njihovih svojstava koja mogu znatno poboljšati kvalitetu približnih rješenja raznih inženjerskih problema. Predmet istraživanja u ovoj disertaciji su finitne bazne funkcije s kompaktnim nosačem neograničene glatkosti koje pripadaju univerzalnom vektorskom prostoru a koje se nazivaju Atomske Bazne Funkcije (ABF). 


\subsection{Pregled dosadašnjih istraživanja o ABF}

Atomske Bazne Funkcije (ABF) su beskonačno derivabilna finitna rješenja funkcionalno diferencijalnih jednadžbi tipa

$$
L y(x)=\lambda \sum_{k=1}^{M} C_{k} y\left(a x-b_{k}\right)
$$

gdje je $L$ linearni diferencijalni operator s konstantnim koeficijentima, $\lambda$ je skalarna veličina različita od nule, $C_{k}$ su koeficijenti rješenja, $a>0$ je parametar duljine nosača finitne funkcije, $b_{k}$ su koeficijenti koji određuju pomake finitnih baznih funkcija.

Tip finitne funkcije iz klase atomskih baznih funkcija određen je izborom operatora $L \mathrm{u}$ jednadžbi (1.1). Tako razlikujemo atomske bazne funkcije algebarskog, eksponencijalnog i trigonometrijskog tipa.

Povijest atomskih baznih funkcija počinje s radom [41]. V. L. Rvačev i V. A. Rvačev 1971. godine su dokazali egzistenciju i jedinstvenost finitnog rješenja jednadžbe $y(x)=$ $2 y(2 x+1)-2 y(2 x-1)$ sa zadanim uvjetima $y(0)=1$ i $\operatorname{supp} y(x)=[-1,1]$. Ovaj problem je 1967 g. u Kharkivu postavio ukrajinski matematičar V. L. Rvačev na seminaru o problemima primijenjene matematike, a rješenje spomenutog problema povezano je $\mathrm{s}$ dolaskom prve i najvažnije atomske bazne funkcije up $(x)$, koja se zbog toga naziva još i „materinska“ atomska bazna funkcija. Zanimljivo je da je, u istoj 1971. godini, W. Hilberg u Njemačkoj objavio članak [20] koji razmatra praktički istu funkciju kao u [41] odnosno, najjednostavniju atomsku funkciju $u p(x)$, ali primijenjenu na rješavanje problema elektrotehnike.

Izraz ,atomska funkcija“ prvi put se pojavljuje 1975.g. u [42], a u nekim radovima se također nazivaju i „Rvačeve funkcije“ .

Glavni rezultati istraživanja V. A. Rvačeva i njegovih učenika za razdoblje 1971.-1986. g. o teoriji atomskih funkcija opisane su u [44], što uključuje i prikaz znatnog broja neriješenih (u to vrijeme) problema teorije atomskih funkcija.

U literaturi [6], [43], izveden je numerički povoljniji izraz za izračunavanje vrijednosti funkcije $u p(x)$, prikladan za njenu praktičnu upotrebu u računalnoj strukturalnoj mehanici, dok je u [6], [7], [24] napravljen pregled osnovnih baznih funkcija iz klase atomskih baznih funkcija. 
Najjednostavnija atomska funkcija $u p(x)$ promovirala je i točnost nekih matematičkih istraživanja u kojima je odmah primjenjivana u multirezolucijskoj analizi kreiranoj pomoću beskonačno derivabilnih funckija s kompaktnim nosačem, [4].

$\mathrm{ABF}$ algebarskog tipa istražuju se već preko 45 godina, a tek u novije vrijeme stječu zasluženu popularnost. Unatoč svojim dobrim aproksimacijskim svojstvima bile su slabo zastupljene $\mathrm{u}$ analizama te je broj autora koji ih je koristio u svojim numeričkim modelima bio prilično skroman. Jedan od razloga je zatvorenost „Kharkivške škole“ te jezična barijera. Drugi je vjerojatno činjenica da postupci izračunavanja vrijednosti atomskih funkcija u proizvoljnim točkama na prvi pogled izgledaju prilično složeno. Međutim, za praktično rješavanje inženjerskih problema dovoljno je izračunati vrijednosti jedne bazne funkcije u malom broju točaka a zatim se po određenim formulama brzo i točno izračunavaju vrijednosti svih potrebnih derivacija, integrala, skalarnih produkata odabrane bazne funkcije sa svojim derivacijama, elementarnim funkcijama, itd.

Atomske bazne funkcije koriste se za rješavanje problema procesuiranja signala [33], [34], u analizi različitih problema strukturalne mehanike i matematičke fizike [1], [8], [9], [12], [13], [16], [26], [27], [28], [29], [30], [43], a zahvaljujući svojim svojstvima veoma uspješno se mogu primijeniti za rješavanje 1D i 2D problema [3], [10], [11], [24], [25]. Razvijena je i efikasna adaptivna Fup kolokacijska metoda koja je uspješno implementirana u problemima mehanike fluida i modeliranju rubno-početnih problema [14], [15], [17], [18], [19], [31], [32]. $\mathrm{U}$ [22] je dan detaljan pregled radova koji koriste atomske bazne funkcije u raznim područjima poput: matematička analiza, teorija aproksimacije, numeričke metode i druga područja primijenjene matematike, tehnička realizacija zvonolikih funkcija, digitalna obrada signala, teorija antena, rješavanje diferencijalnih jednadžbi i rubnih problema matematičke fizike, itd.

Današnji nivo spoznaja vidljiv iz raspoloživih radova su detaljno obrađene algebarske bazne funkcije, kako klasične i splineovi, tako i atomske bazne funkcije algebarskog tipa. Atomske bazne funkcije eksponencijalnog i trigonometrijskog tipa razvijene su samo na osnovnoj razini u [5], [6].

\subsection{Motivacija}

U modernoj numeričkoj analizi gotovo se isključivo koriste algebarske bazne funkcije iako većina fizikalnih i inženjerskih problema nema rješenja iz tog vektorskog prostora. U analiziranju fizikalnih problema čije rješenje nije iz klase algebarskih polinoma javlja se 
potreba za korištenjem baznih funkcija koje će moći bolje opisati funkciju rješenja, odnosno koja će pripadati tom traženom vektorskom prostoru. Ideja da se biraju bazne funkcije koje odgovaraju klasi rješenja čije probleme rješavamo je odavno prihvaćena [6], [44], ali se u praksi rijetko provodila. Inženjerski problemi u kojima se javljaju veliki lokalni gradijenti i singulariteti zahtijevaju eksponencijalne bazne funkcije. Klasični takvi primjeri su advektivno-disperzivna (difuzna) jednadžba i jednadžba provođenja topline koje opisuju pronos/transfer mase i energije, respektivno, grede i ploče na popustljivoj podlozi, specijalni problemi gubitka stabilnosti, itd. Za dobivanje kvalitetnog numeričkog rješenja takvih problema pogodno bi bilo koristiti ABF eksponencijalnog tipa.

$\mathrm{Na}$ osnovi dobrih rezultata postignutih u korištenju ABF algebarskog tipa, proizlazi glavna motivacija za izradu ove disertacije koja ima za cilj razvijanje i istraživanje osnovnih svojstava atomskih baznih funkcija eksponencijalnog tipa te njihovo dovođenje u numerički upotrebljiv oblik za rješavanje različitih inženjerskih zadataka.

\subsection{Metodologija i očekivani doprinos rada}

Iz iskustva je poznato da se određeni fizikalni proces bolje modelira s baznim funkcijama koje su iz klase kao i samo rješenje zadanog problema. Osnovni cilj ove disertacije je istražiti atomske bazne funkcije eksponencijalnog tipa te pokazati da njihova primjena u numeričkim metodama daje bolje i stabilnije približno rješenje od baznih funkcija algebarskog tipa posebice u slučajevima s visokim gradijentima ili „frontovima“, koji se javljaju kod zahtjevnih inženjerskih problema s koncentracijama različitog tipa. Očekuje se da bi spomenute funkcije morale biti pogodne i za primjenu kod adaptivnih postupaka jer sažimanjem baznih funkcija istovremeno se povećava i frekvencija tako da se konvergencija postupka postiže pomoću dva paralelna kriterija iz čega slijedi da bi se bolja rješenja morala dobiti s daleko manjim brojem baznih funkcija.

Aktivnosti na realizaciji ovog istraživanja sastoje se u izučavanju svojstava atomskih baznih funkcija eksponencijalnog tipa do nivoa dovoljnog za praktično korištenje što znači:

- Definirati i verificirati svojstva atomskih baznih funkcija eksponencijalnog tipa kao što su derivacije, integrali, momenti funkcija i sl.

- Izraditi osnovni modul za izračunavanje materinske funkcije $\operatorname{Eup}(\mathrm{x}, \omega)$ te funkcija $\operatorname{EFup}_{n}(\mathrm{x}, \omega)$ 
- Programski modul za izračun podrazumijeva i vlastitu grafičku podršku kako bi se glavni međurezultati neposredno mogli pratiti (Fortran - Winteracter)

- Odrediti kriterij za izbor parametra $\omega$ (frekvencije) baznih funkcija

- Testirati mogućnosti praktične primjene navedenih baznih funkcija na 1D primjerima iz različitih područja tehnike.

\subsection{Prikaz rada}

U prvom poglavlju daje se kratak opis problematike izbora baznih funkcija u numeričkim metodama te pregled postojeće literature iz područja $\mathrm{ABF}$ kao i motivacija za izradu radnje, te su ukratko opisani svi dijelovi rada po poglavljima.

U drugom poglavlju prikazana su osnovna svojstva algebarskih i jedne vrste eksponencijalnih spline funkcija na osnovnoj razini zbog cjelovitosti rada.

U trećem poglavlju detaljno su prikazana poznata svojstva materinske algebarske atomske bazne funkcije $u p(\mathrm{x})$ kao prve iz klase ABF. Dan je izvod same funkcije polazeći od poznate Fourieove transformacije kao i svi izrazi potrebni za definiranje i razvoj materinske ABF eksponencijalnog tipa.

$\mathrm{U}$ četvrtom poglavlju opisane su algebarske $\mathrm{ABF} F u p_{n}(\mathrm{x})$ kao podloga za razvoj eksponencijalnih $\mathrm{ABF}$, te su postojećim izrazima pridruženi i neki novi izrazi potrebni za njihovu primjenu u numeričkim metodama kao npr. skalarni produkti te modificirane rubne funkcije.

$\mathrm{U}$ petom poglavlju izvedena je materinska $\mathrm{ABF}$ eksponencijalnog tipa $\operatorname{Eup}(\mathrm{x}, \omega)$ polazeći od Fourierove transformacije i teorema konvolucije. Izvedeni su izrazi potrebni za njenu praktičnu primjenu poput vrijednosti funkcije i željenog reda derivacije u proizvoljnoj točki nosača, integrali, momenti i sl. a primjena istih pokazana je na primjerima aproksimacije funkcije.

Analogno ABF algebarskog tipa, u šestom poglavlju izvedeni su koeficijenti za razvoj $\mathrm{ABF}$ funkcija $\operatorname{EFup}_{n}(\mathrm{x}, \omega)$ pomoću linearne kombinacije $\operatorname{Eup}(\mathrm{x}, \omega)$ baznih funkcija kao i svi izrazi potrebni za njihovu praktičnu primjenu. Opisan je programski modul EFupnM napravljen u sklopu disertacije za izračun istih. 
Primjena ABF eksponencijalnog tipa je pokazana u sedmom poglavlju na verifikacijskim 1D primjerima aproksimacije zadane funkcije te primjerima rješavanja diferencijalnih jednadžbi. Predstavljena je tzv. trostruka baza za opisivanje približnog rješenja te multirezolucijski postupak.

U osmom poglavlju iznijeti su najvažniji zaključci rada kao i pravci daljnjih istraživanja temeljeni na rezultatima prikazanima u radnji.

Deveto poglavlje sadrži pregled korištene literature. 


\section{SPLINE BAZNE FUNKCIJE}

\subsection{Uvod}

Spline funkcije ili jednostavno splineovi su jedne od najpoznatijih i najčešće korištenih baznih funkcija. Spadaju u klasu finitnih funkcija koje su po dijelovima definirane istovrsnom strukturom. Razlikujemo algebarske, eksponencijalne i trigonometrijske splineove. Splineovi koji su po dijelovima algebarski polinomi (sastavljeni od algebarskih polinoma jednog te istog stupnja $n$ ) nazivaju se algebarski splineovi $n$ - tog stupnja. Također, splineovi koji su po dijelovima eksponencijalni (trigonometrijski) polinomi stupnja $n$ nazivaju se eksponencijalni (trigonometrijski) splineovi $n-\operatorname{tog}$ stupnja.

Splineovi se, u odnosu na klasične bazne funkcije, u prvom redu odlikuju jednostavnošću pri formiranju algoritma prikladnog za obradu pomoću elektroničkog računala. Također, splineovi su finitne bazne funkcije što, u odnosu na klasične bazne funkcije, ima za posljedicu pojasne matrice sustava i njihovu dobru uvjetovanost. Finitne funkcije su definirane na cijeloj realnoj osi, a samo na jednom konačnom intervalu su različite od nul-funkcije. Taj dio realne osi naziva se nosač (support).

Nedostatak u odnosu na klasične polinome je neuniverzalnost i ograničena glatkost. Naime, prostor klasičnih polinoma je univerzalan u smislu što proširivanje podprostora dimenzije $n$ na dimenziju $n+r$ ima za posljedicu da su svi elementi polaznog podprostora sadržani u proširenom. Proširenjem linearnog prostora od spline funkcija "ruši" se struktura elemenata polaznog prostora, jer baza od splineova stupnja $n+r$ ne sadrži spline funkcije stupnja $n$. 
U ovom poglavlju navode se samo osnovna svojstva algebarskih i eksponencijalnih splineova koja su polazna ili u vezi s atomskim baznim funkcijama izloženima u sljedećim poglavljima.

\subsection{Algebarski B-splineovi}

Najjednostavniji primjer baznog splinea je algebarski spline nultog stupnja $B_{0}(\xi)$ :

$$
B_{0}(\xi)=\left\{\begin{array}{lcc}
1 & \text { za } & \xi \in[-1 / 2,1 / 2] \\
0 & \text { inače }
\end{array}\right.
$$

čija se Fourierova transformacija dobiva na sljedeći način

$$
f_{0}(t)=\int_{-\infty}^{+\infty} B_{0}(\xi) \cdot e^{i t \xi} d \xi=\int_{-1 / 2}^{+1 / 2} 1 \cdot \cos (t \cdot \xi) d t=\frac{\sin (t / 2)}{t / 2}
$$
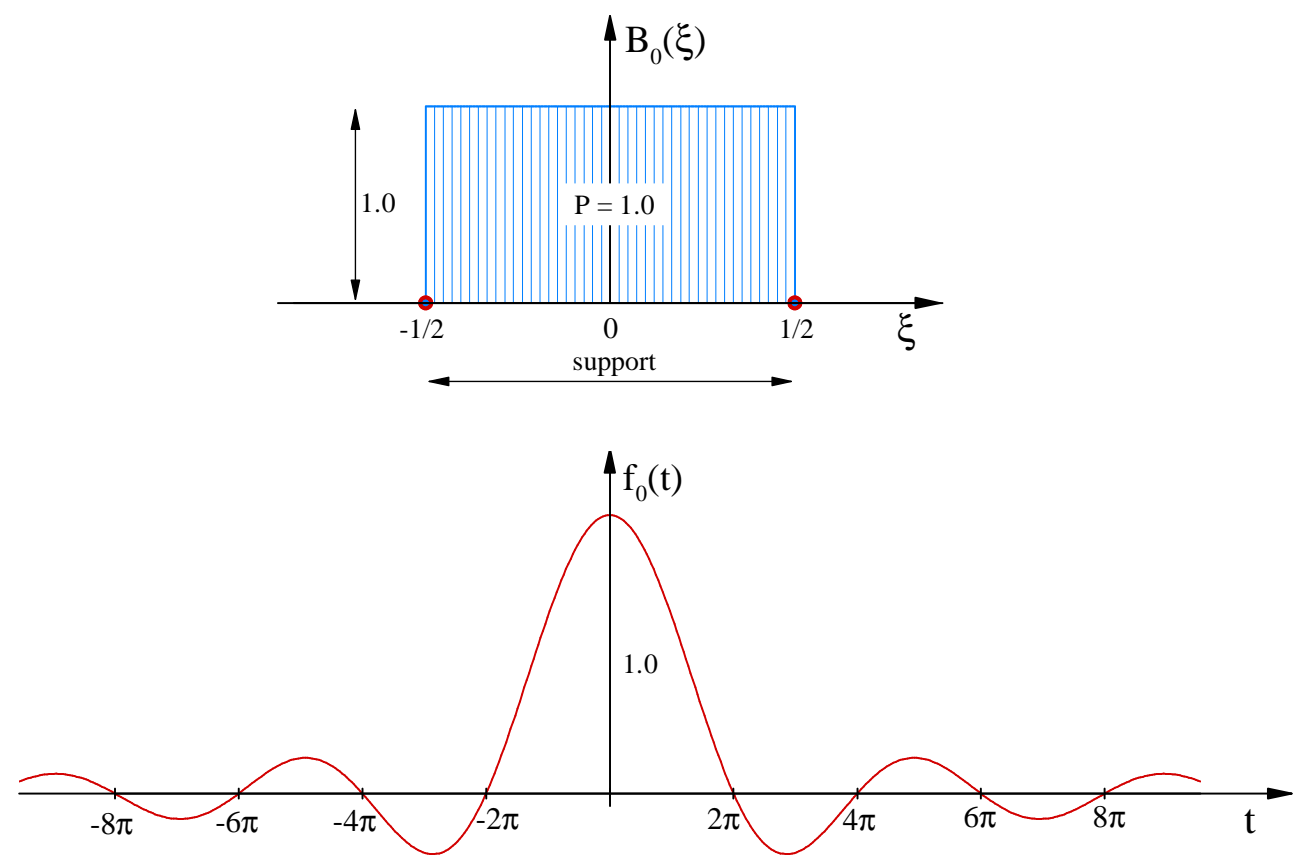

Crtež 2.1 Algebarski spline nultog stupnja $B_{0}(\xi)$ i njegova Fourierova transformacija

S obzirom da $B_{0}(\xi)$ spline u obliku (2.1) ima prekide u točkama $\xi= \pm 1 / 2$, za praktičnu primjenu može se izraziti i u obliku neprekinute funkcije pomoću inverzne Fourierove transformacije gdje se, djelujući integralnim operatorom $\frac{1}{2 \pi} \int_{-\infty}^{\infty} e^{-i t \xi} d t$ na desnu stranu izraza (2.2), FT (slika) preslikava u samu funkciju tj. u algebarski spline $B_{0}(x)$ :

$$
B_{0}(\xi)=\frac{1}{2 \pi} \int_{-\infty}^{\infty} \frac{\sin (t / 2)}{t / 2} \cdot e^{-i t \xi} d t
$$


Na crtežu 2.2 prikazan je algebarski $B_{0}(\xi)$ spline u obliku (2.3) za različita područja integracije.

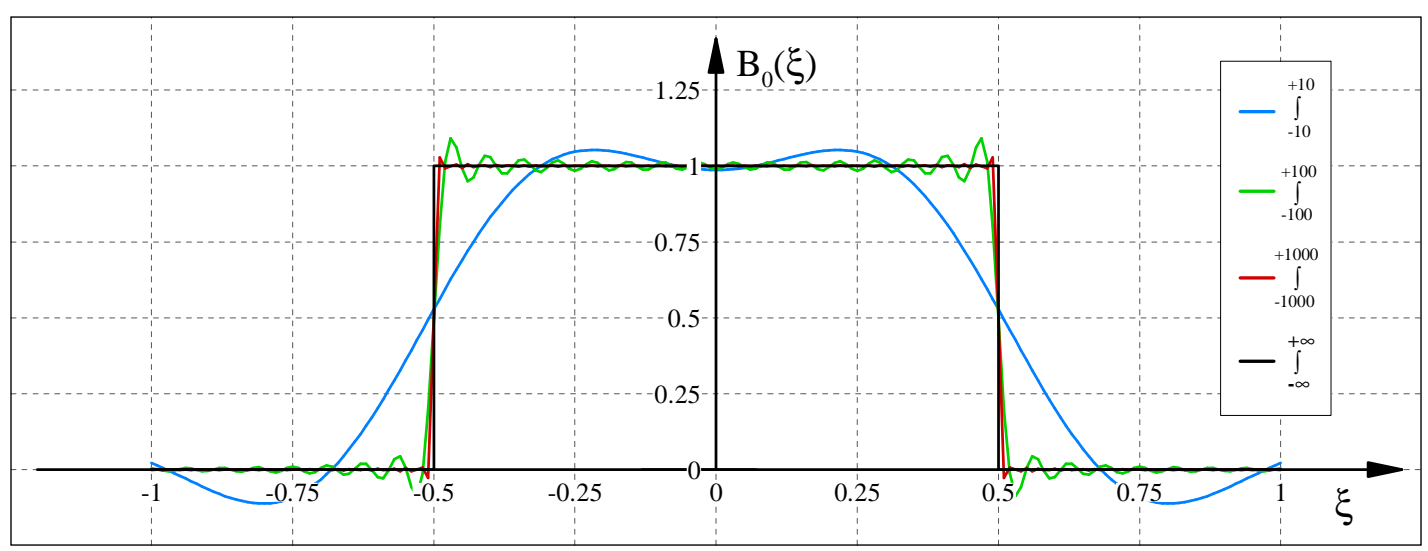

Crtež 2.2 Algebarski $B_{0}(\xi)$ spline u obliku inverzne FT za različita područja integracije

Algebarski $B$ - splineovi $n$ - tog stupnja, za jedinični razmak čvorova s rasporedom po zakonu $\xi_{k}=k-(n+1) / 2, k=0,1, \ldots, n+1$, mogu se izraziti u sljedećem obliku:

$$
B_{n}(\xi)=\frac{1}{n !} \sum_{k=0}^{n+1}(-1)^{k} \cdot C_{n+1}^{k} \cdot\left(\xi+\frac{n+1}{2}-k\right)_{+}^{n}
$$

gdje su $C_{n}^{k}$ binomni koeficijenti određeni sa

$$
C_{n}^{k}=\left(\begin{array}{l}
n \\
k
\end{array}\right)=\frac{(n) !}{(n-k) ! \cdot k !}
$$

Na primjer, za bazne splineove nultog, prvog, drugog i trećeg stupnja iz (2.4) slijedi:

$$
\begin{aligned}
& B_{0}(\xi)=(\xi+1 / 2)_{+}^{0}-(\xi-1 / 2)_{+}^{0} \\
& B_{1}(\xi)=(\xi+1)_{+}^{1}-2(\xi)_{+}^{1}+(\xi-1)_{+}^{1} \\
& B_{2}(\xi)=\left[(2 \xi+3)_{+}^{2}-3(2 \xi+1)_{+}^{2}+3(2 \xi-1)_{+}^{2}-(2 \xi-3)_{+}^{2}\right] / 8 \\
& B_{3}(\xi)=\left[(\xi+2)_{+}^{3}-4(\xi+1)_{+}^{3}+6(\xi)_{+}^{3}-4(\xi-1)_{+}^{3}+(\xi-2)_{+}^{3}\right] / 6
\end{aligned}
$$

Na crtežu 2.3 vidljivo je da se nosač funkcije $B_{n}(\xi)$ sastoji od $(n+1)$-og karakterističnog odsječka i $(n+2)$ čvora, te da je na karakterističnom odsječku $\left[\xi_{k}, \xi_{k+1}\right]$ polinom $n-\operatorname{tog}$ stupnja. Na primjer, algebarski spline trećeg stupnja ima četiri karakteristična odsječka i pet čvorova. Također se vidi da se povećavanjem stupnja splinea povećava i duljina njegovog nosača te kada $n \rightarrow \infty$ duljina nosača teži u neizmjernost. Koordinata $\xi_{T}$ naziva se tjeme bazne funkcije te se pomoću nje određuju pomaci po realnoj osi $\xi$. 
Za bazne splineove $B_{n}(\xi)$ vrijedi Paley-Wienerov teorem [40], tj.

$$
\int_{-\infty}^{\infty} B_{n}(\xi) d \xi<\infty
$$
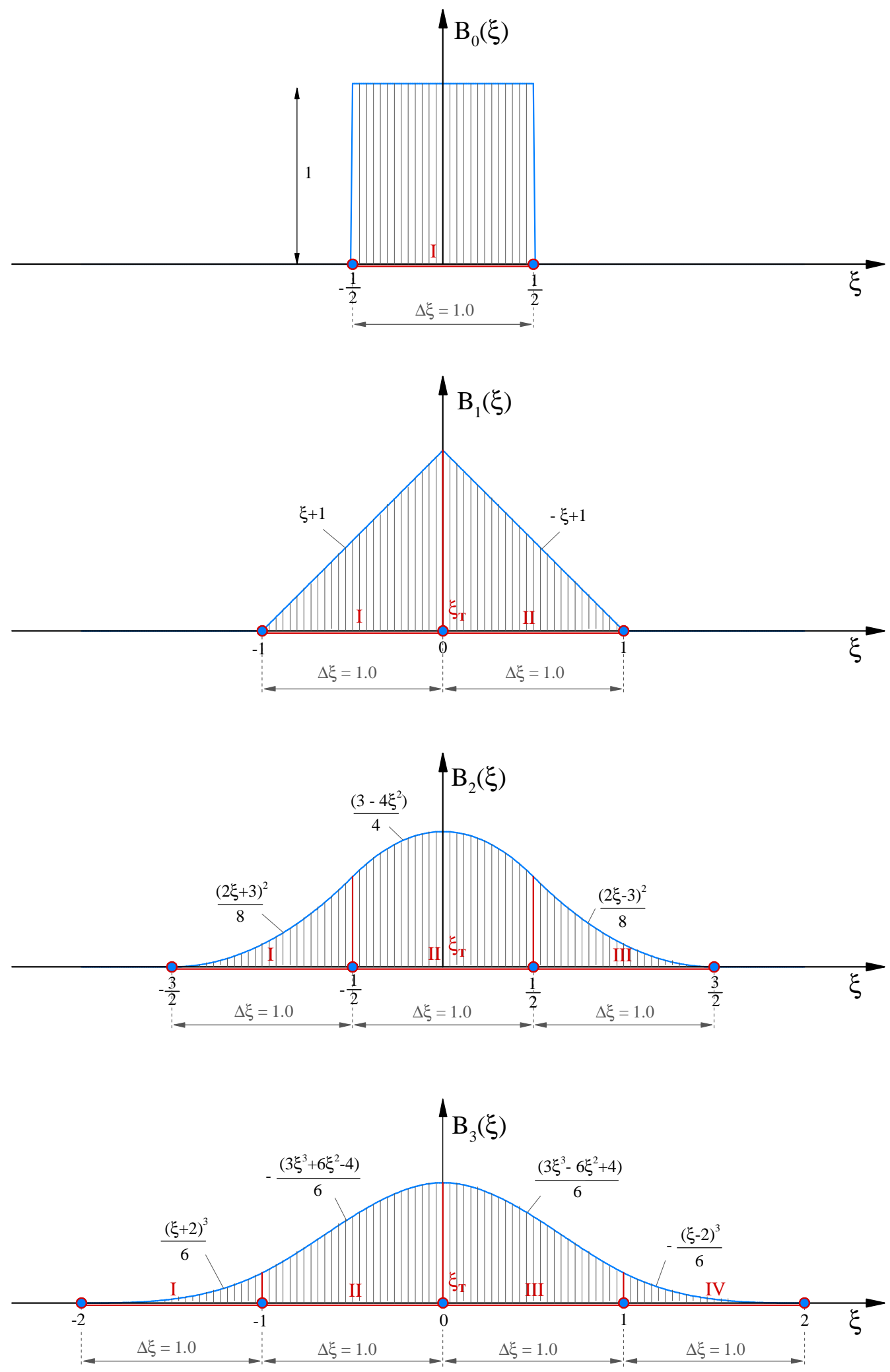

Crtež 2.3 Algebarski splineovi $B_{n}(\xi), n=0,1,2,3$ 
Na crtežu 2.4 prikazan je algebarski spline trećeg stupnja $B_{3}(\xi)$ i njegove prve tri derivacije. Kubični spline $B_{3}(\xi)$ je najčešće korišten i najbolje izučen u smislu aproksimacije i brojnih primjena. Upotreba niskog stupnja polinoma smanjuje rizik od numeričkog osciliranja rješenja, dok je neprekinutost druge derivacije dovoljna u mnogim aplikacijama. Posebnost kubičnog splinea je izravna veza s problemom savijanja grede (žice). Sa crteža 2.4 očigledna je veza derivacija višeg reda s derivacijom nultog reda, odnosno samom funkcijom $B_{n}(\xi)$.

Prva derivacija splinea $B_{3}(\xi)$ može se prikazati u obliku linearne kombinacije sažetih i pomaknutih splineova $B_{2}(\xi)$. Nadalje, druga derivacija splinea $B_{3}(\xi)$ se može prikazati u obliku linearne kombinacije sažetih i pomaknutih splineova $B_{1}(\xi)$, i tako redom. Dakle, $i$ - ta derivacija splinea $B_{n}(\xi)$ je linearna kombinacija pomaknutih splineova $B_{n-i}(\xi)$.
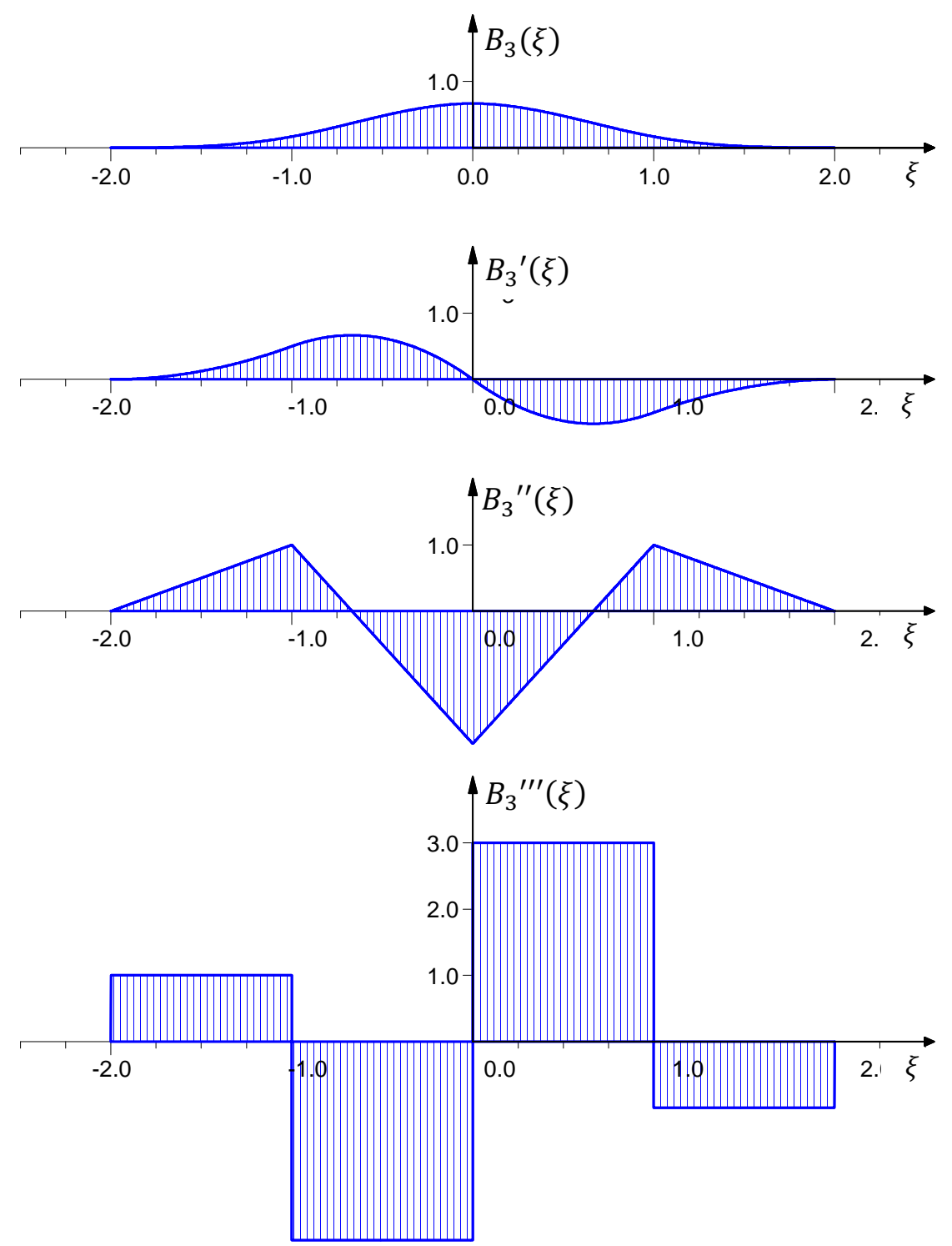

Crtež 2.4 Bazni spline $B_{3}(\xi)$ i njegove prve tri derivacije 
Zahvaljujući toj činjenici, bazni splineovi $B_{n}(\xi)$ se mogu izraziti pomoću teorema konvolucije u slijedećem obliku:

$$
B_{n}(\xi)=\int_{-\infty}^{\infty} B_{n-1}(\xi-t) B_{0}(t) d t
$$

ili

$$
B_{n}(\xi)=B_{n-1}(\xi) * B_{0}(\xi)=\underbrace{B_{0}(\xi) * \ldots * B_{0}(\xi)}_{(n+1) \text { puta }}
$$

gdje je $n$ stupanj baznog splinea, a $B_{0}(\xi)$ je bazni spline nultog stupnja određen izrazom (2.1).

S obzirom da je Fourierova transformacija funkcije izražene pomoću teorema konvolucije jednaka produktu FT članova konvolucije, slijedi da je FT $B_{n}(\xi)$ splinea prema (2.9) jednaka

$$
f_{n}(t)=\left(\frac{\sin t / 2}{t / 2}\right)^{n+1}
$$

pa je inverzna FT $B_{n}(\xi)$ splinea analogno izrazu (2.3) definirana sa:

$$
B_{n}(\xi)=\frac{1}{2 \pi} \int_{-\infty}^{\infty}\left(\frac{\sin t / 2}{t / 2}\right)^{n+1} e^{-i t \xi} d t
$$

Iz (2.9) slijedi da se nosač bazne funkcije $B_{n}(\xi)$ može definirati kao unija $(n+1)-$ og karakterističnog odsječka $\Delta \xi$. Generiranje splinea pomoću teorema konvolucije prikazano je na crtežu 2.5 .

Splineovi se općenito mogu izraziti na više načina. U referenci [38] algebarski splineovi $B_{n}(\xi)$ iz izraza (2.4) označeni su sa ' $Q_{m, k}(\xi)^{\prime}$. Dakle, umjesto stupnja splinea $n$ koristi se broj karakterističnih odsječaka $m$, te se jedinični pomaci po realnoj osi $\xi$ umjesto preko koordinate tjemena bazne funkcije $\xi_{T}$ određuju preko indeksa $k$ lijevog ruba nosača točke $\xi_{k}$.

Takvom nomenklaturom algebarski splineovi za $n>0$ definiraju se rekurzivnom formulom:

$$
Q_{m, k}(\xi)=B_{n}\left(\xi-k-\frac{n+1}{2}\right)=\frac{\xi-\xi_{k}}{\xi_{k+m-1}-\xi_{k}} Q_{m-1, k}(\xi)+\frac{\xi_{k+m}-\xi}{\xi_{k+m}-\xi_{k+1}} Q_{m-1, k+1}(\xi)
$$

S obzirom da algebarski splineovi $n$-tog stupnja imaju $m=(n+1)$ karakterističnih odsječaka, stupanj splinea $n$ može se izraziti preko broja odsječaka na način da je $n=m-1$. 


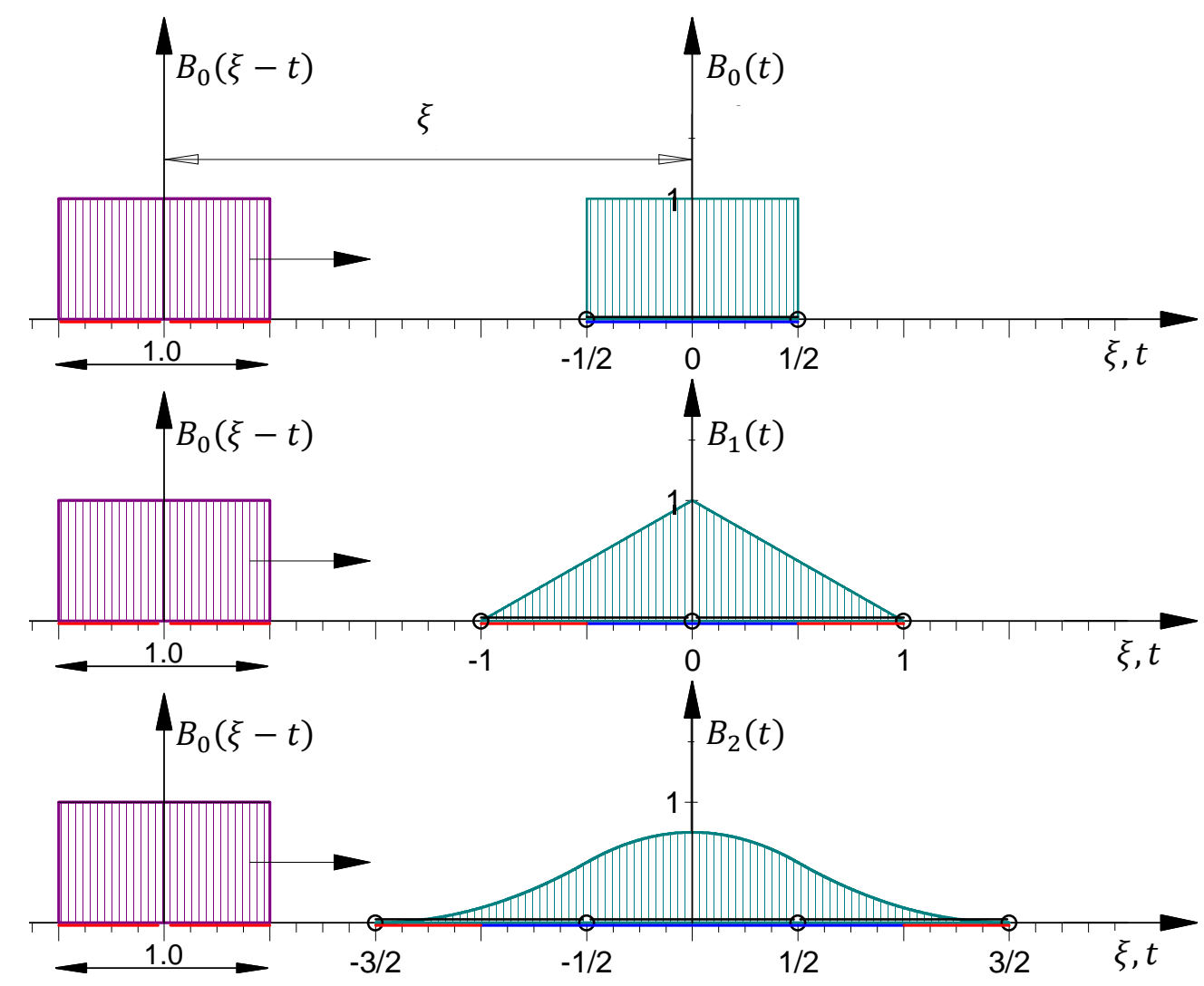

Crtež 2.5 Generiranje baznog splinea $B_{2}(\xi)$ pomoću teorema konvolucije

Algebarski spline nultog stupnja je određen izrazom:

$$
Q_{1, k}(\xi)=B_{0}\left(\xi-\frac{1}{2}-k\right)= \begin{cases}1, & \xi_{k}<\xi \leq \xi_{k+1} \\ 0, & \text { inače }\end{cases}
$$

Splineovi $Q_{m, k}(\xi)$ iz (2.12) prema (2.9) mogu se izraziti kao konvolucija $m$ baznih funkcija $Q_{1}(\xi)$ iz (2.13) u obliku:

$$
Q_{m}(\xi)=\underbrace{Q_{1}(\xi) * \ldots * Q_{1}(\xi)}_{\times m}=Q_{m-1}(\xi) * Q_{1}(\xi)
$$

Rasporedi baznih splineova nultog $Q_{1, k}(\xi)$, prvog $Q_{2, k}(\xi)$ i drugog stupnja $Q_{3, k}(\xi) \mathrm{u}$ kolokacijskim točkama, što formalno odgovara splineovima $B_{0}(\xi-1 / 2-k), B_{1}(\xi-1-k)$ i $B_{2}(\xi-3 / 2-k)$ respektivno, prikazani su na crtežu 2.6. Plavom bojom su označeni splineovi koji su cijelim nosačem unutar područja, crvenom bojom splineovi čiji se nosač jednim dijelom nalazi izvan područja (tzv. rubni splineovi), a crnom splineovi čiji je nosač izvan područja.

Rubni algebarski splineovi (crveno) na lijevom rubu područja, tj., za $k=-m+1, \ldots,-1$, se modificiraju na način da budu definirani samo na dijelu nosača unutar područja tako što se 
u izrazu (2.12) uzme da je $\xi_{-m+1}=\ldots=\xi_{0}=0$. Splineovi kojima je nosač izvan područja $[0, N]$ (crno), crtež 2.6, se nuliraju tj. $Q_{j, k}(\xi) \equiv 0$.
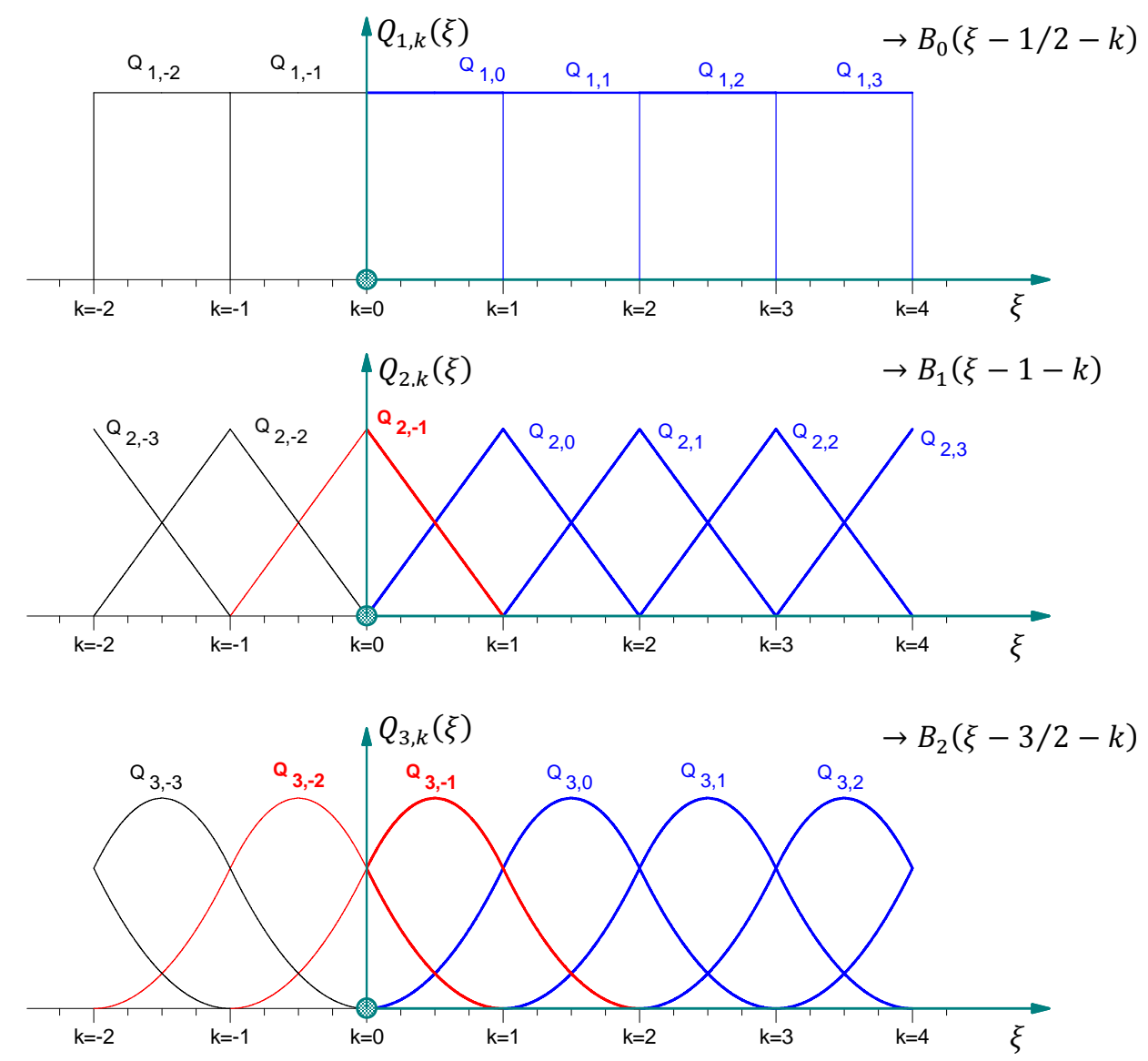

Crtež 2.6 Rasporedi splineova $Q_{1, k}(\xi), Q_{2, k}(\xi), Q_{3, k}(\xi)$

$\mathrm{Na}$ primjer, za modificirane algebarske rubne splineove trećeg stupnja na lijevom rubu područja prikazane na crtežu 2.7 uzima se da je $\xi_{-3}=\xi_{-2}=\xi_{-1}=0$ i $Q_{3,-1}(\xi)=$ $Q_{2,-1}(\xi)=Q_{1,-1}(\xi)=0$ u izrazu (2.12) te se dobiju sljedeći izrazi:

$$
\begin{aligned}
& Q_{4,-3}(\xi)= \begin{cases}(1-\xi)^{3}, & \xi \in[0,1] \\
0, & \text { inače }\end{cases} \\
& Q_{4,-2}(\xi)= \begin{cases}\xi\left(7 \xi^{2}-18 \xi+12\right) / 4, & \xi \in(0,1] \\
(2-\xi)^{3} / 4, & \xi \in(1,2] \\
0, & \text { inače }\end{cases} \\
& Q_{4,-1}(\xi)= \begin{cases}\xi^{2}(18-11 \xi) / 12, & \xi \in(0,1] \\
\left(7 \xi^{3}-36 \xi^{2}+54 \xi-18\right) / 12, & \xi \in(1,2] \\
(3-\xi)^{3} / 6, & \xi \in(2,3] \\
0, & \text { inače }\end{cases}
\end{aligned}
$$



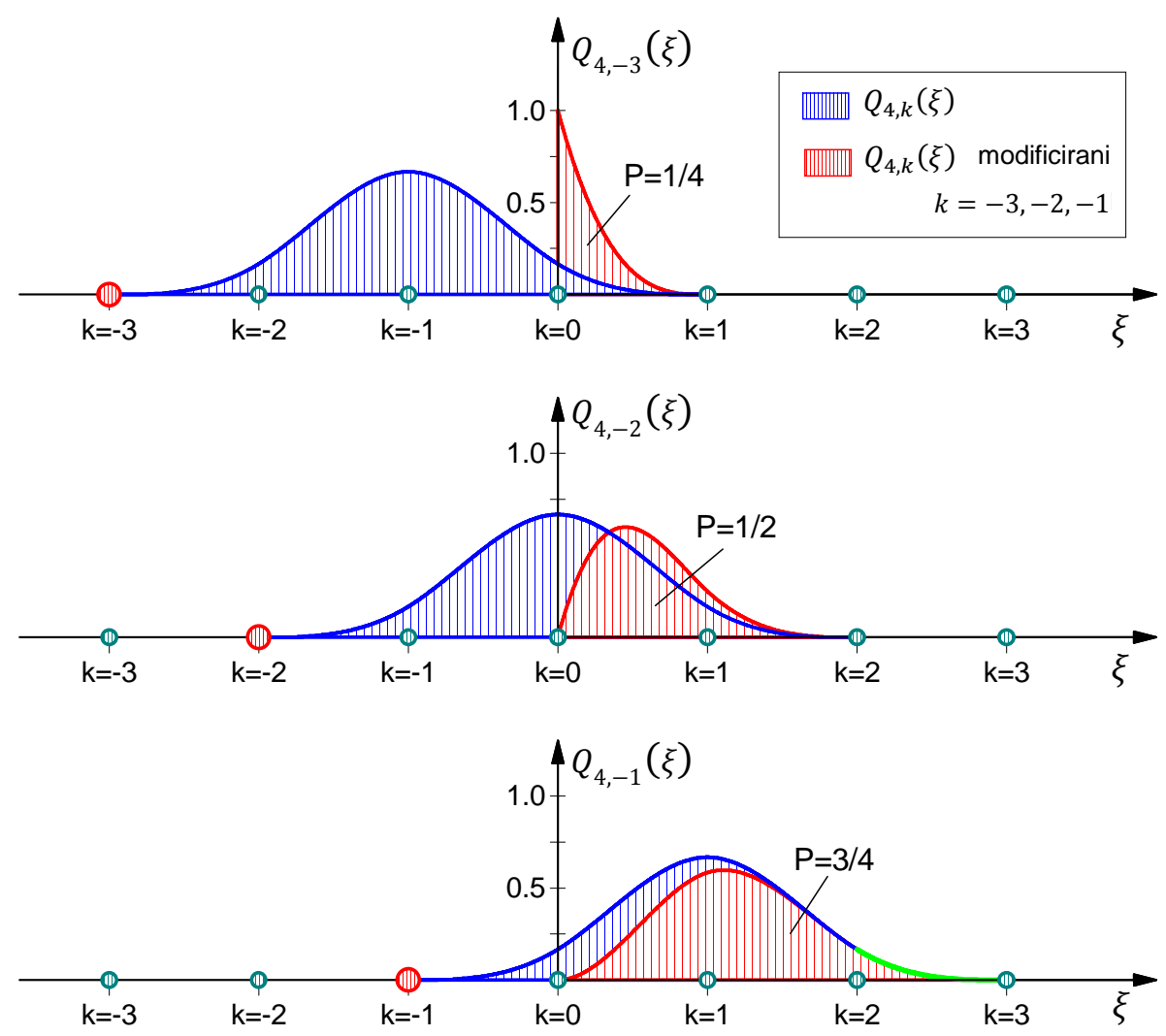

Crtež 2.7 (Ne)modificirani algebarski splineovi trećeg stupnja na lijevom rubu područja

Modificirani rubni splineovi na desnom rubu područja za $k=N-m+1, \ldots, N-1$ dobiju se translacijom i zrcalnom simetrijom rubnih splineova na lijevom rubu, tj. uzima se $Q_{m, k}(\xi)=Q_{m, k}(-\xi+N)$. Na crtežu 2.8 prikazan je raspored algebarskih splineova drugog stupnja na području $[0, N]$, rubni modificirani (crveno) i unutarnji splineovi (plavo).

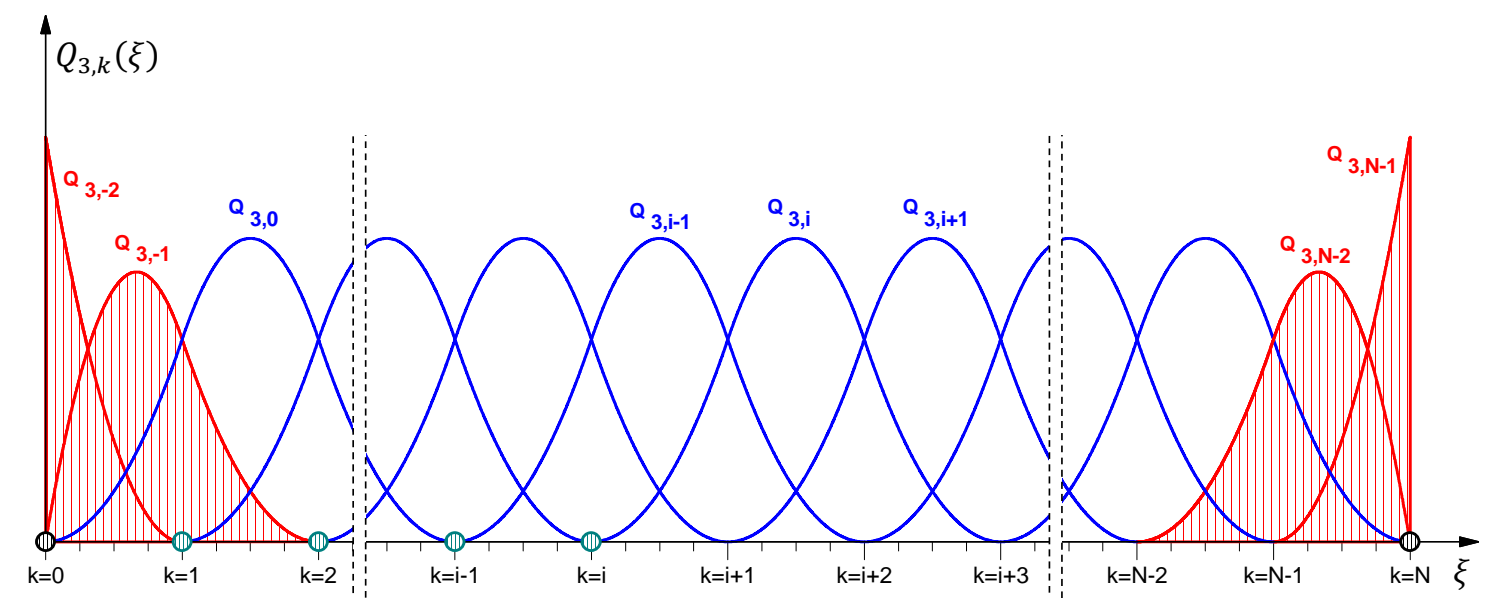

Crtež 2.8 Raspored algebarskih splineova drugog stupnja 
Činjenica da vektorski prostor čiji su elementi splineovi odabranog stupnja ne sadrži splineove nižih stupnjeva ima za posljedicu neuniverzalnost prostora. Posljedica neuniverzalnosti prostora je ta da matrica sustava $n$-tog reda nije sadržana u matrici sustava $(n+1)$-og reda što je nedostatak splineova u odnosu na klasične bazne funkcije.

\subsection{Primjer 1}

Traži se približno rješenje jednadžbe

$$
\begin{array}{r}
-\frac{d^{2} u(x)}{d x^{2}}+f(x)=0 \\
u(0)=u(1)=0.0
\end{array}
$$

na intervalu $(0,1)$ gdje je $f(x)$ zadana funkcija:

$$
f(x)=\left\{\begin{array}{rll}
-16.0, & \text { za } & 0 \leq x<0.5 \\
0.0, & \text { za } & 0.5<x \leq 1
\end{array}\right.
$$

Točno rješenje glasi:

$$
u(x)= \begin{cases}2 x(3-4 x), & \text { za } 0 \leq x<0.5 \\ 2(1-x), & \text { za } 0.5<x \leq 1\end{cases}
$$

Na crtežu 2.9 prikazana je usporedba točnog rješenja s približnim rješenjima dobivenim algebarskim i trigonometrijskim polinomima te spline funkcijama.

Poznato je da primjena algebarskih i trigonometrijskih polinoma kao baznih funkcija kod rješavanja zadaća na nepravilnim područjima gotovo nije moguća. Osim toga, matrica sustava za bazu od klasičnih baznih funkcija je puna i loše uvjetovana što nije pogodno za numeričku obradu. Splineovi, zbog posjedovanja svojstva finitnosti, s numeričkog aspekta imaju niz prednosti u odnosu na klasične bazne funkcije.

Najbolje približno rješenje daju trigonometrijski polinomi, međutim na $2 \mathrm{D}$ i $3 \mathrm{D}$ područjima nisu primjenjivi tako da se njihova izvanredna svojstva ortogonalnosti i univerzalnosti općenito ne mogu iskoristiti. Spline funkcije, iako uzete s minimalnom glatkosti, u tjemenima pojedinog baznog splinea daju točno rješenje. Između tjemena dvaju susjednih baznih splineova približno rješenje ima glatkost splinea tako da se na bolje približenje može utjecati progušćivanjem baznih splineova ili izborom baznih splineova veće glatkosti. 


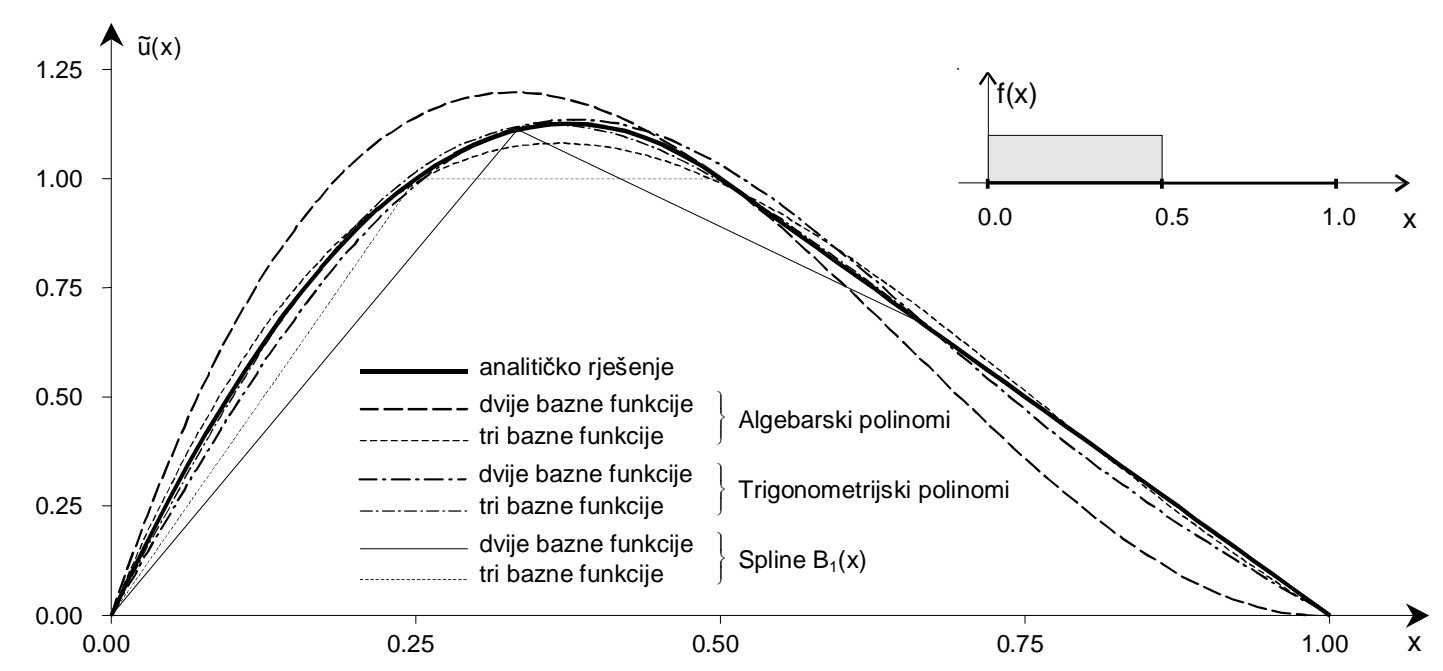

Crtež 2.9 Usporedba rješenja dobivena s različitim baznim funkcijama

\subsection{Eksponencijalni E-splineovi}

U numeričkom modeliranju sve se više javlja potreba za 'novim' baznim funkcijama. Eksponencijalni bazni splineovi $E_{n}(\xi, \omega)$ zadržavaju većinu svojstava algebarskih baznih splineova $B_{n}(\xi)$, a ovisnost o parametru sažimanja ili frekvenciji $\omega$ daje im neka nova svojstva. Za razne vrijednosti parametra $\omega$ splineovi $E_{n}(\xi, \omega)$ imaju otklon u pozitivnom ili negativnom smjeru, što ih čini fleksibilnijima od algebarskih splineova, a time i efikasnijim u aproksimacijskom smislu. Međutim, njihovu praktičnu primjenu uvelike je ograničilo to što nema jedinstvenog kriterija za odabir parametra sažimanja $\omega$ u interpolacijama i aproksimacijama. Mnogi radovi dali su razne algoritme za izbor parametra $\omega$ (npr. [21], [3539]), međutim, to je i dalje ostalo uglavnom otvoreno pitanje. U nastavku se daje kratak pregled jedne vrste eksponencijalnih splineova [38].

$E$-splineovi su glatke funkcije, po dijelovima sastavljene od eksponencijalnih funkcija i algebarskih polinoma s neprekinutim derivacijama do uključivo reda $n-1$. Najjednostavniji primjer eksponencijalnog splinea, eksponencijalni spline nultog stupnja $E_{0}(\xi, \omega)$, prikazan je na crtežu 2.10 . 


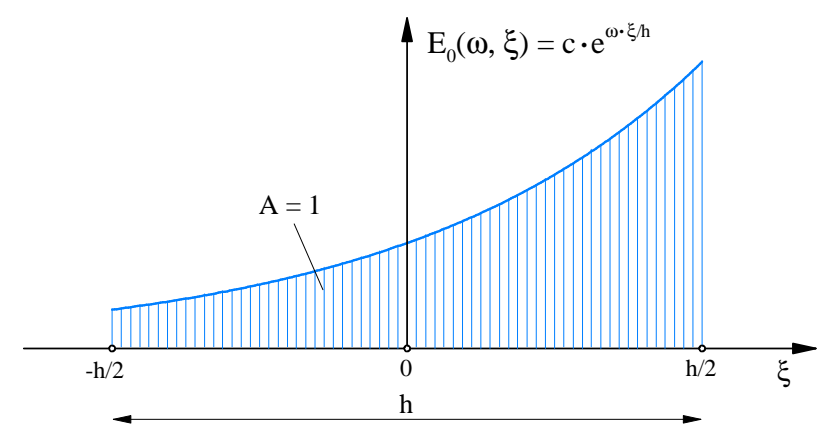

Crtež 2.10 Eksponencijalni spline nultog stupnja $E_{0}(\xi, \omega)$

Koeficijent $c$ određuje se iz normirnog uvjeta, tj. bazni eksponencijalni splineovi zadovoljavaju Paley-Wienerov teorem u obliku:

$$
c \cdot \int_{-\infty}^{\infty} E_{0}(\xi, \omega) d \xi=1
$$

Iz (2.17) slijedi da je $c=\frac{\omega \cdot e^{\omega / 2}}{h \cdot\left(e^{\omega}-1\right)}$. Dakle, eksponencijalni spline nultog stupnja definiran na intervalu $[-1 / 2,1 / 2]$ je jednak

$$
E_{0}(\xi, \omega)= \begin{cases}\frac{\omega \cdot e^{\omega / 2}}{\left(e^{\omega}-1\right)} \cdot e^{\omega \cdot \xi}, & \text { za } \xi \in[-1 / 2,1 / 2] \\ 0, & \text { inače }\end{cases}
$$

U nastavku se koriste oznake prema literaturi [38], pa izraz (2.18) postaje

$$
E_{1}(\xi, \omega)= \begin{cases}\omega \cdot e^{\omega \xi} /\left(e^{\omega}-1\right), & \text { za } \xi \in(0,1] \\ 0, & \text { za } \xi \notin(0,1]\end{cases}
$$

dok se eksponencijalni splineovi za $m>1$ mogu izraziti u slijedećem obliku:

$$
\begin{aligned}
E_{m+1, k}(\xi, \omega) & =\frac{1}{\omega^{m}} \sum_{j=0}^{m}(-1)^{j} C_{m}^{j} E_{1, k+j}(\xi, \omega)- \\
& -\frac{1}{e^{\omega}-1} \sum_{j=1}^{m-1} \frac{1}{\omega^{j}}\left(\sum_{l=0}^{j+1}(-1)^{l} C_{j-1}^{l}\left(\frac{j+1-l}{j+l}+e^{\omega} \frac{l}{j-1}\right) Q_{m-j, k+l}(\xi)\right)
\end{aligned}
$$

gdje je $m$ broj karakterističnih odsječaka, a $k$ indeks lijevog ruba nosača točke $\xi_{k}$.

Eksponencijalni splineovi se po analogiji s algebarskim splineovima mogu definirati pomoću teorema konvolucije, crtež 2.11:

$$
E_{m}(\xi, \omega)=\underbrace{Q_{1}(\xi) * \ldots * Q_{1}(\xi)}_{\times(m-1)} * E_{1}(\xi, \omega)
$$

Sljedeće rekurzivne formule izravna su posljedica (2.21) 


$$
E_{m}(\xi, \omega)=Q_{m-1}(\xi) * E_{1}(\xi, \omega)
$$

i

$$
E_{m}(\xi, \omega)=Q_{1}(\xi) * E_{m-1}(\xi, \omega)
$$

Fourierova transformacija eksponencijalnog splinea $E_{m}(\xi, \omega)$ je prema izrazu $(2.21)$ određena izrazom

$$
F_{m}(t)=\frac{\omega}{2 \operatorname{sh}(\omega / 2)} \cdot \frac{\operatorname{sh}(\omega / 2+i t / 2)}{\omega / 2+i t / 2}\left(\frac{\sin t / 2}{t / 2}\right)^{m-1}
$$
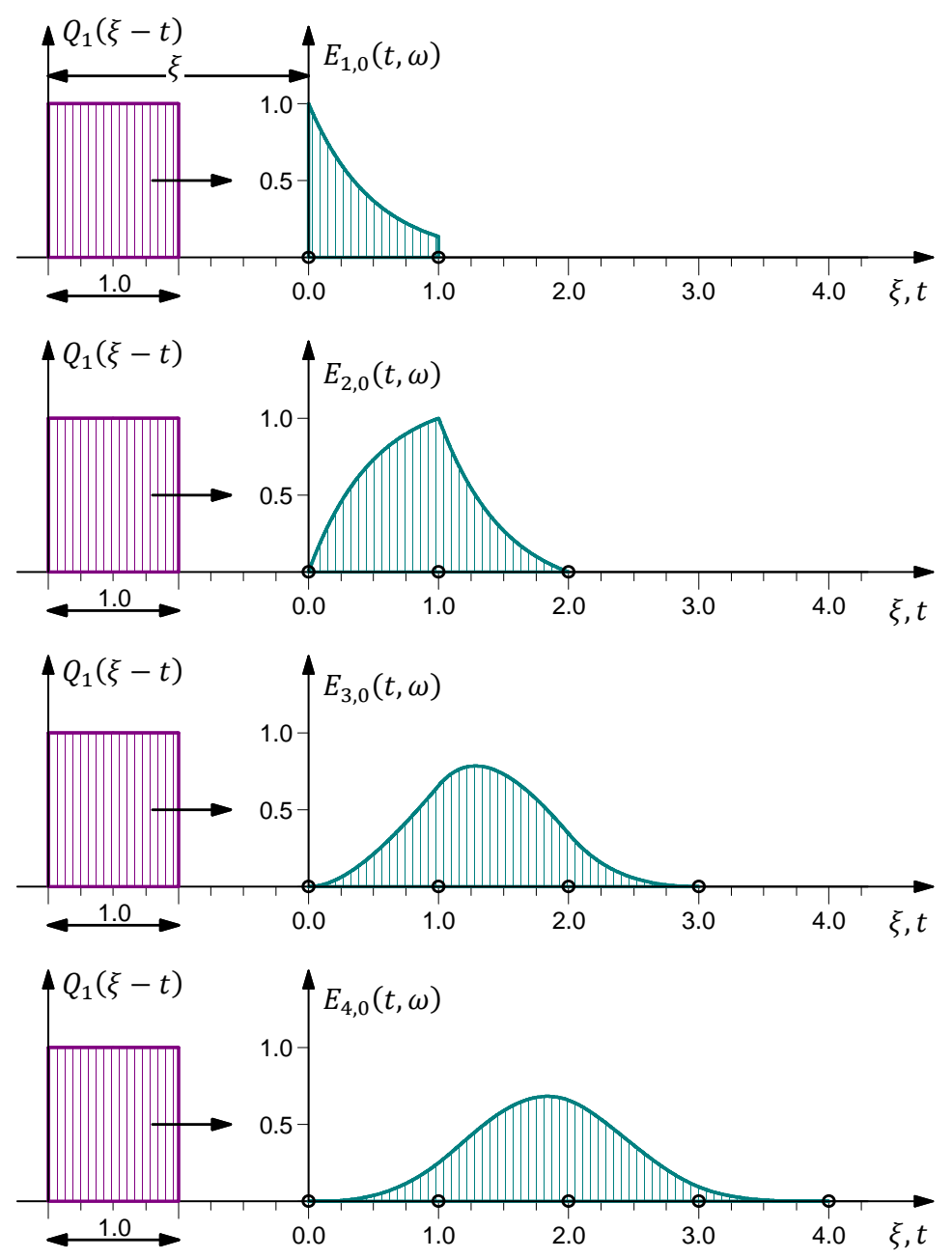

Crtež 2.11 Generiranje $E_{m+1,0}(\xi, \omega)$ splinea pomoću teorema konvolucije

Za granične vrijednosti parametra $\omega$ vrijedi:

kada parametar $\omega$ teži nuli, eksponencijalni splineovi teže odgovarajućim algebarskim splineovima $\mathrm{t}$.

$$
\lim _{\omega \rightarrow 0} E_{m}(\xi, \omega)=Q_{m}(\xi)
$$


kada parametar $\omega$ teži u $-\infty$, eksponencijalni splineovi svode se na algebarske za jedan nižeg stupnja tj.

$$
\lim _{\omega \rightarrow-\infty} E_{m}(\xi, \omega)=Q_{m-1}(\xi)
$$

a)

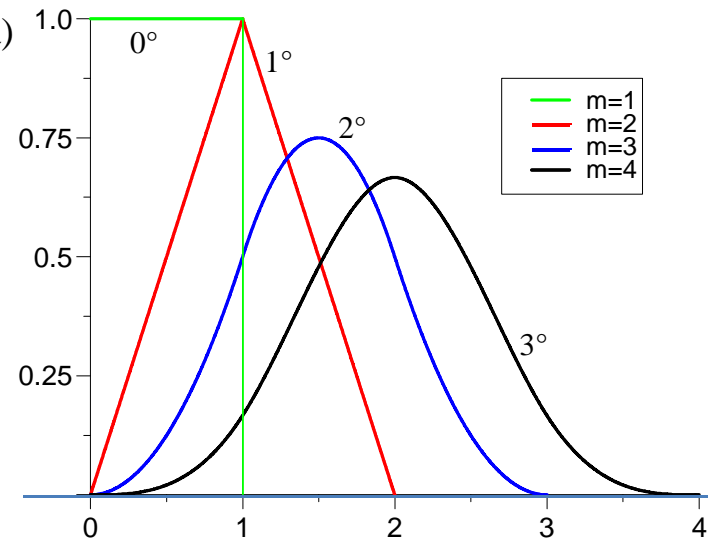

b)

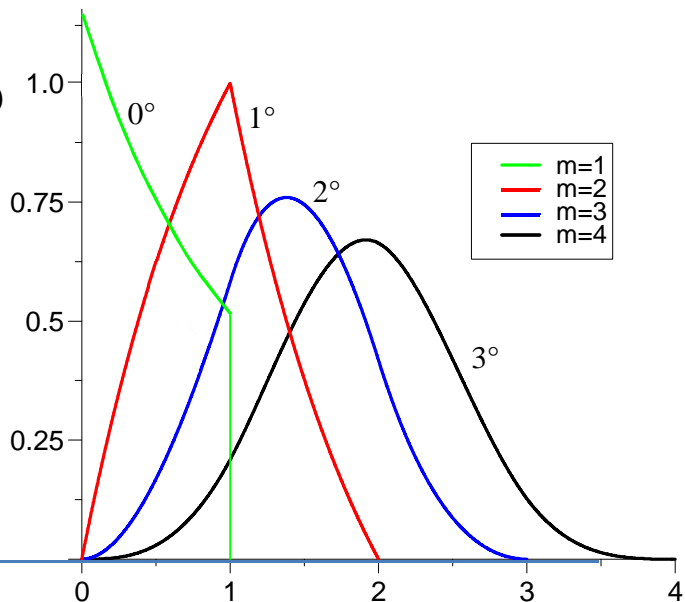

Crtež 2.12 Eksponencijalni splineovi za a) $\omega=0$, b) $\omega=-1$
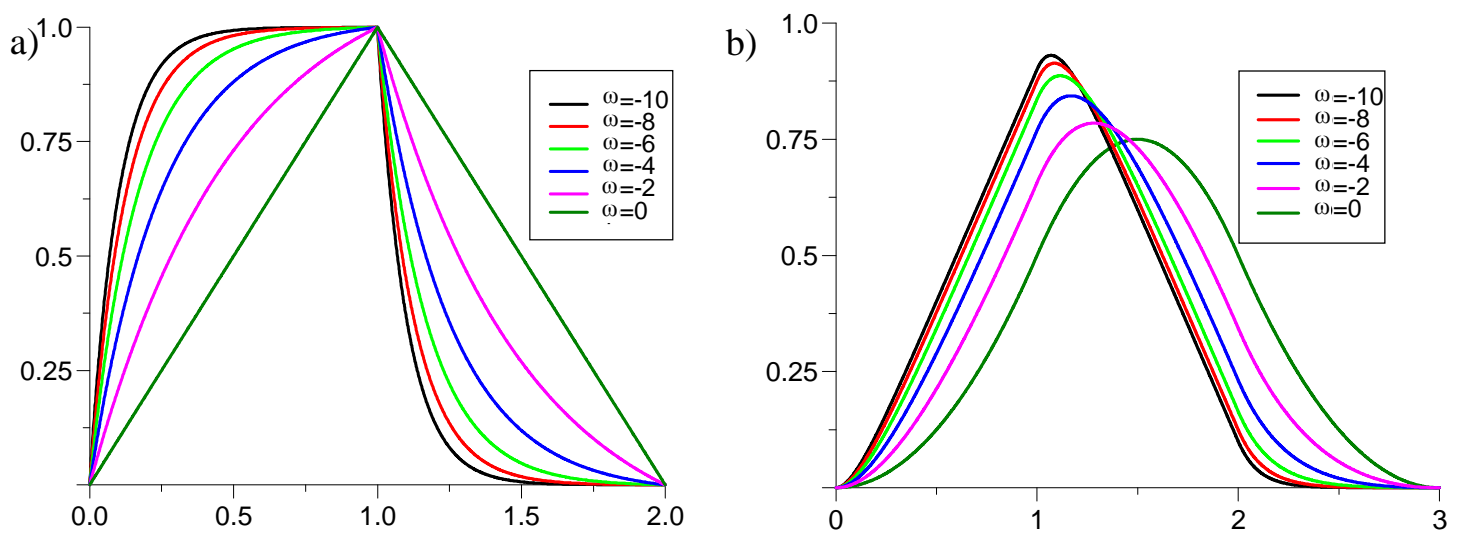

Crtež 2.13 Eksponencijalni splineovi a) prvog i b) drugog stupnja za različite vrijednosti parametra $\omega$

Na crtežu 2.14 prikazan je eksponencijalni spline trećeg stupnja $E_{4,0}(\xi, \omega)$ i njegove prve četiri derivacije. Sa crteža je očigledna veza derivacija višeg reda s derivacijom nultog reda, odnosno samom funkcijom $E_{4,0}(\xi, \omega)$. Analogno algebarskim splineovima vrijedi da je $i-t a$ derivacija splinea $E_{m}(\xi, \omega)$ linearna kombinacija pomaknutih splineova $E_{m-i}(\xi, \omega), i=$ $0, \ldots, m-1$. 

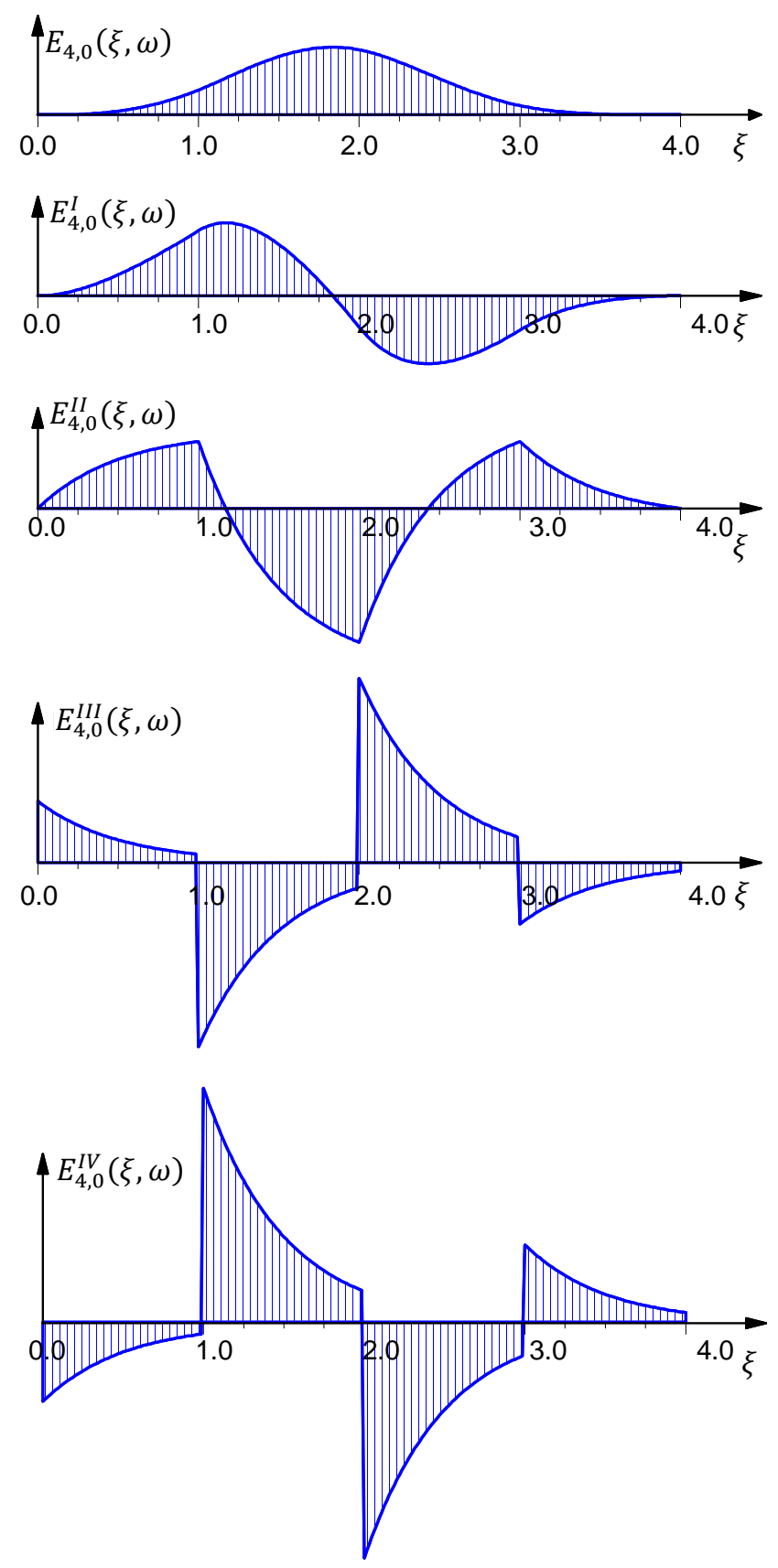

Crtež 2.14 Eksponencijalni spline trećeg stupnja i njegove prve četiri derivacije

Na crtežu 2.15 prikazani su rasporedi baznih splineova nultog $E_{1, k}(\xi, \omega), \operatorname{prvog} E_{2, k}(\xi, \omega)$ i drugog stupnja $E_{3, k}(\xi, \omega)$ koji formiraju baze vektorskih prostora eksponencijalnih splineova na intervalu $[0, N]$. Plavo su označeni splineovi koji su cijelim nosačem unutar područja, crveno splineovi čiji se nosač jednim dijelom nalazi izvan područja (rubni splineovi), a crno splineovi čiji se nosač cijeli nalazi izvan područja. 

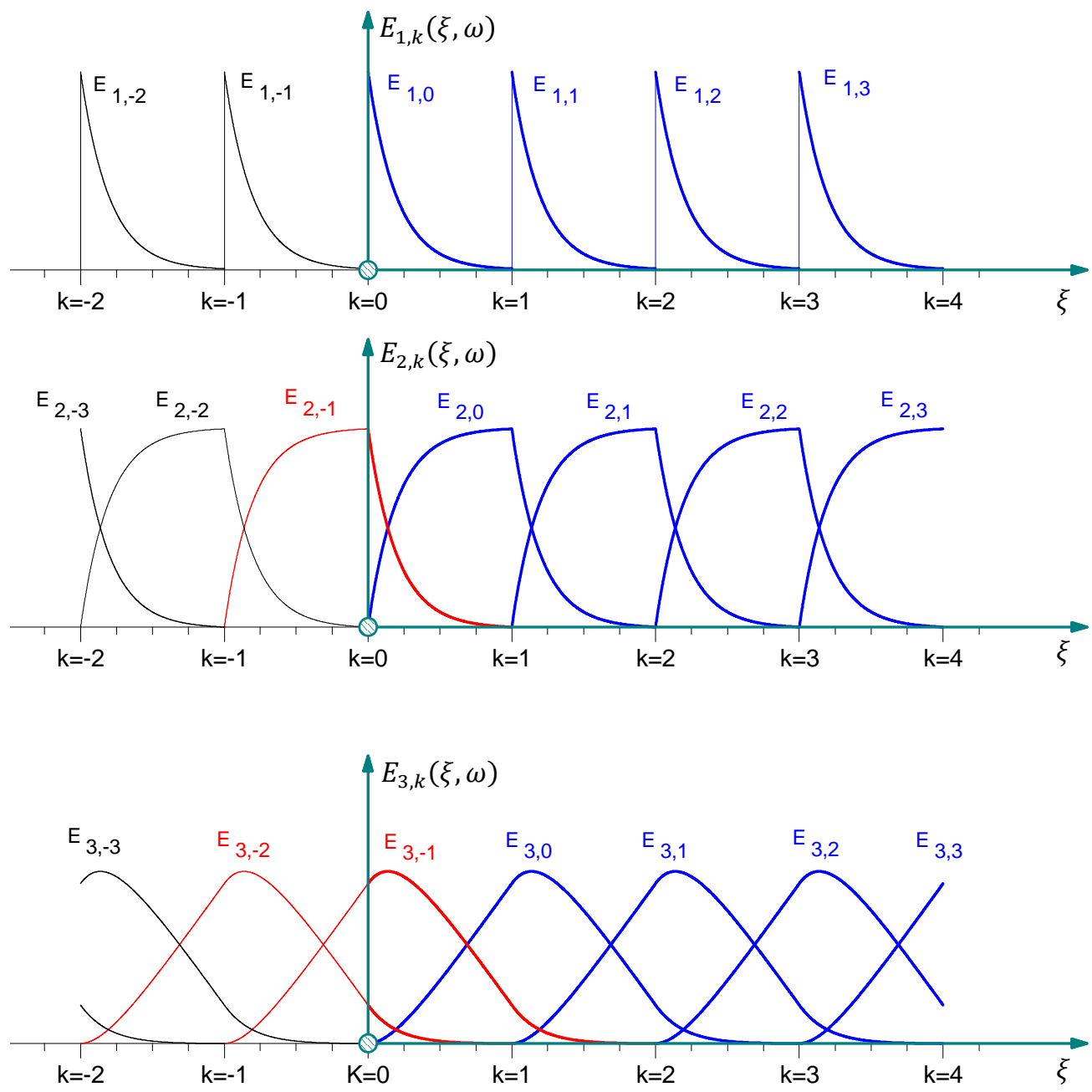

Crtež 2.15 Eksponencijalni splineovi $E_{m+1, k}(\xi, \omega)$ nultog, prvog i drugog stupnja za $\omega=-5$

S obzirom da su eksponencijalni splineovi opisani konvolucijom (2.21) - (2.23) za konstrukciju modificiranih eksponencijalnih rubnih splineova koriste se modificirani rubni algebarski splineovi. Rubni eksponencijalni splineovi prvog $E_{2, k}(\xi, \omega)$ i drugog stupnja $E_{3, k}(\xi, \omega)$, su samo dijelovi odgovarajućeg ne-modificiranog rubnog splinea koji pripadaju području. Modifikacija eksponencijalnih splineova na rubovima počinje sa splineom trećeg stupnja $m=4$, s obzirom da je određen algebarskim splineom drugog stupnja, najnižeg stupnja algebarskih splineova koji se modificiraju na rubu:

$$
E_{4,-3}(\xi, \omega)=\frac{e^{\omega}}{e^{\omega}-1}\left\{\begin{array}{l}
(\xi-1)^{2}+\frac{(\xi-1)}{\omega}+\frac{1}{\omega^{2}}-\frac{e^{\omega(\xi-1)}}{\omega^{2}}, \\
0,
\end{array}\right.
$$




$$
\begin{aligned}
& E_{4,-2}(\xi, \omega)=\frac{1}{e^{\omega}-1} \begin{cases}-(\xi-1)^{2}-\frac{(\xi-1)}{\omega}-\frac{1}{\omega^{2}}+e^{\omega}\left(2 \xi-\frac{3 \cdot \xi^{2}}{2}+\frac{(1-2 \xi)}{\omega}-\frac{2}{\omega^{2}}+3 \frac{e^{\omega(\xi-1)}}{\omega^{2}}\right), & \xi \in(0,1] \\
e^{\omega}\left(\frac{(\xi-2)^{2}}{2}+\frac{(\xi-2)}{2}+\frac{1}{\omega^{2}}-\frac{e^{\omega(\xi-2)}}{\omega^{2}}\right), & \xi \in(1,2] \\
0, & \xi \notin(0,2]\end{cases} \\
& E_{4,-1}(\xi, \omega)=\frac{1}{e^{\omega}-1} \begin{cases}-2 \xi+\frac{3 \xi^{2}}{2}-\frac{(1-2 \xi)}{\omega}+\frac{2}{\omega^{2}}+e^{\omega}\left(\frac{\xi^{2}}{2}+\frac{\xi}{\omega}-\frac{1}{\omega^{2}}-3 \frac{e^{\omega(\xi-1)}}{\omega^{2}}\right), & \xi \in(0,1] \\
\frac{(\xi-2)^{2}}{2}-\frac{(\xi-2)}{\omega}-\frac{1}{\omega^{2}}+e^{\omega}\left(3 \frac{e^{\omega(\xi-2)}}{\omega^{2}}+(\xi-1)(2-\xi)+\frac{1}{2}+\frac{(3-2 \xi)}{\omega}-\frac{2}{\omega^{2}}\right), & \xi \in(1,2] \\
e^{\omega}\left(\frac{(\xi-3)^{2}}{2}+\frac{(\xi-3)}{\omega}+\frac{1}{\omega^{2}}-\frac{e^{\omega(\xi-3)}}{\omega^{2}}\right) & \xi \in(2,3] \\
0, & \xi \notin(0,3]\end{cases}
\end{aligned}
$$

Rubni splineovi na desnom rubu područja dobivaju se zrcalnom simetrijom lijeve strane rubnih splineova, tj. uzima se $E_{m, k}(\xi, \omega)=E_{m, k}(-(\xi-N),-\omega)$.

$\mathrm{Na}$ crtežu 2.16 prikazani su modificirani rubni eksponencijalni splineovi trećeg stupnja $E_{4, k}(\xi, \omega), k=-1,-2,-3$ dok su na crtežu 2.17 prikazani eksponencijalni splineovi $E_{4, k}(\xi, \omega)$ u području (unutarnji) te na lijevom i desnom rubu (rubni) područja $(0, N]$ za $\omega=-5$.
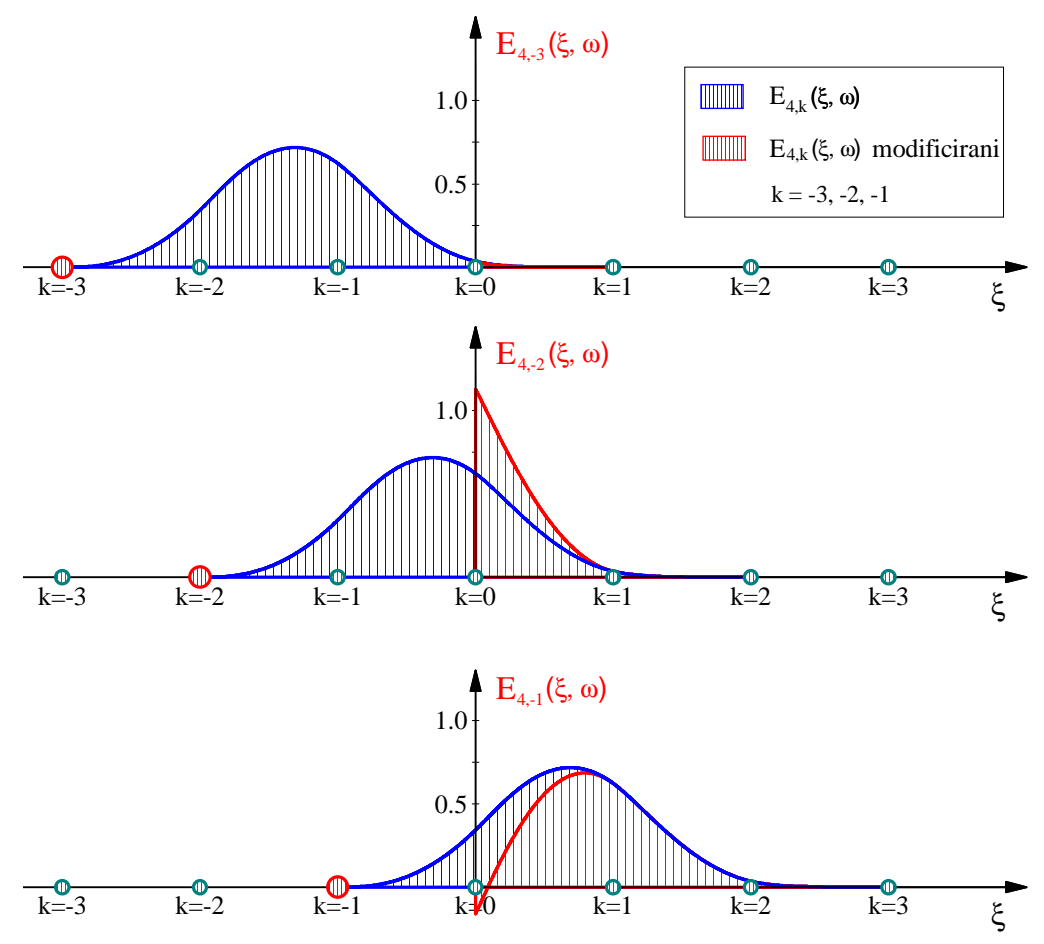

Crtež 2.16 (Ne)modificirani eksponencijalni splineovi $E_{4, k}(\xi, \omega)$ na lijevom rubu područja za $\omega=-5$ 


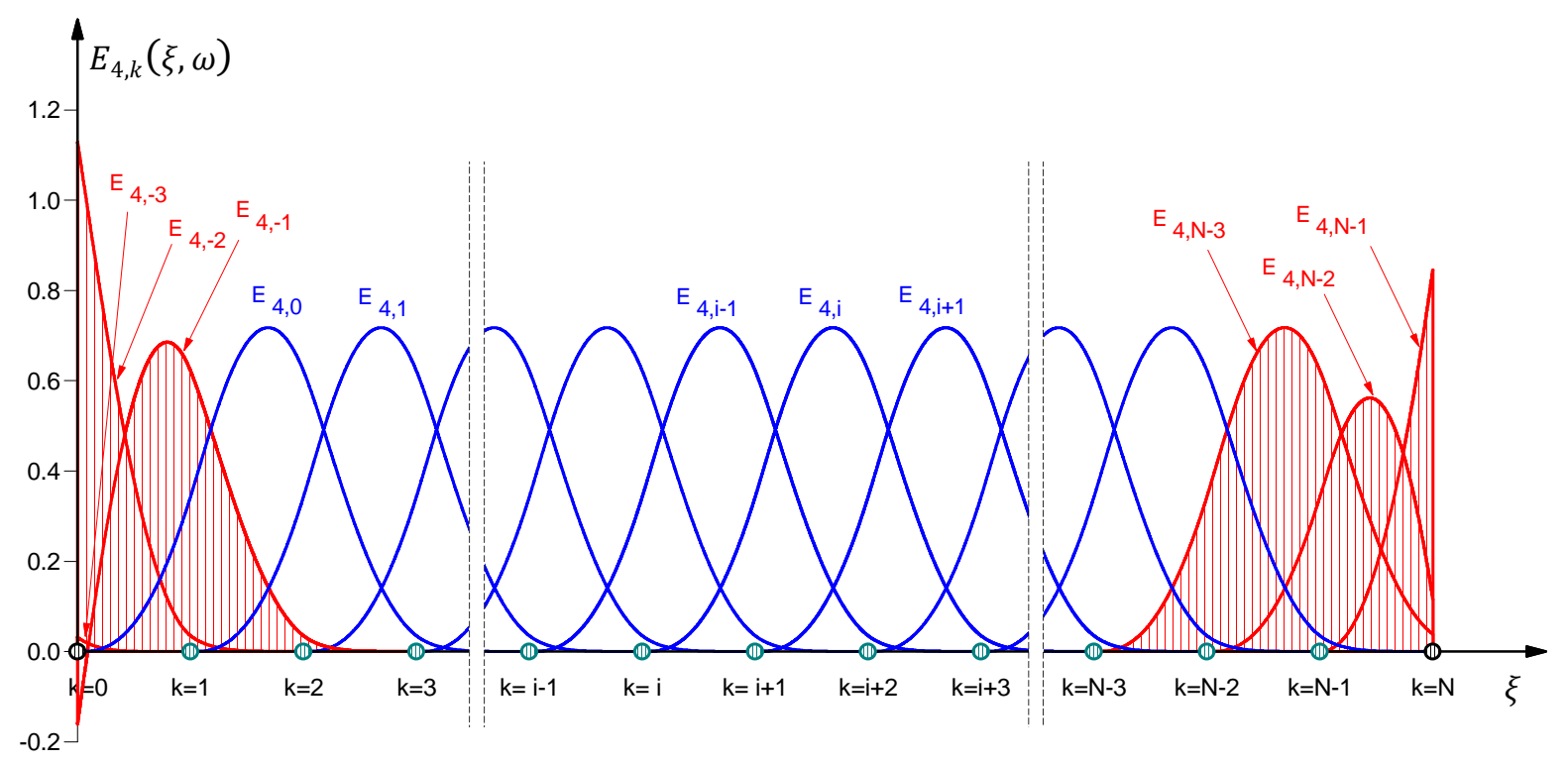

Crtež 2.17 Rubni eksponencijalni splineovi i eksponencijalni splineovi u području za $\omega=-5$

\subsection{Primjer 2}

Ponovo se rješava primjer (2.16) tako da se za približno rješenje koristi linearna kombinacija eksponencijalnih splineova prvog stupnja $E_{2}(x, \omega)$.

Primjer se rješava metodom kolokacije za $n=4$ i $n=8$ karakterističnih odsječaka. $\mathrm{S}$ obzirom da ne postoji univerzalni kriterij za izbor parametra $\omega$, isti je dobiven numeričkim eksperimentom i iznosi $\omega=-4$.

$\mathrm{Na}$ crtežu 2.18 prikazana je usporedba približnog rješenja dobivenog eksponencijalnim splineovima $E_{2}(x,-4)$ sa točnim rješenjem kao i približnim rješenjem dobivenim algebarskim $B_{1}(x)=Q_{2}(x)$ splineovima.
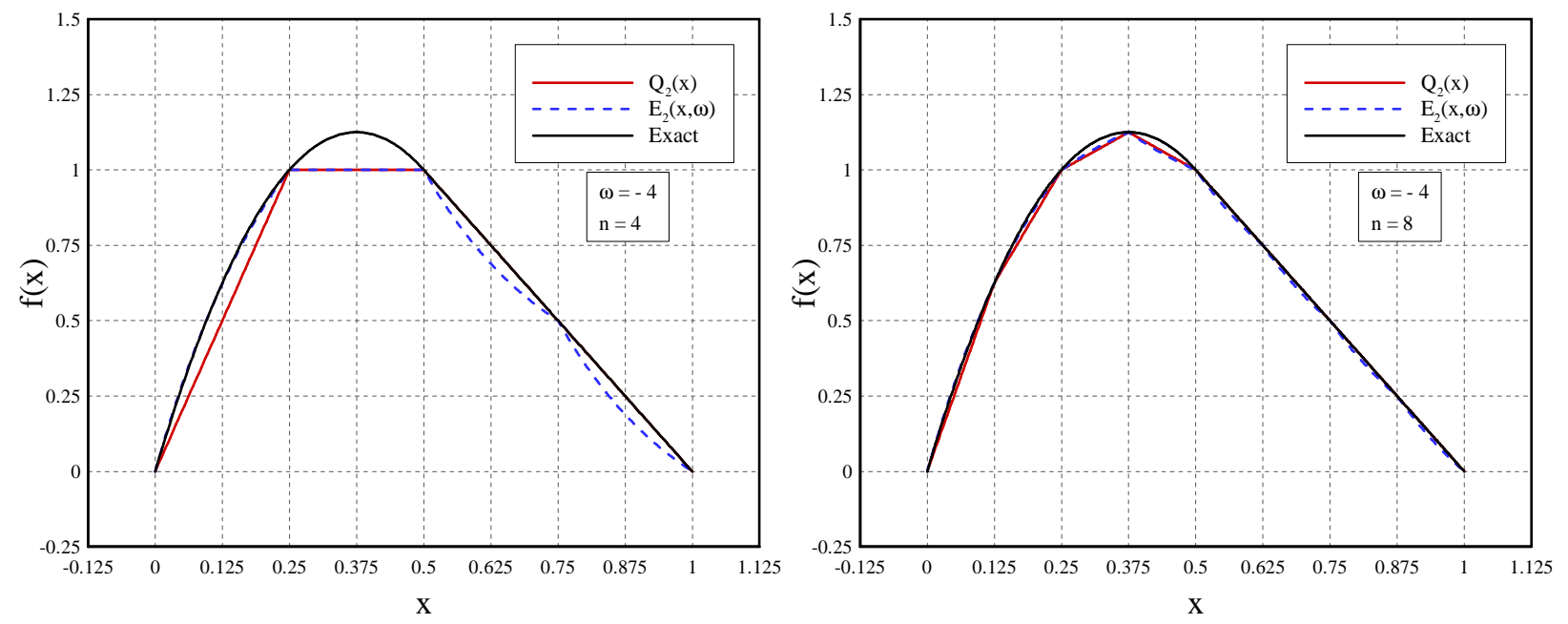

Crtež 2.18 Usporedba točnog rješenja problema (2.16) sa približnim rješenjima dobivenim eksponencijalnim $E_{2}(x,-4)$ i algebarskim $Q_{2}(x)$ splineovima 
Bolje približno rješenje na dijelu gdje točno rješenje odgovara algebarskom polinomu drugog stupnja daju eksponencijalni splineovi $E_{2}(x, \omega)$ upravo zbog svojstva „prilagodljivosti“ koje mu omogućava parametar $\omega$, dok na dijelu gdje je točno rješenje polinom prvog stupnja bolje rješenje daju algebarski $B_{1}(x)=Q_{2}(x)$ splineovi što je i očekivano s obzirom da oni točno razvijaju polinom prvog stupnja. 


\section{ALGEBARSKE ATOMSKE BAZNE FUNKCIJE UP}

\subsection{Definiranje i osnovna svojstva funkcije up( $(\xi)$}

Zajednička karakteristika svih ABF je mogućnost efektne konstrukcije njihove Fourierove Transformacije FT (slike). Iz FT mogu se izračunati vrijednosti funkcije (originala), ali također i sve pomoćne veličine potrebne za praktičnu primjenu funkcije. Prva iz klase atomskih baznih funkcija je funkcija $u p(\xi)$. U nastavku se pokazuje konstrukcija njene FT koristeći stanovite sličnosti s poznatim B- splineovima opisanima u Poglavlju 2.

Poznavajući $B_{0}(\xi)$ spline u obliku (2.1)

$$
B_{0}(\xi)= \begin{cases}1 & z a \quad \xi \in[-1 / 2,1 / 2] \\ 0 & \text { inače }\end{cases}
$$

i njegovu FT $f_{0}(t)(2.2)$

$$
f_{0}(t)=\int_{-\infty}^{+\infty} B_{0}(\xi) \cdot e^{i t \xi} d \xi=\int_{-1 / 2}^{+1 / 2} 1 \cdot e^{i t \xi} d \xi=\frac{\sin (t / 2)}{t / 2}
$$

može se konstruirati algebarski spline $B_{n}(\xi)$ proizvoljnog stupnja $n$, te njegova FT $f_{n}(t) \mathrm{u}$ sljedećem obliku:

$$
\begin{aligned}
B_{n}(\xi) & =\underbrace{B_{0}(\xi) * B_{0}(\xi) * \ldots * B_{0}(\xi)}_{n+1} \\
f_{n}(t) & =\underbrace{f_{0}(t) \cdot f_{0}(t) \cdot \ldots \cdot f_{0}(t)}_{n+1}
\end{aligned}
$$

Funkcija $B_{n}(\xi)$ odgovara konvoluciji $(n+1)$ og splinea nultog stupnja $B_{0}(\xi)$, pa je njezin nosač unija nosača svih faktora u konvoluciji pojedinačne duljine $h_{0}=1$ : 


$$
h_{n}=(n+1) \cdot h_{0}
$$

Očigledno, s porastom stupnja polinoma $n$ raste i duljina nosača funkcije $B_{n}(\xi)$ te kada $n \rightarrow \infty$ i pripadajuća duljina nosača $h_{n} \rightarrow \infty$.

Za funkciju $u p(\xi)$ u [7] korišten je modificirani oblik izraza (3.3), na način da se $B_{0}(\xi)$ sažme na polovicu duljine nosača $\left(h_{0} / 2\right)$ i tako dobije drugi član konvolucije, zatim se on sažima na polovicu svoje duljine nosača $\left(h_{0} / 4\right)$ te tako dobije treći član konvolucije i tako redom:

$$
u p(\xi)=B_{0}(\xi) * B_{0}(2 \xi) * \ldots * B_{0}\left(2^{k} \xi\right) * \ldots * B_{0}\left(2^{\infty} \xi\right)
$$
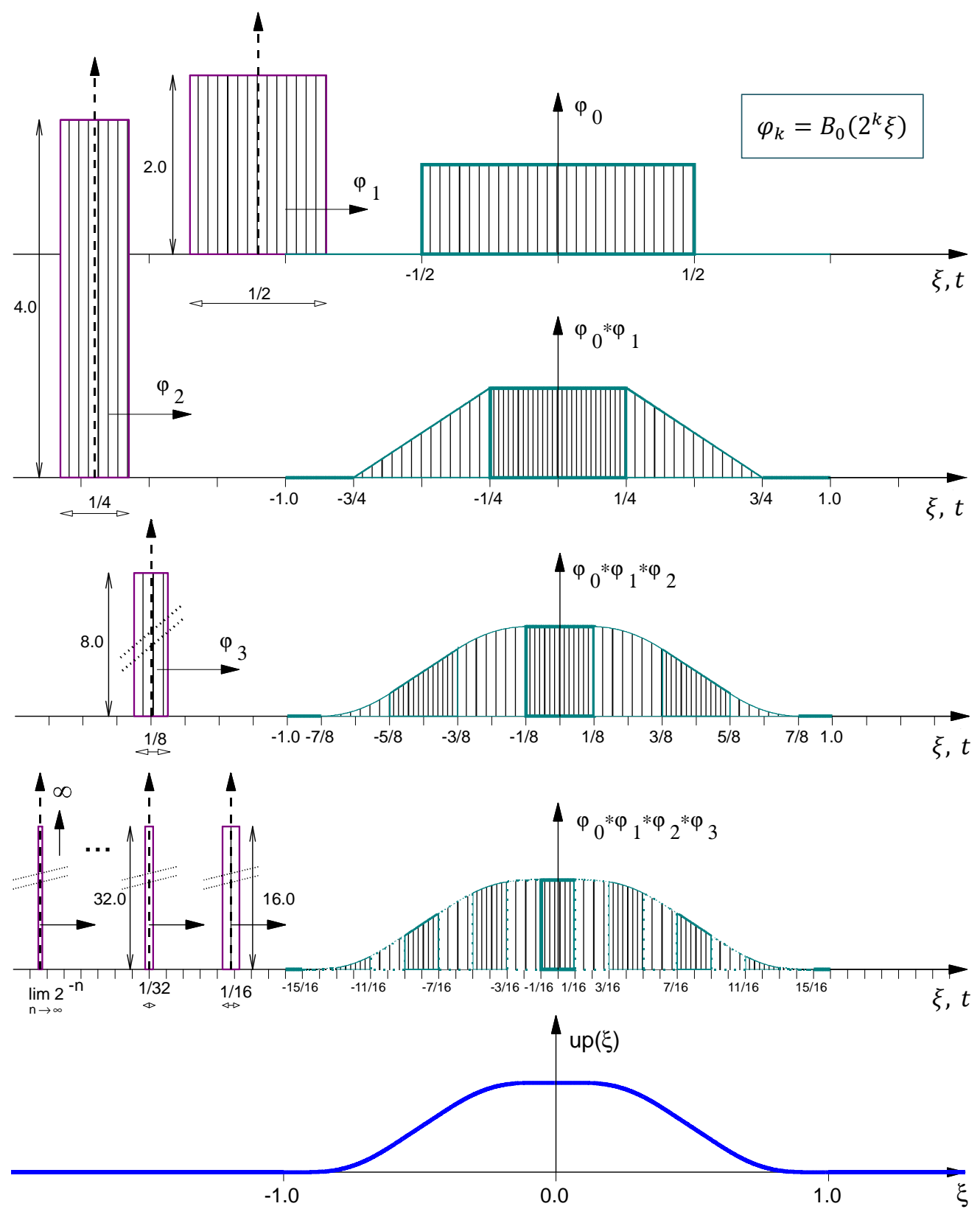

Crtež 3.1 Generiranje funkcije $u p(\xi)$ pomoću teorema konvolucije 
Iz Paley-Wienerovog teorema [40] u obliku $\int_{-\infty}^{+\infty} B_{0}\left(2^{k} \xi\right) d \xi=1$, slijedi da se ordinate svakog sljedećeg člana u (3.5) udvostručuju:

$$
B_{0}\left(2^{k} \xi\right)= \begin{cases}2^{k} & \text { za } \xi \in\left[-2^{-k-1}, 2^{-k-1}\right], \quad k=0,1, \ldots, \infty \\ 0 & \text { inače }\end{cases}
$$

Dakle, funkcija $u p(\xi)$ dobije se konvolucijom beskonačnog broja algebarskih splineova nultog stupnja (3.6) sažetih na duljinu nosača $2^{-k}$ s ordinatama veličine $2^{k}$ kako je prikazano na crtežu 3.1. Prema tome je i nosač funkcije $u p(\xi)$ unija neizmjerno mnogo nosača članova iz konvolucije (3.5), a ipak je njegova duljina konačna, tj.

$$
h_{u p}=\sum_{k=0}^{\infty} \frac{1}{2^{k}}=2 \quad \rightarrow \quad \operatorname{supp} \operatorname{up}(\xi)=[-1,1]
$$

Radi se o kompaktnom nosaču, te je u [6] dokazano da se duljina nosača može prikazati kao mjera skupa svih binarno racionalnih točaka $2^{-k}$, dok sve ostale točke nosača tipa $\pm 1 / 3, \pm 4 / 7, \pm \sqrt{2} / 2, \pm \pi / 8$, itd. tvore skup čija je mjera-prazan skup.

Posljedica uzastopnog sažimanja polaznog $B_{0}(\xi)$ splinea na polovicu prethodne duljine je povećanje stupnja algebarskog polinoma ali uz zadržavanje svih prethodnih stupnjeva polinoma kao što je vidljivo na crtežu 3.1.

Fourierova transformacija osnovne atomske funkcije $u p(\xi)$ prema (3.2), (3.3) i (3.5) odgovara produktu beskonačnog broja Fourierovih transformacija faktora konvolucije

$$
F_{0}(t)=\prod_{j=1}^{\infty} \frac{\sin \left(t / 2^{j}\right)}{t / 2^{j}}
$$

Na crtežu 3.2 prikazana je funkcija $u p(\xi)$ i njena Fourierova transformacija.

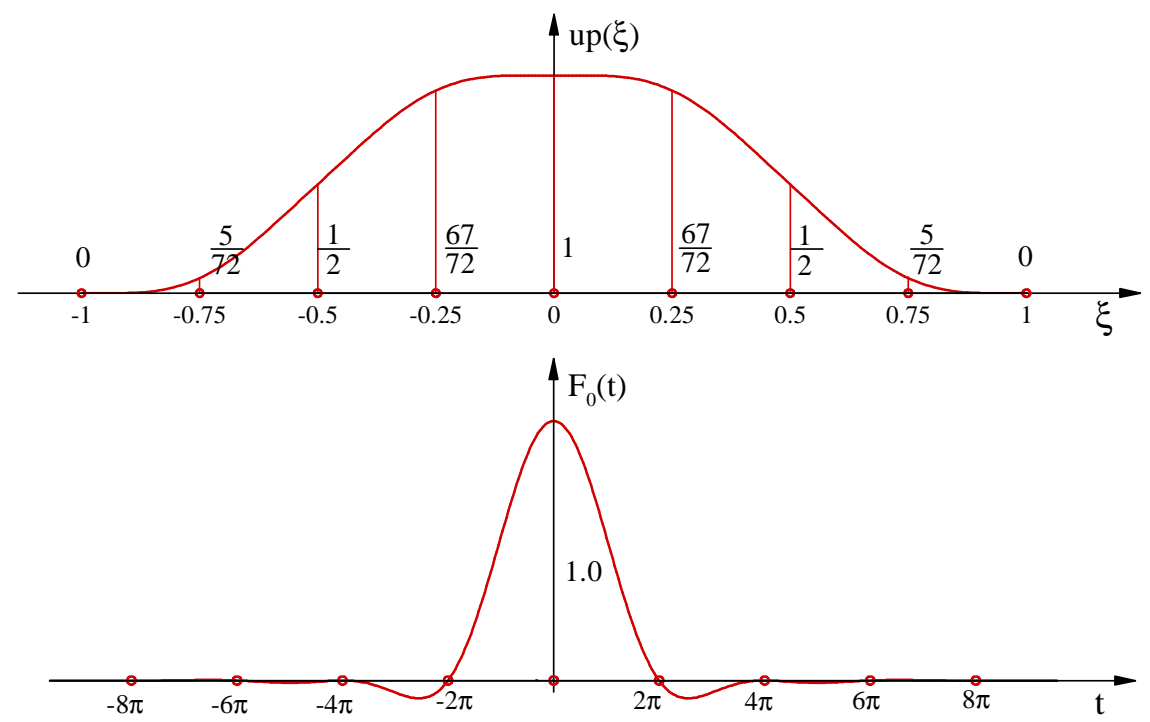

Crtež 3.2 Funkcija $u p(\xi)$ i njena Fourierova transformacija 
Koristeći izraz (3.8) numeričkim postupcima mogu se približno odrediti vrijednosti funkcije $u p(\xi)$ i njezinih derivacija pomoću formule

$$
u p(\xi)=\frac{1}{2 \pi} \int_{-\infty}^{+\infty} e^{-i t \xi} \cdot F_{0}(t) d t
$$

Međutim, na skupu binarno racionalnih točaka

$$
\xi_{b r}=-1+k \cdot 2^{-n}, \quad n \in N, \quad k=1, \ldots, 2^{n+1}
$$

vrijednosti funkcije $u p(\xi)$ i njenih derivacija mogu se odrediti u obliku racionalnih brojeva dakle točno. U ostalim točkama nosača vrijednosti funkcije izračunavaju se s točnosti računala.

O ABF up $(\xi)$ može se govoriti kao o savršenom spline-u koji je beskonačan broj puta derivabilan a ipak u niti jednoj točki svoga nosača nije analitička funkcija. Također njegova finitnost je izraženija nego kod spline funkcija, a glatkost je manja nego kod klasičnih baznih funkcija, kao što su algebarski i trigonometrijski polinomi.

Materinska $\mathrm{ABF} u p(\xi)$ zadržava dobro svojstvo finitnosti B-splineova, a također posjeduje važno svojstvo algebarskih i trigonometrijskih polinoma a to je univerzalnost vektorskog prostora UP kojega one tvore.

\subsection{Karakteristične i binarno racionalne točke funkcije up $(\xi)$}

Nosač funkcije $u p(\xi)$ sastavljen je od dva karakteristična odsječka jedinične duljine $\Delta \xi_{0}=2^{0}=1$. Karakteristične točke $\xi_{k}$ su rubne točke karakterističnih odsječaka.

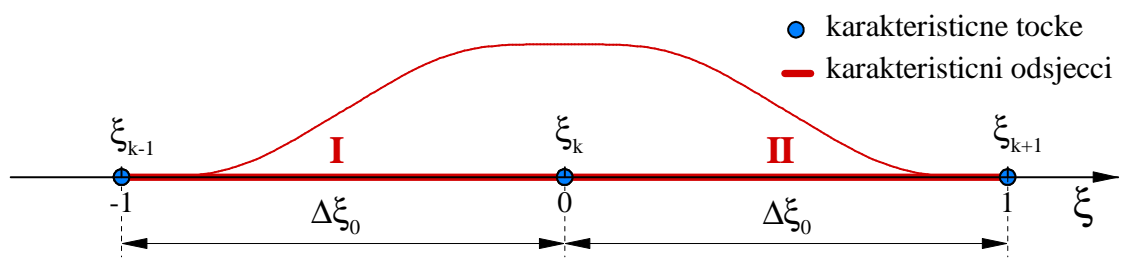

Skup binarno racionalnih točaka zadane gustoće na nosaču funkcije $u p(\xi)$ određen je sa (3.10). Binarno racionalne točke $\xi_{b r}^{(n)}$ su točke u kojima se vrijednost funkcije $u p(\xi)$ i vrijednost prvih $n$ derivacija izračunavaju točno u obliku racionalnog broja. U ostalim točkama nosača navedene vrijednosti funkcije izračunavaju se s točnosti računala, odnosno točnost je u funkciji mogućnosti prikaza vrijednosti koordinate odabrane točke u bazi s kojom računalo radi. Pomoću $n$ je određen razmak binarno racionalnih točaka na nosaču funkcije $u p(\xi)$ 


$$
\Delta \xi_{b r}=2^{-n}
$$

Na primjer, za $n=2$ razmak binarno racionalnih točaka je $1 / 4$. U tom slučaju, na cijelom nosaču funkcije $u p(x)$, odnosno za $\xi \in[-1,1]$, ima $2^{n+1}$ binarno racionalnih točaka.

Položaj točaka na nosaču funkcije $u p(\xi)$ za $n=2$ prema (3.10) je sljedeći

$$
\xi_{b r}=-1+k \cdot 2^{-2}, \quad n \in N, \quad k=0, \ldots, 2^{3}
$$

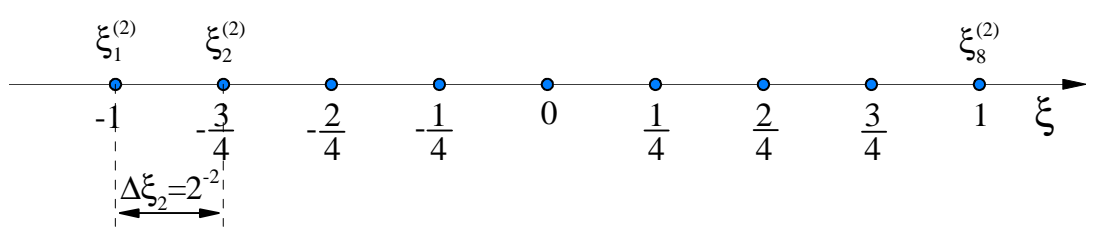

Derivacije funkcije $u p(\xi)$ stupnja većeg od $n$ u binarno racionalnim točkama imaju

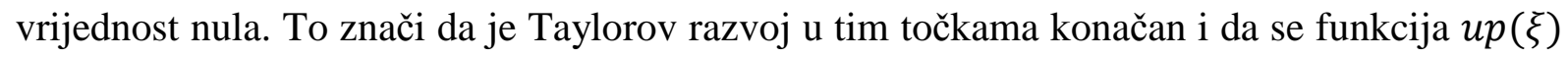
$\mathrm{u}$ binarno racionalnim točkama podudara s polinomom stupnja $n$, što je vidljivo i na crtežu 3.1 .

\subsection{Funkcionalno diferencijalna jednadžba za funkciju up( $(\xi)$}

Fourierova transformacija u obliku (3.8) može se prevesti u drugi oblik prikladniji za opisivanje svojstava funkcije $u p(\xi)$. Iz (3.8) izračuna se $F_{0}(t / 2)$ i zatim se jednadžba (3.8) podijeli tako da se lijeva strana podijeli s $F_{0}(t / 2)$, a desna s $\prod_{j=2}^{\infty} \frac{\sin \left(t / 2^{j}\right)}{t / 2^{j}}$

$$
F_{0}(t)=\frac{\sin (t / 2)}{t / 2} \cdot F_{0}(t / 2)
$$

Iz FT funkcije $u p(\xi)$ napisane $\mathrm{u}$ obliku (3.13) vidljivo je da ona posjeduje svojstvo drobljenja, odnosno da je u svakom njezinom dijelu sadržana cijela funkcija (holografski efekt).

Ako se u (3.13) uvrsti za $\sin (t / 2)=\left(e^{i t / 2}-e^{-i t / 2}\right) /(2 i)$ i tako dobivena jednadžba pomnoži s $(-1)$, nakon sređivanja sljedi

$$
-i t \cdot F_{0}(t)=e^{i t / 2} \cdot F_{0}(t / 2)-e^{-i t / 2} \cdot F_{0}(t / 2)
$$

Primjenom operatora inverzne FT $\left(\frac{1}{2 \pi} \int_{-\infty}^{+\infty} e^{-i t \xi} d \xi\right)$ na sve članove jednadžbe (3.14),

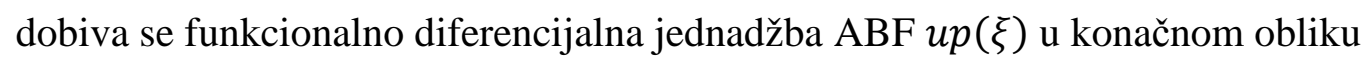

$$
u p^{\prime}(\xi)=2 \cdot u p(2 \xi+1)-2 \cdot u p(2 \xi-1)
$$


Općenito na lijevoj strani jednadžbe (3.15) je linearni diferencijalni operator s konstantnim koeficijentima, a na desnoj strani se nalazi linearna kombinacija sažetih i pomaknutih ABF $u p(\xi)$.

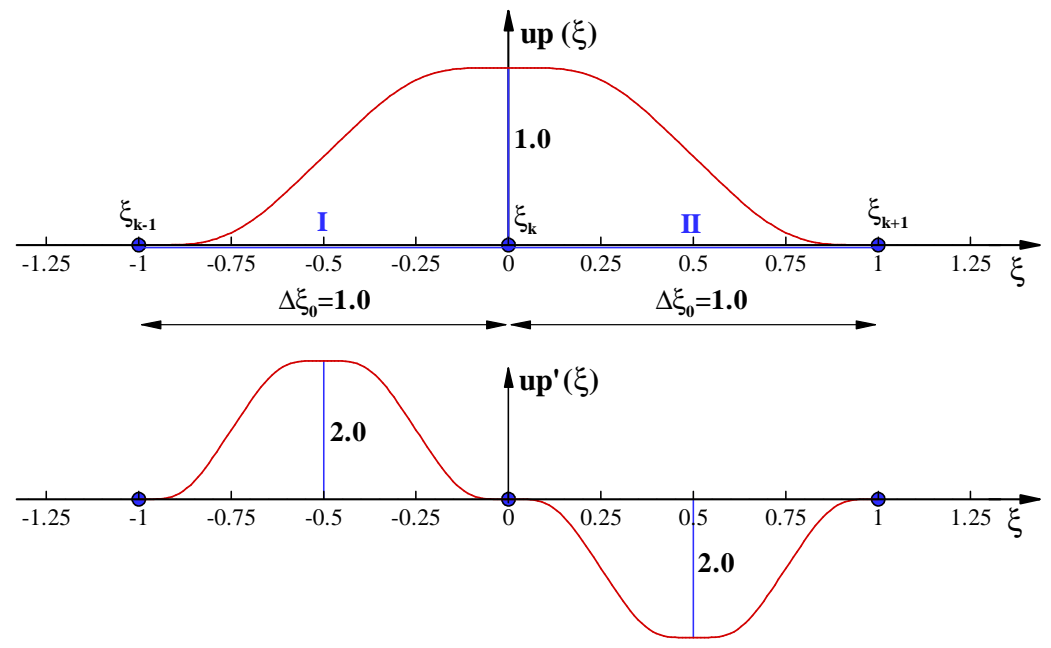

Crtež 3.3 Funkcija $u p(\xi)$ i njena prva derivacija

Na crtežu 3.3 prikazana je funkcija $u p(\xi)$ i njena prva derivacija. Vidljivo je da se radi o parnoj funkciji i da joj je nosač $\operatorname{supp}(u p(\xi))=[-1,1]$ sastavljen od dva karakteristična odsječka $\Delta \xi_{0}$ jedinične duljine.

Vrijednost $\mathrm{u}$ ishodištu $u p(0)=1$ je posljedica izbora normirnog uvjeta, kojim je određena vrijednost integrala $\int_{-\infty}^{+\infty} u p(\xi) d \xi=\int_{-1}^{1} u p(\xi) d \xi=1$ u području originala ili vrijednost FT u ishodištu $F_{0}(0)=1$ u području slike.

Karakteristični odsječak $\Delta \xi_{0}$ je dio nosača na kojemu se može točno prikazati polinom 0.tog stupnja linearnom kombinacijom baznih funkcija $u p(\xi)$ međusobno pomaknutih za duljinu karakterističnog odsječka.

\subsection{Derivacije i integrali funkcije up $(\xi)$}

Prva derivacija funkcije $u p(\xi)$ slijedi iz njene funkcionalno diferencijalne jednadžbe (3.15), a može se prikazati kao linearna kombinacija pomaknute i sažete same funkcije $u p(\xi)$.

Deriviranjem osnovne jednadžbe (3.15) dobiva se

$$
u p^{\prime \prime}(\xi)=4 \cdot u p^{\prime}(2 \xi+1)-4 \cdot u p^{\prime}(2 \xi-1)
$$

Zamjenom prve derivacije funkcije $u p(\xi) \mathrm{u}$ izrazu (3.16) s polaznom jednadžbom (3.15), i druga derivacija se također može prikazati kao linearna kombinacija sažete i pomaknute funkcije $u p(\xi)$ 


$$
u p^{\prime \prime}(\xi)=8 \cdot u p(4 \xi+3)-8 \cdot u p(4 \xi+1)-8 \cdot u p(4 \xi-1)+8 \cdot u p(4 \xi-3)
$$

Nastavljanjem postupka deriviranja i zamjene prve derivacije iz osnovne jednadžbe, dobiva se opći izraz za derivaciju $m$-tog stupnja [6], [43]

$$
u p^{(m)}(\xi)=2^{C_{m+1}^{2}} \sum_{k=1}^{2^{m}} \delta_{k} \cdot u p\left(2^{m} \xi+2^{m}+1-2 k\right), \quad m \in N
$$

gdje su $C_{m+1}^{2}=m(m+1) / 2$ binomni koeficijenti, a $\delta_{k}$ su koeficijenti koji imaju vrijednost \pm 1 i određuju predznak pojedinog pribrojnika mijenjajući se po sljedećim rekurzivnim formulama

$$
\delta_{2 k-1}=\delta_{k} \quad, \quad \delta_{2 k}=-\delta_{k} \quad, \quad k \in N \quad, \quad \delta_{1}=1
$$

Na crtežu 3.4 prikazana je funkcija $u p(\xi)$ i njene prve četiri i sedma derivacija. Vidi se da su derivacije sastavljene od funkcije $u p(\xi)$ "sažete" na odsječak duljine $2^{-m+1}$ i kojoj su ordinate "rastegnute" s faktorom $2^{C_{m+1}^{2}}$. Derivacija funkcije $u p(\xi)$ visokog stupnja kada $m \rightarrow \infty$ postaje niz čiji pojedini član teži Diracovoj funkciji.

Integral funkcije $u p(\xi)$ u granicama od $-\infty$ do $\xi \in(-\infty, 1]$ također slijedi iz osnovne jednadžbe (3.15), a određen je izrazom, [6]:

$$
I_{1}(\xi)=\int_{-\infty}^{\xi} u p(\xi) d \xi=u p\left(\frac{\xi}{2}-\frac{1}{2}\right)
$$

$\mathrm{Za} \xi>1$ funkcija integrala $I_{1}(\xi)$ je jedinični polinom nultog stupnja. Integriranjem jednadžbe (3.20) dobiva se drugi integral funkcije $u p(\xi)$

$$
I_{2}(\xi)=\int_{-\infty}^{\xi} u p\left(\frac{\xi}{2}-\frac{1}{2}\right) d \xi=2 \cdot u p\left(\frac{\xi}{4}-\frac{3}{4}\right)
$$

Nastavljanjem postupka slijedi treći i općenito $m$-ti integral:

$$
I_{m}(\xi)=2^{C_{m}^{2}} \cdot u p\left(2^{-m} \xi-1+2^{-m}\right), \quad m \in N
$$

Dakle, integral funkcije $u p(\xi)$ bilo kojeg reda u granicama od $-\infty$ do $\xi \in(-\infty, 1]$ odgovara funkciji $u p(\xi)$ koja je po osi apscise rastegnuta na $2^{m}$ puta veću duljinu nosača i koja je pomaknuta tako da je prva točka nosača u točki $\xi=-1$.

Prva tri integrala funkcije $u p(\xi)$ prikazana su na crtežu 3.5. 

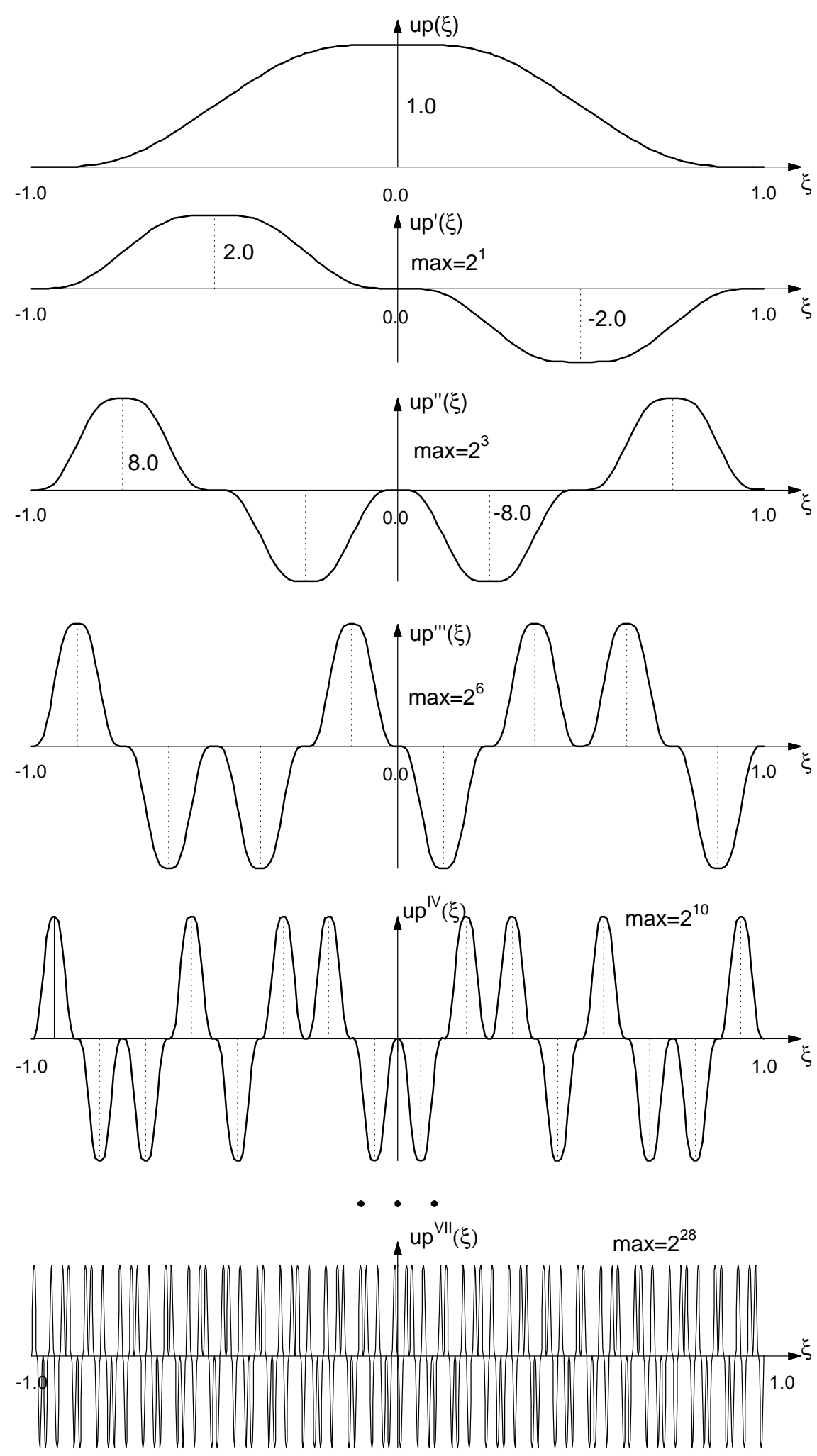

Crtež 3.4 Funkcija $u p(\xi)$, prve četiri i sedma derivacija 

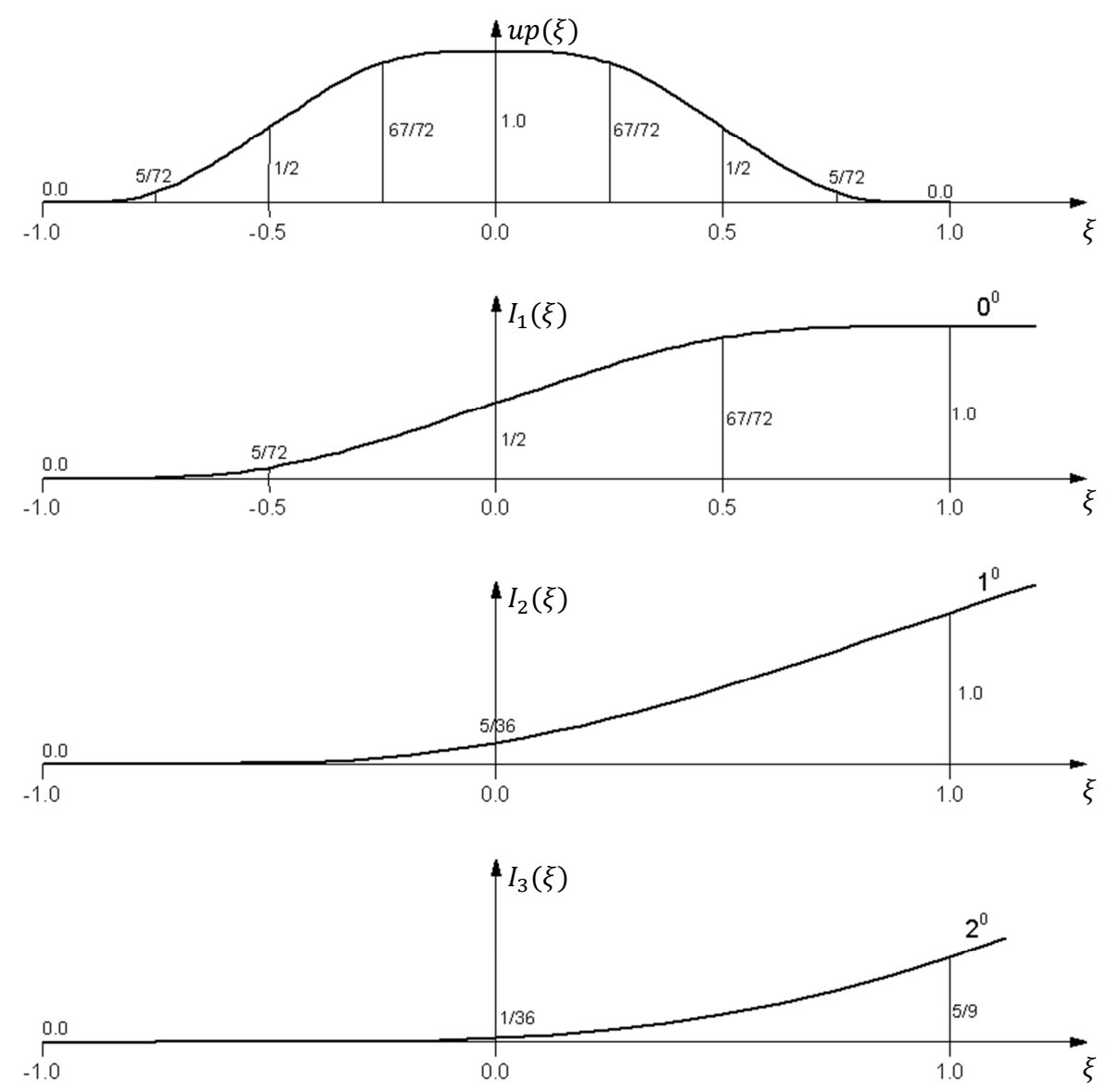

Crtež 3.5 Funkcija $u p(\xi)$ i prva tri integrala

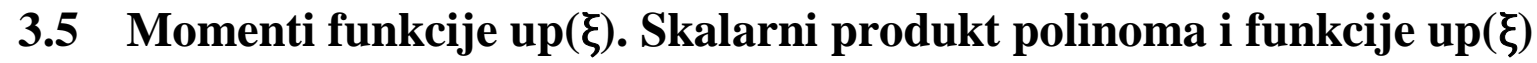

Momenti s parnim indeksom funkcije $u p(\xi)$ na virtualnom području (neparni momenti su jednaki nuli zbog parnosti funkcije)

$$
a_{2 k}=\int_{-1}^{1} \xi^{2 k} \cdot u p(\xi) d \xi, k \in N
$$

mogu se izračunati po sljedećoj formuli izvedenoj u [6], [43]

$$
a_{2 k}=\frac{(2 k) !}{2^{2 k}-1} \sum_{l=1}^{k} \frac{a_{2 k-2 l}}{(2 k-2 l) !(2 l+1) !}, \quad k \in N \quad ; \quad a_{0}=1
$$

Pomoćni momenti, odnosno skalarni produkti polinoma $\xi^{m}, m \in N$ i funkcije $u p(\xi)$ na pozitivnoj polovici virtualnog nosača, su

$$
b_{m}=\int_{0}^{1} \xi^{m} \cdot u p(\xi) d \xi, \quad m \in N
$$

Kako je funkcija $u p(\xi)$ parna, uspoređivanjem izraza (3.23) i (3.25) slijedi 


$$
b_{2 k}=\frac{1}{2} a_{2 k}, \quad k \in N
$$

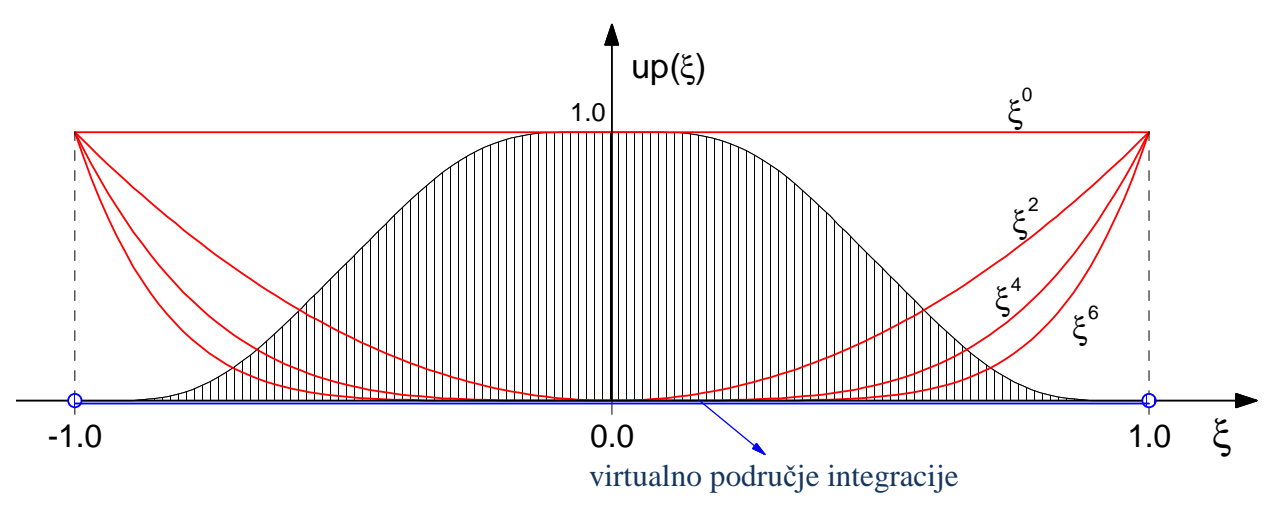

Crtež 3.6 Parni momenti $a_{2 k}$

Za pozitivne neparne indekse, prema (3.25) koristeći (3.24), dobiva se

$$
\begin{aligned}
& b_{2 k+1}=\frac{1}{(k+1) \cdot 2^{2 k+3}} \sum_{1=0}^{k+1} a_{2 \ell} \cdot C_{2(k+1)}^{2 \ell} ; \quad k \in N \\
& b_{-1}=1 \quad(\text { po definiciji) }
\end{aligned}
$$

Na negativnoj polovici virtualnog nosača pomoćni momenti $b_{m}$ su negativnog predznaka.

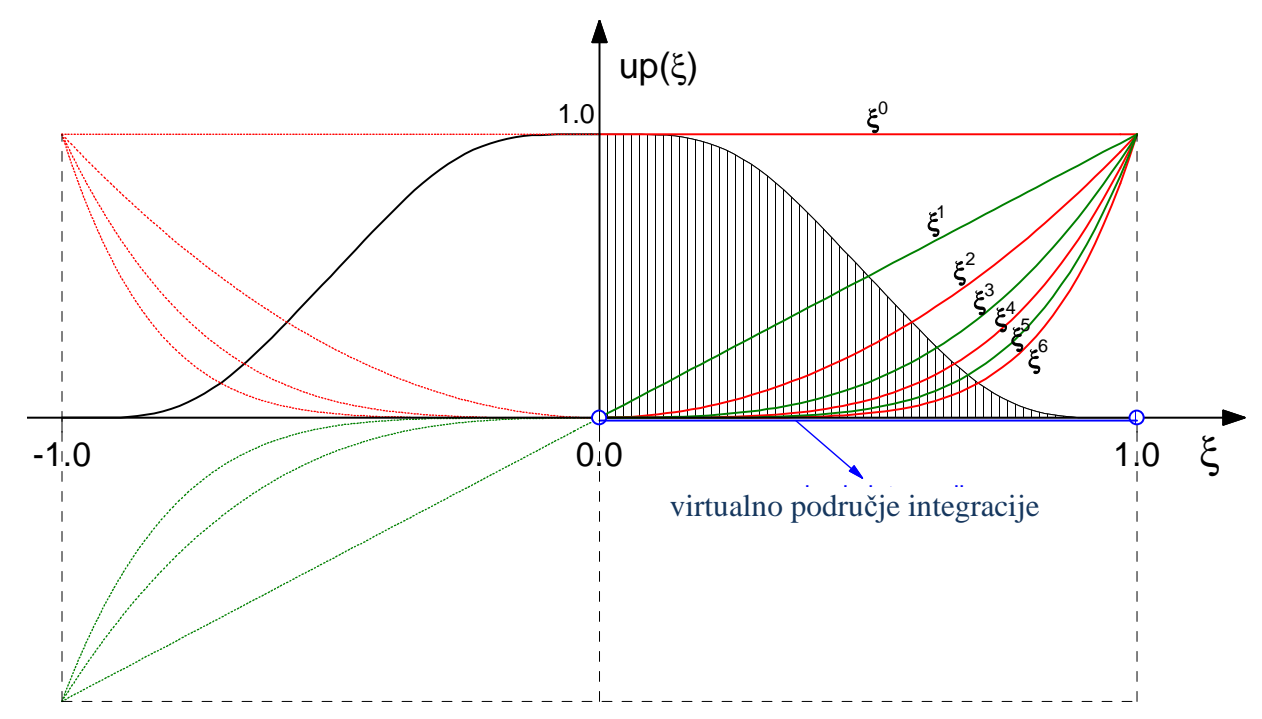

Crtež 3.7 Pomoćni momenti $b_{n}$

Za praktično korištenje potrebno je odrediti skalarni produkt polinoma $\xi^{m}, m \in N$ i funkcije $u p(\xi)$ na virtualnom karakterističnom odsječku $\Delta \xi_{n}=\left[k 2^{-n},(k+1) 2^{-n}\right]$

$$
M_{\text {virt }}(n, m, k)=\int_{-1+k / 2^{n}}^{-1+(k+1) / 2^{n}} \xi^{m} \cdot u p\left(\xi-1+k 2^{-n}\right) d \xi ; n, m \in N
$$


gdje $n$ određuje duljinu karakterističnog odsječka $\Delta \xi_{n}, \quad k=0, \ldots, 2^{n+1}-1$ indeks karakterističnog odsječka gledano s lijevog kraja nosača prema desnom, dok je $m$ stupanj polinoma u skalarnom produktu.

Uzastopnim parcijalnim integriranjem desne strane izraza $(3.28)(n+1)$ puta uz potrebne zamjene, integral u (3.28) može se napisati u sljedećem obliku

$$
\begin{aligned}
M_{\text {virt }}(n, m, k)=\frac{m !}{2^{n(m+1)}} & \left\{\sum_{l=0}^{n}(-1)^{l} \frac{u p^{(l)}\left(-1+(k+1) 2^{-n}\right)}{(l+m+1) ! 2^{n l}}+\right. \\
& \left.+\frac{(-1)^{n+1} \delta_{k+1}}{2^{(m+1)+n(n+1) / 2}} \sum_{i=0}^{m+n+1} \frac{a_{2(m+n+1-i)}}{i !(m+n+1-i) !}\right\}
\end{aligned}
$$

gdje su $\delta_{k+1}$ koeficijenti određeni izrazom (3.19), a $a_{2(m+n+1-i)}$ su parni momenti definirani izrazom (3.24).

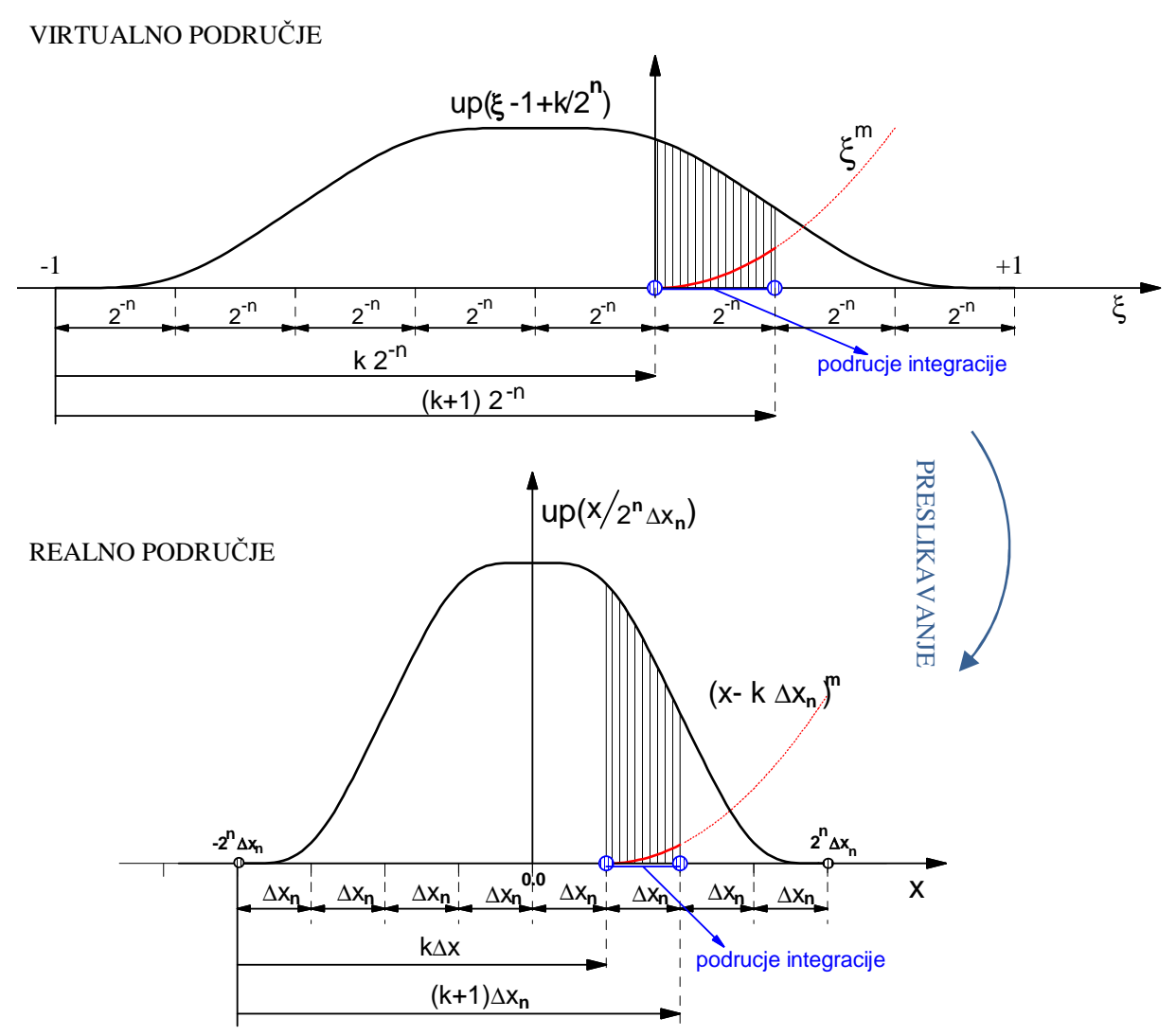

Crtež 3.8 Skalarni produkt polinoma i funkcije $u p(x)$ na virtualnom i realnom području

Skalarni produkt polinoma $x^{m}, m \in N$ i funkcije $u p(x)$ na realnom području na karakterističnom odsječku proizvoljne duljine $\Delta x_{n}$ može se napisati kao 


$$
M_{\text {real }}(n, m, k)=\int_{k / 2^{n}}^{(k+1) / 2^{n}}\left(x-k 2^{-n}\right)^{m} \cdot u p\left(\frac{x}{2^{n} \Delta x_{n}}\right) d x ; n, m \in N
$$

Primjenom odgovarajućih supstitucija (3.30) postaje

$$
M_{\text {real }}(n, m, k)=\left(2^{n} \Delta x_{n}\right)^{m+1} \int_{-1+k / 2^{n}}^{-1+(k+1) / 2^{n}}\left(\xi+1-k 2^{-n}\right)^{m} \cdot u p(\xi) d \xi
$$

odnosno

$$
M_{\text {real }}(n, m, k)=\left(2^{n} \Delta x_{n}\right)^{m+1} \sum_{l=0}^{m}\left(1-k 2^{-n}\right)^{l} \cdot C_{m}^{l} \cdot M_{v i r t}(n, m-l, k)
$$

gdje su $C_{m}^{l}$ binomni koeficijenti, a $M_{\text {virt }}(n, m-l, k)$ skalarni produkti na virtualnom karakterističnom odsječku $\Delta \xi_{n}$ definirani izrazom (3.29).

\subsection{Vrijednost funkcije up $(\xi)$ u binarno racionalnoj točki}

U literaturi [6], [43] izveden je numerički povoljniji izraz za izračunavanje vrijednosti funkcije $u p(\xi)$ u binarno racionalnoj točki $x_{b r}$

$$
u p\left(\xi_{b r}\right)=\frac{2^{-n(n+1) / 2}}{n !} \sum_{j=1}^{k} \delta_{j} \sum_{\ell=0}^{[n / 2]} C_{n}^{2 \ell} \cdot(2(k-j)+1)^{n-2 \ell} \cdot a_{2 \ell}
$$

gdje su $\delta_{j}$ koeficijenti koji imaju ulogu predznaka prema izrazu (3.19), $C_{n}^{2 \ell}$ su binomni koeficijenti, $a_{2 \ell}$ su parni momenti funkcije $u p(\xi)$ određeni sa (3.24), a uglate zagrade u izrazu $[n / 2]$ označavaju najveću cjelobrojnu vrijednost razlomka unutar zagrada.

$\mathrm{U}$ binarno racionalnoj točki $\xi_{1}=-1+2^{-n}$, izraz (3.33) može se jednostavnije napisati

$$
u p\left(-1+2^{-n}\right)=\frac{b_{n-1}}{2^{n(n-1) / 2} \cdot(n-1) !}, \quad n=0,1, \ldots
$$

gdje je pomoćni moment $b_{n-1}$ određen izrazom (3.27). Uvrštavanjem (3.34) u opći izraz za derivaciju funkcije $u p(\xi)$ (3.18) dobiva se vrijednost derivacije funkcije $u p(\xi) \mathrm{u}$ binarno racionalnoj točki $\xi_{1}=-1+2^{-n}$

$$
u p^{(\ell)}\left(-1+2^{-n}\right)=\frac{2^{-n(n-2 \ell-1) / 2}}{(n-\ell-1) !} \cdot b_{n-\ell-1}
$$




\subsection{Vrijednost funkcije up( $(\xi)$ u proizvoljnoj točki}

S obzirom da je riječ o parnoj funkciji, dovoljno je promatrati točke iz odsječka $\xi \in$ $[-1,0]$. Za funkciju

$$
\varphi_{n}(\xi)=u p(\xi)+u p\left(\xi-2^{-n}\right)
$$

na odsječku $\left[-1+2^{-n},-1+2^{-n+1}\right]$ dobiva se prema (3.18) $\varphi_{n}^{(n+1)}(\xi) \equiv 0$, jer je $\delta_{2}=-\delta_{1}$. Koristeći Taylor-ovu formulu u karakterističnoj točki $\xi_{k}=-1+2^{-n}$, na tom odsječku je:

$$
\varphi_{n}(\xi)=\sum_{l=0}^{n} \frac{\varphi_{n}^{(l)}\left(-1+2^{-n}\right)}{l !} \cdot\left(\xi-\left(-1+2^{-n}\right)\right)^{l}
$$

gdje je prema (3.36)

$$
\begin{aligned}
\varphi_{n}^{(l)}\left(-1+2^{-n}\right) & =u p^{(l)}\left(-1+2^{-n}\right)+u p^{(l)}\left(-1+2^{-n}-2^{-n}\right) \\
& =u p^{(l)}\left(-1+2^{-n}\right)+u p^{(l)}(-1) \\
& =u p^{(l)}\left(-1+2^{-n}\right)
\end{aligned}
$$

Grafička interpretacija izraza (3.36) za $n=0,1,2,3$ dana je na crtežu 3.9.

Uvrštavajući (3.38) u (3.37) pa potom u (3.36), slijedi da je na odsječku $\left[-1+2^{-n},-1+\right.$ $\left.2^{-n+1}\right]$ vrijednost funkcije $u p(\xi)$ jednaka

$$
u p(\xi)=\sum_{l=0}^{n} \frac{u p^{(l)}\left(-1+2^{-n}\right)}{l !} \cdot\left(\xi+1-2^{-n}\right)^{l}-u p\left(\xi-2^{-n}\right)
$$

Dakle, za izračunavanje vrijednosti funkcije $u p(\xi)$ u točkama $\xi \in\left[-1+2^{-n},-1+\right.$ $\left.2^{-n+1}\right]$, potrebno je poznavati njezine vrijednosti u točkama $\xi \in\left[-1,-1+2^{-n}\right]$.

Ako se odsječak $\left[-1,-1+2^{-n}\right]$ raspolovi na odsječke $\left[-1,-1+2^{-n-1}\right]$ i $[-1+$ $\left.2^{-n-1},-1+2^{-n}\right]$, tada se izračunavanje vrijednosti funkcije $u p(\xi)$ na odsječku $[-1+$ $\left.2^{-n-1},-1+2^{-n}\right]$ svodi na određivanje njezinih vrijednosti na odsječku $[-1,-1+$ $\left.2^{-n-1}\right]$. Nastavljanjem postupka dobiva se mogućnost konstruiranja reda za izračunavanje vrijednosti funkcije $u p(\xi)$ u bilo kojoj točki nosača.

Na temelju činjenice da Taylorov razvoj funkcije up $(\xi)$ u binarno racionalnim točkama $\xi_{b r}$ predstavlja polinom $n$-tog stupnja (vidi točku 3.2), u literaturi [6], [43] predložen je specijalni red za izračunavanje vrijednosti funkcije $u p(\xi)$ u proizvoljnoj točki $\xi \in[0,1] \mathrm{u}$ obliku:

$$
u p(\xi)=1-u p(\xi-1)=1-\sum_{k=1}^{\infty}(-1)^{1+p_{1}+\cdots+p_{k}} p_{k} \sum_{j=0}^{k} C_{j k} \cdot \Delta_{k}^{j}
$$



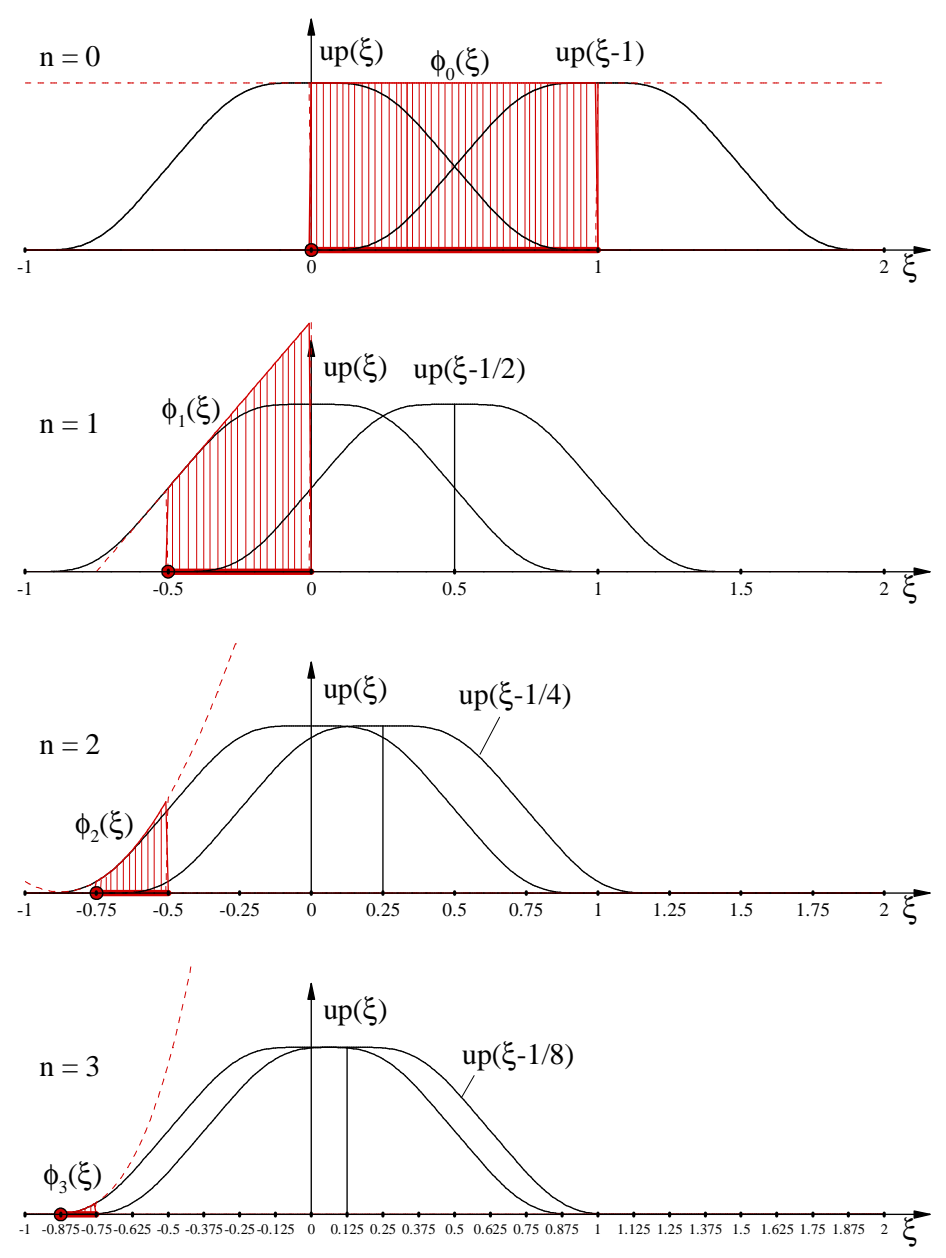

Crtež 3.9 Razvoj funkcije $u p(\xi)$ u Taylorov red u točki $\xi=-1+2^{-n}, n=0,1,2,3$

gdje su koeficijenti $C_{j k}$ racionalni brojevi koji u sebi sadrže vrijednosti funkcije $u p(\xi) \mathrm{u}$ točkama tipa $\xi_{k}=-1+1 / 2^{n}$. Određuju se prema sljedećem izrazu, a izračunati su i tabelirani u [6]:

$$
C_{j k}=\frac{1}{j !} 2^{j(j+1) / 2} u p\left(-1+2^{-(k-j)}\right) ; \quad j=0,1, \ldots, k ; k=1,2, \ldots, \infty
$$

Izraz $\Delta_{k}$ u (3.40) predstavlja razliku između stvarne vrijednosti koordinate $\xi$ i njezina binarnog prikaza s $k$ bitova, gdje su $p_{1} \ldots p_{k}$ znamenke 0 ili 1 binarnog razvoja vrijednosti koordinate $\xi$ :

$$
\Delta_{k}=\xi-\sum_{i=1}^{k} p_{i} \cdot \frac{1}{2^{i}}
$$

Dakle, točnost prikaza koordinate $\xi$, a time i točnost funkcije $u p(\xi)$ u proizvoljnoj točki, ovisi o točnosti elektroničkog računala. Za neki $n$ pogreška izračunate vrijednosti funkcije $u p(\xi)$ u proizvoljnoj točki $\xi$, odnosno ostatak reda iz (3.40) kada je $k=1, \ldots, n$, ne prelazi vrijednost funkcije up $\left(-1+2^{-n}\right)$ dobivene prema (3.34) i dane u Dodatku A.1. 
Za ilustraciju, na crtežu 3.10 prikazan je postupak dobivanja vrijednosti funkcije $u p(\xi) \mathrm{u}$ binarno racionalnim točkama $\mathrm{s}$ gustoćom $2^{-6}$ prema izrazu (3.39). Dakle, ako se zna vrijednost funkcije $u p(\xi)$ i prvih šest derivacija u točki $\xi=-1+2^{-6}$, može se izračunati vrijednost funkcije $u p(\xi)$ u točkama na razmaku $\Delta \xi=\frac{1}{64}$ kojih na cijelom nosaču ima ukupno 128. U svim ostalim točkama između, vrijednost funkcije $u p(\xi)$ izračunava se približno prema (3.40) a pri tome greška nije veća od vrijednosti up $\left(-1+2^{-6}\right)=0.205$. $10^{-8}$.

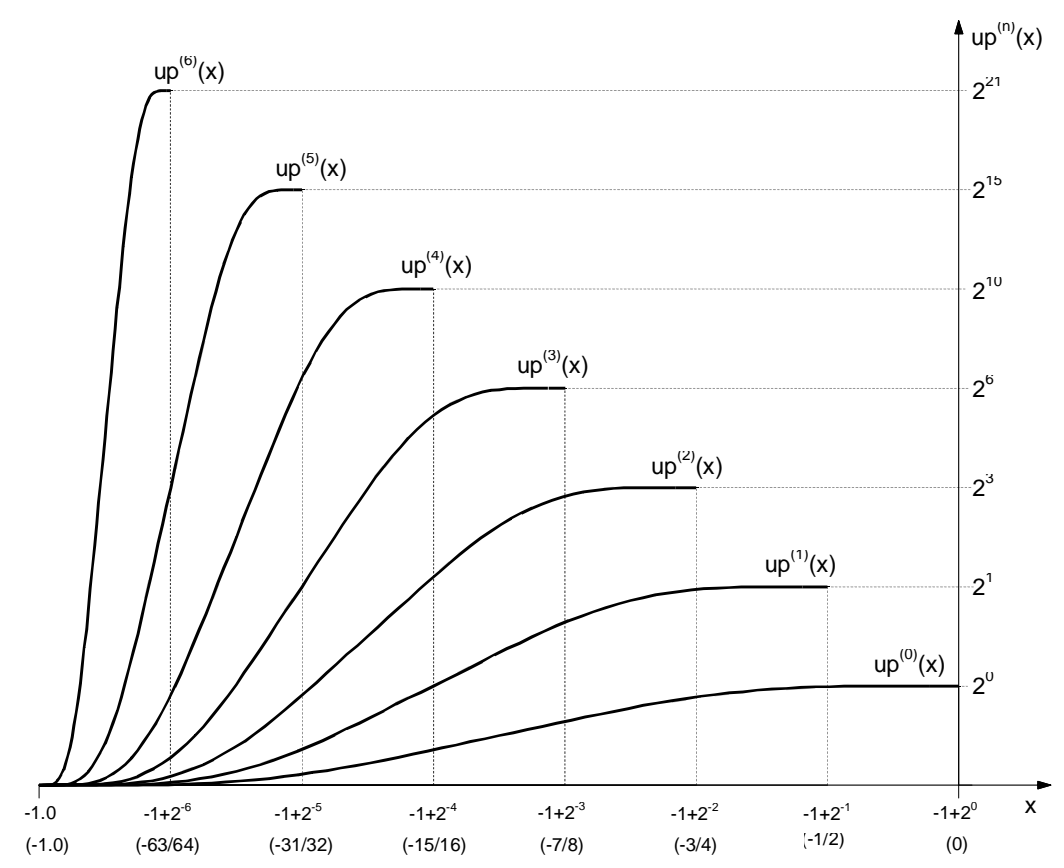

Crtež 3.10 Određivanje vrijednosti funkcije $u p(\xi)$ u binarno racionalnim točkama

Primjer. Izračunati vrijednost funkcije $u p(\xi)$ u točki $\xi=0.4375$ pomoću reda (3.40)

$$
\begin{array}{c|c|c|c|c|c|c|c|c}
\Delta_{1} & =0.4375-\left(0 \cdot 1+0 \cdot \frac{1}{2}\right)=0.4375 \\
\xi & p_{1} & p_{2} & p_{3} & p_{4} \\
\hline 0.4375 & 0 & 1 & 1 & 1
\end{array} \rightarrow \begin{aligned}
& \Delta_{2}=0.4375-\left(0 \cdot 1+0 \cdot \frac{1}{2}+1 \cdot \frac{1}{4}\right)=0.1875 \\
& \Delta_{3}=0.4375-\left(0 \cdot 1+0 \cdot \frac{1}{2}+1 \cdot \frac{1}{4}+1 \cdot \frac{1}{8}\right)=0.0625 \\
& \Delta_{4}=0.4375-\left(0 \cdot 1+0 \cdot \frac{1}{2}+1 \cdot \frac{1}{4}+1 \cdot \frac{1}{8}+1 \cdot \frac{1}{16}\right)=0
\end{aligned}
$$




$$
\begin{aligned}
u p(0.4375)=1- & \left\{-0 \cdot\left[u p\left(-\frac{1}{2}\right)+u p^{\prime}\left(-\frac{1}{2}\right) \cdot \Delta_{1}\right]-\right. \\
& +1 \cdot\left[u p\left(-\frac{3}{4}\right)+u p^{\prime}\left(-\frac{3}{4}\right) \cdot \Delta_{2}+\frac{1}{2 !} \cdot u p^{\prime \prime}\left(-\frac{3}{4}\right) \cdot \Delta_{2}{ }^{2}\right]- \\
& -1 \cdot\left[u p\left(-\frac{7}{8}\right)+u p^{\prime}\left(-\frac{7}{8}\right) \cdot \Delta_{3}+\frac{1}{2 !} \cdot u p^{\prime \prime}\left(-\frac{7}{8}\right) \cdot \Delta_{3}^{2}+\frac{1}{3 !} \cdot u p^{\prime \prime \prime}\left(-\frac{7}{8}\right) \cdot \Delta_{3}^{3}\right]+ \\
& \left.+1 \cdot\left[u p\left(-\frac{15}{16}\right)\right]\right\} \\
=1- & \left\{\left[\frac{5}{72}+1 \cdot 0.1875+\frac{1}{2} \cdot 8 \cdot 0.1875^{2}\right]-\right. \\
& \quad-\left[\frac{1}{288}+\frac{5}{36} \cdot 0.0625+\frac{1}{2} \cdot 4 \cdot 0.0625^{2}+\frac{1}{6} \cdot 64 \cdot 0.0625^{3}\right]+ \\
& \left.+\left[\frac{143}{2073600}\right]\right\} \\
= & \frac{1295857}{2073600}
\end{aligned}
$$

\subsection{Polinom kao linearna kombinacija pomaknutih up( $(\xi)$ funkcija}

Da bi linearna kombinacija baznih funkcija $u p(\xi)$, međusobno pomaknutih za $\Delta \xi_{n}=2^{-n}$, točno razvijala monom do uključivo stupnja $n, \mathrm{tj}$.

$$
\xi^{n}=\sum_{k=-\infty}^{\infty} C_{k} \cdot u p\left(\xi-k \cdot \Delta \xi_{n}\right), \quad k \in Z
$$

nužno je i dovoljno da $(n+1)$ derivacija od (3.43) bude jednaka nuli, odnosno:

$$
\left(\xi^{n}\right)^{(n+1)}=\sum_{k=-\infty}^{\infty} C_{k} \cdot u p^{(n+1)}\left(\xi-k \cdot \Delta \xi_{n}\right) \equiv 0
$$

Iz (3.44) prema izrazu za derivaciju (3.18) slijedi da koeficijenti $C_{k}$ na odsječku $[k, k+$ $\left.2^{-n}\right]$ moraju zadovoljiti sljedeću jednadžbu

$$
\sum_{j=1}^{2^{n+1}} C_{k+j} \cdot \delta_{j}=0
$$

Na crtežu 3.11 ilustrirani su izrazi (3.44) i (3.45) za monome $\xi^{0} \mathrm{i} \xi^{1}$. 

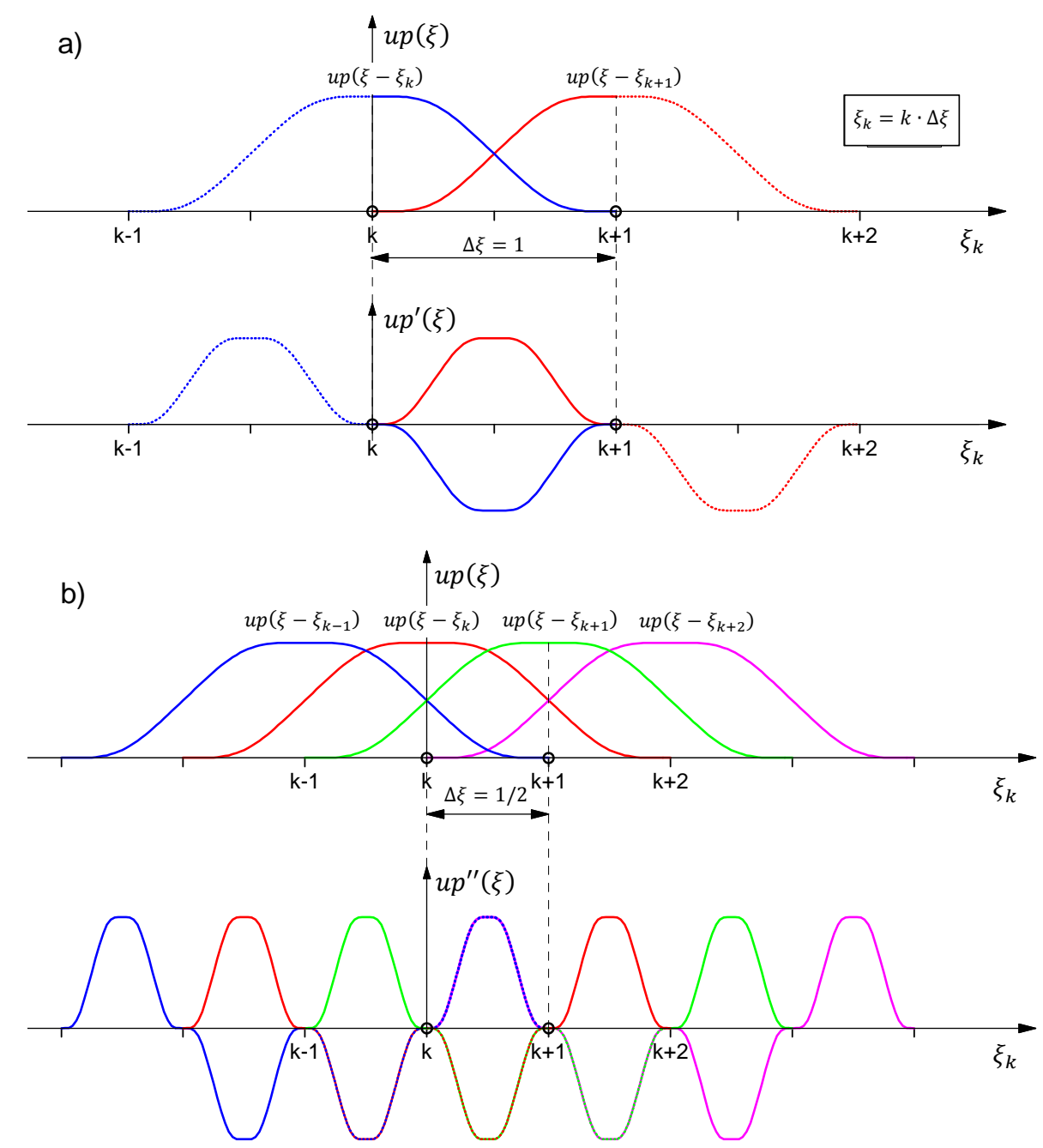

Crtež 3.11 Linearna kombinacija baznih funkcija i pripadajućih $(n+1)$-ih derivacija za: a) $n=0$; b) $n=1$

Linearnom kombinacijom baznih funkcija $u p(\xi)$ međusobno pomaknutih za $\Delta \xi_{n}=2^{-n}$ točno se razvijaju monomi do uključivo stupnja $n$. Prema [6], [43] koeficijenti $C_{k}$ za točan razvoj monoma $m$ - tog stupnja $(m=0,1, \ldots, n)$ prema izrazu (3.45) moraju i sami biti polinomi stupnja $m$ od indeksa $k$ oblika

$$
C_{k} \quad \rightarrow \quad C_{n}^{(m)}(k)=2^{-n} \cdot\left(\Delta \xi_{n}\right)^{m} \cdot \sum_{i=0}^{m} A_{m-i}^{(m, n)} \cdot k^{m-i}
$$

gdje je $m$ stupanj polinoma, dok $n$ označava najveći stupanj polinoma sadržan u vektorskom prostoru $U P_{n}$.

Na primjer, za monome do drugog stupnja i raspored baznih funkcija prikazan na crtežu 3.12c) (dakle za $n=2$ ) koeficijenti $C_{2}^{(m)}(k)$ se prema (3.46) mogu prikazati u općem obliku: 


$$
\begin{aligned}
n=2, & m=0 \rightarrow C_{2}^{(0)}(k)=2^{-2} \cdot\left(2^{-2}\right)^{0} \cdot\left(A_{0}^{(0,2)} \cdot k^{0}\right) \\
& m=1 \rightarrow C_{2}^{(1)}(k)=2^{-2} \cdot\left(2^{-2}\right)^{1} \cdot\left(A_{1}^{(1,2)} \cdot k^{1}+A_{0}^{(1,2)} \cdot k^{0}\right) \\
& m=2 \rightarrow C_{2}^{(2)}(k)=2^{-2} \cdot\left(2^{-2}\right)^{2} \cdot\left(A_{2}^{(2,2)} \cdot k^{2}+A_{1}^{(2,2)} \cdot k^{1}+A_{0}^{(2,2)} \cdot k^{0}\right)
\end{aligned}
$$

Koeficijenti $A_{m-i}^{(m, n)}$ mogu se odrediti metodom kolokacije na način da se (3.43) izrazi u $(m+1)$ kolokacijskih točaka međusobno razmaknutih za $\Delta \xi_{n}=2^{-n}$

$$
\begin{array}{r}
{\left[(k+i) \cdot \Delta \xi_{n}\right]^{m}=\sum_{j=k+i-\left(2^{n}-1\right)}^{k+i+\left(2^{n}-1\right)} C_{n}^{(m)}(j) \cdot u p\left(\xi-(j-i) \cdot \Delta \xi_{n}\right)} \\
i=0, \ldots, m ; m=0, \ldots, n ; n \in N
\end{array}
$$

gdje su $C_{n}^{(m)}(k)$ određeni sa (3.46).

Na primjer, za $n=2$ i $m=2$ sustav je slijedeći

$$
\begin{aligned}
& C_{2}^{(m)}(k-3) \cdot u p\left(-\frac{3}{4}\right)+C_{2}^{(m)}(k-2) \cdot u p\left(-\frac{1}{2}\right)+C_{2}^{(m)}(k-1) \cdot u p\left(-\frac{1}{4}\right)+C_{2}^{(m)}(k) \cdot u p(0)+ \\
& +C_{2}^{(m)}(k+1) \cdot u p\left(\frac{1}{4}\right)+C_{2}^{(m)}(k+2) \cdot u p\left(\frac{1}{2}\right)+C_{2}^{(m)}(k+3) \cdot u p\left(\frac{3}{4}\right)=\left[(k) \cdot 2^{-2}\right]^{2} \\
& C_{2}^{(m)}(k-2) \cdot u p\left(-\frac{3}{4}\right)+C_{2}^{(m)}(k-1) \cdot u p\left(-\frac{1}{2}\right)+C_{2}^{(m)}(k \quad) \cdot u p\left(-\frac{1}{4}\right)+C_{2}^{(m)}(k) \cdot u p(k+1)+ \\
& +C_{2}^{(m)}(k+2) \cdot u p\left(\frac{1}{4}\right)+C_{2}^{(m)}(k+3) \cdot u p\left(\frac{1}{2}\right)+C_{2}^{(m)}(k+4) \cdot u p\left(\frac{3}{4}\right)=\left[(k+1) \cdot 2^{-2}\right]^{2} \\
& C_{2}^{(m)}(k-1) \cdot u p\left(-\frac{3}{4}\right)+C_{2}^{(m)}(k \quad) \cdot u p\left(-\frac{1}{2}\right)+C_{2}^{(m)}(k+1) \cdot u p\left(-\frac{1}{4}\right)+C_{2}^{(m)}(k) \cdot u p(k+2) \\
& C_{2}^{(m)}(k+3) \cdot u p\left(\frac{1}{4}\right)+C_{2}^{(m)}(k+4) \cdot u p\left(\frac{1}{2}\right)+C_{2}^{(m)}(k+5) \cdot u p\left(\frac{3}{4}\right)=\left[(k+2) \cdot 2^{-2}\right]^{2}
\end{aligned}
$$

Koeficijenti $A_{m-i}^{(m, n)}$ izračunati iz (3.46) i sustava (3.48) mogu se napisati u poopćenom obliku:

$$
\begin{aligned}
& A_{m}^{(m, n)}=1 \\
& A_{m-2 i+1}^{(m, n)}=0, \quad \mathrm{i}=1,2, \ldots,[m / 2] \\
& A_{m-2 i}^{(m, n)}=-\frac{2^{1-n}}{(m-2 i) !} \sum_{l=0}^{i-1}\left\{A_{m-2 l}^{(m, n)} \cdot \frac{(2 i-2 l) !}{(m-2 l) !} \sum_{j=1}^{2^{n}-1}\left[u p\left(\frac{j}{2^{n}}\right) \cdot j^{2(i-l)}\right]\right\}
\end{aligned}
$$

Prema (3.49) koeficijenti $A_{m-i}^{(m, 2)}, i=1,2, \ldots,[m / 2]$ za pripadajući $m$ iz (3.47) imaju sljedeće vrijednosti

$$
\begin{gathered}
A_{0}^{(0,2)}=1 \\
A_{1}^{(1,2)}=1 ; A_{0}^{(1,2)}=0 \\
A_{2}^{(2,2)}=1 ; A_{1}^{(2,2)}=0 ; A_{0}^{(2,2)}=-\frac{16}{9}
\end{gathered}
$$

tako da se prema (3.43), te (3.47) i (3.50) mogu izraziti monomi do drugog stupnja s rasporedom baznih funkcija prema crtežu 3.12c) na način: 

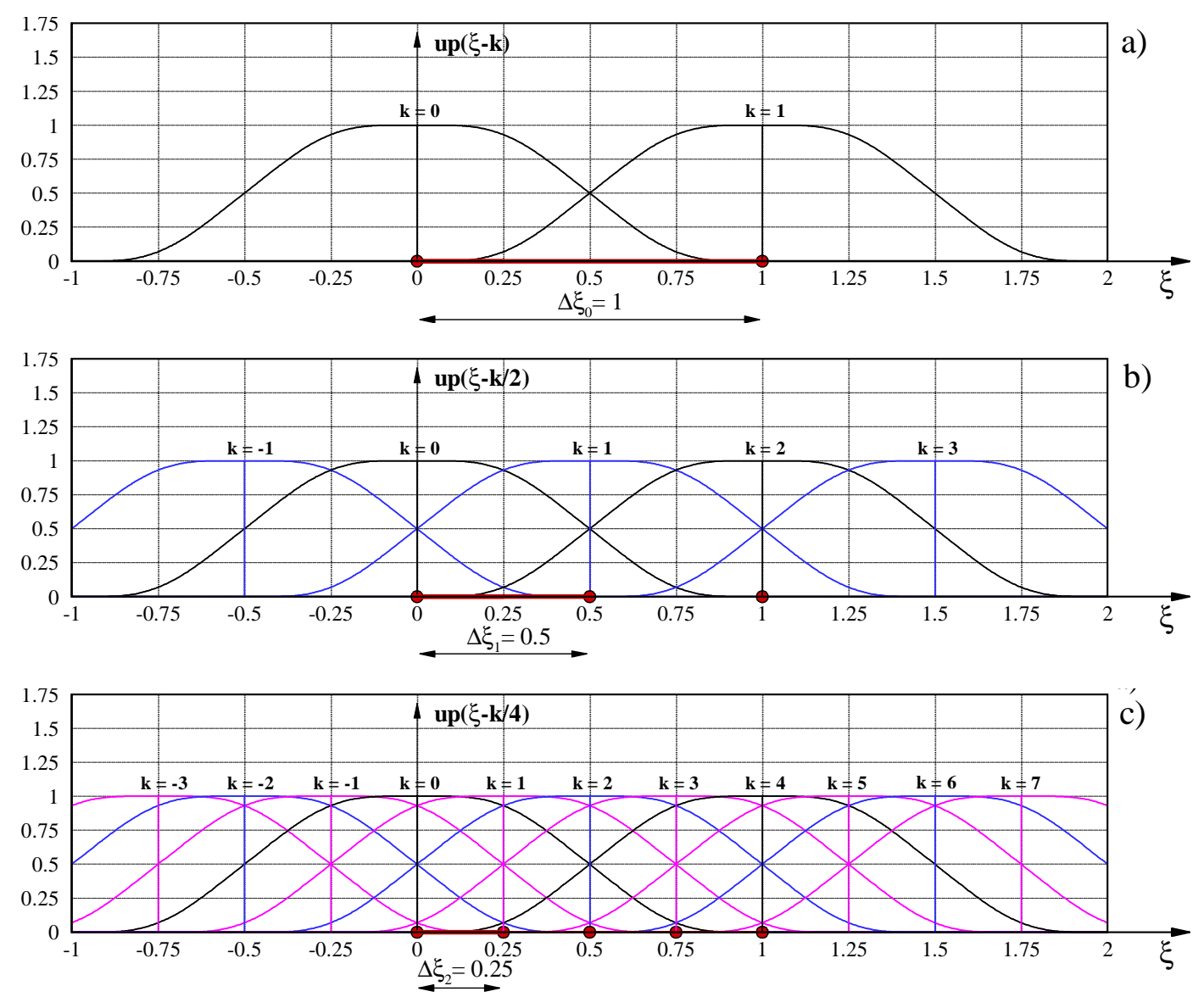

Crtež 3.12 Raspored baznih funkcija za točan prikaz polinoma stupnja 0,1 i 2

$$
\begin{aligned}
n=2, & m=0 \rightarrow 1=2^{-2} \sum_{k=-\infty}^{\infty} u p(\xi-k / 4) \\
m=1 & \rightarrow \xi=2^{-4} \sum_{k=-\infty}^{\infty} k \cdot u p(\xi-k / 4) \\
m=2 & \rightarrow \xi^{2}=2^{-6} \sum_{k=-\infty}^{\infty}\left(k^{2}-\frac{16}{9}\right) \cdot u p(\xi-k / 4)
\end{aligned}
$$

Na crtežu 3.12 prikazan je raspored baznih funkcija dobivenih pomicanjem funkcije up $(\xi)$ za $k \cdot \Delta \xi_{n}, k \in Z, n=0,1,2$, čijom se linearnom kombinacijom na odsječku $\Delta \xi_{n}$ mogu točno izraziti polinomi stupnja $n$ prema izrazima iz (3.51).

Korištenjem koeficijenata (3.46) i (3.49) na virtualnom području i preslikavanjem odsječka $2^{-n}$ na realnu duljinu odsječka $\Delta x_{n}$, linearna kombinacija (3.43) u realnom području postaje

$$
x^{m}=\Delta x_{n}^{m} \cdot \Delta \xi_{n} \cdot \sum_{k=-\infty}^{\infty}\left\{\left(\sum_{i=0}^{m} A_{m-i}^{(m, n)} \cdot k^{m-i}\right) \cdot u p\left(\frac{x}{2^{n} \Delta x_{n}}-\frac{k}{2^{n}}\right)\right\}
$$




\subsection{Skalarni produkt međusobno pomaknutih funkcija up( $(\xi)$}

Neka je zadana funkcija $f(\xi)$ i njezina aproksimacija u obliku

$$
\tilde{f}(\xi)=c_{i} \cdot \psi_{i}(\xi) ; i \in Z
$$

Ako se za određivanje nepoznatih koeficijenata $c_{i}$ iz (3.53) odabere nejaka (integralna) formulacija tada je potrebno riješiti sustav jednadžbi

$$
a_{i j} \cdot c_{j}=b_{j} ; \quad i, j \in N
$$

gdje je

$$
a_{i j}=\int_{-\infty}^{\infty} \psi_{i}(\xi) \cdot \psi_{j}(\xi) d \xi \quad ; \quad b_{j}=\int_{-\infty}^{\infty} f(\xi) \cdot \psi_{j}(\xi) d \xi
$$

Ukoliko se funkcije $\psi_{i}$ odaberu iz vektorskog prostora $U P_{n}$ tada se prema (3.55) javlja potreba izračunavanja skalarnog produkta međusobno pomaknutih funkcija $u p(\xi)$ tipa:

$$
\int_{\alpha_{1}}^{\alpha_{2}} u p(\xi-\beta) \cdot u p(\xi) d \xi
$$

Pomak $\beta$ može se prikazati kao višekratnik karakterističnog odsječka $\Delta \xi_{n}$

$$
\beta=k \cdot 2^{-n}, \quad k \in Z, n \in N
$$

a područje integracije $\left[\alpha_{1}, \alpha_{2}\right]$ kao $\Delta_{n}$ :

$$
\Delta_{n}=\left[l 2^{-n},(l+1) 2^{-n}\right], \quad l \in Z
$$

Kako bi se izbjegla numerička integracija izraza (3.56), u nastavku su dani izvodi formula

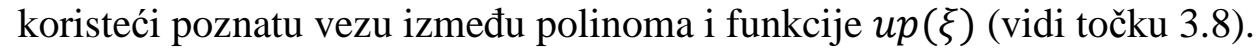

Ako je zadana funkcija $f(\xi)$ polinom $n-\operatorname{tog}$ stupnja $\xi^{n}, n \in N$ koeficijenti linearne kombinacije $c_{i}$ su poznati brojevi određeni izrazima (3.46) i (3.49), a desna strana $b_{j}$ iz (3.55) predstavlja skalarni produkt polinoma $\xi^{n}, n \in N$ i funkcije $u p(\xi)$ na karakterističnom odsječku $\Delta \xi_{n}=2^{-n}$ određen izrazom (3.29).

Elementi matrice sustava u (3.55) su skalarni produkti baznih funkcija prema (3.56) i označeni su sa $\gamma_{i j}^{(n)}$. Pri tome $i$ označava indeks prvog faktora, $j$ indeks drugog faktora $\mathrm{u}$ skalarnom produktu, a $n$ je stupanj polinoma koji se može izraziti pomoću linearne kombinacije funkcija $u p(\xi)$ pomaknutih za veličinu $\beta$ iz (3.57) prema (3.43).

U literaturi [6] pokazano je da se svi koeficijenti $\gamma_{i j}^{(n)} \operatorname{mogu}$ izraziti preko samo jedne veličine $\gamma$ u obliku 


$$
\gamma=\int_{-1}^{1} u p^{2}(\xi) d \xi
$$

a čija se vrijednost određuje numerički i iznosi

$$
\gamma=0.808873535967970562931242982288212447845879929
$$

što predstavlja točnost daleko iznad praktičnih potreba, tako da se vrijednosti svih koeficijenata $\gamma_{i j}^{(n)}$ mogu izračunavati s točnosti računala.

Koeficijenti $\gamma_{i j}^{(n)}, n \in N ; i, j=1,2, \ldots, 2^{n+1}$ simetrični su u odnosu na glavnu i na sporednu dijagonalu matrice sustava, pa umjesto $2^{2(n+1)}$ ima ukupno $\left(2^{2 n}+2^{n}\right)$ nepoznatih koeficijenata.

Za određivanje $2^{n}$ nepoznatih elemenata na glavnoj dijagonali $\gamma_{i j}^{(n)}, i=j$ izveden je izraz analogan onome za određivanje koeficijenta $\gamma \mathrm{u}$ obliku sljedećeg reda

$$
\begin{aligned}
\gamma_{i j}(n, k, s)= & \sum_{l}^{s-1}(-1)^{l} 2^{l(l+1)} u p\left(-1+\frac{k}{2^{n+l+1}}\right) \sum_{i=1}^{k 2^{s-n-1}} \delta_{i} u p\left(\frac{k}{2^{n-l}}-(2 i-1)\right)+ \\
+ & (-1)^{s} \sum_{l=0}^{s} \frac{a_{2 l}}{(2 l) !} 2^{s(s-1) / 2-2 s l} \sum_{j=1}^{k 2^{s-n-1}} \delta_{j} \cdot \\
& \cdot \begin{cases}2^{(s-2 l)(s-2 l-1) / 2} u p\left(-1+2^{-2(s-l)}(2 j-1)\right) & s \geq 2 l \\
2^{(2 l-s)(2 l-s+1) / 2} \sum_{r=1}^{2^{2 l-s}} \delta_{r} u p\left(2^{-2(s-l)}(2 j-1)-(2 i-1)\right) ; & s<2 l\end{cases}
\end{aligned}
$$

gdje $n \in N$ određuje duljinu karakterističnog odsječka (područje integracije), $k=$ $0,1, \ldots, 2^{n}-1$ je indeks karakterističnih odsječaka, $s \in N$ je parametar točnosti. Također, $\delta_{i(j, r)}$ su koeficijenti određeni izrazom (3.19), a $a_{2 l}$ su momenti definirani sa (3.24). Ostali $2^{2 n}$ nepoznati koeficijenti određuju se iz veze polinoma i funkcije $u p(\xi)$. Na primjer, za $n=0$ na odsječku $[1,2]$ koeficijenti $\gamma_{i j}^{(0)} ; \mathrm{i}, \mathrm{j}=1,2$ prikazani su u sljedećoj tablici:

\begin{tabular}{|c|c|}
\hline$\gamma_{11}^{(0)}, \ldots$ &,$\gamma_{12}^{(0)} \cdots$ \\
\hline$\gamma_{21}^{(0)}=\gamma_{12}^{(0)}$ & $\gamma_{22}^{(1)}=\gamma_{11}^{(0)}$ \\
\hline
\end{tabular}

Koeficijent na glavnoj dijagonali $\gamma_{11}^{(0)}$ određuje se iz (3.61)

$$
\gamma_{11}^{(0)}=\gamma_{22}^{(0)}=\frac{\gamma}{2}
$$


dok se nepoznati koeficijent izvan glavne dijagonale $\gamma_{12}^{(0)}$ određuje pomoću razvoja konstante u prostoru $U P_{n}$ te iznosi

$$
\gamma_{12}^{(0)}=\gamma_{21}^{(0)}=\frac{1}{2}-\frac{\gamma}{2}
$$

Za $n=1$ koeficijenti $\gamma_{i j}^{(1)}, \mathrm{i}, \mathrm{j}=1, \ldots, 4$ prikazani su u slijedećoj tablici

\begin{tabular}{|c|c|c|c|}
\hline$\cdots \gamma_{11}^{(1)}$ & $\gamma_{12}^{(1)}$ & $\gamma_{13}^{(1)}$ & $\gamma_{14}^{(1)^{-}}$ \\
\hline$\gamma_{21}^{(1)}=\gamma_{12}^{(1)}$ & $\gamma_{22}^{(1)}$ & $\gamma_{23}^{(1)} \cdots$ & $\gamma_{24}^{(1)}=\gamma_{13}^{(1)}$ \\
\hline$\gamma_{31}^{(1)}=\gamma_{13}^{(1)}$ & $\gamma_{32}^{(1)}=\gamma_{23}^{(1)}$ & $\gamma_{33}^{(1)}=\gamma_{22}^{(1)}$ & $\gamma_{34}^{(1)}=\gamma_{12}^{(1)}$ \\
\hline$\gamma_{41}^{(1)}=\gamma_{14}^{(1)}$ & $\gamma_{42}^{(1)}=\gamma_{13}^{(1)}$ & $\gamma_{43}^{(1)}=\gamma_{12}^{(1)}$ & $\gamma_{44}^{(1)}=\gamma_{11}^{(1)}$ \\
\hline
\end{tabular}

a njihova grafička interpretacija je dana na crtežu 3.13 .

Koeficijenti na glavnoj dijagonali prema (3.61) iznose

$$
\gamma_{11}^{(1)}=-\frac{26}{144}+\frac{\gamma}{4} ; \quad \gamma_{22}^{(1)}=\frac{26}{144}+\frac{\gamma}{4}
$$

a nepoznati koeficijenti izvan glavne dijagonale određuju se iz sustava jednadžbi koje se napišu pomoću razvoja polinoma nultog i prvog stupnja po funkcijama $u p(\xi-\beta)$ u (3.51) i iznose

$$
\gamma_{12}^{(1)}=\frac{39}{144}-\frac{\gamma}{4} ; \quad \gamma_{13}^{(1)}=\frac{36}{144}-\frac{\gamma}{4} ; \quad \gamma_{14}^{(1)}=-\frac{29}{144}+\frac{\gamma}{4} ; \quad \gamma_{23}^{(1)}=\frac{23}{144}+\frac{\gamma}{4}
$$

\subsection{Preslikavanje nosača funkcije up( ()}

Kod praktične primjene funkcije $u p(\xi)$ treba preslikati nosač funkcije s odsječka $[-1,1]$ na proizvoljni odsječak $[A, B]$. Ako je $\xi \in[-1,1]$ točka nosača funkcije $u p(\xi)$ koja se preslikava u točku $x \in[A, B]=\left[-\Delta x_{0}, \Delta x_{0}\right]$ nosača funkcije up $(x)$, tada je:

$$
u p(x)=u p(\xi)
$$

Dakle, nosač normirane duljine $[-1,1]$ preslika se na nosač $\left[-\Delta x_{0}, \Delta x_{0}\right]$ zadane duljine, gdje je:

$$
\Delta x_{0}=\left|\frac{B-A}{2}\right|
$$




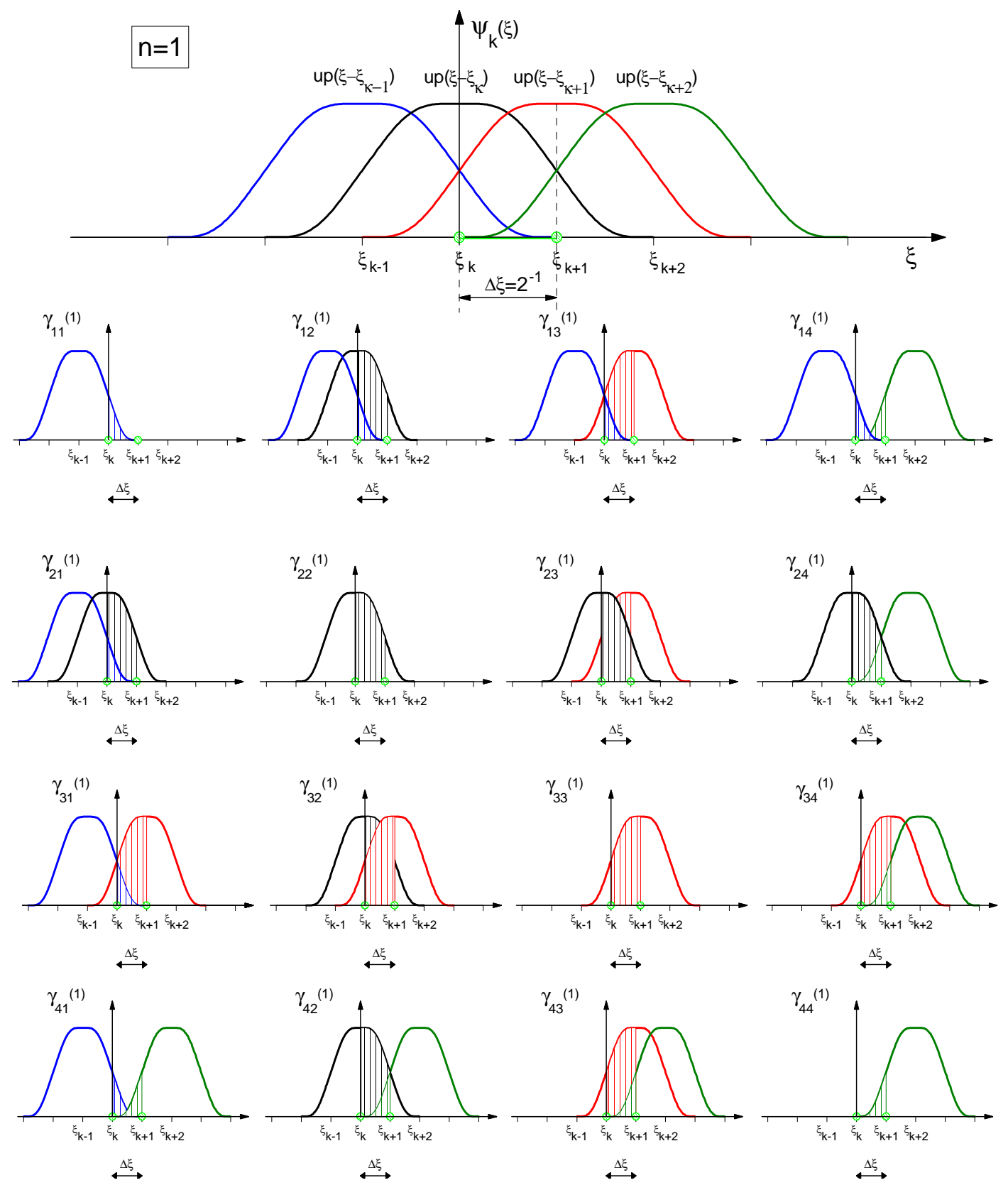

Crtež 3.13 Grafička interpretacija elemenata matrice za $n=1$

Derivacije funkcije $u p(x)$ u točkama nosača opće duljine, koristeći (3.18), mogu se izraziti u obliku:

$$
u p^{(m)}(x)=\frac{1}{\Delta x_{0}{ }^{m}} u p^{(m)}(\xi), \quad m=0,1, \ldots,
$$

Integral funkcije $u p(x)$ reda $m$, koristeći (3.22), je:

$$
\mathrm{I}_{m}(x)=\Delta x_{0}{ }^{m} \mathrm{I}_{m}(\xi), \quad m \in N \quad ; \quad x \in[A, B] \quad ; \quad \xi \in[-1,1]
$$


Pomak funkcije $\Delta x_{n}$, koji je potreban da se linearnom kombinacijom baznih funkcija dobivenih pomicanjem funkcije $u p(x)$ za $k \cdot \Delta x_{n}, k \in Z$ točno prikaže polinom stupnja $n$, dobiva se preslikavanjem pomaka $\Delta \xi_{n}=2^{-n}$ :

$$
\Delta x_{n}=\Delta \xi_{n} \cdot \Delta x_{0}
$$

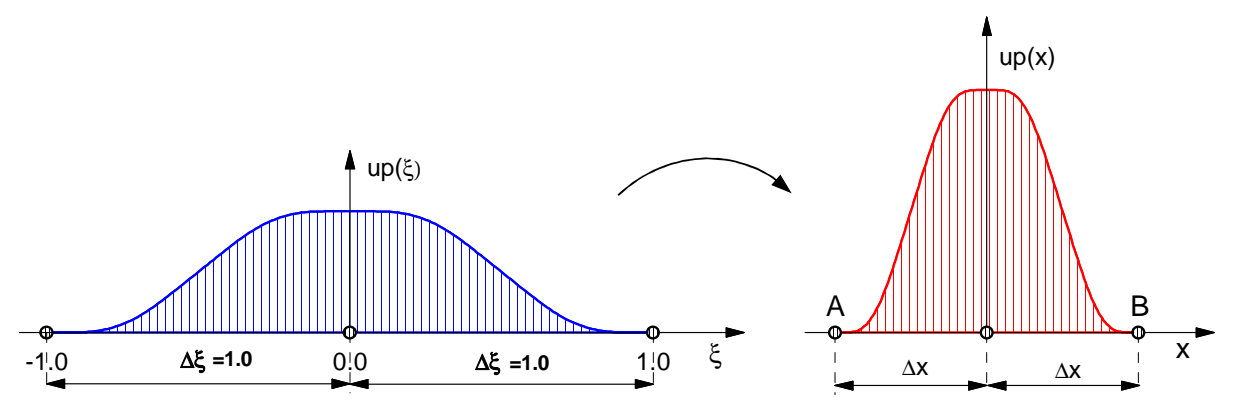

Crtež 3.14 Preslikavanje nosača funkcije up $(\xi)$

\subsection{Vektorski prostor funkcija $\mathbf{U P}_{\mathrm{n}}$}

Kao što se na crtežu 3.12 vidi, za točan prikaz monoma $\xi^{n}$ na odsječku duljine $2^{-n}$ potrebno je $2^{n+1}$ baznih funkcija, pa je u tom slučaju dimenzija vektorskog prostora

$$
\operatorname{dim} U P_{n}=2^{n+1}
$$

Za točan prikaz monoma $\xi^{n+1}$ potrebno je $2^{n+2}$ baznih funkcija, dakle vektorski prostor $U P_{n+1}$ ima dimenziju $2^{n+2}$. Pri tome, linearni vektorski prostor funkcija $U P_{n+1}$ sadrži prostor $U P_{n}$ jer se dobije proširenjem prostora $U P_{n}$ za $2^{n+1}$ linearno nezavisnih vektora tj. pomaknutih funkcija $u p(\xi)$. Prema tome, za razliku od prostora izgrađenog od baznih splineova, prostor funkcija $U P_{n}$ je univerzalan, odnosno

$$
U P_{0} \subset U P_{1} \subset \quad \ldots \quad \subset U P_{n} \subset U P_{n+1}
$$

Ova činjenica omogućava formiranje iterativnog postupka kod kojeg se rješenje iz prostora $U P_{n}$ koristi kao polazno za traženje približnog rješenja iz prostora $U P_{n+1}$.

\subsection{Aproksimacija zadane funkcije u obliku algebarskog polinoma}

Neka je zadana funkcija $f(x)=-1+4 x-2 x^{2}, x \in[0,1]$. Aproksimacija funkcije traži se kao linearna kombinacija baznih funkcija prikazanih na crtežu 3.12a, 3.12b i 3.12c respektivno.

Koristeći metodu kolokacije dobiva se sustav jednadžbi i pripadajuća aproksimacija.

a) Za dvije kolokacijske točke duljina karakterističnog odsječka je $\Delta x_{a}=1$. Dobiva se sustav jednadžbi i koeficijenti $C_{i}, i=0,1$ : 


$$
\left[\begin{array}{ll}
1 & 0 \\
0 & 1
\end{array}\right] \cdot\left[\begin{array}{l}
C_{0} \\
C_{1}
\end{array}\right]=\left[\begin{array}{l}
f(0) \\
f(1)
\end{array}\right] \rightarrow\left[\begin{array}{l}
C_{0} \\
C_{1}
\end{array}\right]=\left[\begin{array}{l}
f(0) \\
f(1)
\end{array}\right]=\left[\begin{array}{r}
-1 \\
1
\end{array}\right]
$$

Aproksimacija zadane funkcije $f(x)$ ima oblik $\widetilde{f}_{a}(x)=C_{0} \cdot u p(x)+C_{1} \cdot u p(x-1)$ i prikazana je na crtežu 3.15 .

b) Za tri kolokacijske točke raspored baznih funkcija i kolokacijskih točaka prikazan je na crtežu 3.12b. Duljina karakterističnog odsječka je $\Delta x_{b}=\Delta x_{a} / 2$. Pet je nepoznatih koeficijenata, a samo su tri kolokacijske točke. Kod spline funkcija, kao dodatni uvjet na rubu koristi se prva derivacija tako da su na rubu dvostruke kolokacijske točke, a u konkretnom slučaju dobila bi se sljedeća matrica sustava $A_{s}$ :

$$
A_{s}=\left[\begin{array}{ccccc}
-2 & 0 & 2 & 0 & 0 \\
1 / 2 & 1 & 1 / 2 & 0 & 0 \\
0 & 1 / 2 & 1 & 1 / 2 & 0 \\
0 & 0 & 1 / 2 & 1 & 1 / 2 \\
0 & 0 & -2 & 0 & 2
\end{array}\right], \quad A_{R}=\left[\begin{array}{ccccc}
1 & -2 & 1 & 0 & 0 \\
1 / 2 & 1 & 1 / 2 & 0 & 0 \\
0 & 1 / 2 & 1 & 1 / 2 & 0 \\
0 & 0 & 1 / 2 & 1 & 1 / 2 \\
0 & 0 & 1 & -2 & 1
\end{array}\right]
$$

Sustav $A_{s}$ iz (3.74) je singularan. U [23] sustav je preuvjetovan i riješen iterativnim postupkom.

Pomoću baznih funkcija iz vektorskog prostora $U P_{n}$ mogu se točno opisati algebarski polinomi $n$-tog stupnja kako je opisano u prethodnoj točki. Međutim, osim ABF up(x) vektorski prostor $U P_{n}$ sadrži i bazne funkcije $F u p_{n}(x)$. Bazna funkcija $F u p_{n}(x)$ dobije se kao rezultat posebne linearne kombinacije funkcija $u p(x)$ o čemu će biti govora detaljnije $\mathrm{u}$ sljedećem poglavlju. Na karakterističnom odsječku, također, opisuju točno algebarske polinome do stupnja $n$, a treba ih manji broj nego funkcija $u p(x)$. S obzirom da sve derivacije iznad $n$-tog reda moraju biti jednake nuli u svim točkama, dodatne jednadžbe mogu se napisati tako da se umjesto poznate derivacije na rubu postavi uvjet da $(n+1)$ derivacija linearne kombinacije $\mathrm{ABF} \operatorname{Fup}_{n}(x)$ bude jednaka nuli na sredini prvog i posljednjeg karakterističnog odsječka.

Dodatne jednadžbe na početku i kraju matrice koeficijenata sustava formalno se podudaraju s pripadajućim operatorima konačnih razlika. Za prvih pet derivacija koeficijenti matrice $A$ su:

$$
\begin{array}{ccccccc}
\text { I. } & 1 & -1 & & & & \\
\text { II. } & 1 & -2 & 1 & & & \\
\text { III. } & 1 & -3 & 3 & -1 & & \\
\text { IV. } & 1 & -4 & 6 & -4 & 1 & \\
\text { V. } & 1 & -5 & 10 & -10 & 5 & -1
\end{array}
$$


Za raspored baznih funkcija prema crtežu 3.12b $(n=1)$ druga derivacija linearne kombinacije baznih funkcija na prvom i posljednjem odsječku područja mora biti jednaka nuli pa koristeći (3.75) zamjenom prvog i posljednjeg retka matrica $A_{s}$ iz (3.74) postaje regularna matrica $A_{R}$.

Vektor desne strane je $B=[0,-1 / 8,1 / 2,7 / 8,0]^{T}$, a koeficijenti za linearnu kombinaciju su $C=[-3 / 2,-1 / 2,1 / 2,1 / 2,1 / 2]^{T}$. Dobivena aproksimacija $\widetilde{f}_{b}(x)$ prikazana je na crtežu 3.15 .

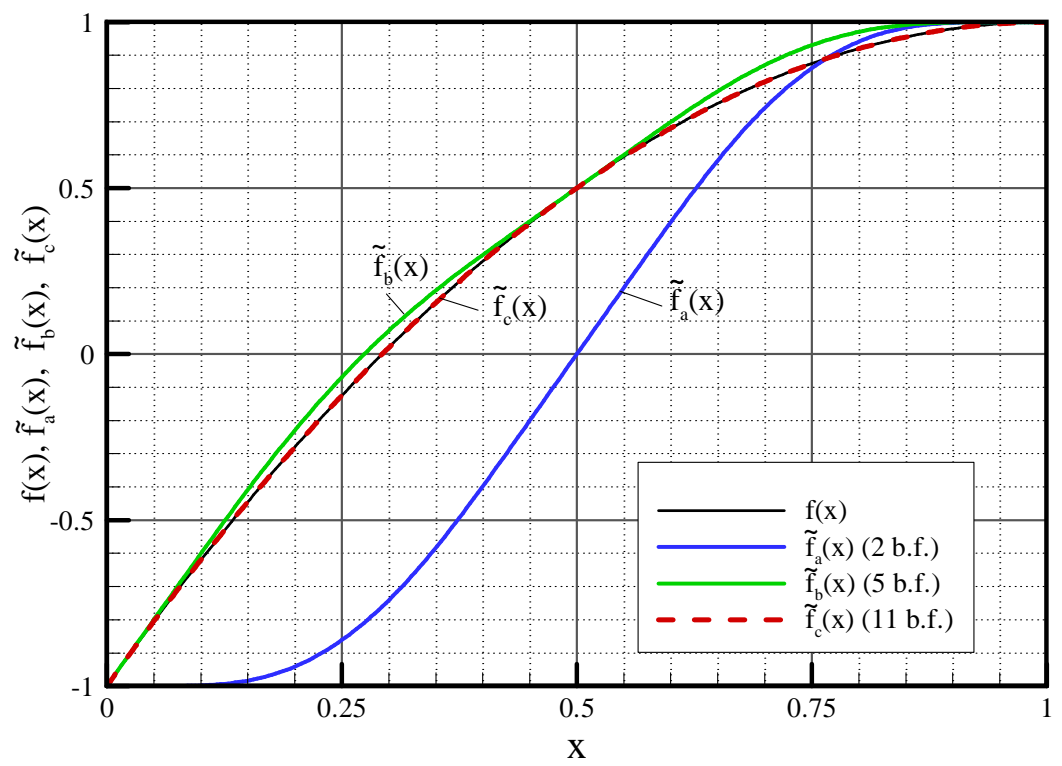

Crtež 3.15 Funkcija $f(x)$ i aproksimacije funkcije $\tilde{f}_{a}(x), \tilde{f}_{b}(x), \tilde{f}_{c}(x)$

c) Linearnom kombinacijom ABF raspoređenih prema crtežu 3.12c $(n=2)$ mogu se točno opisati algebarski monomi nultog, prvog i drugog stupnja ili polinom nastao njihovom kombinacijom. Koristeći $\Delta x_{c}=\Delta x_{b} / 2=\Delta x_{a} / 4$ te kolokacijski postupak i dodatne jednadžbe iz (3.75) dobivaju se vrijednosti traženih koeficijenata.

Matrica za određivanje koeficijenata koji pomnoženi s pripadajućim baznim funkcijama sa crteža 3.12 c točno opisuju zadanu funkciju ima sljedeći oblik

$$
A=\left[\begin{array}{rrrrrrrrrrr}
-1 & 3 & -3 & 1 & 0 & 0 & 0 & 0 & 0 & 0 & 0 \\
1 & -4 & 6 & -4 & 1 & 0 & 0 & 0 & 0 & 0 & 0 \\
-1 & 5 & -10 & 10 & -5 & 1 & 0 & 0 & 0 & 0 & 0 \\
5 / 72 & 1 / 2 & 67 / 72 & 1 & 67 / 72 & 1 / 2 & 5 / 72 & 0 & 0 & 0 & 0 \\
0 & 5 / 72 & 1 / 2 & 67 / 72 & 1 & 67 / 72 & 1 / 2 & 5 / 72 & 0 & 0 & 0 \\
0 & 0 & 5 / 72 & 1 / 2 & 67 / 72 & 1 & 67 / 72 & 1 / 2 & 5 / 72 & 0 & 0 \\
0 & 0 & 0 & 5 / 72 & 1 / 2 & 67 / 72 & 1 & 67 / 72 & 1 / 2 & 5 / 72 & 0 \\
0 & 0 & 0 & 0 & 5 / 72 & 1 / 2 & 67 / 72 & 1 & 67 / 72 & 1 / 2 & 5 / 72 \\
0 & 0 & 0 & 0 & 0 & -1 & 5 & -10 & 10 & -5 & 1 \\
0 & 0 & 0 & 0 & 0 & 0 & 1 & -4 & 6 & -4 & 1 \\
0 & 0 & 0 & 0 & 0 & 0 & 0 & -1 & 3 & -3 & 1
\end{array}\right]
$$

a koeficijenti linearne kombinacije su 


$$
C=\frac{1}{288}[-353,-236,-137,-56,7,52,79,88,79,52,7]^{T}
$$

Linearna kombinacija baznih funkcija prikazanih na crtežu 3.12c opisuje zadanu funkciju $f(x)$ točno kao što je vidljivo na crtežu 3.15. 


\section{A. DODATAK: ALGEBARSKE ABF UP}

\section{A.1. Izravno računanje vrijednosti funkcije up $(\xi)$ u točkama tipa $\xi_{\mathrm{n}}=$ - $1+k / 2^{n}$}

U literaturi [6] pokazana je mogućnost izračunavanja točnih vrijednosti funkcije $u p(\xi)$ na diskretnom skupu binarno racionalnih točaka $\xi_{n}=-1+k \cdot 2^{-n} ; k=1,2, \ldots, 2^{n+1} n=$ $0,1, \ldots, N$ bez korištenja Fourierove transformacije.

S obzirom na parnost funkcije $u p(\xi)$ promatraju se točke $\xi_{n} \in(-1,0]$. Funkcija $u p(\xi)$ može se tretirati kao univerzalni spline, odnosno finitna funkcija koja po dijelovima sadrži algebarske polinome svih stupnjeva. Drugim riječima, vrijednost funkcije $u p(\xi)$ u binarnoracionalnoj točki $\xi_{n}$ odgovara približno vrijednosti algebarskog polinoma stupnja $n$ definiranog na odsječku duljine $\left[\xi_{n}-\Delta \xi, \xi_{n}+\Delta \xi\right]$, gdje se duljina $\Delta \xi$ može definirati na sljedeći način:

$$
\Delta \xi=2^{-(n+m+1)}, \quad n=0,1,2, \ldots, N, \quad m=1,2, \ldots, \infty
$$

Stezanje duljine intervala simetrično oko točke $\xi_{n}$ postiže se povećavanjem broja konvolucijskih faktora odnosno integrala od $m=1, m=2$ do $m \rightarrow \infty$. Vrijednost polinoma stupnja $n$ u točki $\xi_{n}$ sve je bliža točnoj vrijednosti funkcije $u p\left(\xi_{n}\right)$, dakle u limesu se te dvije funkcije podudaraju na odsječku duljine $2 \Delta \xi$. Kada $m \rightarrow \infty$ funkcija $u p(\xi)$ odgovara polinomu $P_{n}(\xi)$ na odsječku duljine $2 \Delta \xi$ kod čega prema (A.1) $\Delta \xi \rightarrow 0$. S druge strane, funkcija $u p(\xi)$ u točki $\xi_{n}$ ima konačnu vrijednost što znači da doprinos beskonačnog broja konvolucijskih članova konvergira konačnoj vrijednosti up $\left(\xi_{n}\right) \equiv P_{n}\left(\xi_{n}\right)$. 
Osim u točki $\xi_{n}$ funkcija $u p\left(\xi_{n}\right)$ odgovara polinomu stupnja $n$ i u svim točkama nosača određenih izrazom:

$$
\xi_{k}=-1+k \cdot 2^{-n}, \quad n \in N, \quad k=1,2, \ldots, 2^{n+1}
$$

Proces približavanja polinoma $P_{2}(\xi)$ vrijednosti funkcije $u p(\xi)$ u bliskoj okolini apscise $\xi=-3 / 4$ prikazan je grafički na crtežu A.1, odnosno analitički slijedećim izrazima:

$$
\begin{aligned}
& P_{2}^{(0)}(\xi)=4 \xi^{2}+7 \xi+49 / 16 \quad \rightarrow P_{2}^{(0)}(-3 / 4)=\quad 1 / 16=0.062500 \\
& P_{2}^{(1)}(\xi)=4 \xi^{2}+7 \xi+589 / 192 \quad \rightarrow \quad P_{2}^{(1)}(-3 / 4)=\quad 13 / 192=0.067708 \\
& P_{2}^{(5)}(\xi)=4 \xi^{2}+7 \xi+150869 / 49152 \rightarrow P_{2}^{(5)}(-3 / 4)=3413 / 49152=0.069437 \\
& P_{2}^{(\infty)}(\xi)=4 \xi^{2}+7 \xi+221 / 72 \quad \rightarrow \quad P_{2}^{(\infty)}(-3 / 4)=\quad 5 / 72=0.06944 \dot{4}
\end{aligned}
$$

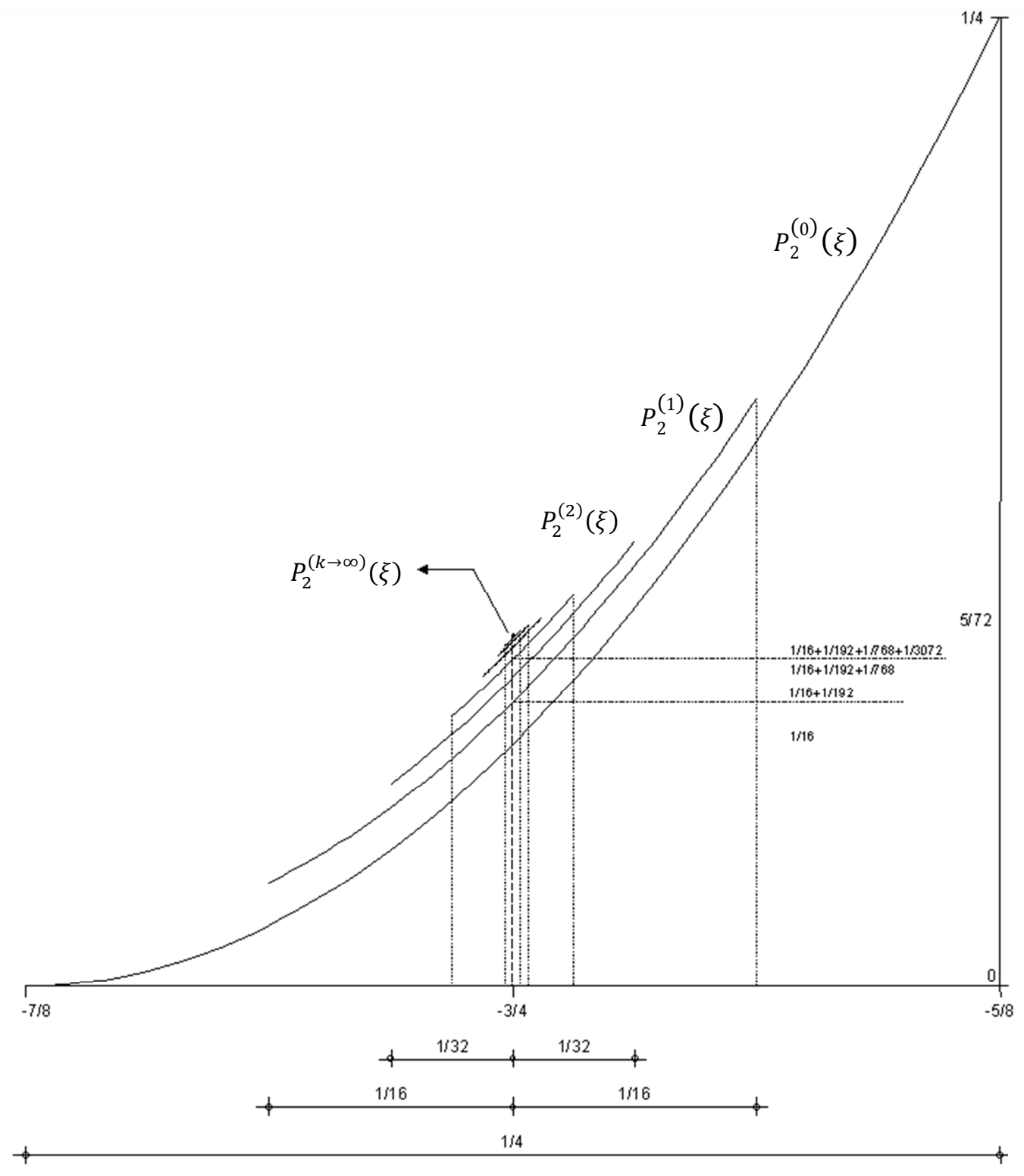

Crtež A.1 Približavanje polinoma $P_{2}(\xi)$ funkciji $u p(\xi)$ za apscisu $\xi=\xi_{2}=-3 / 4$ 
Općenito, za okolinu bilo koje točke $\xi_{n}=1-2^{-n}$ prema (A.3) vrijedi analogan postupak:

$$
\begin{aligned}
P_{n}^{(0)}(\xi) & =\frac{2^{n(n+1) / 2}}{n !}\left(\xi+1-2^{-n-1}\right)^{n} \\
P_{n}^{(1)}(\xi) & =2^{n+1} \int_{\xi+2^{-n-2}} P_{n}^{(0)}(\xi) d \xi \\
& \ldots \ldots \ldots .2^{-n-2} \\
P_{n}^{(k)}(\xi) & =2^{n+k} \int_{\xi+2^{-n-k-1}} P_{n}^{(k-1)}(\xi) d \xi \\
& \ldots \ldots \ldots . . \\
\lim _{k \rightarrow \infty} P_{n}^{(k)}\left(\xi_{n}\right) & =u p\left(\xi_{n}\right)
\end{aligned}
$$

Točne vrijednosti funkcije up $\left(-1+2^{-n}\right)=u p(n)$, za $n=0,1,2, \ldots, 20 \mathrm{su}$ :

$$
\begin{aligned}
& u p(0)=1 \\
& \operatorname{up}(1)=\frac{1}{2} \\
& \operatorname{up}(2)=\frac{5}{72}=\frac{5}{2^{3} \cdot 3^{2}} \\
& \operatorname{up}(3)=\frac{1}{288}=\frac{1}{2^{5} \cdot 3^{2}} \\
& \operatorname{up}(4)=\frac{143}{2073600}=\frac{11 \cdot 13}{2^{10} \cdot 3^{4} \cdot 5^{2}} \\
& \operatorname{up}(5)=\frac{19}{33177600}=\frac{19}{2^{14} \cdot 3^{4} \cdot 5^{2}} \\
& \operatorname{up}(6)=\frac{1153}{561842749440}=\frac{1153}{2^{20} \cdot 3^{7} \cdot 5 \cdot 7^{2}} \\
& \operatorname{up}(7)=\frac{11 \cdot 53}{2^{26} \cdot 3^{7} \cdot 5^{2} \cdot 7^{2}} \\
& \operatorname{up}(8)=\frac{487 \cdot 3319}{2^{36} \cdot 3^{9} \cdot 5^{4} \cdot 7^{2} \cdot 17} \\
& \operatorname{up}(9)=\frac{59 \cdot 2251}{2^{44} \cdot 3^{9} \cdot 5^{4} \cdot 7^{2} \cdot 17} \\
& \operatorname{up}(10)=\frac{6229 \cdot 21661}{2^{54} \cdot 3^{11} \cdot 5^{3} \cdot 7^{2} \cdot 11^{2} \cdot 17 \cdot 31} \\
& \operatorname{up}(11)=\frac{46840699}{2^{64} \cdot 3^{11} \cdot 5^{4} \cdot 7^{2} \cdot 11^{2} \cdot 17 \cdot 31} \\
& \operatorname{up}(12)=\frac{29 \cdot 127 \cdot 64483 \cdot 284413}{2^{77} \cdot 3^{14} \cdot 5^{6} \cdot 7^{4} \cdot 11^{2} \cdot 13^{2} \cdot 17 \cdot 31} \\
& \operatorname{up}(13)=\frac{211 \cdot 4933 \cdot 3909247}{2^{89} \cdot 3^{14} \cdot 5^{6} \cdot 7^{4} \cdot 11^{2} \cdot 13^{2} \cdot 17 \cdot 31}= \\
& \operatorname{up}(14)=\frac{23 \cdot 78713 \cdot 227090429}{2^{103} \cdot 3^{16} \cdot 5^{5} \cdot 7^{4} \cdot 11 \cdot 13^{2} \cdot 17 \cdot 31 \cdot 43 \cdot 127} \\
& \operatorname{up}(15)=\frac{2967343 \cdot 405941377}{2^{117} \cdot 3^{16} \cdot 5^{6} \cdot 7^{4} \cdot 11^{2} \cdot 13^{2} \cdot 17 \cdot 31 \cdot 43 \cdot 127} \\
& \operatorname{up}(16)=\frac{619 \cdot 118610340787938551}{2^{136} \cdot 3^{18} \cdot 5^{8} \cdot 7^{4} \cdot 11^{2} \cdot 13 \cdot 17^{2} \cdot 31 \cdot 43 \cdot 127 \cdot 257}
\end{aligned}
$$




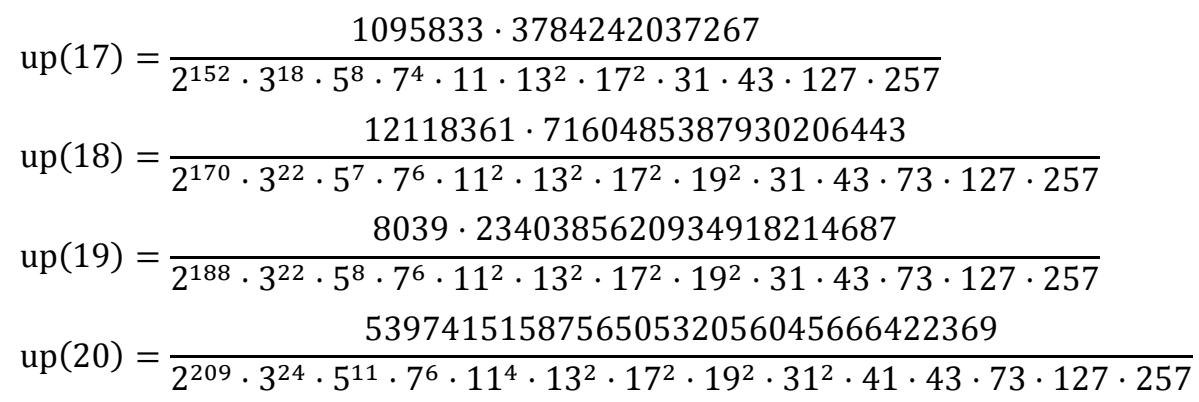

ili u decimalnoj reprezentaciji:

$$
\begin{aligned}
& \operatorname{up}(0)=1.0 \\
& \operatorname{up}(1)=0.5 \\
& \operatorname{up}(2)=0.694444444444444444444444444444 \cdot 10^{-1} \\
& \operatorname{up}(3)=0.347222222222222222222222222222 \cdot 10^{-2} \\
& \operatorname{up}(4)=0.689621913580246913580246913580 \cdot 10^{-4} \\
& \operatorname{up}(5)=0.572675540123456790123456790123 \cdot 10^{-6} \\
& \operatorname{up}(6)=0.205217563303828046993831826283 \cdot 10^{-8} \\
& \operatorname{up}(7)=0.324267778095543558644308203391 \cdot 10^{-11} \\
& \operatorname{up}(8)=0.229530318063432131756225676522 \cdot 10^{-14} \\
& \operatorname{up}(9)=0.736701215146999670767611558274 \cdot 10^{-18} \\
& \operatorname{up}(10)=0.108253310620573900576532930264 \cdot 10^{-21} \\
& \operatorname{up}(11)=0.734002873444621651059738345679 \cdot 10^{-26} \\
& \operatorname{up}(12)=0.231150207744895722114032513815 \cdot 10^{-30} \\
& \operatorname{up}(13)=0.339957499287999065134325679940 \cdot 10^{-35} \\
& \operatorname{up}(14)=0.234606013355730663099996702021 \cdot 10^{-40} \\
& \operatorname{up}(15)=0.762806613377867828352443780747 \cdot 10^{-46} \\
& \operatorname{up}(16)=0.117275003248629690840319784168 \cdot 10^{-51} \\
& \operatorname{up}(17)=0.855233951904316299950099499468 \cdot 10^{-58} \\
& \operatorname{up}(18)=0.296670414258739459330860188106 \cdot 10^{-64} \\
& \operatorname{up}(19)=0.490758028367886665297901358579 \cdot 10^{-71} \\
& \operatorname{up}(20)=0.388016715697356973825911192054 \cdot 10^{-78}
\end{aligned}
$$




\section{ALGEBARSKE ATOMSKE BAZNE FUNKCIJE FUP}

\subsection{Funkcija $\operatorname{Fup}_{n}(\xi)$}

U prethodnom poglavlju opisana je funkcija $u p(\xi)$. Pokazano je da za točan razvoj polinoma stupnja $n$ na odsječku duljine $\Delta \xi_{n}=2^{-n}$ treba $2^{n+1}$ baznih funkcija dobivenih pomicanjem funkcije $u p(\xi)$ za $\Delta \xi_{n}$. Za približno rješenje višeg stupnja glatkosti, potreban broj baznih funkcija raste vrlo brzo. Zbog toga je primjena funkcije $u p(\xi)$ u numeričkim metodama za rješavanje praktičnih inženjerskih zadataka ograničena.

Funkcije $\operatorname{Fup}_{n}(\xi)$, također iz klase atomskih baznih funkcija, zadržavaju sva dobra svojstva funkcije $u p(\xi)$, a za razvoj neke funkcije potreban ih je znatno manji broj nego baznih funkcija dobivenih pomicanjem funkcije $u p(\xi)$. Na primjer, za razvoj polinoma 4-tog stupnja potrebno je 6 međusobno pomaknutih baznih funkcija $F u p_{4}(\xi)$ u odnosu prema 32 međusobno pomaknute bazne funkcije $u p(\xi)$.

Funkcije $\operatorname{Fup}_{n}(\xi)$ su finitne funkcije iz klase $C^{\infty}$ s kompaktnim nosačem, a ujedno su elementi univerzalnog vektorskog prostora $U P_{n}$. Indeks $n$ označava najviši stupanj polinoma koji se može točno prikazati u obliku linearne kombinacije baznih funkcija dobivenih pomicanjem funkcije $\operatorname{Fup}_{n}(\xi)$ za karakteristični odsječak $\Delta \xi_{n}=2^{-n}$.

Nosač funkcije $\operatorname{Fup}_{n}(\xi)$ je:

$$
\operatorname{supp} \operatorname{Fup}_{n}(\xi)=\left[-(n+2) \cdot 2^{-n-1},(n+2) \cdot 2^{-n-1}\right]
$$

Za $n=0$ vrijedi:

$$
\operatorname{Fup}_{0}(\xi)=u p(\xi)
$$




\subsection{Fourierova transformacija funkcija $\operatorname{Fup}_{\mathbf{n}}(\xi)$}

Fourierova transformacija funkcije $F u p_{0}(\xi)$ prema (4.2) odgovara upravo FT funkcije $u p(\xi)$ iz izraza (3.8), tj.:

$$
F_{0}(t)=\prod_{j=1}^{\infty} \frac{\sin \left(t \cdot 2^{-j}\right)}{t \cdot 2^{-j}}=\frac{\sin (t / 2)}{t / 2} \cdot \frac{\sin (t / 4)}{t / 4} \cdot \prod_{j=3}^{\infty} \frac{\sin \left(t \cdot 2^{-j}\right)}{t \cdot 2^{-j}}
$$

Koristeći osnovnu trigonometrijsku relaciju $\sin (\xi)=2 \sin (\xi / 2) \cdot \cos (\xi / 2)$ izraz (4.3) može se prikazati na sljedeći način

$$
F_{0}(t)=\frac{2 \sin (t / 4) \cdot \cos (t / 4)}{t / 2} \cdot \frac{\sin (t / 4)}{t / 4} \cdot \prod_{j=3}^{\infty} \frac{\sin \left(t \cdot 2^{-j}\right)}{t \cdot 2^{-j}}
$$

Izostavljanjem faktora $\cos (t / 4) \mathrm{u}(4.4)$ dobiva se Fourierova transformacija nove finitne funkcije $\operatorname{Fup}_{1}(\xi)$ u obliku

$$
F_{1}(t)=\left(\frac{\sin (t / 4)}{t / 4}\right)^{2} \cdot \prod_{j=3}^{\infty} \frac{\sin \left(t \cdot 2^{-j}\right)}{t \cdot 2^{-j}}
$$

Nastavljanjem tzv. postupka drobljenja ili cijepanja provedenim u (4.5) na jednadžbu (4.4) dobiva se Fourierova transformacija finitne funkcije $\mathrm{Fup}_{2}(\xi)$

$$
F_{2}(t)=\left(\frac{\sin (t / 8)}{t / 8}\right)^{3} \cdot \prod_{j=4}^{\infty} \frac{\sin \left(t \cdot 2^{-j}\right)}{t \cdot 2^{-j}}
$$

Prikazanim postupkom tzv. drobljenja izraza (4.3) za $j=1, \ldots, n+1$ generira se cijela klasa Fourierovih transformacija novih finitnih funkcija $F u p_{n}(\xi)$ općeg oblika

$$
F_{n}(t)=\left(\frac{\sin t 2^{-n-1}}{t 2^{-n-1}}\right)^{n+1} \prod_{j=n+2}^{\infty} \frac{\sin t 2^{-j}}{t 2^{-j}}
$$

pa se prema (4.7) funkcije $\mathrm{Fup}_{n}(\xi)$ mogu napisati u integralnom obliku:

$$
\operatorname{Fup}_{n}(\xi)=\frac{1}{2 \pi} \int_{-\infty}^{\infty} e^{i t \xi} \cdot F_{n}(t) d t
$$

Iz poznate FT, slično kao što je pokazano na funkciji $u p(\xi)$, funkcije $F u p_{n}(\xi)$ mogu se također generirati pomoću teorema konvolucije, Crtež 4.1.

U (4.7) vidi se da je FT baznih funkcija $F u p_{n}(\xi)$ jednaka umnošku FT B-splinea $n$-tog stupnja iz izraza (2.4) sažetog na duljinu nosača $(n+1) 2^{-n}$ i FT funkcije up $(\xi)$ sažete na nosač duljine $2^{-n}$. Dakle, funkcije $\operatorname{Fup}_{n}(\xi)$ mogu se napisati pomoću teorema konvolucije u obliku 
a)

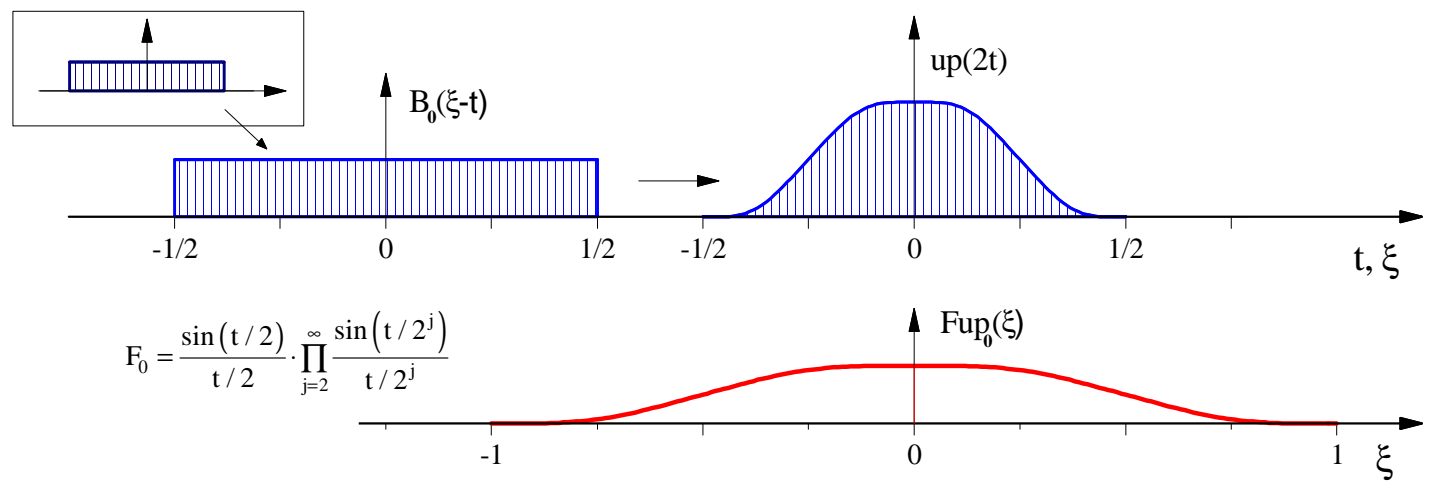

b)

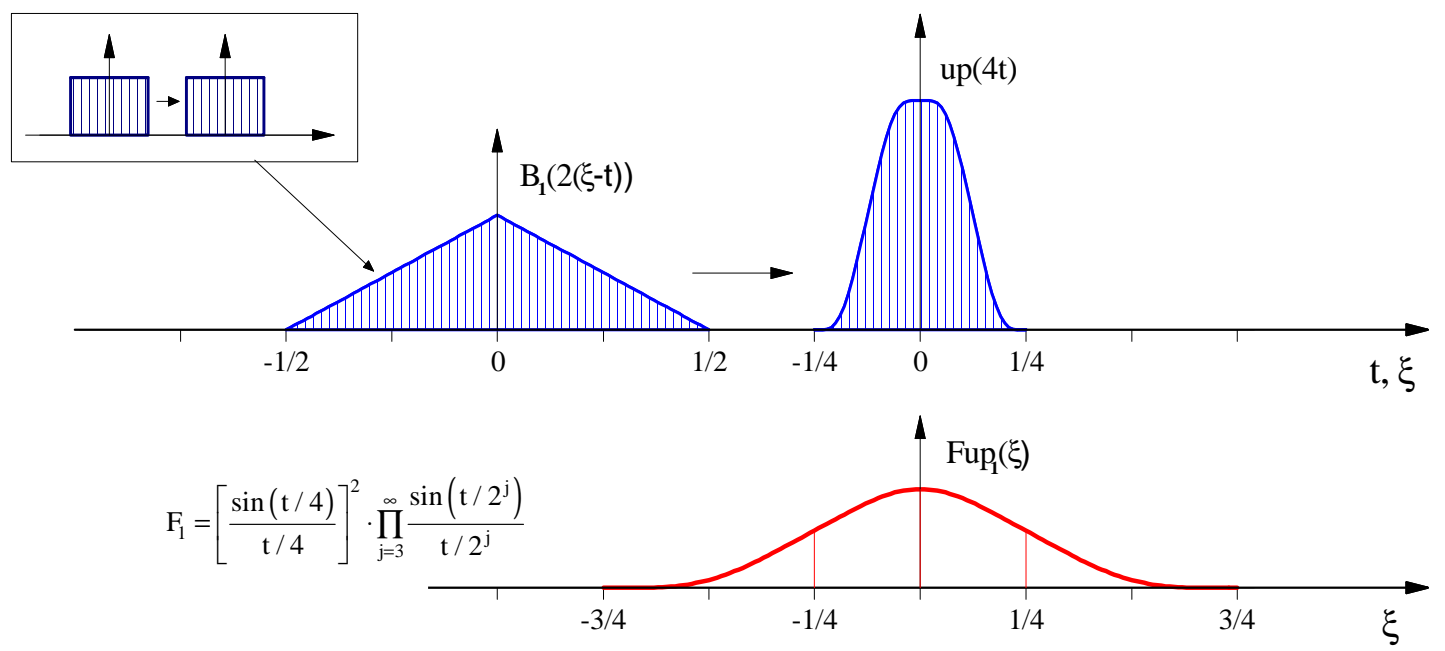

c)

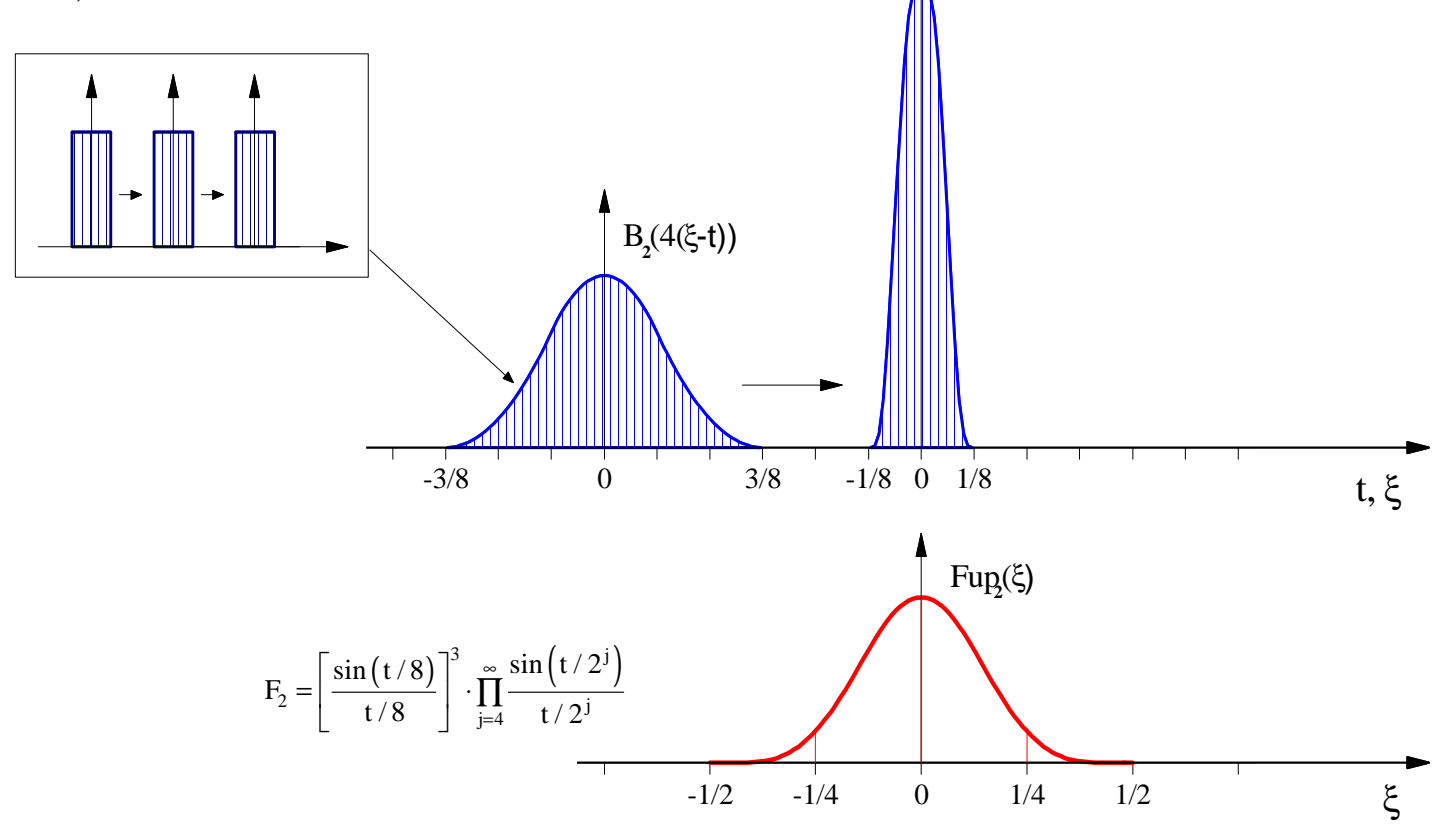

Crtež 4.1 Generiranje baznih funkcija $\operatorname{Fup}_{n}(\xi), n=0,1,2$ pomoću teorema konvolucije 


$$
\operatorname{Fup}_{n}(\xi)=B_{n}\left(2^{n} \xi\right) * u p\left(2^{n+1} \xi\right)
$$

\subsection{Funkcionalno diferencijalna jednadžba funkcija $\operatorname{Fup}_{\mathbf{n}}(\xi)$}

Fourierova transformacija baznih funkcija $\operatorname{Fup}_{n}(\xi)$ iz (4.7) može se napisati u sljedećem obliku:

$$
F_{n}(t)=\sin \left(t / 2^{n+2}\right) /\left(t / 2^{n+2}\right) \cdot\left[\cos \left(t / 2^{n+2}\right)\right]^{n+1} \cdot F_{n}(t / 2)
$$

Iz Fourierove transformacije $F_{n}(t)$ napisane u obliku (4.10) može se izvesti funkcionalno diferencijalna jednadžba, čije je rješenje upravo tražena finitna funkcija $F u p_{n}(\xi)$. Množeći izraz (4.10) s it, te primjenom inverzne Fourierove transformacije $\frac{1}{2 \pi} \int_{-\infty}^{\infty} e^{-i t \xi} d t$ dobije se

$$
\frac{1}{2 \pi} \int_{-\infty}^{\infty} i t \cdot e^{-i t \xi} \cdot F_{n}(t) d t=\frac{i \cdot 2^{n+1}}{2 \pi} \int_{-\infty}^{\infty} e^{-i t \xi} \cdot \sin \left(\frac{t}{2^{n+2}}\right) \cdot \cos ^{n+1}\left(\frac{t}{2^{n+2}}\right) \cdot F_{n}\left(\frac{t}{2}\right) d t
$$

Na primjer, za baznu funkciju $\mathrm{Fup}_{2}(\xi)(4.11)$ ima sljedeći oblik

$$
\frac{1}{2 \pi} \int_{-\infty}^{\infty} i t \cdot e^{-i t \xi} \cdot F_{2}(t) d t=\frac{i \cdot 8}{2 \pi} \int_{-\infty}^{\infty} e^{-i t \xi} \sin (t / 16) \cdot \cos ^{3}(t / 16) \cdot F_{2}\left(\frac{t}{2}\right) d t
$$

ili u eksponencijalnom obliku

$$
\frac{1}{2 \pi} \int_{-\infty}^{\infty} i t \cdot e^{-i t \xi} \cdot F_{2}(t) d t=\frac{8 i}{2 \pi} \int_{-\infty}^{\infty} e^{-i t \xi} \cdot\left(e^{\frac{i t}{4}}+2 e^{\frac{i t}{8}}-2 e^{-\frac{i t}{8}}-e^{-\frac{i t}{4}}\right) \cdot F_{2}\left(\frac{t}{2}\right) d t
$$

Lijeva strana izraza (4.13) prema (4.8) predstavlja prvu derivaciju funkcije $F u p_{2}(\xi)$, dok desna strana predstavlja linearnu kombinaciju sažetih i pomaknutih samih funkcija $F u p_{2}(\xi)$

$$
\begin{aligned}
\operatorname{Fup}_{2}^{\prime}(\xi) & =2 \cdot \operatorname{Fup}_{2}(2 \xi+1 / 2)+4 \cdot \operatorname{Fup}_{2}(2 \xi+1 / 4)- \\
& -4 \cdot \operatorname{Fup}_{2}(2 \xi-1 / 4)-2 \cdot \operatorname{Fup}_{2}(2 \xi-1 / 2)
\end{aligned}
$$

Izraz (4.14) je funkcionalno diferencijalna jednadžba funkcije $F u p_{2}(\xi)$. Analognim postupkom određuju se funkcionalno diferencijalne jednadžbe ostalih baznih funkcija $\operatorname{Fup}_{n}(\xi)$ koje se u općem obliku mogu napisati kao

$$
\operatorname{Fup}_{n}^{\prime}(\xi)=2 \sum_{k=0}^{n+2}\left(C_{n}^{k}-C_{n}^{k-2}\right) \cdot \operatorname{Fup}_{n}\left(2 \xi-\frac{k}{2^{n}}+\frac{n+2}{2^{n+1}}\right)
$$

gdje su $C_{n}^{k}$ binomni koeficijenti. 

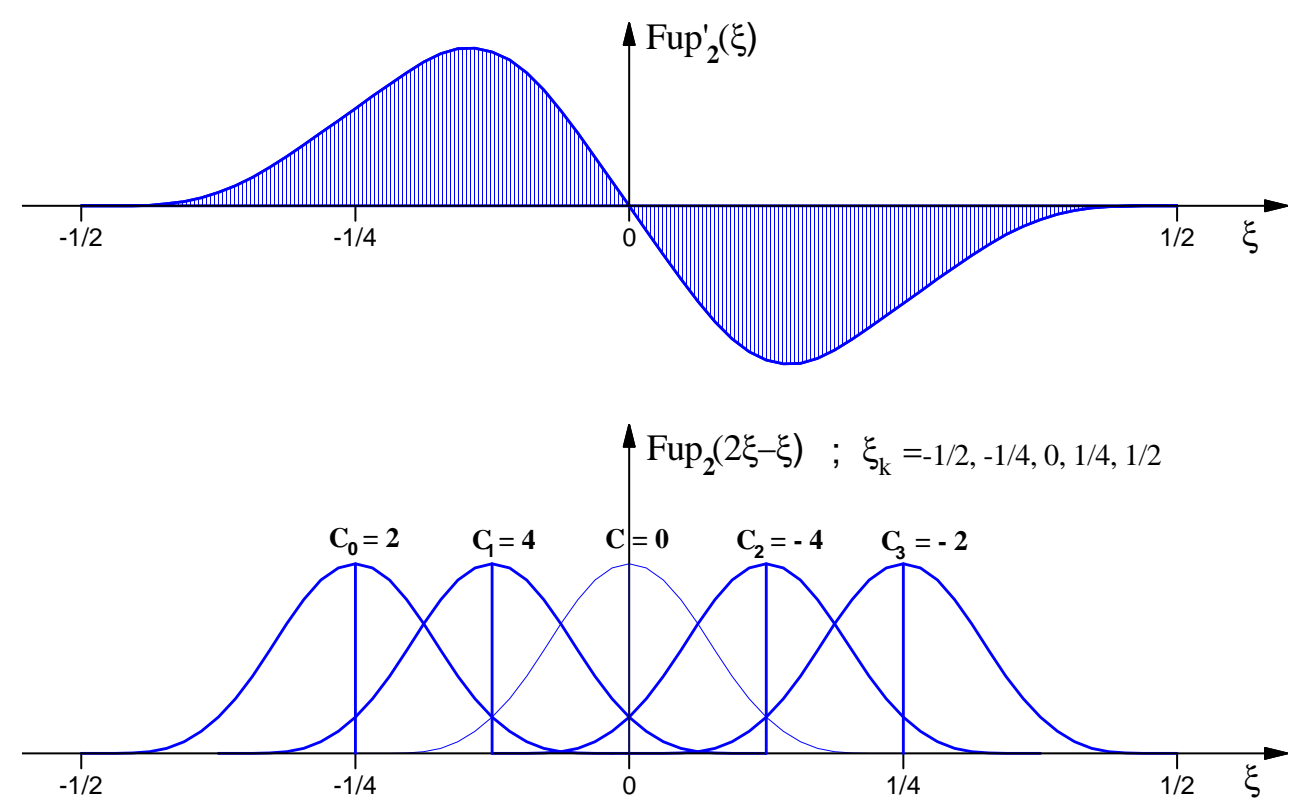

Crtež 4.2 Grafički prikaz elemenata funkcionalno diferencijalne jednadžbe funkcije $F u p_{2}(\xi)$

Rješavanje funkcionalno diferencijalne jednadžbe (4.15), kao ni izrazi (4.8) i (4.9) nisu numerički povoljni za izračunavanje vrijednosti funkcije $F u p_{n}(\xi)$. Praktično je najpovoljnija mogućnost konstruiranja funkcija $\operatorname{Fup}_{n}(\xi)$ u obliku linearne kombinacije pomaknutih $u p(\xi)$ funkcija, što će biti pokazano u sljedećim točkama.

\subsection{Veza baznih funkcija $\operatorname{Fup}_{n}(\xi)$ i $\operatorname{Fup}_{n+1}(\xi)$}

Veza baznih funkcija $\operatorname{Fup}_{n}(\xi)$ i $F u p_{n+1}(\xi)$ slijedi iz odnosa njihovih Fourierovih transformacija koja se prema [6],[43] može napisati u općem obliku:

$$
F_{n}(t)=\cos \left(\frac{t}{2^{n+2}}\right)^{n+1} \cdot F_{n+1}(t)
$$

Na primjer za bazne funkcije $F u p_{0}(\xi)$ i $F u p_{1}(\xi)$ prema (4.4) i (4.5) vrijedi

$$
F_{0}(t)=\cos (t / 4) \cdot F_{1}(t)
$$

Uvrštavanjem (4.17) u original funkcije $F u p_{0}(\xi)$ (4.8) dobije se

$$
\operatorname{Fup}_{0}(\xi)=\frac{1}{2 \pi} \int_{-\infty}^{\infty} e^{i t \xi} \cdot \cos (t / 4) \cdot F_{1}(t) d t
$$

Odnosno nakon sređivanja slijedi

$$
\operatorname{Fup}_{0}(\xi)=\frac{1}{2}\left[\operatorname{Fup}_{1}(\xi-1 / 4)+F u p_{1}(\xi+1 / 4)\right]
$$



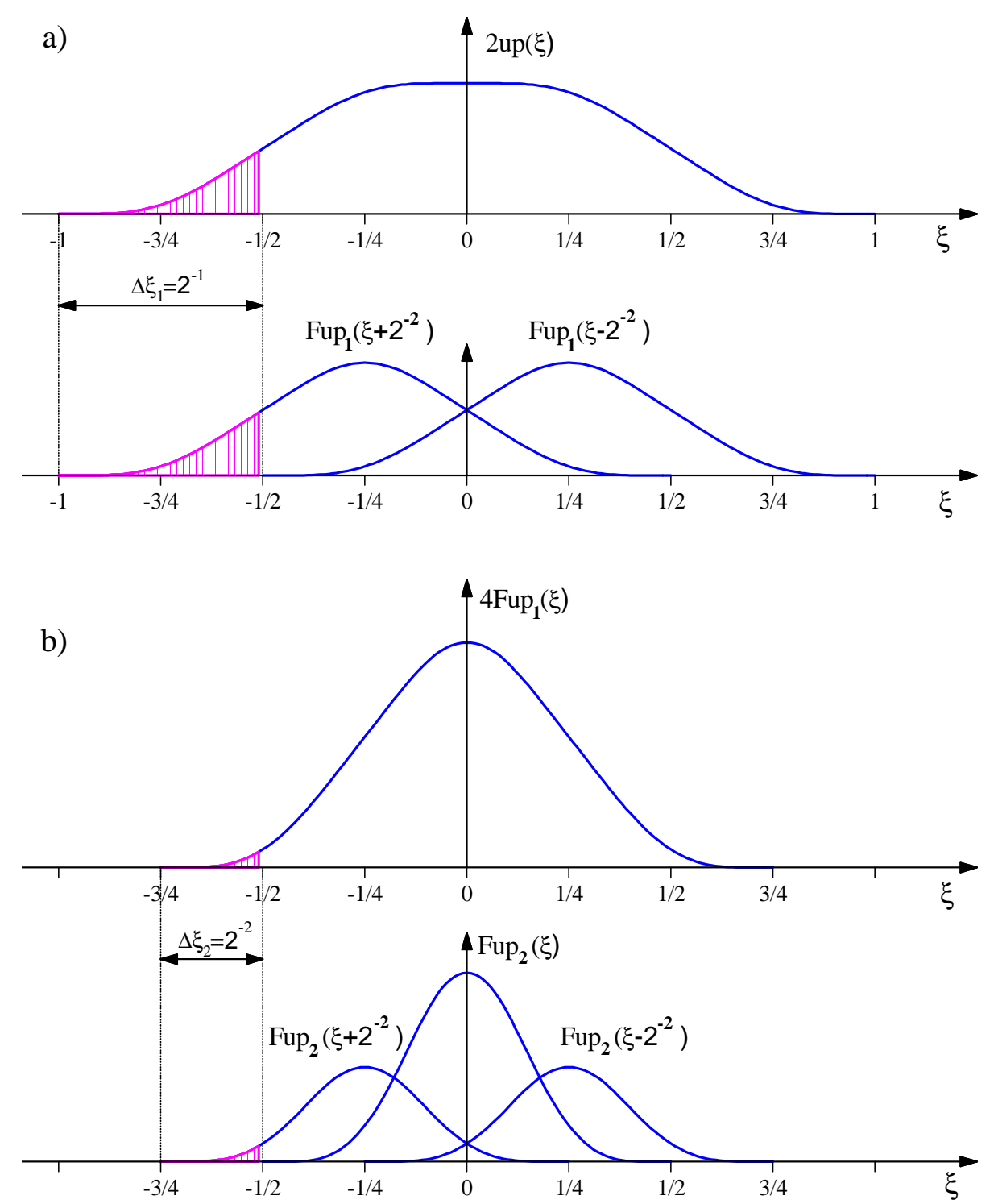

Crtež 4.3 a) Funkcija $u p(\xi)$ u obliku linearne kombinacije $F u p_{1}(\xi)$ baznih funkcija

b) Funkcija $F_{1}(\xi)$ u obliku linearne kombinacije $F u p_{2}(\xi)$ baznih funkcija

Analognim postupkom određuje se veza ostalih baznih funkcija $F u p_{n}(\xi)$ s pomaknutim funkcijama $\operatorname{Fup}_{n+1}(\xi)$, a može se napisati u općem obliku

$$
\operatorname{Fup}_{n}(\xi)=\frac{1}{2^{n+1}} \sum_{k=0}^{n+1} C_{n+1}^{k} \cdot \operatorname{Fup}_{n+1}\left(\xi-\frac{k}{2^{n+1}}+\frac{n+1}{2^{n+2}}\right)
$$

gdje su $C_{n}^{k}$ binomni koeficijenti.

\section{5 $\operatorname{Fup}_{\mathbf{n}}(\xi)$ kao linearna kombinacija pomaknutih funkcija up( $(\xi)$}

Nosač funkcije $\operatorname{Fup}_{n}(\xi)$ prema (4.1) je odsječak sastavljen od $n+2$ podintervala duljine $2^{-n}$. Iz općeg izraza za Fourierovu transformaciju (4.7) i mogućnosti prikazivanja funkcije $\mathrm{Fup}_{n}(\xi)$ primjenom teorema konvolucije (4.9), dolazi se do sljedećeg izraza: 


$$
\operatorname{Fup}_{n}(\xi)=2^{C_{n+1}^{2}} \cdot u p\left(\xi-1+(n+2) \cdot 2^{-n-1}\right)
$$

Iz gornje formule je vidljivo da je funkcija $\operatorname{Fup}_{n}(\xi)$ na prvom podintervalu proporcionalna vrijednostima funkcije $u p(\xi)$ na odsječku $\left[-1,-1+2^{-n}\right]$.

$\mathrm{Na}$ ostalim podintervalima funkcija $\mathrm{Fup}_{n}(\xi)$ je linearna kombinacija funkcije $u p(\xi)$ međusobno pomaknutih za karakteristični odsječak $2^{-n}$

$$
\operatorname{Fup}_{n}(\xi)=\sum_{k=0}^{\infty} C_{k}(n) \cdot u p\left(\xi-1-\frac{k}{2^{n}}+\frac{n+2}{2^{n+1}}\right)
$$

Nulti koeficijent slijedi iz (4.21) i iznosi:

$$
C_{0}=2^{C_{n+1}^{2}}=2^{n(n+1) / 2}
$$

Ostali koeficijenti izračunati su u [13] u obliku $C_{k}(n)=C_{0}(n) \cdot C_{k}^{\prime}(n)$ gdje se pomoćni koeficijenti $C_{k}^{\prime}(n)$ izračunavaju po rekurzivnoj formuli:

$$
\begin{aligned}
& C_{0}^{\prime}(n)=1, \text { za } k=0 ; \quad \text { odnosno za } k>0 \\
& C_{k}^{\prime}(n)=(-1)^{k} C_{n+1}^{k}-\sum_{j=1}^{\min \left\{k ; 2^{n+1}-1\right\}} C_{k-j}^{\prime}(n) \cdot \delta_{j+1}
\end{aligned}
$$

Kao primjer, na crtežu 4.4 prikazana je funkcija $\mathrm{Fup}_{4}(\xi)$ i pomaknute funkcije $u p(\xi)$ od kojih se linearnom kombinacijom dobiva $\mathrm{Fup}_{4}(\xi)$ prema (4.22). Nosač funkcije $\mathrm{Fup}_{4}(\xi)$ je prema (4.1) odsječak $\left[-\frac{3}{16}, \frac{3}{16}\right]$, nulti koeficijent $C_{0}=2^{C_{5}^{2}}=1024$, a ostali koeficijenti $C_{k}^{\prime}$ izračunati po formuli (4.24) napisani su u petom retku tablice 4.1.

Tablica 4.1 Koeficijenti linearne kombinacije funkcija $u p(\xi), n=0, \ldots, 6$

\begin{tabular}{|c|c|c|c|c|c|c|c|c|c|c|}
\hline $\mathrm{n} C_{\mathrm{k}}^{\prime}$ & $C^{\prime}{ }_{0}$ & $C^{\prime}{ }_{1}$ & $C^{\prime}{ }_{2}$ & $C^{\prime}{ }_{3}$ & $C^{\prime}{ }_{4}$ & $C^{\prime}{ }_{5}$ & $C^{\prime}{ }_{6}$ & $C^{\prime}{ }_{7}$ & $C^{\prime}{ }_{8}$ & $C^{\prime}{ }_{9}$ \\
\hline 0 & 1 & 0 & 0 & 0 & 0 & 0 & 0 & 0 & 0 & 0 \\
\hline 1 & 1 & -1 & 1 & -1 & 1 & -1 & 1 & -1 & 1 & -1 \\
\hline 2 & 1 & -2 & 2 & -2 & 3 & -4 & 4 & -4 & 5 & -6 \\
\hline 3 & 1 & -3 & 4 & -4 & 5 & -7 & 8 & -8 & 10 & -14 \\
\hline $\mathbf{4}$ & $\mathbf{1}$ & $\mathbf{- 4}$ & $\mathbf{7}$ & $\mathbf{- 8}$ & $\mathbf{9}$ & $\mathbf{- 1 2}$ & $\mathbf{1 5}$ & $\mathbf{- 1 6}$ & $\mathbf{1 8}$ & $\mathbf{- 2 4}$ \\
\hline 5 & 1 & -5 & 11 & -15 & 17 & -21 & 27 & -31 & 34 & -42 \\
\hline 6 & 1 & -6 & 16 & -26 & 32 & -38 & 48 & -58 & 65 & -76 \\
\hline
\end{tabular}



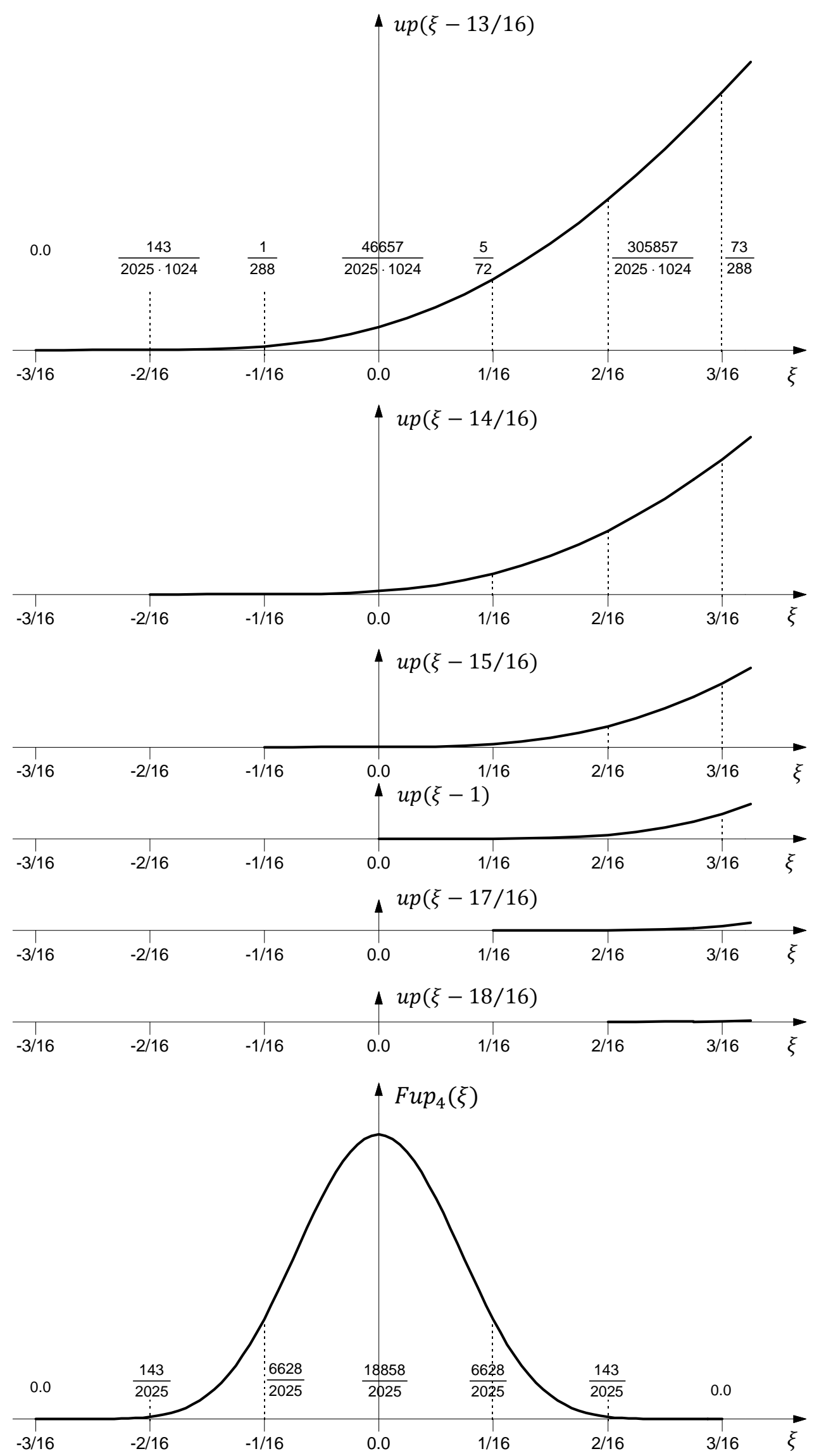

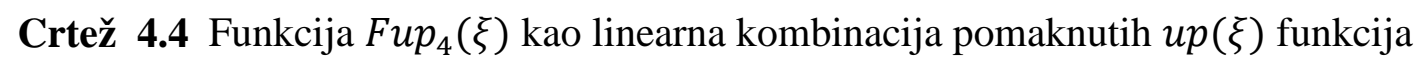




\subsection{Derivacije i integrali funkcija $\operatorname{Fup}_{\mathbf{n}}(\xi)$}

Derivacije funkcije $\mathrm{Fup}_{n}(\xi)$ dobivaju se linearnom kombinacijom derivacija pomaknutih funkcija $u p(\xi)$ pomoću koeficijenata iz tablice 4.1, (vidi točku 3.4) odnosno

$$
\operatorname{Fup}_{n}^{(m)}(\xi)=\sum_{k=0}^{\infty} C_{k}(n) \cdot u p^{(m)}\left(\xi-1-\frac{k}{2^{n}}+\frac{n+2}{2^{n+1}}\right)
$$

Crtež 4.5 prikazuje funkciju $\operatorname{Fup}_{2}(\xi)$ i njene prve tri derivacije. Treća, a i sve daljnje derivacije funkcije $\mathrm{Fup}_{2}(\xi)$ po dijelovima odgovaraju sažetoj funkciji $u p(\xi)$.

Integrali funkcije $\operatorname{Fup}_{n}(\xi)$ također se dobivaju linearnom kombinacijom integrala pomaknutih funkcija $u p(\xi)$ pomoću koeficijenata iz tablice 4.1

$$
\int_{-\infty}^{\xi} F u p_{n}(\xi) d \xi=\sum_{k=0}^{\infty} C_{k} \int_{-\infty}^{\xi} u p\left(\xi-1-\frac{k}{2^{n}}+\frac{n+2}{2^{n+1}}\right) d \xi
$$
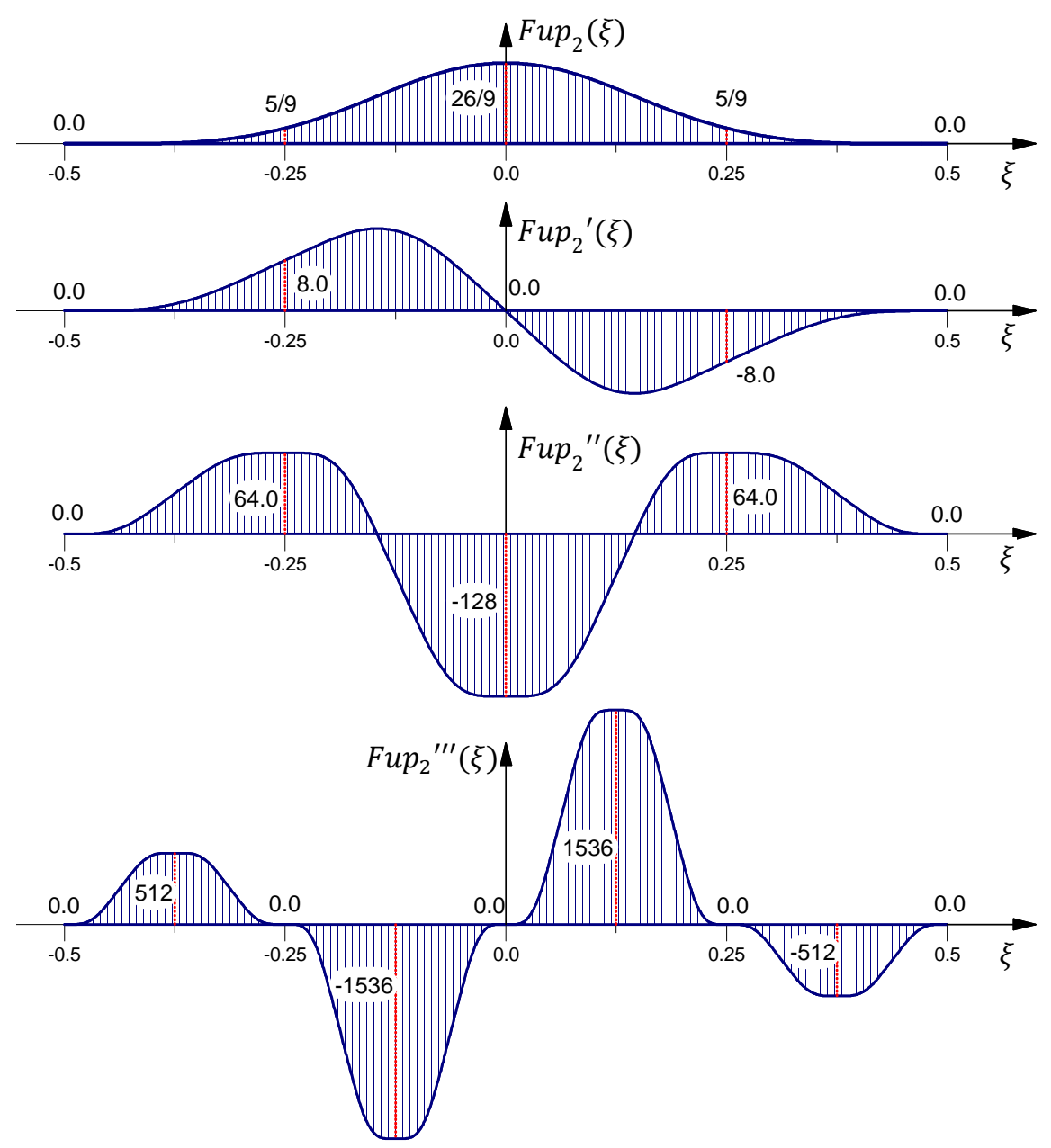

Crtež 4.5 Funkcija $\operatorname{Fup}_{2}(\xi)$ i prve tri derivacije 


\subsection{Razvoj polinoma po bazi pomaknutih $\operatorname{Fup}_{\mathbf{n}}(\xi)$ funkcija}

Raspoređujući bazne funkcije $\operatorname{Fup}_{n}\left(\frac{\xi}{2^{n} \Delta \xi}-\frac{k}{2^{n}}\right)$ na ekvidistantne razmake na način da se brojač baznih funkcija $k$ nalazi u tjemenu (vertex-u) bazne funkcije (vidi crtež 4.6), može se točno razviti polinom stupnja $m \leq n$ na cijeloj realnoj osi u obliku:

$$
\xi^{m}=\frac{\Delta \xi^{m}}{2^{n}} \cdot \sum_{k=-\infty}^{k=+\infty} C_{k}(m, n) \cdot \operatorname{Fup}_{n}\left(\frac{\xi}{2^{n} \cdot \Delta \xi}-\frac{k}{2^{n}}\right)
$$

gdje su koeficijenti linearne kombinacije $C_{k}(m, n)$ polinomi stupnja $m$ od indeksa $k$ u obliku

$$
C_{k}(m, n)=\sum_{i=0}^{m} A_{i} \cdot k^{m-i}
$$

a)
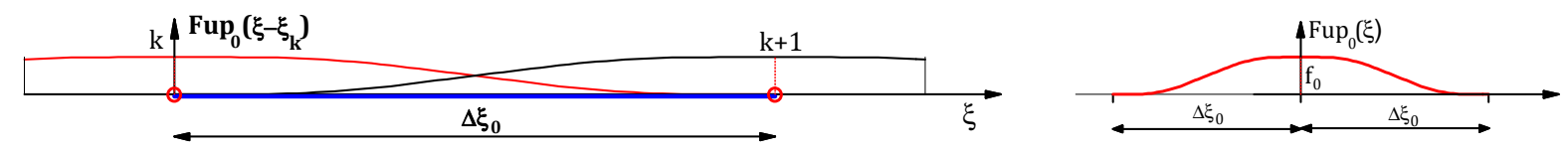

b)
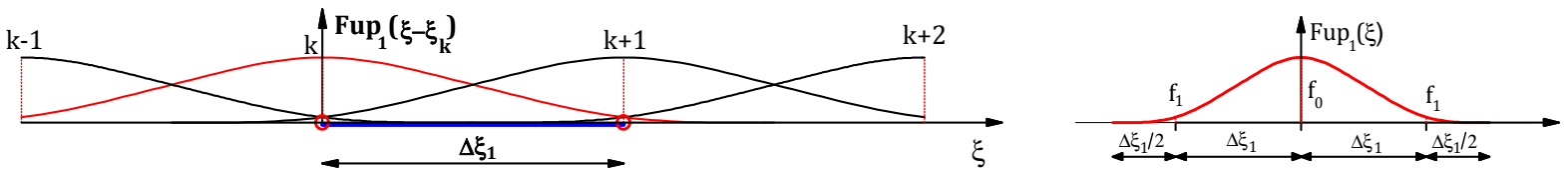

c)
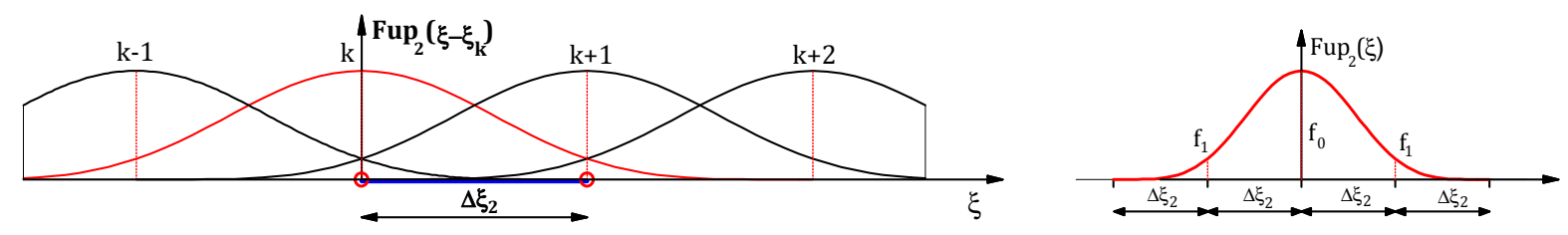

d)
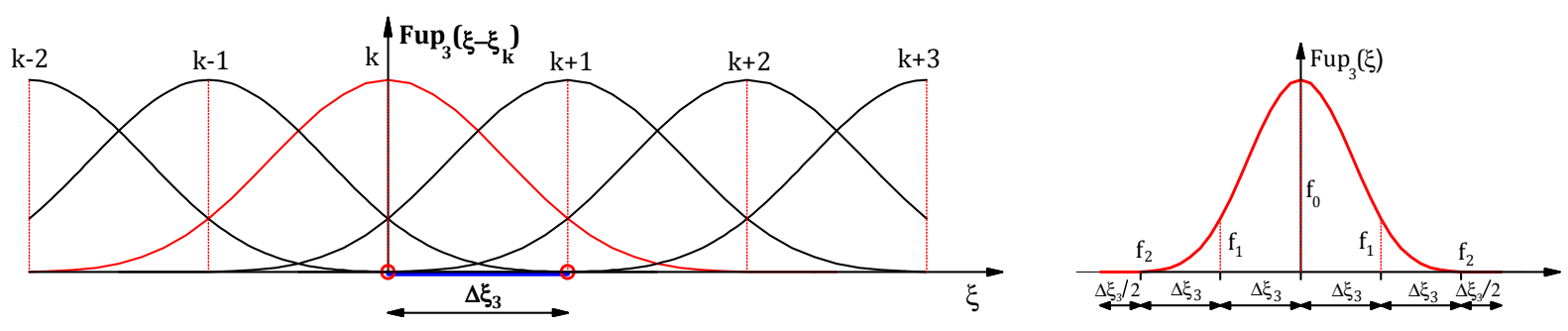

e)
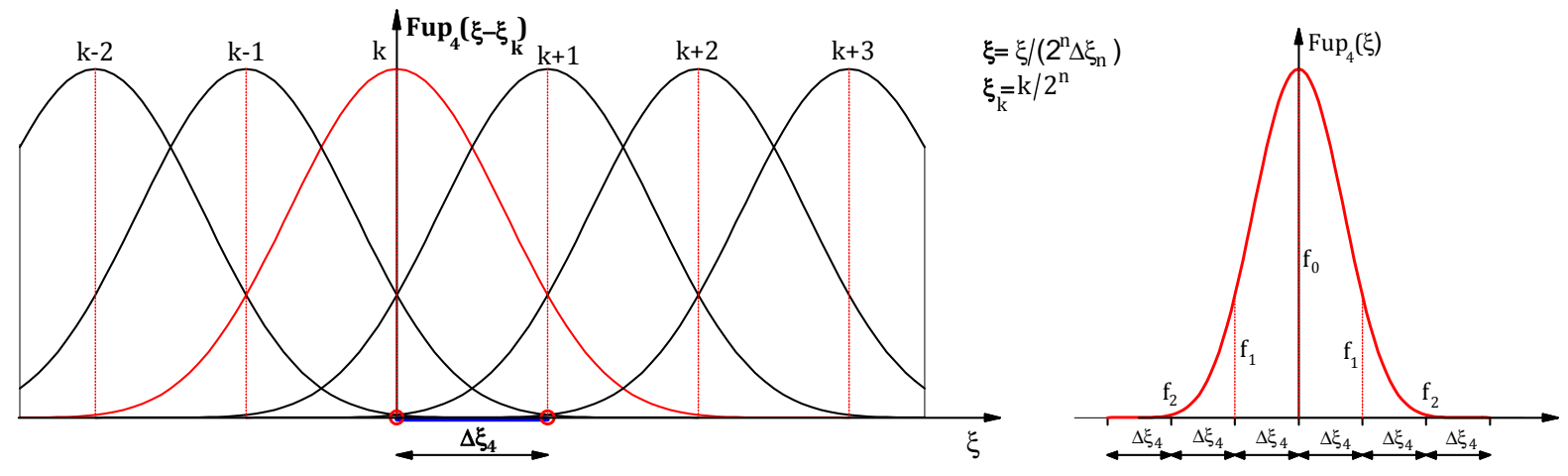

Crtež 4.6 Razvoj polinoma po bazi pomaknutih funkcija $F u p_{n}(\xi)$ 
Nepoznati koeficijenti $A_{i}, i=0, \ldots, m$ iz (4.28) mogu se odrediti metodom kolokacije na način da se zadani polinom $\xi^{m}$ izrazi u obliku linearne kombinacije međusobno pomaknutih baznih funkcija $\operatorname{Fup}_{n}(\xi)$ u $(m+1)$ kolokacijskih točaka, iz čega se dobije sustav jednadžbi

$$
\begin{gathered}
{[(k+i) \Delta \xi]^{m}=\frac{\Delta \xi^{m}}{2^{n}} \sum_{j=k+i-\left[\frac{n+1}{2}\right]+p}^{k+i+\left[\frac{\mathrm{n}}{2}\right]} C_{j}(m, n) \cdot \operatorname{Fup}_{n}\left(\frac{\xi}{2^{n} \cdot \Delta x}-\frac{j}{2^{n}}\right)} \\
i=0, \ldots, m ; \quad p=0, \ldots, n+1 ; \quad k \in Z
\end{gathered}
$$

gdje [·] označava cjelobrojnu vrijednost.

Vrijednosti funkcija $\operatorname{Fup}_{n}(\xi)$ u točkama tipa $\xi_{p}= \pm p /\left(2^{n} \Delta \xi\right)$ zbog jednostavnosti zapisa, a uzimajući u obzir simetriju funkcija, označavaju se sa $f_{p}$ na način kako je prikazano na crtežu 4.6, odnosno:

$$
\operatorname{Fup}_{n}\left( \pm \frac{p}{2^{n} \Delta \xi}\right)=f_{p} ; p=0,1, \ldots,[(n+1) / 2]
$$

Tada, na primjer, za $n=4$ i $m=2, i=0,1,2$ iz (4.29) slijedi

$$
\begin{aligned}
& i=0 \rightarrow \frac{\Delta \xi^{2}}{2^{4}}\left(C_{k-2} f_{2}+C_{k-1} f_{1}+C_{k} f_{0}+C_{k+1} f_{1}+C_{k+2} f_{2}\right)=[k \Delta \xi]^{2} \\
& i=1 \rightarrow \frac{\Delta \xi^{2}}{2^{4}}\left(C_{k-1} f_{2}+C_{k} f_{1}+C_{k+1} f_{0}+C_{k+2} f_{1}+C_{k+3} f_{2}\right)=[(k+1) \Delta \xi]^{2} \\
& i=2 \rightarrow \frac{\Delta \xi^{2}}{2^{4}}\left(C_{k} f_{2}+C_{k+1} f_{1}+C_{k+2} f_{0}+C_{k+3} f_{1}+C_{k+4} f_{2}\right)=[(k+2) \Delta \xi]^{2}
\end{aligned}
$$

Uvrštavanjem (4.28) u sustav (4.31), dobiva se

$$
A_{0}=1 ; A_{1}=0 ; A_{2}=-4 / 9
$$

što znači da se polinom 2.-og stupnja izražava u obliku linearne kombinacije međusobno pomaknutih $\mathrm{Fup}_{4}(\xi)$ baznih funkcija na sljedeći način

$$
\xi^{2}=\frac{\Delta \xi^{2}}{2^{4}} \cdot \sum_{k=-\infty}^{k=+\infty}\left(k^{2}-\frac{4}{9}\right) \cdot \operatorname{Fup}_{4}\left(\frac{\xi}{2^{4} \cdot \Delta \xi}-\frac{k}{2^{4}}\right)
$$

Na crtežu 4.6 prikazani su rasporedi pomaknutih funkcija $F u p_{n}(\xi), n=0, \ldots, 4$ za točan razvoj polinoma do uključivo stupnja $n$. Može se uočiti da je za točan razvoj polinoma stupnja $n$ na odsječku duljine $\Delta \xi_{n}=2^{-n}$ potrebno $(n+2)$ - je bazne funkcije dobivene pomicanjem funkcije $\mathrm{Fup}_{n}(\xi)$ za $2^{-n}$. Npr. za razvoj polinoma 4.-tog stupnja potrebno je 6 pomaknutih funkcija $\mathrm{Fup}_{4}(\xi)$, dok bi pomaknutih funkcija $u p(\xi)$ bile potrebne 32. 
Dakle, polinom $m$ - tog stupnja za $m \leq n$ može se točno prikazati linearnom kombinacijom $\mathrm{Fup}_{n}(\xi)$ baznih funkcija, dok se polinomi viših stupnjeva, tj. za $m>n$, mogu prikazati približno.

Koeficijenti $A_{i}$ iz (4.28) mogu se napisati u općem obliku u ovisnosti o redu bazne funkcije $\operatorname{Fup}_{n}(\xi)$, te o stupnju polinoma $m$ kako je pokazano u nastavku.

Za 'nulte' koeficijente vrijedi

$$
A_{0}(m, n)=1
$$

Isto tako su neparni koeficijenti $A_{i}(m, n)$ jednaki nuli, zbog čega se koeficijenti $C_{k}(m, n)$ iz (4.28) mogu napisati u novom obliku

$$
C_{k}(m, n)=\sum_{i=0}^{[m / 2]} A_{2 i}(m, n) \cdot k^{m-2 \cdot i}
$$

Nadalje, vrijedi i sljedeće

$$
f_{0}+2 \cdot \sum_{p=1}^{[(\mathrm{n}+1) / 2]} f_{p}=2^{n}
$$

Na primjer, za baznu funkciju $\mathrm{Fup}_{4}(\xi)$ prema (4.36) slijedi

$$
f_{0}+2 \cdot\left(f_{1}+f_{2}\right)=2^{4}
$$

Iz sustava (4.29) za $i=0$ i $m=2$ dobije se sljedeće

$$
\frac{(\Delta \xi)^{2}}{2^{4}} \cdot\left(C_{k-2} f_{2}+C_{k-1} f_{1}+C_{k} f_{0}+C_{k+1} f_{1}+C_{k+2} f_{2}\right)=(k \Delta \xi)^{2}
$$

gdje je

$$
C_{k}=\frac{\Delta \xi}{2^{4}} \cdot\left(A_{0} \cdot k^{2}+A_{2}\right)
$$

Uvrštavanjem (4.37) i (4.39) u (4.38) za $k=0$ dobije se koeficijent $A_{2}$ u ovisnosti o poznatom koeficijentu $A_{0}(m, n)=1 \mathrm{u}$ obliku:

$$
A_{2}=-2^{-3} \cdot C_{m}^{2}\left(f_{1}+2^{2} f_{2}\right) \cdot A_{0}
$$

$\mathrm{Na}$ analogan način se koeficijent $A_{4}$ dobije izražen preko poznatih koeficijenta $A_{0}$ i $A_{2}$

$$
A_{4}=-2^{-3} \cdot C_{m}^{4}\left[\left(f_{1}+2^{4} f_{2}\right) \cdot A_{0}+\frac{C_{n}^{2}}{C_{m}^{2}}\left(f_{1}+2^{2} f_{2}\right) \cdot A_{2}\right]
$$

Ponavljanjem postupka dolazi se do općeg izraza za koeficijente $A_{2 i}$ u obliku rekurzivne formule: 


$$
\begin{gathered}
A_{m-2 i}^{(m)}(m, n)=-2^{1-n} \cdot C_{m}^{2 i} \sum_{j=0}^{i-1}\left(\sum_{l=1}^{[(n+1) / 2]} \alpha_{l}^{(n)} \cdot l^{2 i-2 j}\right) \frac{C_{2 i}^{2 j}}{C_{m}^{2 j}} \cdot A_{m-2 j}^{(m)}(m, n) \\
\alpha_{l}^{(n)}=\operatorname{Fup}_{n}\left(\frac{l}{2^{n}}\right) ; \quad l=1,2, \ldots \ldots,[(n+1) / 2]
\end{gathered}
$$

gdje su $C_{m}^{2 i}$ binomni koeficijenti.

Raspoređujući bazne funkcije $\operatorname{Fup}_{n}\left(\frac{x}{2^{n} \Delta x}-\frac{2 k+1}{2} \frac{1}{2^{n}}\right)$ na ekvidistantne razmake proizvoljne duljine $\Delta x$, na način da je brojač pomaknut za $\Delta x / 2$ u odnosu na koordinatu tjemena može se točno razviti polinom stupnja $m \leq n$ na cijeloj realnoj osi u sljedećem obliku:

$$
x^{m}=\frac{\Delta x^{m}}{2^{n}} \cdot \sum_{k=-\infty}^{k=+\infty} C_{k}^{*}(m, n) \cdot \operatorname{Fup}_{n}\left(\frac{x}{2^{n} \cdot \Delta x}-\frac{2 k+1}{2} \frac{1}{2^{n}}\right)
$$

gdje su koeficijenti linearne kombinacije $C_{k}^{*}(m, n)$ prema (4.28) određeni sljedećim izrazom

$$
C_{k}^{*}(m, n)=\sum_{j=0}^{m} A_{j}^{*}(m, n) \cdot k^{m-j}
$$

Linearna kombinacija iz (4.27), odnosno iz (4.43) opisuju zadani polinom $x^{m}$ na identičan način, iz čega se može zaključiti da postoji izravna ovisnost koeficijenata $A_{j}{ }^{*}(m, n)$ o koeficijentima $A_{2 i}(m, n)$ :

$$
C_{k}(m, n)=\sum_{j=0}^{m} A_{j}^{*}(m, n) \cdot k^{m-j}=\sum_{i=0}^{[m / 2]} A_{2 i}(m, n) \cdot\left(k-\frac{1}{2}\right)^{m-2 i}
$$

Izraz (4.45) može se napisati u obliku prikladnom za uspoređivanje pojedinih članova na lijevoj i desnoj strani, tj.:

$$
C_{k}(m, n)=\sum_{j=0}^{m} A_{j}^{*}(m, n) \cdot k^{m-j}=\sum_{i=0}^{[m / 2]}\left(\sum_{r=0}^{m-2 i} \frac{(-1)^{r}}{2^{r}} C_{m-2 i}^{r} k^{m-2 i-r}\right) A_{2 i}(m, n)
$$

iz čega slijedi

$$
A_{j}^{*}(m, n)=\sum_{i=0}^{j / 2}(-1)^{j-2 i} \cdot 2^{2 i-j} \cdot C_{m-2 i}^{j-2 i} \cdot A_{2 i}(m, n)
$$

gdje su $C_{m-2 i}^{j-2 i}$ binomni koeficijenti. 


\subsection{Skalarni produkti baznih funkcija $\operatorname{Fup}_{n}(x)$}

Kod primjene nejake (integralne) formulacije, bilo za aproksimaciju zadane funkcije ili za određivanje približnog rješenja diferencijalne jednadžbe, neophodno je izračunavanje skalarnog produkta, kako baznih funkcija $\operatorname{Fup}_{n}(x)$ i polinoma $x^{m}, m \in N$, tako i skalarnog produkta međusobno pomaknutih baznih funkcija $\operatorname{Fup}_{n}(x)$, kao i skalarnog produkta njezinih derivacija.

Skalarni produkt polinoma $x^{m}, m \in N$ i funkcije $F u p_{n}(x)$ na realnom karakterističnom odsječku $\Delta x_{n}$ proizvoljne duljine može se napisati kao

$$
S_{m}(n, k)=\int_{k \Delta x_{n}}^{(k+1) \Delta x_{n}} x^{m} \operatorname{Fup}_{n}\left(\frac{x}{2^{n} \Delta x_{n}}-\frac{(n+2) / 2-k}{2^{n}}\right) d x ; k=0,1, \ldots, n+1
$$

gdje je $k$ indeks karakterističnog odsječka funkcije $\operatorname{Fup}_{n}(x)$ definiran s lijeva nadesno, $n$ određuje baznu funkciju iz klase $\operatorname{Fup}_{n}(x)$ baznih funkcija, a $m$ je stupanj polinoma u skalarnom produktu.

$\mathrm{S}$ obzirom da je funkciju $\operatorname{Fup}_{n}(x)$ praktično najpovoljnije izraziti u obliku linearne kombinacije međusobno pomaknutih $u p(x)$ funkcija (vidi točku 4.5), slijedi da se i skalarni produkt polinoma i funkcije $\operatorname{Fup}_{n}(x)$ iz (4.48) može izraziti u obliku linearne kombinacije skalarnih produkata polinoma i baznih funkcija $u p(x)$ iz izraza (3.32) koristeći koeficijente iz tablice 4.1 .

U Dodatku B.2 prikazani su skalarni produkti polinoma $x^{m}, m=0, \ldots, 5$ i baznih funkcija $\operatorname{Fup}_{2}(x)$, te skalarni produkti polinoma $x^{m}, m=0, \ldots, 5$ i funkcija $\operatorname{Fup}_{n}(x), n=1,2,3,4$.

Skalarni produkt međusobno pomaknutih baznih funkcija $F u p_{n}(x)$ na karakterističnom odsječku $\Delta x_{n}=2^{-n}$ može se napisati kao

$$
\Gamma(n, i, k)=\int_{i 2^{-n}}^{(i+1) 2^{-n}} \operatorname{Fup}_{n}\left(x-k 2^{-n}\right) \cdot \operatorname{Fup}_{n}(x) d x ; k \in Z, \quad i \in Z
$$

Slično kao i kod funkcije up $(x)$, umjesto numeričkog integriranja izraza (4.49), koristi se poznata veza polinoma i funkcija $\operatorname{Fup}_{n}(x)$ (točka 4.7).

Ako se zadana funkcija $f(x)=x^{n}, n \in N$ aproksimira u obliku linearne kombinacije baznih funkcija $\operatorname{Fup}_{n}(x)$ nejakom formulacijom potrebno je riješiti sustav jednadžbi

$$
a_{i j} \cdot c_{j}=b_{j} ; \quad i, j \in N
$$


gdje su koeficijenti $c_{i}$ poznati brojevi određeni izrazima (4.35) i (4.42), a desna strana $b_{j}$ je skalarni produkt iz (4.48) (vidi Dodatak B.2).

Elementi matrice sustava $a_{i j}$ su skalarni produkti baznih funkcija prema (4.49) i označeni su sa $\Gamma_{i j}^{(n)}$. Pri tome $i$ označava indeks prvog faktora, a $j$ indeks drugog faktora u skalarnom produktu. Od ukupno $(n+2)^{2}$ nepoznatih elemenata matrice, zbog simetričnosti matrice oko glavne i sporedne dijagonale, ostaje $-([n / 2]+2)([n / 2]-n-1)$ međusobno različitih skalarnih produkata $\Gamma_{i j}^{(n)}$ ([·] označava cjelobrojnu vrijednost izraza unutar uglatih zagrada).

Elementi na glavnoj dijagonali određuju se u obliku linearne kombinacije skalarnih produkata $\gamma_{i j}^{(n)}$ međusobno pomaknutih $u p(x)$ baznih funkcija uz koeficijente linearne koombinacije iz tablice 4.1. Preostali $([(n+1) / 2]+1)$ nepoznati elementi matrice određuju se pomoću razvoja polinoma po funkcijama $\operatorname{Fup}_{n}\left(x-k 2^{-n}\right)$ u (4.27) koristeći (4.35) i (4.42).

Na primjer, matrica sustava iz (4.50) za baznu funkciju $\operatorname{Fup}_{1}(x)$ je

\begin{tabular}{|c|c|c|}
\hline$\because \Gamma_{11}^{(1)}$ & $\Gamma_{12}^{(1)}$ & $\Gamma_{13}^{(1)}$ \\
\hline$\Gamma_{21}^{(1)}=\Gamma_{12}^{(1)}$ & & $\Gamma_{23}^{(1)}=\Gamma_{12}^{(1)}$ \\
\hline$\Gamma_{31}^{(1)}=\bar{\prime}^{\prime \prime} \bar{\Gamma}_{13}^{\prime(1)}$ & $\Gamma_{32}^{(1)}=\Gamma_{12}^{(1)}$ & $\Gamma_{33}^{(1)}=\gamma_{11}^{(1)}$ \\
\hline
\end{tabular}

Dijagonalni članovi mogu se napisati u obliku linearne kombinacije kao

$$
\begin{gathered}
\Gamma_{11}^{(1)}=\left(C_{0}\right)^{2} \gamma_{11}^{(1)} \\
\Gamma_{22}^{(1)}=\left(C_{0}\right)^{2} \gamma_{22}^{(1)}+2 C_{0} C_{1} \gamma_{12}^{(1)}+\left(C_{1}\right)^{2} \gamma_{11}^{(1)}
\end{gathered}
$$

pa prema (3.64) i (3.65) te koeficijentima iz tablice 4.1 za $n=1$ slijedi

$$
\Gamma_{11}^{(1)}=-\frac{26}{36}+\gamma \quad ; \quad \Gamma_{22}^{(1)}=-\frac{78}{36}+4 \gamma
$$

gdje je $\gamma$ dat izrazom (3.59).

Koeficijenti izvan glavne dijagonale određuju se iz sustava jednadžbi

$$
\begin{aligned}
& \frac{1}{2} \Gamma_{11}^{(1)}+\frac{1}{2} \Gamma_{12}^{(1)}+\frac{1}{2} \Gamma_{13}^{(1)}=\frac{5}{36} \\
& \frac{1}{2} \Gamma_{12}^{(1)}+\frac{1}{2} \Gamma_{22}^{(1)}+\frac{1}{2} \Gamma_{12}^{(1)}=\frac{13}{18}
\end{aligned}
$$


iz kojega slijedi

$$
\Gamma_{12}^{(1)}=\frac{65}{36}-2 \gamma \quad ; \quad \Gamma_{13}^{(1)}=-\frac{29}{36}+\gamma
$$

$\mathrm{Na}$ analogan način određuju se skalarni produkti ostalih međusobno pomaknutih $\operatorname{Fup}_{n}(x)$ baznih funkcija, kao i skalarni produkti međusobno pomaknutih derivacija baznih funkcija $\operatorname{Fup}_{n}(x)$.

U Dodatku B.3 dani su izrazi kao i grafička interpretacija skalarnih produkata međusobno pomaknutih baznih funkcija $\mathrm{Fup}_{2}(x)$ i skalarnih produkata međusobno pomaknutih prvih derivacija baznih funkcija $\operatorname{Fup}_{2}(x)$.

\subsection{Modificirane rubne bazne funkcije $\operatorname{Fup}_{\mathbf{n}}(\xi)$}

U pojedinim numeričkim metodama, kao na primjer kod nejake formulacije, javlja se potreba za „modificiranjem“ rubnih baznih funkcija. Pod pojmom „rubne bazne funkcije“ podrazumijevaju se funkcije u linearnoj kombinaciji čiji se nosač jednim dijelom nalazi izvan područja definicije problema.

Modificirane rubne $\mathrm{ABF} \operatorname{Fup}_{n}(\xi)$ zbog jednostavnijeg zapisa označavaju se sa $\varphi_{n, j}$, $j=-[(n+1) / 2], \ldots,[n / 2]$ na lijevom rubu područja $\xi_{A}$, te $j=N-[n / 2], \ldots, N+$ $[(n+1) / 2]$ na desnom rubu područja $\xi_{B}(N$ je broj odsječaka na promatranom području).

Modificirane rubne funkcije $\varphi_{n, j}$ prikazuju se u obliku linearne kombinacije izvornih baznih funkcija $\operatorname{Fup}_{n}(\xi)$ koje se u nastavku označavaju sa $y_{n, i}(x), i=-[(n+1) / 2], \ldots, j$, odnosno $i=j, \ldots, N+[(n+1) / 2]$.

Rubne $\operatorname{ABF} \varphi_{n, j}$ na lijevom rubu modificiraju se tako da je zadovoljena $i$-ta derivacija na način

$$
\begin{array}{llrl}
\varphi_{n, j}^{(i)}\left(\xi_{A}\right) \neq 0 & \text { za } \quad & j+[(n+1) / 2] \leq i \leq n \\
\varphi_{n, j}^{(i)}\left(\xi_{A}\right)=0 & \text { inače } ; & i \in N
\end{array}
$$

$\mathrm{Na}$ desnom rubu područja modifikacija se postiže translacijom i zrcaljenjem lijevog ruba.

U linearnoj kombinaciji međusobno pomaknutih $\mathrm{ABF} F u p_{n}(\xi)$ potrebno je modificirati $(n+1)$ baznu funkciju na lijevom, odnosno desnom rubu čiji je nosač jednim dijelom izvan područja.

U nastavku su pokazane modificirane rubne $\mathrm{ABF} F u p_{2}(\xi)$ za različiti indeks $N$ podjele područja. 
I. Ako je linearna kombinacija međusobno pomaknutih $\mathrm{ABF} F u p_{2}(\xi)$ definirana na intervalu $I=[A, B]$, pri čemu je duljina intervala $I$ veća ili jednaka duljini tri karakteristična odsječka tj. $I \geq 3 \Delta \xi_{2} \quad(N \geq 3)$ modificirane rubne $\mathrm{ABF} F u p_{2}(\xi)$ na lijevom rubu određene su izrazima

$$
\begin{gathered}
\varphi_{2,-1}(\xi)=\frac{36}{5} y_{2,-1}(\xi) \\
\varphi_{2,0}(\xi)=-\frac{36}{5} y_{2,-1}(\xi)+\frac{18}{13} y_{2,0}(\xi) \\
\varphi_{2,1}(\xi)=y_{2,-1}(\xi)-\frac{5}{13} y_{2,0}(\xi)+y_{2,1}(\xi)
\end{gathered}
$$

dok se modificirane rubne $\mathrm{ABF} F u p_{2}(\xi)$ na desnom rubu dobiju translacijom funkcija sa lijevog ruba za duljinu $L=N \cdot \Delta \xi_{2}$ i njihovom zrcalnom simetrijom oko desnog ruba, tj. $\varphi_{2, j}(\xi)=\varphi_{2, j}(-\xi-L):$

$$
\begin{gathered}
\varphi_{2, N-1}(\xi)=y_{2, N+1}(\xi)-\frac{5}{13} y_{2, N}(\xi)+y_{2, N-1}(\xi) \\
\varphi_{2, N}(\xi)=-\frac{36}{5} y_{2, N+1}(\xi)+\frac{18}{13} y_{2, N}(\xi) \\
\varphi_{2, N+1}(\xi)=\frac{36}{5} y_{2, N+1}(\xi)
\end{gathered}
$$

Na crtežu 4.7a) prikazana je linearna kombinacija baznih funkcija $y_{2, i}(\xi)$, dok su na crtežu 4.7b) prikazane modificirane rubne $\operatorname{ABF} \varphi_{2, j}(\xi)$ na lijevom i desnom rubu područja.

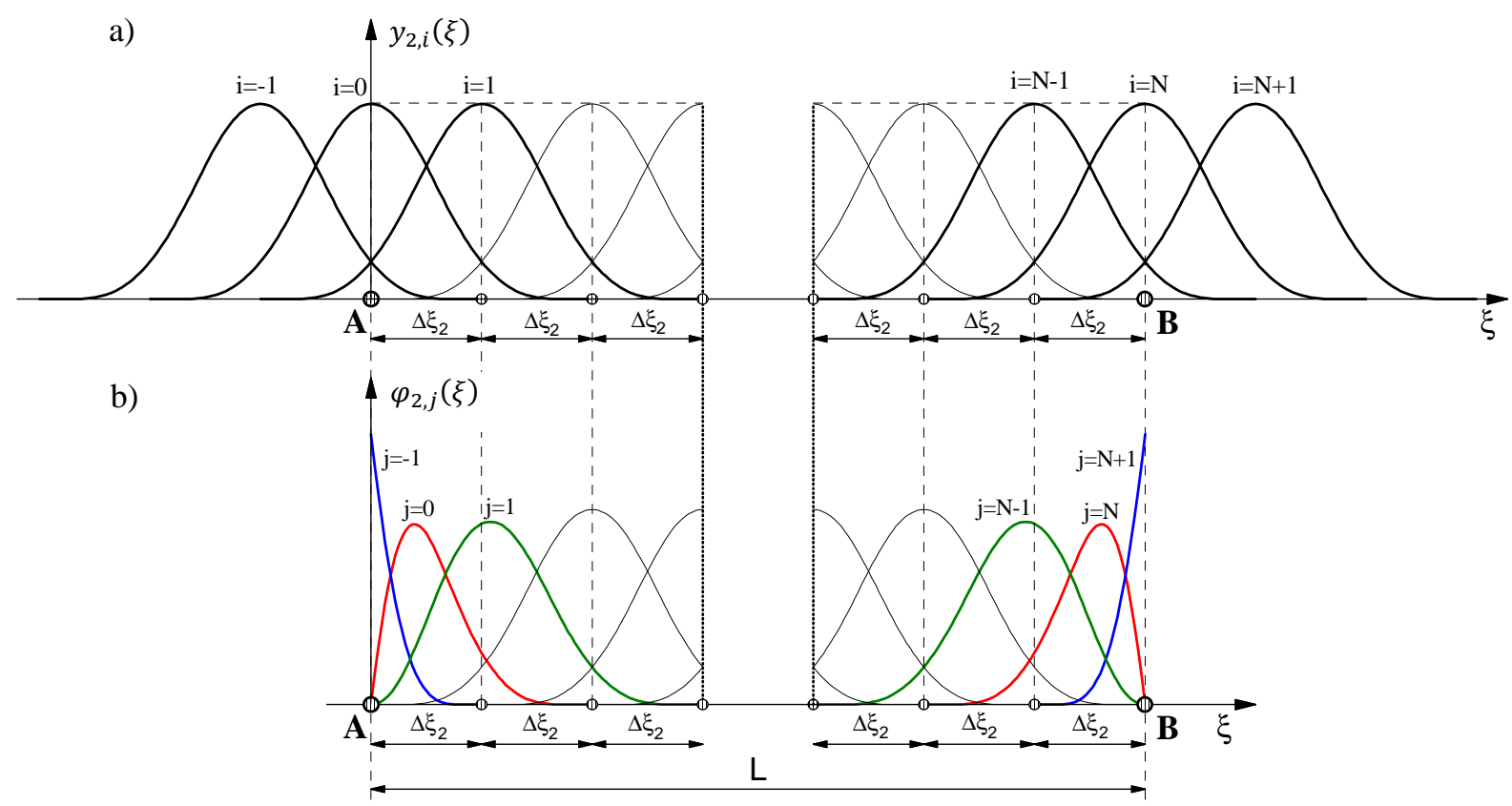

Crtež 4.7 a) Linearna kombinacija međusobno pomaknutih baznih funkcija $y_{2, i}(\xi)$

b) Modificirane rubne $\operatorname{ABF} \varphi_{2, j}(\xi)$ na lijevom i desnom rubu područja 
II. Ako je linearna kombinacija $\mathrm{ABF}$ definirana na intervalu duljine dva karakteristična odsječka tj., $I=2 \Delta \xi_{2},(N=2)$ Crtež 4.8a), modificirane rubne $\mathrm{ABF} F u p_{2}(\xi)$ na lijevom rubu $\varphi_{2,-1}(\xi)$ i $\varphi_{2,0}(\xi)$ odgovaraju baznim funkcijama iz izraza (4.56), dok modificirane rubne $\mathrm{ABF}$ na desnom rubu $\varphi_{2,2}(\xi)$ i $\varphi_{2,3}(\xi)$ odgovaraju baznim funkcijama $\varphi_{2, N}(\xi)$ i $\varphi_{2, N+1}(\xi)$ iz izraza (4.57). Srednja $\operatorname{ABF} \varphi_{2,1}(\xi)$ u linearnoj kombinaciji presjeca oba ruba i određena je izrazom

$$
\varphi_{2,1}(\xi)=y_{2,-1}(\xi)-\frac{5}{13} y_{2,0}(\xi)+y_{2,1}(\xi)-\frac{5}{13} y_{2,2}(\xi)+y_{2,3}(\xi)
$$

III. Ako je linearna kombinacija $\mathrm{ABF}$ definirana na intervalu duljine jednog karakterističnog odsječka tj., $I=\Delta \xi_{2},(N=1)$ Crtež $\left.4.8 \mathrm{~b}\right)$, ABF na lijevom rubu $\varphi_{2,-1}(\xi)$, odnosno $\varphi_{2,2}(\xi)$ na desnom, odgovaraju baznim funkcijama $\varphi_{2,-1}(\xi)$ i $\varphi_{2, N+1}(\xi)$ iz izraza (4.56) i (4.57), respektivno, dok su srednje modificirane bazne funkcije sljedećeg oblika

$$
\begin{gathered}
\varphi_{2,0}(\xi)=\frac{1}{40}\left(-313 y_{2,-1}(\xi)+65 y_{2,0}(\xi)-25 y_{2,1}(\xi)+65 y_{2,2}(\xi)\right) \\
\varphi_{2,1}(\xi)=\frac{1}{40}\left(65 y_{2,-1}(\xi)-25 y_{2,0}(\xi)+65 y_{2,1}(\xi)-313 y_{2,2}(\xi)\right)
\end{gathered}
$$

a)

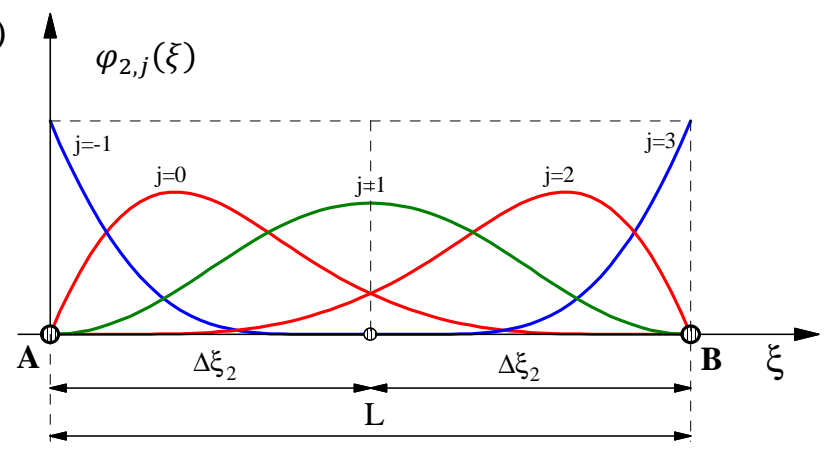

b)

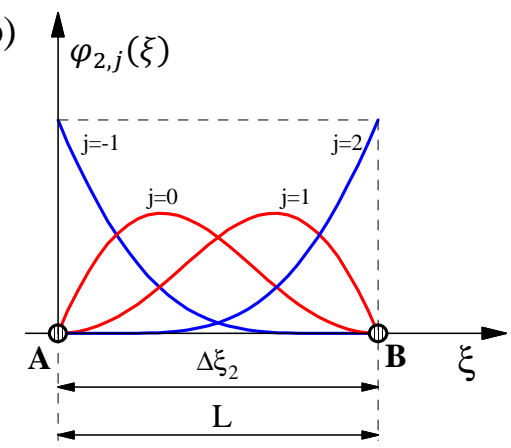

Crtež 4.8 a) Modificirane rubne $\operatorname{ABF} \varphi_{2, j}(\xi)$ na intervalu $I=2 \Delta \xi_{2}$

b) Modificirane rubne $\operatorname{ABF} \varphi_{2, j}(\xi)$ na intervalu $I=\Delta \xi_{2}$

U Dodatku B.1 dani su izrazi za modificirane rubne bazne funkcije $\varphi_{4, j}$. 


\section{B.DODATAK: ALGEBARSKE ABF FUP}

\section{B.1. Modificirane rubne bazne funkcije $\operatorname{Fup}_{\mathbf{n}}(\mathbf{x})$}

U točki 4.9 opisan je postupak modificiranja rubnih baznih funkcija $F u p_{n}(x)$ općenito, te su prikazane modificirane rubne $\operatorname{ABF} \varphi_{2, j}(x)\left(F u p_{2}(x)\right)$ za različite podjele područja $I=[A, B]$.

Uz bazne funkcije $\operatorname{Fup}_{2}(x)$ kao jedne od najčešće korištenih baznih funkcija iz klase algebarskih $\mathrm{ABF}$ su i bazne funkcije $\operatorname{Fup}_{4}(x)$. Stoga su u nastavku dani izrazi i za modificirane rubne bazne funkcije $\varphi_{4, j}(x)\left(F_{u p}(x)\right)$, crtež B.1. Izrazi se odnose na modificirane bazne funkcije $\varphi_{4, j}(x)$ na lijevom rubu područja, dok se funkcije na desnom rubu dobiju translacijom funkcija sa lijevog ruba za duljinu $L=N \cdot \Delta x_{4}$ i njihovom zrcalnom simetrijom oko desnog ruba, tj. $\varphi_{4, j}(x)=\varphi_{4, j}(-x-L)$. Indeks podjele područja je $N \geq 6$ odnosno, minimalno jedna bazna funkcija se cijela nalazi unutar područja:

$$
\begin{gathered}
\varphi_{4,-2}(x)=\frac{32400}{143} y_{4,-2}(x) \\
\varphi_{4,-1}(x)=-\frac{1620}{217}\left\{\frac{6628}{143} y_{4,-2}(x)-y_{4,-1}(x)\right\} \\
\varphi_{4,0}(x)=\frac{28800}{14231}\left\{\frac{1347}{310}\left[16 y_{4,-2}(x)-y_{4,-1}(x)\right]+y_{4,0}(x)\right\} \\
\varphi_{4,1}(x)=\frac{1350}{14231}\left\{-224 y_{4,-2}(x)+\frac{1}{1151}\left[30345 y_{4,-1}(x)-13712 y_{4,0}(x)+14231 y_{4,1}(x)\right]\right\} \\
\varphi_{4,2}(x)=\left\{y_{4,-2}(x)+\frac{1}{1151}\left[-199 y_{4,-1}(x)+5999 y_{4,0}(x)-199 y_{4,1}(x)\right]+y_{4,2}(x)\right\}
\end{gathered}
$$




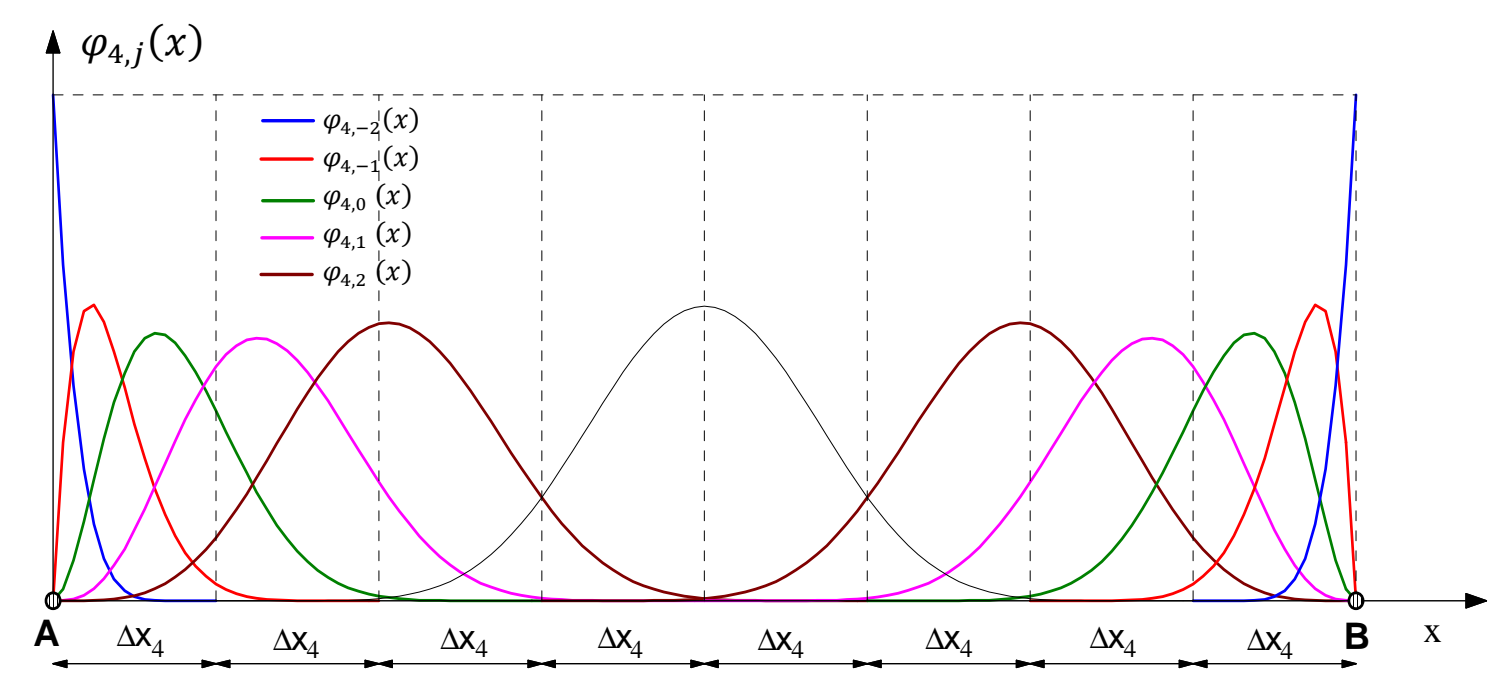

Crtež B.1 Modificirane rubne $\mathrm{ABF} \varphi_{4, j}(x)$

\section{B.2. Skalarni produkt polinoma $x^{\mathrm{m}}$ i funkcije $\operatorname{Fup}_{\mathrm{n}}(\mathbf{x})$ na karakterističnom odsječku $\Delta \mathbf{x}_{n}$}

Skalarni produkti polinoma $x^{m}$ i baznih funkcija $\operatorname{Fup}_{2}(x)$ iz točke 4.8, na karakterističnom odsječku proizvoljne duljine $\Delta x_{2}$, mogu se općenito napisati u sljedećem obliku

$$
\begin{gathered}
S_{m}(2, j, k)=\left(4 \Delta x_{2}\right)^{m+1} \frac{a_{j, m, k}}{b_{m}} \\
m \in N ; \quad n=2 ; \quad j=-1, \ldots, N+1 ; \quad k=0, \ldots, n+1
\end{gathered}
$$

gdje je $m$ stupanj polinoma u skalarnom produktu, indeks $j$ označava (ne)modificiranu baznu funkciju $\mathrm{Fup}_{2}(x)$, a $k$ određuje indeks karakterističnog odsječka bazne funkcije, odnosno područje integracije, crtež B.2.

I. Koeficijenti $b_{m}$ u izrazu (B.2), za bazne funkcije u linearnoj kombinaciji kada je $I \geq$ $3 \Delta x_{2}$, su sljedeći brojevi:

$$
\begin{gathered}
b_{0}=2340 ; b_{1}=8424000 ; b_{2}=16848000 \\
b_{3}=11887948800 ; b_{4}=59439744000 ; b_{5}=1455084933120000
\end{gathered}
$$

dok su $a_{j, m, k}$ dani u sljedećoj tablici: 
Tablica B.1 Koeficijenti $a_{j, m, k}$ iz izraza (B.2) za bazne funkcije $F u p_{2}(x)$

\begin{tabular}{|c|c|c|c|c|c|c|c|}
\hline$\varphi_{2, j}(x)$ & $k$ & $m=0$ & $m=1$ & $m=2$ & $m=3$ & $m=4$ & $m=5$ \\
\hline$j=-1$ & 0 & 468 & 66924 & 8892 & 539604 & 272844 & 756453204 \\
\hline \multirow{2}{*}{$j=0$} & 0 & 1062 & 461466 & 138528 & 16652376 & 15389046 & 73629868986 \\
\hline & 1 & 90 & 12870 & 1710 & 103770 & 52470 & 145471770 \\
\hline \multirow{3}{*}{$j=1$} & 0 & 745 & 475405 & 182390 & 25966460 & 27127805 & 142343217005 \\
\hline & 1 & 1080 & 378040 & 105995 & 12387605 & 11296790 & 53683046090 \\
\hline & 2 & 65 & 9295 & 1235 & 74945 & 37895 & 105062945 \\
\hline \multirow{4}{*}{$j=i$} & 0 & 65 & 49205 & 21190 & 3278860 & 3647605 & 20100690805 \\
\hline & 1 & 1105 & 612885 & 222105 & 30667065 & 31440435 & 162901021335 \\
\hline & 2 & 1105 & 381615 & 106470 & 12416430 & 11311365 & 53723454915 \\
\hline & 3 & 65 & 9295 & 1235 & 74945 & 37895 & 105062945 \\
\hline \multirow{3}{*}{$j=N-1$} & 0 & 65 & 49205 & 21190 & 3278860 & 3647605 & 20100690805 \\
\hline & 1 & 1080 & 593960 & 213955 & 29405965 & 30037510 & 155169986410 \\
\hline & 2 & 745 & 195095 & 42235 & 3900265 & 2866495 & 11169906745 \\
\hline \multirow{2}{*}{$j=N$} & 0 & 90 & 68130 & 29340 & 4539960 & 5050530 & 27831725730 \\
\hline & 1 & 1062 & 494334 & 154962 & 18854298 & 17270154 & 80830286514 \\
\hline$j=N+1$ & 0 & 468 & 354276 & 152568 & 23607792 & 26262756 & 144724973796 \\
\hline
\end{tabular}
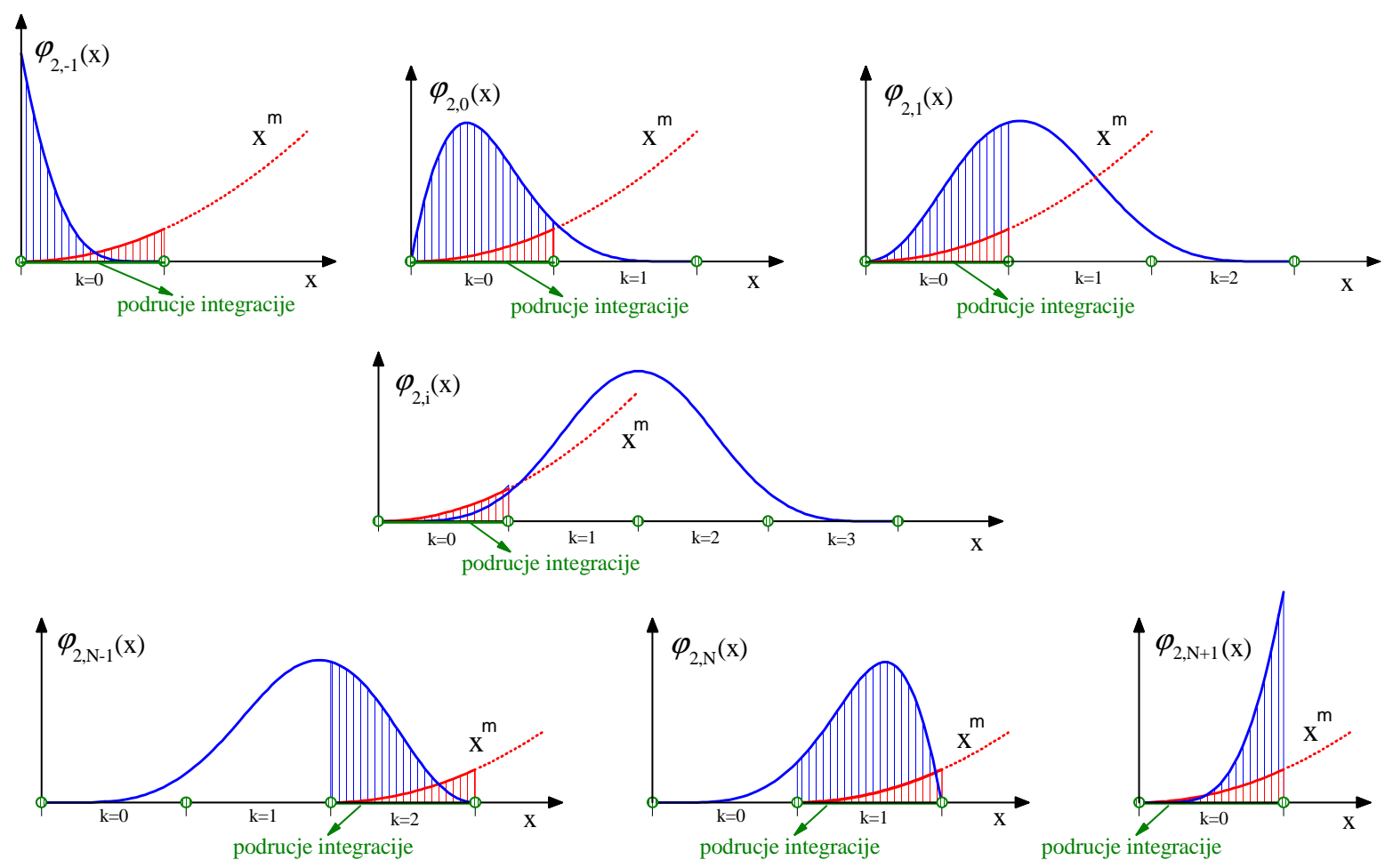

Crtež B.2 Skalarni produkt polinoma $x^{m}$ i baznih funkcija $F u p_{2}(x)$ kada je $I \geq 3 \Delta x_{2}$ 
II. Koeficijenti $b_{m}$ iz izraza (B.2), za bazne funkcije u linearnoj kombinaciji kada je duljina područja $I=2 \Delta x_{2}$, su sljedeći brojevi:

$$
\begin{gathered}
b_{0}=130 ; b_{1}=468000 ; b_{2}=936000 \\
b_{3}=660441600 ; b_{4}=3302208000 ; b_{5}=80838051840000
\end{gathered}
$$

Koeficijenti $a_{j, m, k}$ dani u tablici B.2.

Tablica B.2 Koeficijenti $a_{j, m, k}$ iz izraza (B.2)

\begin{tabular}{|c|c|c|c|c|c|c|c|}
\hline$\varphi_{2, j}(x)$ & $k$ & $m=0$ & $m=1$ & $m=2$ & $m=3$ & $m=4$ & $m=5$ \\
\hline \hline$j=-1$ & 0 & 26 & 3718 & 494 & 29978 & 15158 & 42025178 \\
\hline \hline$j=0$ & 0 & 59 & 25637 & 7696 & 925132 & 854947 & 4090548277 \\
\cline { 2 - 8 } & 1 & 5 & 715 & 95 & 5765 & 2915 & 8081765 \\
\hline \hline$j=1$ & 0 & 40 & 25360 & 9680 & 1372520 & 1429160 & 7478454560 \\
\hline \hline & 1 & 40 & 10640 & 2320 & 215080 & 158440 & 618305440 \\
\hline \hline$j=2$ & 0 & 5 & 3785 & 1630 & 252220 & 280585 & 1546206985 \\
\hline \hline & 1 & 59 & 27463 & 8609 & 1047461 & 959453 & 4490571473 \\
\hline
\end{tabular}
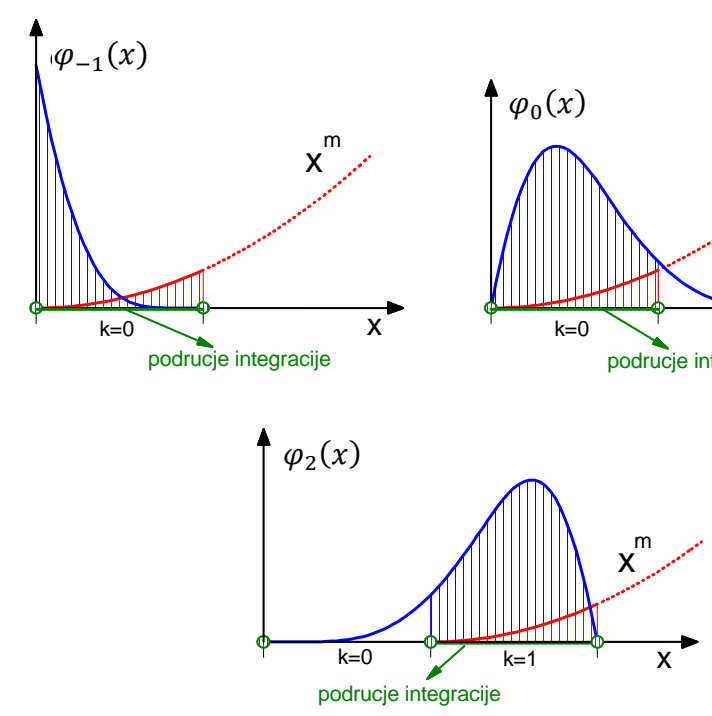
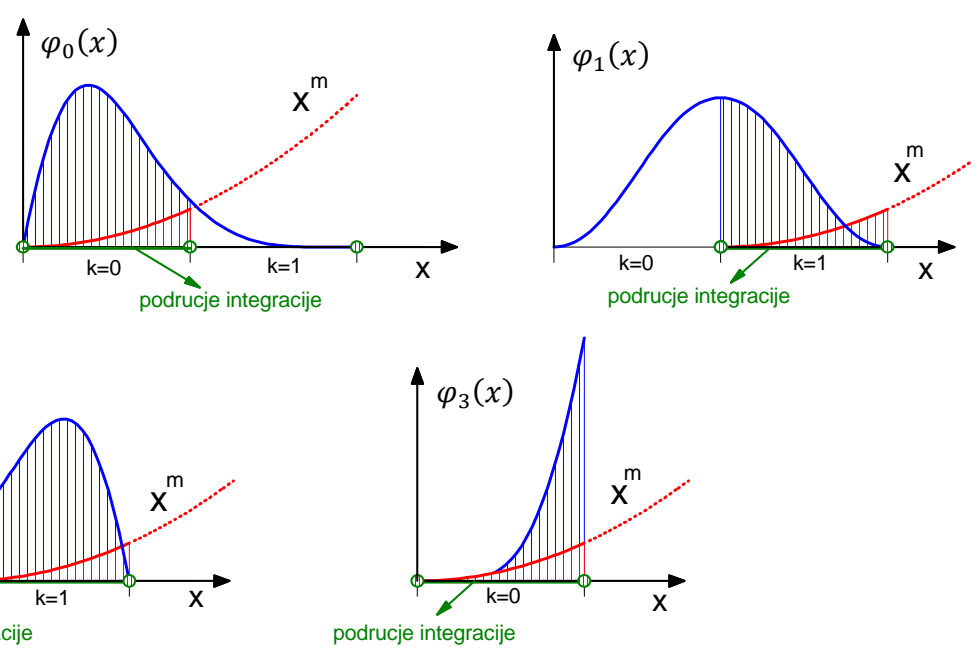

Crtež B.3 Skalarni produkt polinoma $x^{m}$ i baznih funkcija $F u p_{2}(x)$ kada je $I=2 \Delta x_{2}$ 
III. Koeficijenti $b_{m}$ iz izraza (B.2), za bazne funkcije u linearnoj kombinaciji kada je duljina područja $I=\Delta x_{2}$, su:

$$
\begin{gathered}
b_{0}=10 ; b_{1}=18000 ; b_{2}=36000 \\
b_{3}=50803200 ; b_{4}=254016000 ; b_{5}=3109155840000
\end{gathered}
$$

dok su $a_{j, m, k}$ dani u tablici B.3.

Tablica B.3 Koeficijenti $a_{j, m, k}$ iz izraza (B.2)

\begin{tabular}{|c|c|c|c|c|c|c|c|}
\hline$\varphi_{2, j}(x)$ & $k$ & $m=0$ & $m=1$ & $m=2$ & $m=3$ & $m=4$ & $m=5$ \\
\hline \hline$j=-1$ & 0 & 2 & 143 & 19 & 2306 & 1166 & 1616353 \\
\hline \hline$j=0$ & 0 & 3 & 522 & 126 & 24579 & 18639 & 37027737 \\
\hline \hline$j=1$ & 0 & 3 & 828 & 279 & 70677 & 66411 & 158162013 \\
\hline \hline$j=2$ & 0 & 2 & 757 & 326 & 100888 & 112234 & 309241397 \\
\hline
\end{tabular}
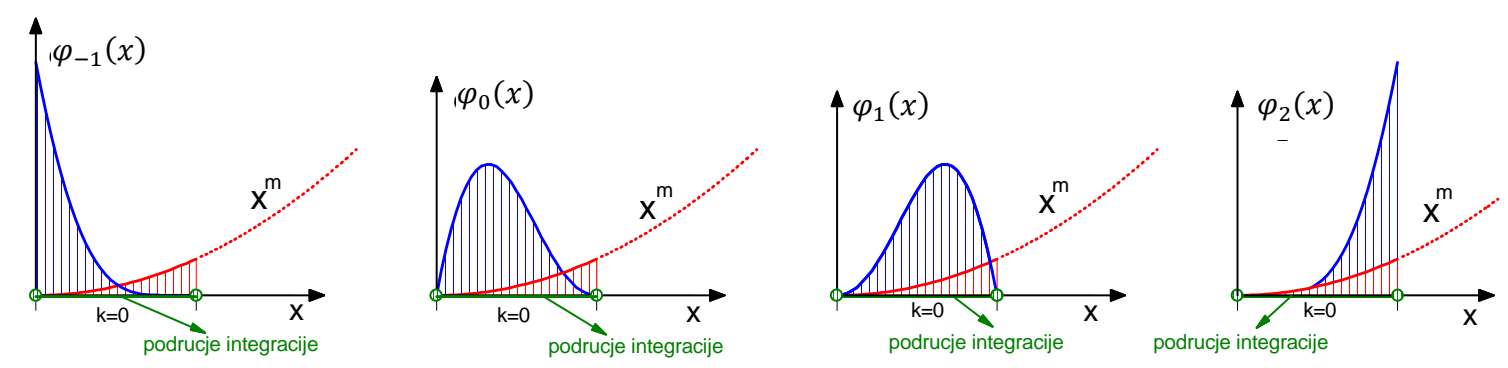

Crtež B.4 Skalarni produkt polinoma $x^{m}$ i baznih funkcija $F u p_{2}(x)$ kada je $I=\Delta x_{2}$

Na sličan način može se prikazati i skalarni produkt polinoma $x^{m}$ i baznih funkcija $\operatorname{Fup}_{n}(x)$ za $n=1,3,4$ u sljedećem obliku:

$$
s_{n}(m, k)=\left(2^{n} \Delta x_{n}\right)^{m+1} \frac{a_{m, k}}{b_{m}^{(n)}}
$$

gdje $n$ označava red $\mathrm{ABF} \operatorname{Fup}_{n}(x), k$ određuje indeks karakterističnog odsječka bazne funkcije. (U izrazu (B.6) ne pojavljuje se indeks ' ${ }^{\prime}$ ' za razliku od izraza (B.2) zbog toga što su u nastavku dani koeficijenti za izračun skalarnih produkata polinoma $x^{m}$ i izvornih ili nemodificiranih baznih funkcija $\operatorname{Fup}_{n}(x), n=1,3,4$.)

Koeficijenti $b_{m}^{(n)}$ i $a_{m, k}$ dani su u tablicama B.4 i B.5, respektivno. 
Tablica B.4 Koeficijenti $b_{m}^{(n)}$ iz izraza (B.6)

\begin{tabular}{|l|c|c|c|}
\hline & $n=1$ & $n=3$ & $n=4$ \\
\hline \hline$m=0$ & 36 & 32400 & 32400 \\
\hline$m=1$ & 72 & 259200 & 1371686400 \\
\hline$m=2$ & 64800 & 548674560 & 10973491200 \\
\hline$m=3$ & 43200 & 7315660800 & 1790873763840000 \\
\hline$m=4$ & 11430720 & 447718440960000 & 7163495055360000 \\
\hline$m=5$ & 22861440 & 716349505536000 & 309545509854589747200 \\
\hline \hline
\end{tabular}

Tablica B.5 Koeficijenti $a_{m, k}$ iz izraza (B.6)

\begin{tabular}{|c|c|c|c|c|c|c|c|}
\hline$n$ & $\mathrm{k}$ & $m=0$ & $m=1$ & $m=2$ & $m=3$ & $m=4$ & $m=5$ \\
\hline \multirow{3}{*}{1} & 0 & 5 & 4 & 1493 & 424 & 48781 & 43108 \\
\hline & 1 & 26 & 13 & 3764 & 907 & 92950 & 75379 \\
\hline & 2 & 5 & 1 & 143 & 19 & 1153 & 583 \\
\hline \multirow{5}{*}{3} & 0 & 143 & 124 & 28936 & 43108 & 298015603 & 54352184 \\
\hline & 1 & 6628 & 4559 & 928103 & 1259243 & 8126440838 & 1405557889 \\
\hline & 2 & 18858 & 9429 & 1630239 & 1996503 & 12003023868 & 1970767479 \\
\hline & 3 & 6628 & 2069 & 269249 & 272663 & 1432155338 & 212731639 \\
\hline & 4 & 143 & 19 & 1153 & 583 & 1616353 & 132809 \\
\hline \multirow{6}{*}{4} & 0 & 19 & 44509 & 19955 & 184416347 & 42134206 & 104753307620 \\
\hline & 1 & 2193 & 4273009 & 1706813 & 14532126965 & 3120904735 & 7390793719889 \\
\hline & 2 & 13988 & 21438454 & 7579118 & 59743708670 & 12158848750 & 27668969523344 \\
\hline & 3 & 13988 & 15573794 & 4646788 & 32931420730 & 6230146280 & 13443964170334 \\
\hline & 4 & 2193 & 1529669 & 335143 & 1912970935 & 309085220 & 592318103644 \\
\hline & 5 & 19 & 5765 & 583 & 1616353 & 132809 & 134926369 \\
\hline
\end{tabular}




\section{B.3. Skalarni produkti međusobno pomaknutih baznih funkcija $\operatorname{Fup}_{2}(x)$ na karakterističnom odsječku $\Delta \mathbf{x}_{2}$}

Skalarni produkti međusobno pomaknutih baznih funkcija $F u p_{n}(\xi)$ na karakterističnom odsječku $2^{-n}$ opisan je u točki 4.8 .

$\mathrm{Na}$ crtežima B.5, B.6 i B.7 u nastavku grafički su prikazani skalarni produkti s pripadajućim izrazima međusobno pomaknutih baznih funkcija $\operatorname{Fup}_{2}(\xi)$ kao i međusobno pomaknutih prvih derivacija baznih funkcija $F u p_{2}(\xi)$ na prvom, drugom i općem odsječku $\Delta \xi$ respektivno, kada je linearna kombinacija baznih funkcija definirana na intervalu duljine $I \geq(n+2) \Delta \xi_{2}$, tj. $I \geq 4 \Delta \xi_{2}$ (minimalno jedna bazna funkcija $F u p_{2}(\xi)$ se cijelim nosačem nalazi unutar područja). Zbog svojstva simetrije $\mathrm{ABF} F u p_{n}(\xi)$, skalarni produkti međusobno pomaknutih funkcija, kao i derivacija funkcija, na predzadnjem, tj. $(N-1)$-om odsječku odgovaraju skalarnim produktima na drugom odsječku zrcaljenim oko sporedne dijagonale. Također, skalarni produkti na zadnjem, tj. N-tom odsječku odgovaraju skalarnim produktima na prvom odsječku zrcaljenim oko sporedne dijagonale.

$\mathrm{Na}$ crtežu B.8 prikazani su skalarni produkti s pripadajućim izrazima međusobno pomaknutih baznih funkcija $\operatorname{Fup}_{2}(\xi)$ kao i međusobno pomaknutih prvih derivacija baznih funkcija $\operatorname{Fup}_{2}(\xi)$ na drugom odsječku kada je linearna kombinacija baznih funkcija definirana na intervalu duljine $I=3 \Delta \xi_{2}$. Skalarni produkti na prvom i trećem odsječku odgovaraju skalarnim produktima na prvom i zadnjem odsječku respektivno kada je $I \geq$ $4 \Delta \xi_{2}$.

Nadalje, na crtežu B.9 prikazani su skalarni produkti s pripadajućim izrazima međusobno pomaknutih baznih funkcija $\mathrm{Fup}_{2}(\xi)$ kao i međusobno pomaknutih prvih derivacija baznih funkcija $\mathrm{Fup}_{2}(\xi)$ na prvom odsječku kada je linearna kombinacija baznih funkcija definirana na intervalu duljine $I=2 \Delta \xi_{2}$. Skalarni produkti na drugom odsječku dobiju se zrcalnom simetrijom oko sporedne dijagonale skalarnih produkata prvog odsječka.

$\mathrm{Na}$ crtežu B.10 prikazani su skalarni produkti s pripadajućim izrazima međusobno pomaknutih baznih funkcija $\operatorname{Fup}_{2}(\xi)$ kao i međusobno pomaknutih prvih derivacija baznih funkcija $\operatorname{Fup}_{2}(\xi)$ kada je linearna kombinacija baznih funkcija definirana na intervalu duljine $I=\Delta \xi_{2}$. 
A) $[A, B] \geq 4 \Delta \xi_{2}$

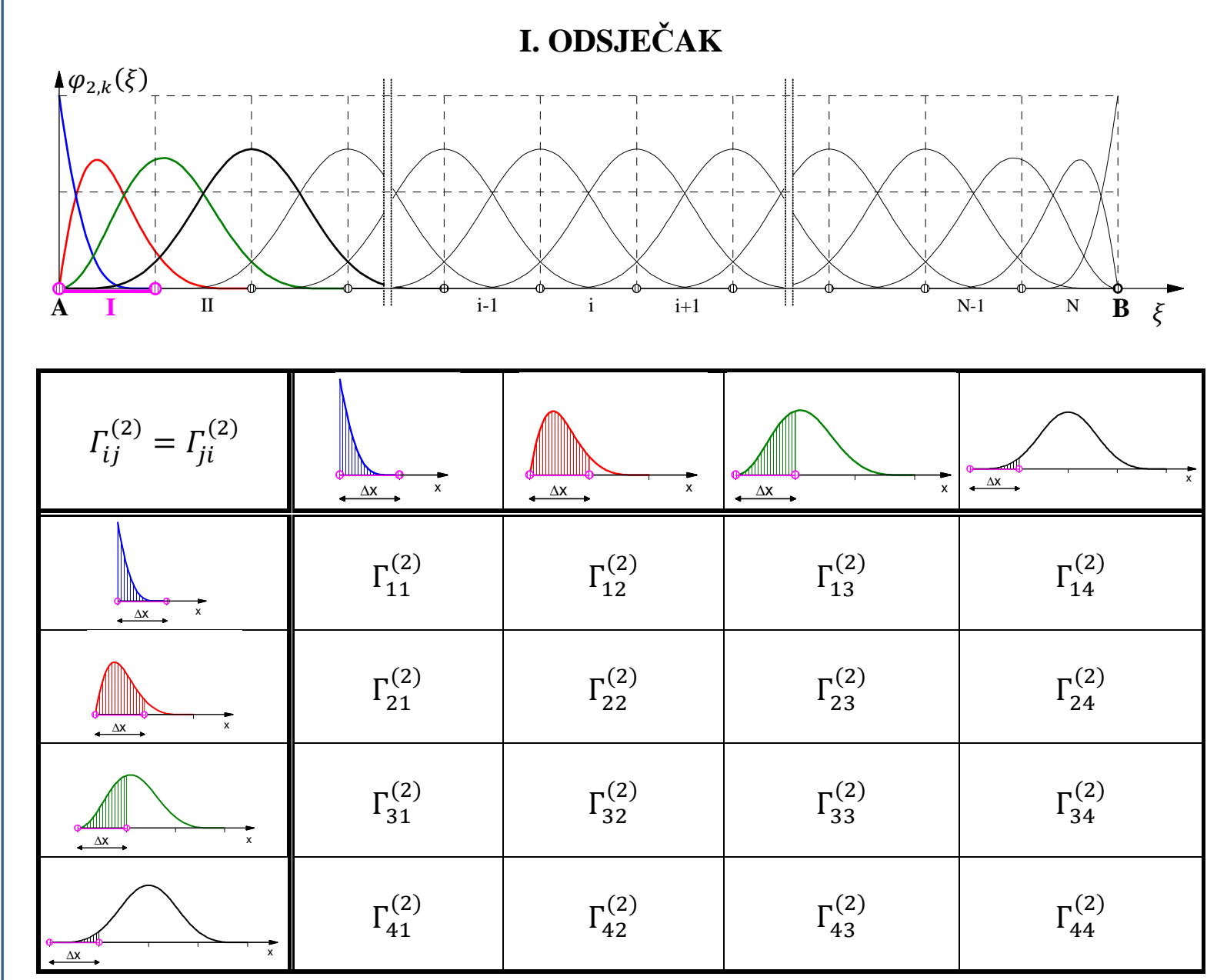

$$
b_{2}=34222500
$$

$\Gamma_{11}^{(2)}=(-11464373232+14192755200 \gamma) / b_{2} ; \quad \Gamma_{12}^{(2)}=(18113373252-22380883200 \gamma) / b_{2}$ $\Gamma_{13}^{(2)}=(-8216101530+10159344000 \gamma) / b_{2} ; \Gamma_{14}^{(2)}=(1594479510-1971216000 \gamma) / b_{2}$ $\Gamma_{22}^{(2)}=(-28515257172+35292931200 \gamma) / b_{2} ; \quad \Gamma_{23}^{(2)}=(12977121780-16020504000 \gamma) / b_{2}$ $\Gamma_{24}^{(2)}=(-2513110860+3108456000 \gamma) / b_{2} ; \quad \Gamma_{33}^{(2)}=(-5861020775+7272180000 \gamma) / b_{2}$ $\Gamma_{34}^{(2)}=(1143583025-1411020000 \gamma) / b_{2} ; \Gamma_{44}^{(2)}=(-221149175+273780000 \gamma) / b_{2}$

$$
b^{\prime}{ }_{2}=38025
$$

$\Gamma_{11}^{(2)}=(-45556992+63078912 \gamma) / b^{\prime}{ }_{2} ; \quad \Gamma_{12}^{(2)}=(76220352-99470592 \gamma) / b^{\prime}{ }_{2}$ $\Gamma_{13}^{(2)}=(-37720800+45152640 \gamma) / b^{\prime}{ }_{2} ; \quad \Gamma_{14}^{(2)}=(7057440-8760960 \gamma) / b^{\prime}{ }_{2}$ $\Gamma_{22}^{(2)}=(-122046912+156857472 \gamma) / b^{\prime}{ }_{2} ; \quad \Gamma_{23}^{(2)}=(57283200-71202240 \gamma) / b^{\prime}{ }_{2}$ $\Gamma_{24}^{(2)}=(-11456640+13815360 \gamma) / b^{\prime}{ }_{2} ; \quad \Gamma_{33}^{(2)}=(-24840400+32320800 \gamma) / b^{\prime}{ }_{2}$ $\Gamma_{34}^{(2)}=(5278000-6271200 \gamma) / b_{2}^{\prime} ; \Gamma_{44}^{(2)}=(-878800+1216800 \gamma) / b^{\prime}{ }_{2}$

Crtež B.5 Skalarni produkti međusobno pomaknutih baznih funkcija $\mathrm{Fup}_{2}(\xi)$ i međusobno pomaknutih baznih funkcija $\operatorname{Fup}_{2}{ }^{\prime}(\xi)$ na I. odsječku kada je $[A, B] \geq 4 \Delta \xi_{2}$ 
A) $[A, B] \geq 4 \Delta \xi_{2}$

\section{ODSJEČAK}

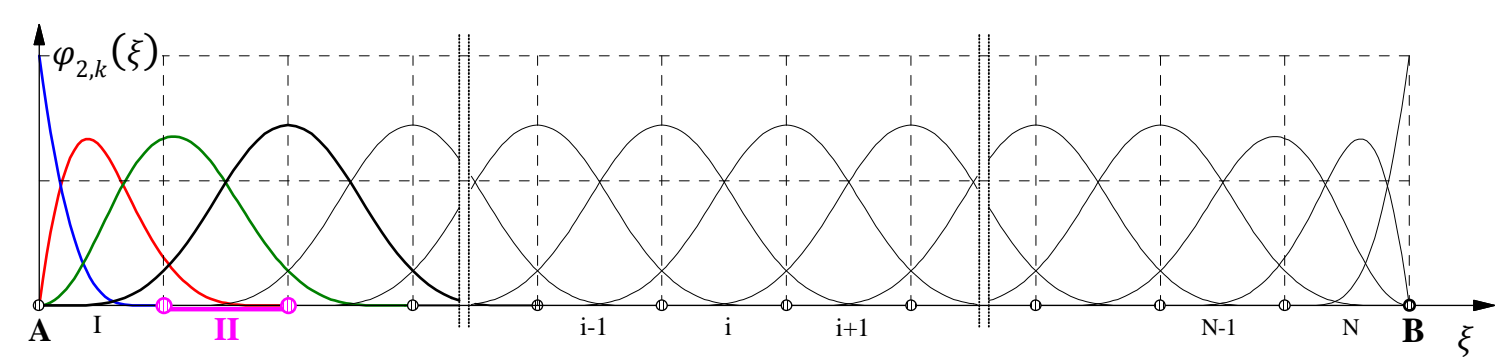

\begin{tabular}{|c||c|c|c|c|}
\hline$\Gamma_{i j}^{(2)}=\Gamma_{j i}^{(2)}$ & $\Gamma_{11}^{(2)}$ & $\Gamma_{12}^{(2)}$ & $\Gamma_{13}^{(2)}$ & $\Gamma_{14}^{(2)}$ \\
\hline & $\Gamma_{21}^{(2)}$ & $\Gamma_{22}^{(2)}$ & $\Gamma_{23}^{(2)}$ & $\Gamma_{24}^{(2)}$ \\
\hline & $\Gamma_{31}^{(2)}$ & $\Gamma_{32}^{(2)}$ & $\Gamma_{33}^{(2)}$ & $\Gamma_{34}^{(2)}$ \\
\hline & $\Gamma_{41}^{(2)}$ & $\Gamma_{42}^{(2)}$ & $\Gamma_{43}^{(2)}$ & $\Gamma_{44}^{(2)}$ \\
\hline
\end{tabular}

$$
b_{2}=2737800
$$

$\Gamma_{11}^{(2)}=(-33918264+41990400 \gamma) / b_{2} ; \quad \Gamma_{12}^{(2)}=(83299518-102643200 \gamma) / b_{2}$ $\Gamma_{13}^{(2)}=(-73490508+90979200 \gamma) / b_{2} \quad ; \quad \Gamma_{14}^{(2)}=(24530454-30326400 \gamma) / b_{2}$ $\Gamma_{22}^{(2)}=(-200262182+250905600 \gamma) / b_{2} \quad ; \quad \Gamma_{23}^{(2)}=(181907557-222393600 \gamma) / b_{2}$ $\Gamma_{24}^{(2)}=(-59890493+74131200 \gamma) / b_{2} \quad ; \quad \Gamma_{33}^{(2)}=(-156601822+197121600 \gamma) / b_{2}$ $\Gamma_{34}^{(2)}=(53356173-65707200 \gamma) / b_{2} ; \quad \Gamma_{44}^{(2)}=(-17691934+21902400 \gamma) / b_{2}$

$$
b_{2}^{\prime}=1521
$$

$$
\begin{array}{ll}
\Gamma_{11}^{(2)}=(-67392+93312 \gamma) / b^{\prime}{ }_{2} ; & \Gamma_{12}^{(2)}=(189072-228096 \gamma) / b^{\prime}{ }_{2} \\
\Gamma_{13}^{(2)}=(-175968+202176 \gamma) / b^{\prime}{ }_{2} ; & \Gamma_{14}^{(2)}=\left(\begin{array}{r}
54288-67392 \gamma) / b^{\prime}{ }_{2} \\
\Gamma_{22}^{(2)}=(-416208+557568 \gamma) / b^{\prime}{ }_{2} ;
\end{array} \Gamma_{23}^{(2)}=(369304-494208 \gamma) / b^{\prime}{ }_{2}\right. \\
\Gamma_{24}^{(2)}=(-142168+164736 \gamma) / b^{\prime}{ }_{2} & ; \Gamma_{33}^{(2)}=(-316368+438048 \gamma) / b^{\prime}{ }_{2} \\
\Gamma_{34}^{(2)}=(123032-146016 \gamma) / b^{\prime}{ }_{2} ; & \Gamma_{44}^{(2)}=(-35152+48672 \gamma) / b^{\prime}{ }_{2}
\end{array}
$$

Crtež B.6 Skalarni produkti međusobno pomaknutih baznih funkcija $F u p_{2}(\xi)$ i međusobno pomaknutih baznih funkcija $\operatorname{Fup}_{2}{ }^{\prime}(\xi)$ na II. odsječku kada je $[A, B] \geq 4 \Delta \xi_{2}$ 
A) $[A, B] \geq 4 \Delta \xi_{2}$

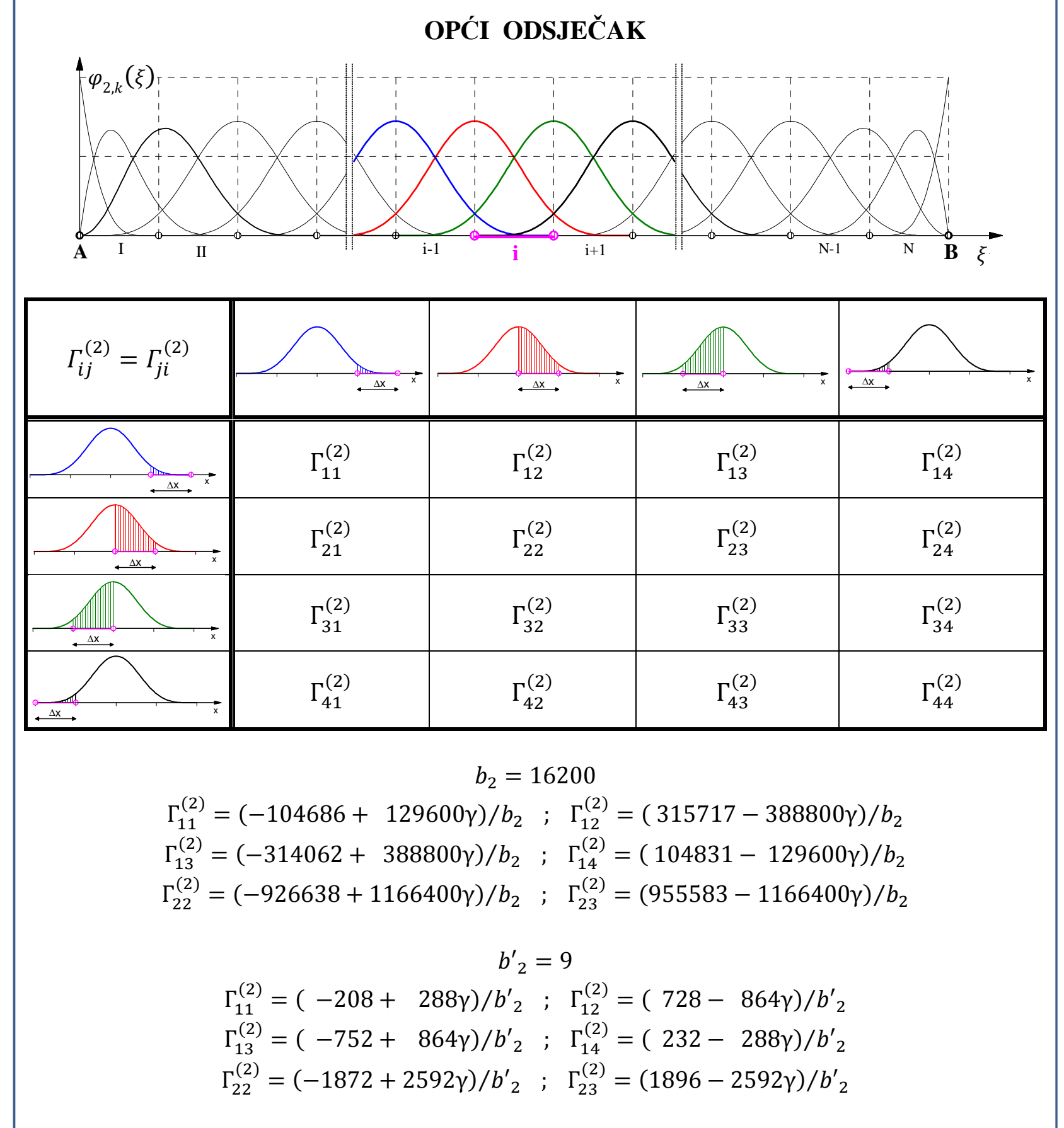

Crtež B.7 Skalarni produkti međusobno pomaknutih baznih funkcija Fup $_{2}(\xi)$ i međusobno pomaknutih baznih funkcija $\operatorname{Fup}_{2}{ }^{\prime}(\xi)$ na općem odsječku kada je $[A, B] \geq 4 \Delta \xi_{2}$ 
B) $[\mathrm{A}, \mathrm{B}]=3 \Delta \xi_{2}$

\section{ODSJEČAK}

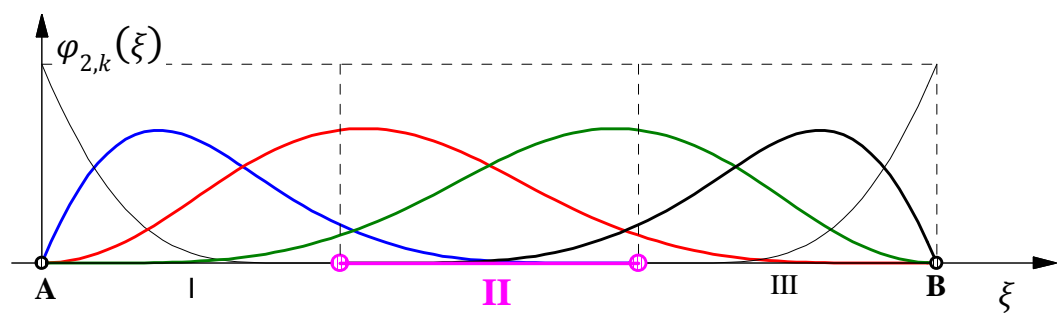

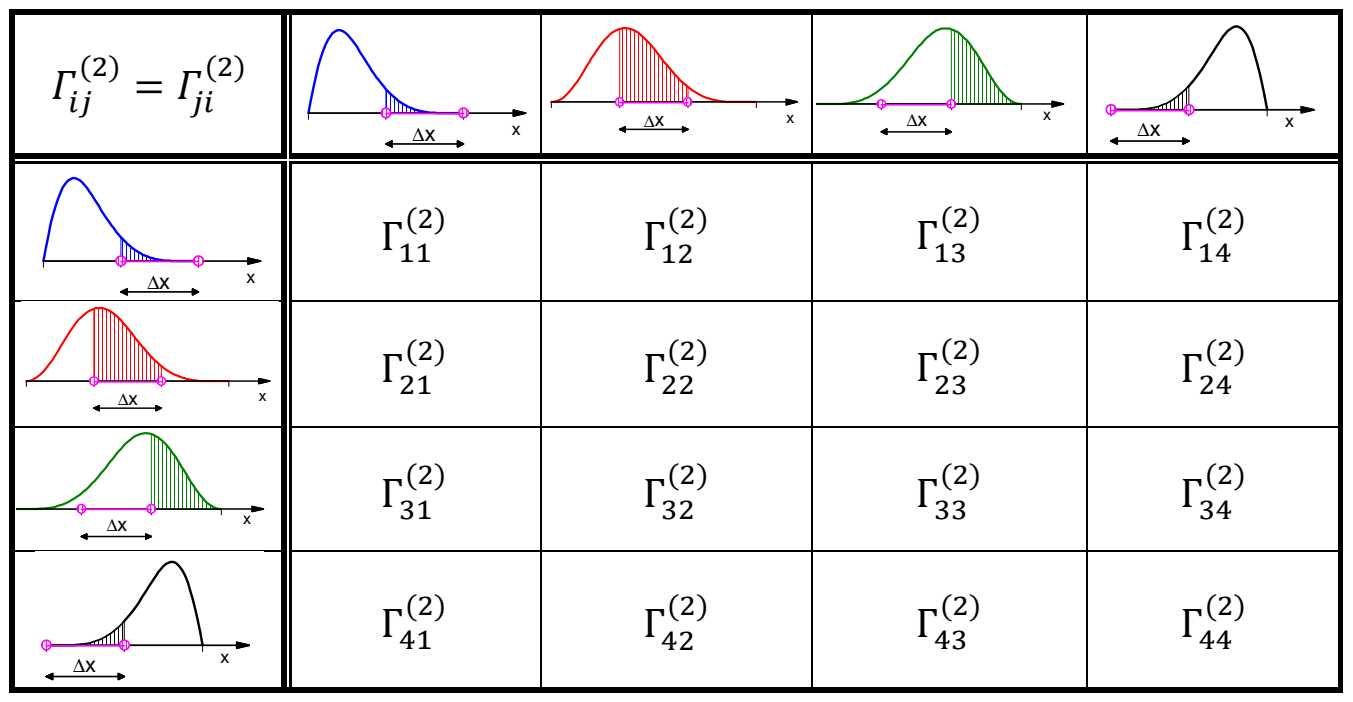

$b_{2}=1368900$

$\Gamma_{11}^{(2)}=(-16959132+20995200 \gamma) / b_{2} ; \quad \Gamma_{12}^{(2)}=(\quad 41649759-51321600 \gamma) / b_{2}$ $\Gamma_{13}^{(2)}=(-41462649+51321600 \gamma) / b_{2} ; \Gamma_{14}^{(2)}=(16982622-20995200 \gamma) / b_{2}$ $\Gamma_{22}^{(2)}=(-100131091+125452800 \gamma) / b_{2} ; \quad \Gamma_{23}^{(2)}=(102471181-125452800 \gamma) / b_{2}$ $\Gamma_{24}^{(2)}=(-41462649+51321600 \gamma) / b_{2} ; \Gamma_{33}^{(2)}=(-100131091+125452800 \gamma) / b_{2}$ $\Gamma_{34}^{(2)}=(41649759-51321600 \gamma) / b_{2} ; \Gamma_{44}^{(2)}=(-16959132+20995200 \gamma) / b_{2}$

$$
b_{2}^{\prime}=507
$$

$\Gamma_{11}^{(2)}=(-22464+31104 \gamma) / b^{\prime}{ }_{2} ; \Gamma_{12}^{(2)}=(\quad 63024-76032 \gamma) / b^{\prime}{ }_{2}$

$\Gamma_{13}^{(2)}=(-65616+76032 \gamma) / b^{\prime}{ }_{2} ; \Gamma_{14}^{(2)}=(25056-31104 \gamma) / b^{\prime}{ }_{2}$

$\Gamma_{22}^{(2)}=(-138736+185856 \gamma) / b^{\prime}{ }_{2} ; \quad \Gamma_{23}^{(2)}=(141328-185856 \gamma) / b^{\prime}{ }_{2}$

$\Gamma_{24}^{(2)}=(-65616+76032 \gamma) / b^{\prime}{ }_{2} ; \Gamma_{33}^{(2)}=(-138736+185856 \gamma) / b^{\prime}{ }_{2}$

$\Gamma_{34}^{(2)}=(63024-76032 \gamma) / b_{2}^{\prime} ; \Gamma_{44}^{(2)}=(-22464+31104 \gamma) / b_{2}^{\prime}$

Crtež B.8 Skalarni produkti međusobno pomaknutih baznih funkcija $F u p_{2}(\xi)$ i međusobno pomaknutih baznih funkcija $\operatorname{Fup}_{2}{ }^{\prime}(\xi)$ na II. odsječku kada je $[A, B]=3 \Delta \xi_{2}$ 
C) $[\mathrm{A}, \mathrm{B}]=2 \Delta \xi_{2}$

\section{ODSJEČAK}

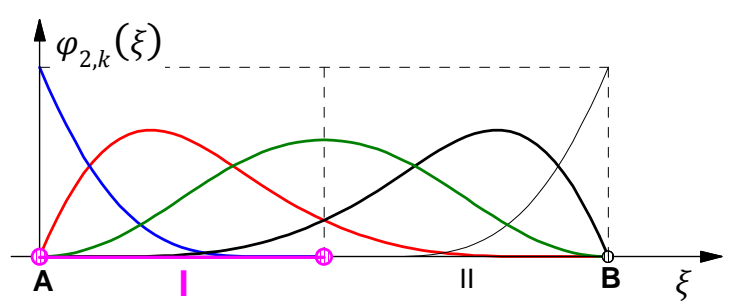

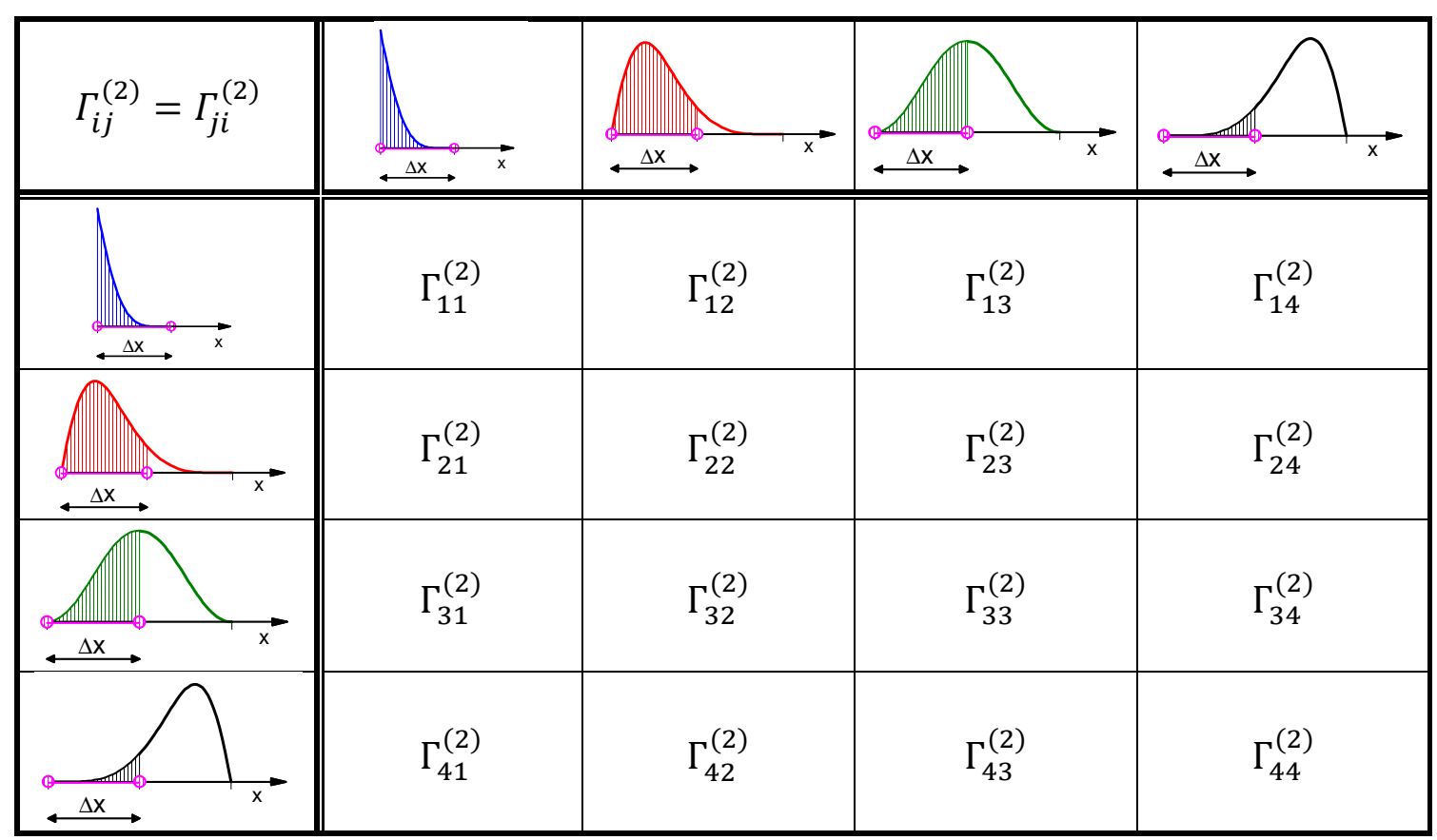

$$
b_{2}=105625
$$

$\Gamma_{11}^{(2)}=(-35383868+43804800 \gamma) / b_{2} ; \quad \Gamma_{12}^{(2)}=(55905473-69076800 \gamma) / b_{2}$

$\Gamma_{13}^{(2)}=(-27251120+33696000 \gamma) / b_{2} \quad ; \quad \Gamma_{14}^{(2)}=(\quad 6814015-8424000 \gamma) / b_{2}$

$\Gamma_{22}^{(2)}=(-88010053+108928800 \gamma) / b_{2} ; \quad \Gamma_{23}^{(2)}=(43036120-53136000 \gamma) / b_{2}$

$\Gamma_{24}^{(2)}=(-10739790+13284000 \gamma) / b_{2} ; \quad \Gamma_{33}^{(2)}=(-20905600+25920000 \gamma) / b_{2}$

$\Gamma_{34}^{(2)}=(\quad 5250600-6480000 \gamma) / b_{2} ; \Gamma_{44}^{(2)}=(-1308575+1620000 \gamma) / b_{2}$

$$
b^{\prime}{ }_{2}=4225
$$

$\Gamma_{11}^{(2)}=(-5061888+7008768 \gamma) / b^{\prime}{ }_{2} ; \quad \Gamma_{12}^{(2)}=(8468928-11052288 \gamma) / b^{\prime}{ }_{2}$

$\Gamma_{13}^{(2)}=(-4492800+5391360 \gamma) / b^{\prime}{ }_{2} ; \Gamma_{14}^{(2)}=(1085760-1347840 \gamma) / b^{\prime}{ }_{2}$

$\Gamma_{22}^{(2)}=(-13560768+17428608 \gamma) / b^{\prime}{ }_{2} ; \quad \Gamma_{23}^{(2)}=(6854400-8501760 \gamma) / b^{\prime}{ }_{2}$

$\Gamma_{24}^{(2)}=(-1762560+2125440 \gamma) / b^{\prime}{ }_{2} ; \quad \Gamma_{33}^{(2)}=(-3225600+4147200 \gamma) / b^{\prime}{ }_{2}$

$\Gamma_{34}^{(2)}=(\quad 864000-1036800 \gamma) / b^{\prime}{ }_{2} ; \Gamma_{44}^{(2)}=(-187200+259200 \gamma) / b^{\prime}{ }_{2}$

Crtež B.9 Skalarni produkti međusobno pomaknutih baznih funkcija $F u p_{2}(\xi)$ i međusobno pomaknutih baznih funkcija $\operatorname{Fup}_{2}{ }^{\prime}(\xi)$ na I. odsječku kada je $[A, B]=2 \Delta \xi_{2}$ 
D) $[\mathbf{A}, \mathbf{B}]=\Delta \xi_{2}$

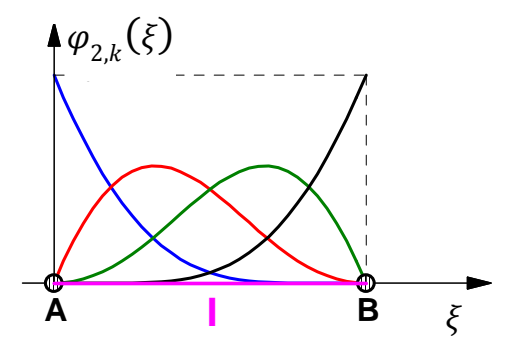

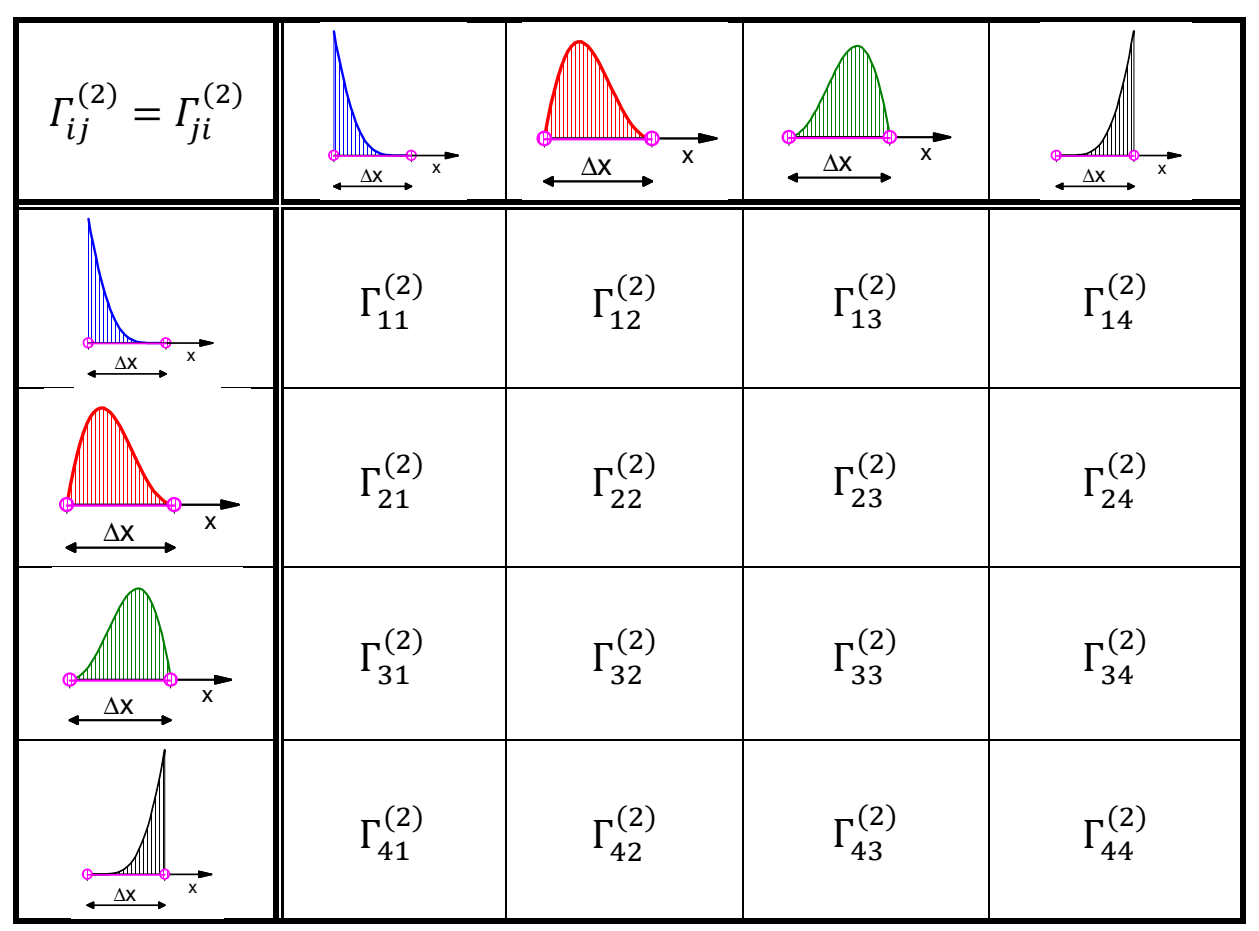

$$
\begin{aligned}
& b_{2}=625 \\
& \Gamma_{11}^{(2)}=(-209372+259200 \gamma) / b_{2} ; \quad \Gamma_{12}^{(2)}=(\quad 471902-583200 \gamma) / b_{2} \\
& \Gamma_{13}^{(2)}=(-471692+583200 \gamma) / b_{2} ; \Gamma_{14}^{(2)}=(\quad 209662-259200 \gamma) / b_{2} \\
& \Gamma_{22}^{(2)}=(-1061082+1312200 \gamma) / b_{2} ; \quad \Gamma_{23}^{(2)}=(1061622-1312200 \gamma) / b_{2} \\
& \Gamma_{24}^{(2)}=(-471692+583200 \gamma) / b_{2} ; \Gamma_{33}^{(2)}=(-1061082+1312200 \gamma) / b_{2} \\
& \Gamma_{34}^{(2)}=(471902-583200 \gamma) / b_{2} \quad ; \quad \Gamma_{44}^{(2)}=(-209372+259200 \gamma) / b_{2} \\
& b^{\prime}{ }_{2}=25 \\
& \Gamma_{11}^{(2)}=(-29952+41472 \gamma) / b^{\prime}{ }_{2} ; \Gamma_{12}^{(2)}=(\quad 73152-93312 \gamma) / b^{\prime}{ }_{2} \\
& \Gamma_{13}^{(2)}=(-76608+93312 \gamma) / b^{\prime}{ }_{2} ; \Gamma_{14}^{(2)}=(33408-41472 \gamma) / b^{\prime}{ }_{2} \\
& \Gamma_{22}^{(2)}=(-166752+209952 \gamma) / b^{\prime}{ }_{2} ; \Gamma_{23}^{(2)}=(170208-209952 \gamma) / b^{\prime}{ }_{2} \\
& \Gamma_{24}^{(2)}=(-76608+93312 \gamma) / b^{\prime}{ }_{2} ; \quad \Gamma_{33}^{(2)}=(-166752+209952 \gamma) / b^{\prime}{ }_{2} \\
& \Gamma_{34}^{(2)}=(73152-93312 \gamma) / b^{\prime}{ }_{2} ; \Gamma_{44}^{(2)}=(-29952+41472 \gamma) / b^{\prime}{ }_{2}
\end{aligned}
$$

Crtež B.10 Skalarni produkti međusobno pomaknutih baznih funkcija $F u p_{2}(\xi)$ i međusobno pomaknutih baznih funkcija $\operatorname{Fup}_{2}{ }^{\prime}(\xi)$ kada je $[A, B]=\Delta \xi_{2}$ 


\section{EKSPONENCIJALNE ATOMSKE BAZNE FUNKCIJE EUP}

\section{1 'Materinska' bazna funkcija $\operatorname{Eup}(\xi, \omega)$}

Za određivanje numeričkih rješenja fizikalnih problema čija su rješenja iz klase eksponencijalnih funkcija, bazne funkcije algebarskog tipa se pokazuju neprikladne. Logično je za očekivati da bazne funkcije s kojima se može točno prikazati eksponencijalna funkcija zadane frekvencije dobro opisuju rješenja koja su iz klase eksponencijalnih funkcija.

Materinska bazna funkcija $\operatorname{Eup}(\xi, \omega)$, također iz klase atomskih baznih funkcija, je beskonačno derivabilno rješenje funkcionalno diferencijalne jednadžbe čijom se linearnom kombinacijom točno razvijaju eksponencijalni polinomi. Za razliku od algebarske materinske bazne funkcije $u p(\xi)$, eksponencijalna materinska bazna funkcija $\operatorname{Eup}(\xi, \omega)$ posjeduje parametar sažimanja $\omega$, ili analogno trigonometrijskim funkcijama, frekvenciju koja omogućava bolja aproksimacijska svojstva.

\subsection{Generiranje Fourierove transformacije funkcije $\operatorname{Eup}(\xi, \omega)$}

U prethodnim poglavljima pokazana je konstrukcija Fourierovih transformacija atomskih baznih funkcija algebarskog tipa, i to FT materinske funkcije $u p(\xi)$ te FT familije baznih funkcija $\operatorname{Fup}_{n}(\xi)$. Naime, mogućnost efektne konstrukcije Fourierovih transformacija, kao i efektan prikaz različitih svojstava baznih funkcija pomoću Fourierovih transformacija, zajedničko je svim atomskim baznim funkcijama. 
FT funkcije $\operatorname{Eup}(\xi, \omega)$ konstruira se sličnim postupkom primijenjenim za funkciju up $(\xi)$ (točka 3.1), uz korištenje istog normirnog uvjeta

$$
\int_{-1}^{1} \operatorname{Eup}(\xi, \omega) d \xi=1
$$

i karakteristika kompaktnog nosača

$$
\operatorname{supp} \operatorname{Eup}(\xi, \omega)=[-1,1]
$$

Na crtežu 5.1 vidljiva je grafička interpretacija postupka generiranja funkcije $\operatorname{Eup}(\xi, \omega)$ pomoću teorema konvolucije.
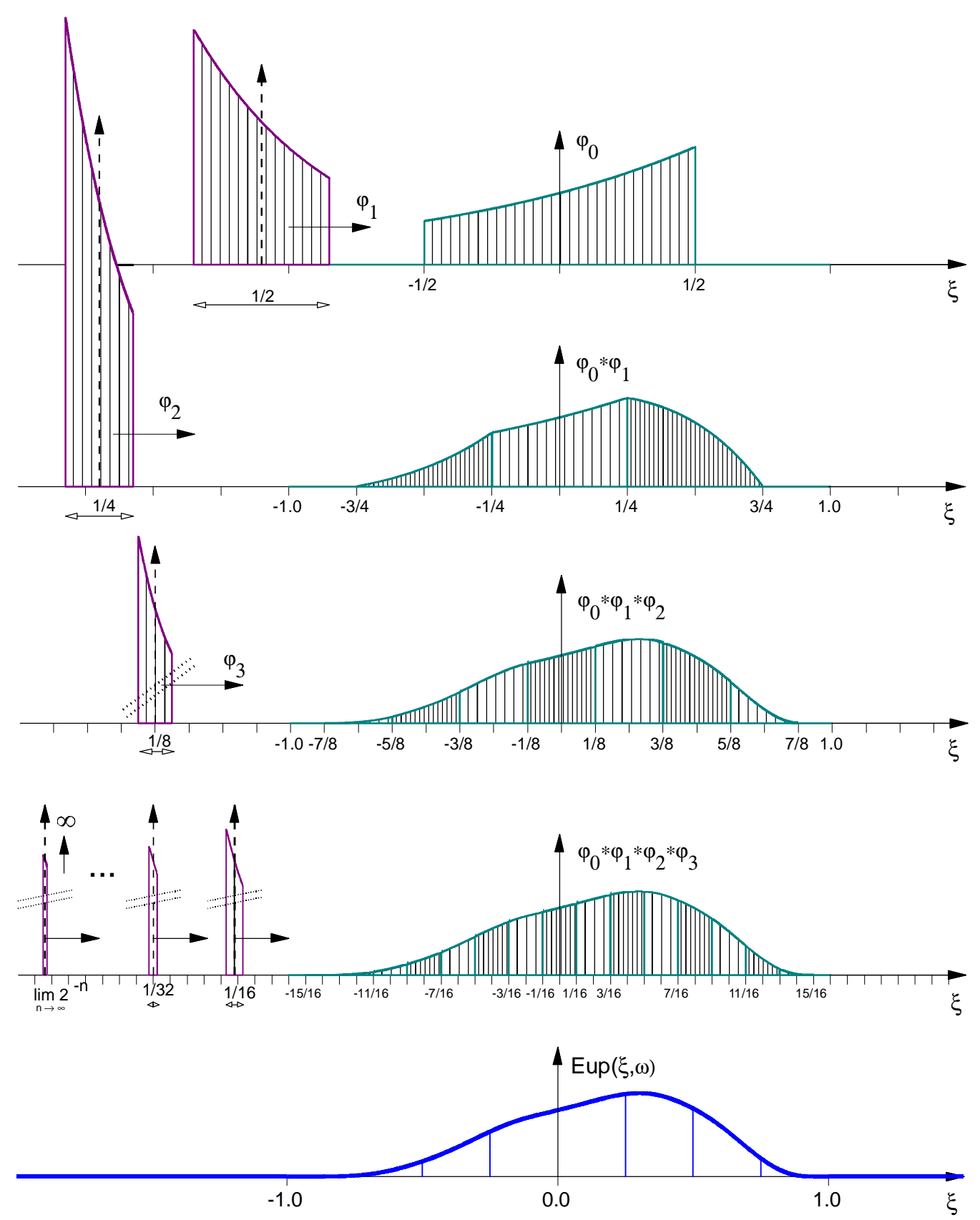

Crtež 5.1 Generiranje eksponencijalne bazne funkcije $\operatorname{Eup}(\xi, \omega)$ 
Analogno funkciji $u p(\xi)$, funkcija $\operatorname{Eup}(\xi, \omega)$ u limesu, kao što se vidi na crtežu 5.1, predstavlja rezultat konvolucije neizmjernog broja eksponencijalnih splineova nultog stupnja $\varphi_{j}(\xi, \omega), j=0,1,2, \ldots$ čija se duljina nosača smanjuje po zakonu $h=2^{-j}$ :

$$
\operatorname{Eup}(\xi, \omega)=\underbrace{\varphi_{0}(\xi, \omega)}_{\text {supp }=[-1 / 2,1 / 2]} * \underbrace{\varphi_{1}(\xi, \omega)}_{\operatorname{supp}=[-1 / 4,1 / 4]} * \ldots * \underset{\lim _{j \rightarrow \infty}\left[-2^{-j-1}, 2^{-j-1}\right]=0}{\varphi_{j}(\xi, \omega)}
$$

gdje je

$$
\varphi_{j}(\xi, \omega)=\left\{\begin{array}{cl}
\frac{\omega \cdot e^{\omega / 2^{j+1}}}{e^{\omega / 2^{j}}-1} e^{\omega \xi} & \text { za } \xi \in\left[-2^{-(\mathrm{j}+1)}, 2^{-(\mathrm{j}+1)}\right] \\
0 & \text { inače }
\end{array}\right.
$$

FT funkcije $\operatorname{Eup}(\xi, \omega)$ prema (5.3) odgovara produktu beskonačnog broja Fourierovih transformacija sažetih eksponencijalnih splineova nultog stupnja (5.4):

$$
F(t)=\prod_{j=1}^{\infty} \frac{\omega}{2 \operatorname{sh}(\omega / 2)} \frac{\operatorname{sh}\left(\omega / 2+i \cdot t / 2^{j}\right)}{\omega / 2+i \cdot t / 2^{j}}
$$

Kada parametar $\omega$ teži nuli izraz (5.5) prelazi u izraz (3.8). Dakle, eksponencijalna ABF $\operatorname{Eup}(\xi, \omega)$ prelazi u algebarsku $\mathrm{ABF} u p(\xi)$ kada parametar $\omega$ postane nula.

Inverzna Fourierova transformacija, odnosno funkcija $\operatorname{Eup}(\xi, \omega)$, uz zadovoljenje PaleyWienerovog normirnog uvjeta (5.2) može se izraziti u obliku:

$$
\operatorname{Eup}(\xi, \omega)=\frac{1}{2 \pi} \int_{-\infty}^{\infty} F(t) \cdot e^{-i t \xi} d t
$$

Razvojem desne strane izraza (5.6) u Fourierov red može se odrediti "original" funkcije $\operatorname{Eup}(\xi, \omega)$ u diskretnim točkama. Međutim takav oblik rješenja nije prikladan za sofisticiranu praktičnu primjenu. Stoga će se, kao i u prethodnom poglavlju za funkciju $u p(\xi)$, tražiti točno rješenje u binarno racionalnim točkama tipa $\xi_{b r}=-1+k / 2^{m}, k=1,2, \ldots 2^{m+1}, m \in N$, izraženo preko vrijednosti funkcije u ishodištu $\operatorname{Eup}(0, \omega)=\lambda_{0}$, koju se, za razliku od funkcije $u p(\xi)$, mora prethodno neovisno numerički izračunati.

Parametar $\omega$ ima ulogu frekvencije slično kao kod trigonometrijskih funkcija. Na crtežu 5.2 prikazana je funkcija $\operatorname{Eup}(\xi, \omega)$ za različite vrijednosti parametra $\omega$. Vidi se da je funkcija $\operatorname{Eup}(\xi, \omega)$ nagnuta u lijevo za negativne vrijednosti parametra $\omega<0$, dok je za pozitivne nagnuta u desno. U graničnom slučaju kada $\omega \rightarrow 0$ funkcija $\operatorname{Eup}(\xi, \omega)$ teži funkciji $u p(\xi)$. Dakle, vektorski prostor EUP iz kojega je funkcija $\operatorname{Eup}(\xi, \omega)$ je "gušći" od prostora $U P$, pa je vektorski prostor $U P \subset E U P$. 


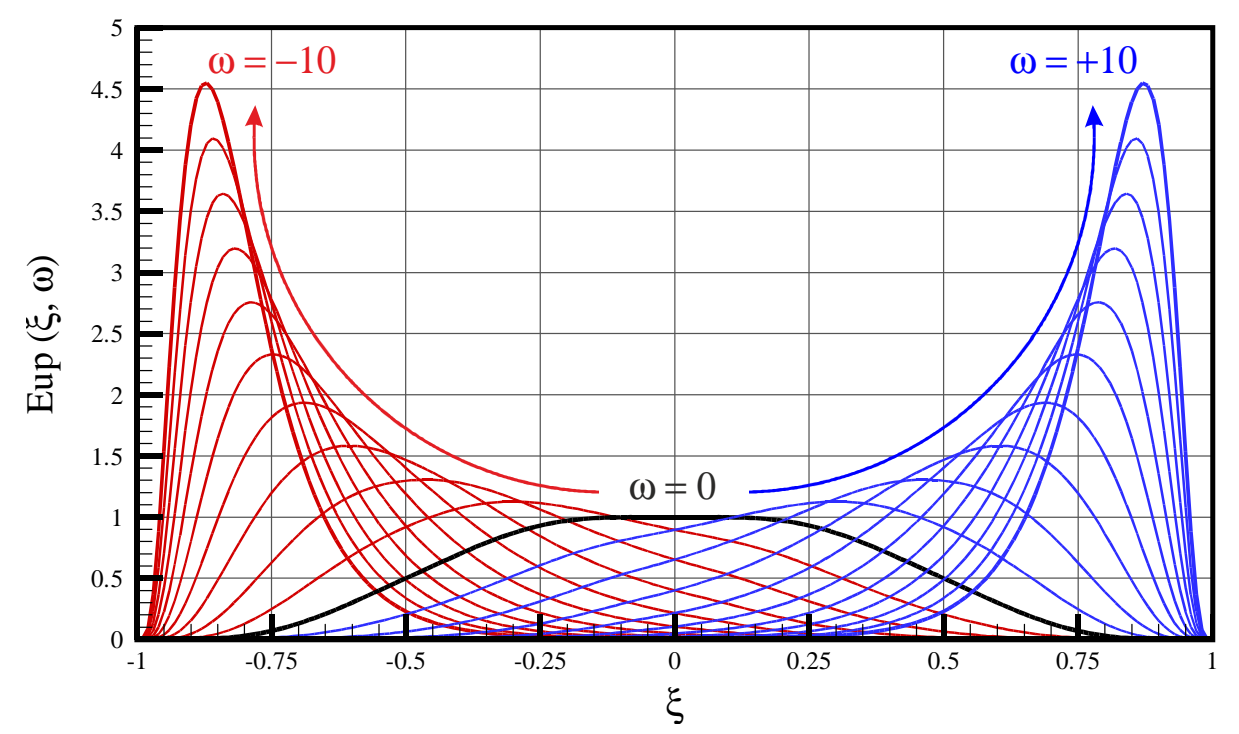

Crtež 5.2 Funkcija $\operatorname{Eup}(\xi, \omega)$ za različite vrijednosti parametra $\omega$

\subsection{Funkcionalno diferencijalna jednadžba za funkciju $\operatorname{Eup}(\xi, \omega)$}

Funkcionalno diferencijalna jednadžba za funkciju $\operatorname{Eup}(\xi, \omega)$ konstruira se iz njene poznate Fourierove transformacije (5.5), a koja se može izraziti u sljedećem obliku:

$$
F(t)=\frac{\omega}{2 \cdot \operatorname{sh}(\omega / 2)} \cdot \frac{\operatorname{sh}(\omega / 2+i t / 2)}{\omega / 2+i t / 2} \cdot F(t / 2)
$$

Množenjem izraza (5.7) sa $(\omega+i t)$, te uvođenjem zamjene:

$$
\operatorname{sh}(\omega / 2+i t / 2)=\frac{e^{\omega / 2+i t / 2}-e^{-(\omega / 2+i t / 2)}}{2}
$$

dobije se

$$
\omega \cdot F(t)+i t \cdot F(t)=\frac{\omega}{2 \cdot \operatorname{sh}(\omega / 2)} \cdot\left(e^{\omega / 2+i t / 2}-e^{-(\omega / 2+i t / 2)}\right) \cdot F(t / 2)
$$

Inverzna Fourierova transformacija izraza (5.8) je

$$
\begin{aligned}
\omega \cdot \frac{1}{2 \pi} \int_{-\infty}^{\infty} F(t) & \cdot e^{-i t \xi} d t+\frac{1}{2 \pi} \int_{-\infty}^{\infty} i t \cdot F(t) \cdot e^{-i t \xi} d t \\
& =\frac{\omega}{2 \cdot \operatorname{sh}(\omega / 2)}\left\{\frac{1}{2 \pi} \int_{-\infty}^{\infty}\left(e^{\omega / 2+i t / 2}-e^{-\omega / 2-i t / 2}\right) \cdot F(t / 2) \cdot e^{-i t \xi} d t\right\}
\end{aligned}
$$

Zbog kratkoće zapisa, bazne funkcije $\operatorname{Eup}(\xi, \omega)$ će se u daljnjem tekstu označavati i sa $y_{\omega}(\xi)$. 
U izrazu (5.9) prvi član lijeve strane predstavlja samu funkciju $\operatorname{Eup}(\xi, \omega)$ pomnoženu s parametrom $\omega$, dok drugi član lijeve strane predstavlja prvu derivaciju funkcije $\operatorname{Eup}(\xi, \omega)$. Integrali desne strane izraza (5.9) mogu se izraziti u obliku

$$
\frac{1}{2 \pi} \int_{-\infty}^{\infty} e^{ \pm \frac{\omega}{2}} \cdot e^{ \pm \frac{i t}{2} \cdot(-i t \xi)} \cdot F(t / 2) d t
$$

Sređivanjem integrala (5.10) na način

$$
\begin{aligned}
& \frac{1}{2 \pi} \int_{-\infty}^{\infty} e^{i t(1 / 2 \pm \xi)} \cdot F(t / 2) d t=\left\{\begin{array}{l}
u=t / 2 \rightarrow u=2 t \\
d u=d t / 2 \rightarrow d u=2 d t
\end{array}\right\} \\
& =2 \cdot \frac{1}{2 \pi} \int_{-\infty}^{\infty} e^{-i u(2 \xi \pm 1)} \cdot F(u) d u=2 \cdot y_{\omega}(2 \xi \mp 1)
\end{aligned}
$$

i uvrštavanjem u (5.9) dobije se funkcionalno diferencijalna jednadžba funkcije $\operatorname{Eup}(\xi, \omega)$ :

$$
\omega \cdot y_{\omega}(\xi)-y_{\omega}{ }^{\prime}(\xi)=\frac{\omega}{2 \cdot \operatorname{sh}(\omega / 2)}\left\{e^{\omega / 2} \cdot y_{\omega}(2 \xi-1)-e^{-\omega / 2} \cdot y_{\omega}(2 \xi+1)\right\}
$$

ili u konačnom obliku

$$
y_{\omega}{ }^{\prime}(\xi)-\omega \cdot y_{\omega}(\xi)=a \cdot y_{\omega}(2 \xi+1)-b \cdot y_{\omega}(2 \xi-1)
$$

gdje su koeficijenti $a$ i $b$ određeni izrazima

$$
a=\frac{\omega \cdot e^{-\omega / 2}}{\operatorname{sh}(\omega / 2)}=\frac{2 \cdot \omega}{e^{\omega}-1}, \quad b=a \cdot e^{\omega}
$$

Posebno, za vrijednost parametra $\omega=0$, dobiva se $a=2, b=2$ tako da je u tom slučaju jednadžba (5.11) ekvivalentna jednadžbi (3.15).

Iz jednadžbe (5.11) potvrđuje se još jedno zajedničko svojstvo svih atomskih baznih funkcija, a to je mogućnost prikazivanja derivacija kao linearne kombinacije sažetih i pomaknutih samih funkcija. Zato se jednadžba (5.11) naziva funkcionalno diferencijalna jednadžba.

\subsection{Derivacije funkcije $\operatorname{Eup}(\xi, \omega)$}

Derivacije funkcije $\operatorname{Eup}(\xi, \omega)$ određuju se na isti način kao i kod bazne funkcije $u p(\xi)$. Prva derivacija funkcije $\operatorname{Eup}(\xi, \omega)$ slijedi iz funkcionalno diferencijalne jednadžbe (5.11). Deriviranjem izraza za prvu derivaciju, odnosno osnovne jednadžbe (5.11), te zamjenom iste u dobivenu jednadžbu, slijedi izraz za drugu derivaciju funkcije $\operatorname{Eup}(\xi, \omega)$ : 


$$
\begin{aligned}
& y_{\omega}{ }^{(2)}(\xi)-3 \cdot \omega \cdot y_{\omega}{ }^{(1)}(\xi)+2 \cdot \omega^{2} \cdot y_{\omega}(\xi)= \\
= & 2\left[a^{2} \cdot y_{\omega}(4 \xi+3)-a \cdot b \cdot y_{\omega}(4 \xi+1)-a \cdot b \cdot y_{\omega}(4 \xi-1)+b^{2} \cdot y_{\omega}(4 \xi-3)\right]
\end{aligned}
$$

Deriviranjem jednadžbe (5.13) te zamjenom prve (5.11) i druge (5.13) derivacije u novu jednadžbu slijedi izraz za treću derivaciju, i tako redom.

S obzirom da na lijevoj strani jednadžbi (5.11) i (5.13) postoje i dodatni članovi koji sadrže samu funkciju $\operatorname{Eup}(\xi, \omega)$ i njenu derivaciju, nije moguće kao u slučaju bazne funkcije $u p(\xi)$ u izrazu (3.18), derivacije izraziti direktno preko sažetih funkcija na desnoj strani jednadžbe.

Međutim, to se ipak postiže primjenom diferencijalnog operatora, [43],

$$
L_{n}=\prod_{j=1}^{n}\left(d / d \xi-2^{j-1} \omega\right)
$$

koji u sebi sadrži cijelu lijevu stranu jednadžbe (5.11) odnosno (5.13), tako da se desna strana dobiva samo od sažetih i pomaknutih funkcija desne strane polazne jednadžbe.

Diferencijalni operator (5.14) je takav da djelujući na eksponencijalni polinom $E_{n}(\xi)=$ $\sum_{i=0}^{n} a_{i} \cdot e^{2^{i} \omega x}$ stupnja $n$ vrijedi

$$
L_{n}\left[E_{n}(\xi)\right] \equiv 0
$$

Tako će, na primjer, operator trećeg reda „poništiti“ eksponencijalni polinom trećeg stupnja, tj.

$$
\frac{d^{3}\left(E_{3}(\xi)\right)}{d x^{3}}-7 \cdot \omega \cdot \frac{d^{2}\left(E_{3}(\xi)\right)}{d x^{2}}+14 \cdot \omega^{2} \cdot \frac{d\left(E_{3}(\xi)\right)}{d x}-8 \cdot \omega^{3} \cdot\left(E_{3}(\xi)\right) \equiv 0
$$

gdje je $E_{3}(\xi)=a_{0} e^{2^{0} \omega x}+a_{1} e^{2^{1} \omega x}+a_{2} e^{2^{2} \omega x}+a_{3} e^{2^{3} \omega x}$. Upravo zbog ovog svojstva baznih funkcija $\operatorname{Eup}(\xi, \omega)$, a to je da diferencijalni operator poništava lijevu stranu jednadžbi (5.11) i (5.13), njihovom linearnom kombinacijom točno se opisuju eksponencijalni polinomi odgovarajućeg stupnja o čemu će se detaljnije govoriti u sljedećim točkama.

Sada je pomoću diferencijalnog operatora (5.14) moguće napisati opći oblik za bilo koju derivaciju funkcije $\operatorname{Eup}(\xi, \omega)$ tako da bude analogan izrazu (3.18) kod baznih funkcija $\operatorname{up}(\xi)$ :

$$
L_{n} y_{\omega}(\xi)=2^{n(n+1) / 2} \cdot \sum_{j=1}^{2^{n+1}} D_{j}^{(n)} \cdot y_{\omega}\left(2^{n+1} \xi-2 j+2^{n+1}+1\right)
$$

Koeficijenti $D_{j}^{(n)}$ računaju se pomoću sljedeće rekurzivne formule [6] ,[43] za $n>0$ : 


$$
\begin{gathered}
D_{j}^{(n)}=D_{k}^{(0)} \cdot D_{l}^{(n-1)} \\
j=1, \ldots, 2^{n+1} ; \quad k=1,2 ; \quad l=1, \ldots, 2^{n}
\end{gathered}
$$

gdje su $D_{k}^{(0)}$ određeni koeficijentima iz jednadžbe (5.12) tj.,

$$
D_{1}^{(0)}=a \quad ; \quad D_{2}^{(0)}=-b
$$

Na primjer, prve četiri derivacije prema izrazu (5.17) izražene su u slijedećem obliku:

$$
\begin{aligned}
& y_{\omega}{ }^{(1)}(\xi)-\omega \cdot y_{\omega}(\xi)=\sum_{j=1}^{2} D_{j}^{(1)} y_{\omega}(2 \xi-2 j+3) \\
& y_{\omega}{ }^{(2)}(\xi)+2 \omega^{2} y_{\omega}(\xi)-3 \omega y_{\omega}^{(1)}(\xi)=2 \sum_{j=1}^{4} D_{j}^{(2)} y_{\omega}(4 \xi-2 j+5) \\
& y_{\omega}^{(3)}(\xi)-8 \omega^{3} y_{\omega}(\xi)+14 \omega^{2} y_{\omega}^{(1)}(\xi)-7 \omega y_{\omega}^{(2)}(\xi)=8 \sum_{j=1}^{8} D_{j}^{(3)} y_{\omega}(8 \xi-2 j+9) \\
& y_{\omega}{ }^{(4)}(\xi)+64 \omega^{4} y_{\omega}(\xi)-120 \omega^{3} y_{\omega}{ }^{(1)}(\xi)+70 \omega^{2} y_{\omega}{ }^{(2)}(\xi)-15 \omega y_{\omega}^{(3)}(\xi)=64 \sum_{j=1}^{16} D_{j}^{(4)} y_{\omega}(16 \xi-2 j+17)
\end{aligned}
$$

ili nakon sređivanja

$$
\begin{aligned}
y_{\omega}{ }^{(1)}(\xi) & =\omega y_{\omega}(\xi)+ \\
y_{\omega}{ }^{(2)}(\xi)=\omega^{2} y_{\omega}(\xi) & +3 \omega \sum_{j=1}^{2} D_{j}^{(1)} y_{\omega}(2 \xi-2 j+3) \\
y_{\omega}{ }^{(3)}(\xi)=\omega^{3} y_{\omega}(\xi) & +7 \omega^{2} \sum_{j=1}^{2} D_{j}^{(1)} y_{\omega}(2 \xi-2 j+3)+14 \omega \sum_{j=1}^{4} D_{j}^{(2)} y_{\omega}(4 \xi-2 j+5)+ \\
& +8 \sum_{j=1}^{8} D_{j}^{(3)} y_{\omega}(8 \xi-2 j+9) \\
y_{\omega}^{(4)}(\xi)=\omega^{4} y_{\omega}(\xi) & +15 \omega^{3} \sum_{j=1}^{2} D_{j}^{(1)} y_{\omega}(2 \xi-2 j+3)-70 \omega^{2} \sum_{j=1}^{4(2)} y_{\omega}(4 \xi-2 j+5) \\
& +120 \omega \sum_{j=1}^{8} D_{j}^{(3)} y_{\omega}(8 \xi-2 j+9)+64 \sum_{j=1}^{16} D_{j}^{(4)} y_{\omega}(16 \xi-2 j+17)
\end{aligned}
$$

Iz izraza (5.20) vidljivo je da prva derivacija funkcije $\operatorname{Eup}(\xi, \omega)$ predstavlja linearnu kombinaciju dviju komponenata. Prva komponenta je nulta derivacija funkcije $\operatorname{Eup}(\xi, \omega)$, odnosno sama funkcija pomnožena s koeficijentom koji je u ovom slučaju upravo parametar $\omega$. Druga komponenta je kombinacija sažetih (na polovicu duljine nosača) i pomaknutih funkcija $\operatorname{Eup}(\xi, \omega)$ što odgovara prvoj derivaciji kod bazne funkcije $u p(\xi)$. 
Druga derivacija funkcije $\operatorname{Eup}(\xi, \omega)$ je linearna kombinacija triju komponenata: prve dvije komponente formalno odgovaraju komponentama iz prve derivacije, dok je treća komponenta kombinacija sažetih (na četvrtinu duljine nosača) i pomaknutih funkcija $\operatorname{Eup}(\xi, \omega)$ slično drugoj derivaciji bazne funkcije $u p(\xi)$.

Nastavljanjem postupka deriviranja slijedi da se derivacija funkcije $\operatorname{Eup}(\xi, \omega)$ reda $n$ dobije linearnom kombinacijom svih derivacija funkcije do reda $(n-1)$ i posljednje komponente koja predstavlja sažete i pomaknute same funkcije $\operatorname{Eup}(\xi, \omega)$, a što formalno odgovara $n$-toj derivaciji bazne funkcije $u p(\xi)$.

Na crtežu 5.3 prikazane su komponente s pripadajućim koeficijentima za izračun do uključivo četvrte derivacije funkcije $\operatorname{Eup}(\xi, \omega)$. Tako je, na primjer, treća derivacija u točki $\xi=-1 / 2$ :

$$
y_{\omega}^{(3)}\left(-\frac{1}{2}\right)=\omega^{3} \cdot y_{\omega}\left(-\frac{1}{2}\right)+7 \cdot \omega^{2} \cdot a \cdot y_{\omega}(0)+14 \cdot \omega \cdot a^{2} \cdot 0
$$

ili četvrta derivacija u točki $\xi=13 / 16$ :

$$
\begin{aligned}
y_{\omega}(4)\left(\frac{13}{16}\right)= & \omega^{4} \cdot y_{\omega}\left(\frac{13}{16}\right)-15 \cdot \omega^{3} \cdot a \cdot e^{\omega} \cdot y_{\omega}\left(\frac{5}{8}\right)+70 \cdot \omega^{2} \cdot a^{2} \cdot e^{2 \omega} \cdot y_{\omega}\left(\frac{1}{4}\right) \\
& -120 \cdot \omega \cdot a^{3} \cdot e^{3 \omega} \cdot y_{\omega}\left(-\frac{1}{2}\right)-64 \cdot a^{4} \cdot e^{3 \omega} \cdot y_{\omega}(0)
\end{aligned}
$$

Na crtežu 5.4 prikazana je funkcija $\operatorname{Eup}(\xi, \omega)$ i njene prve četiri derivacije u konačnom (zbrojenom) obliku. 


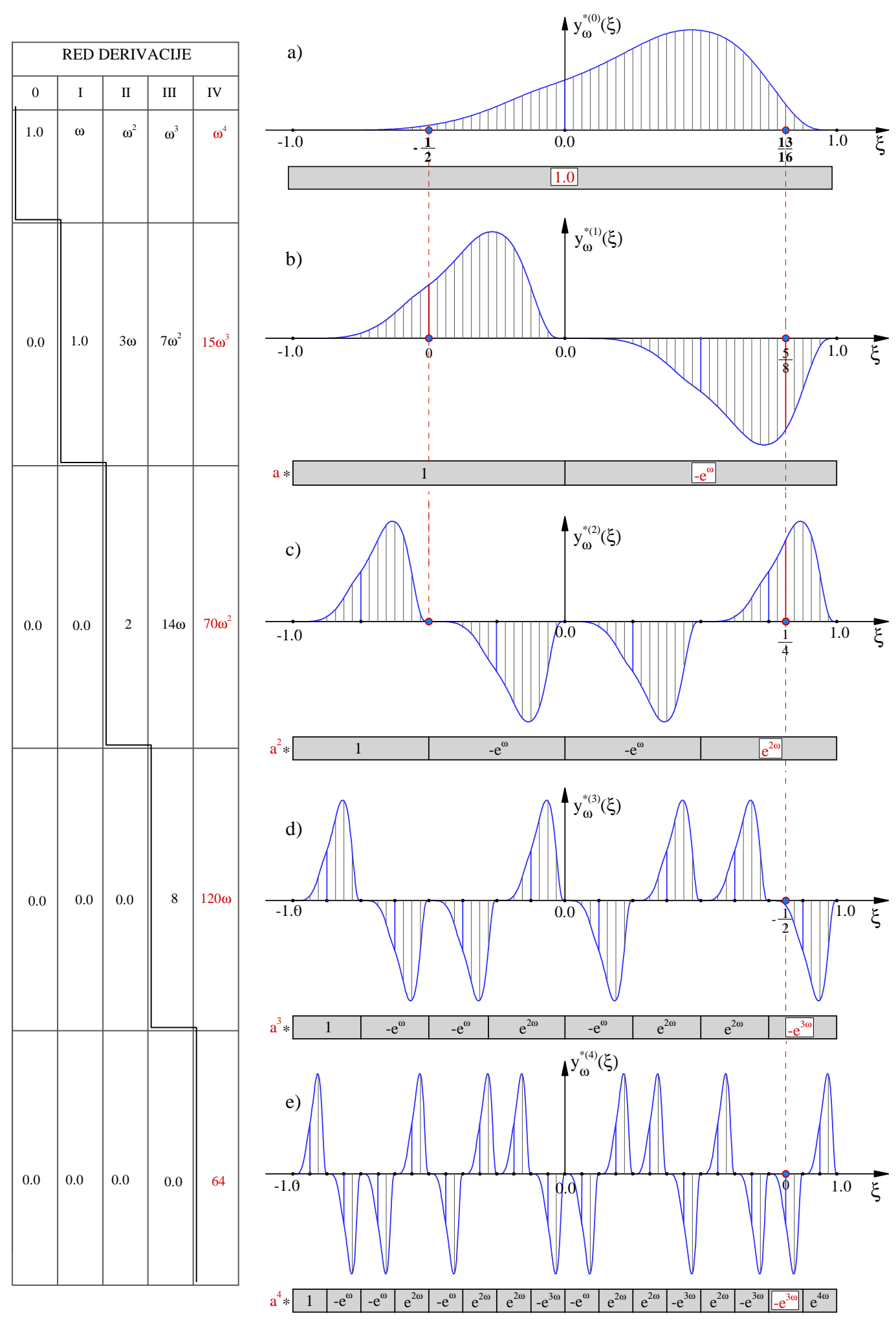

Crtež 5.3 Komponente za izračun do uključivo četvrte derivacije funkcije $\operatorname{Eup}(\xi, \omega)$ 

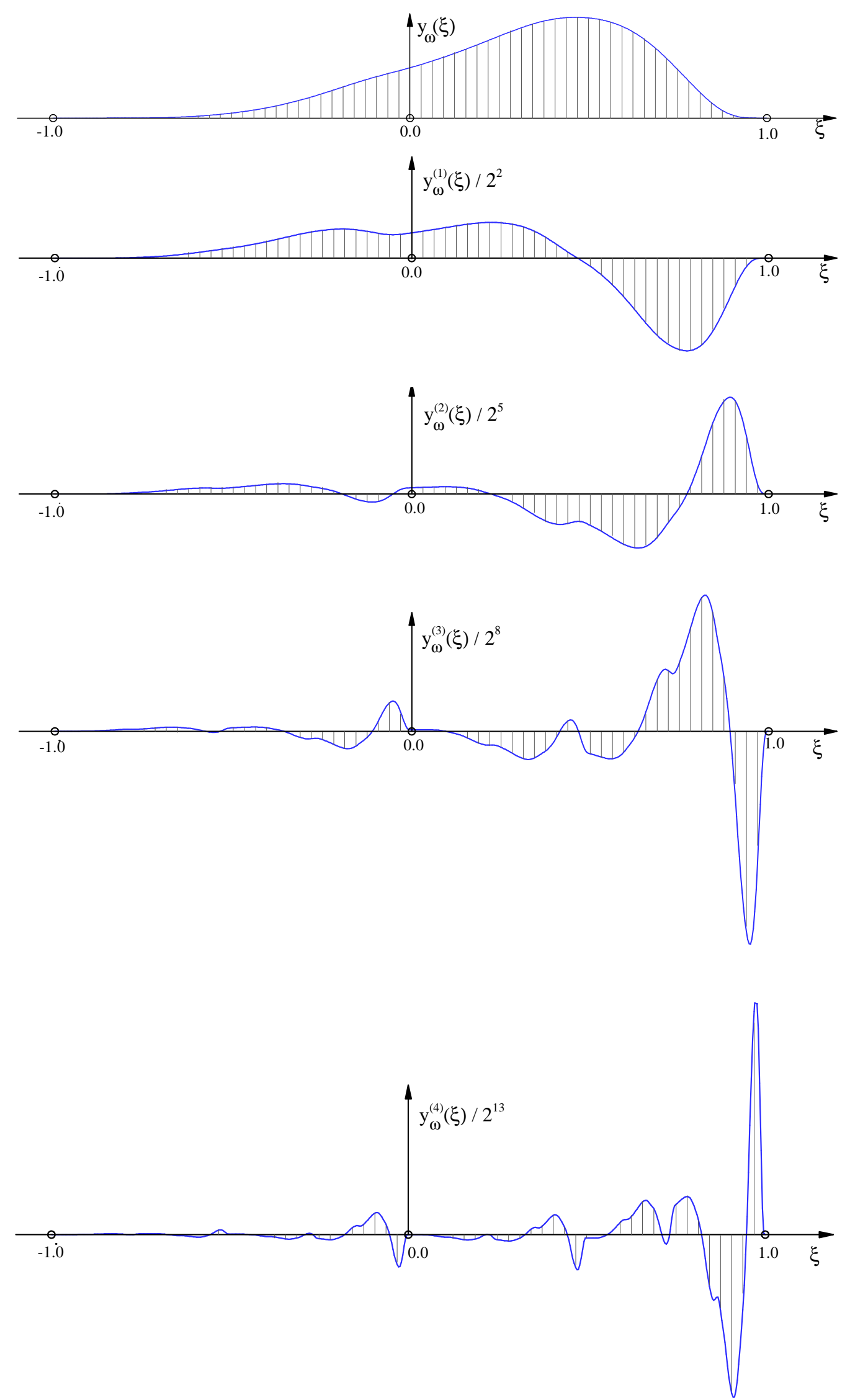

Crtež 5.4 Prve četiri derivacije funkcije $\operatorname{Eup}(\xi, \omega)$ 


\subsection{Integral funkcije $\operatorname{Eup}(\xi, \omega)$}

Integral funkcije $\operatorname{Eup}(\xi, \omega)$ u granicama od $-\infty$ do proizvoljne točke $\xi \in(-\infty, 1]$ slijedi, slično funkciji $u p(\xi)$, iz integrala osnovne jednadžbe (5.11), a određen je izrazom:

$$
I_{1}(\xi)=\frac{1}{\omega} y_{\omega}(\xi)-\frac{a}{2 \omega} \cdot I_{1}(2 \xi+1, \omega)+\frac{b}{2 \omega} \cdot I_{1}(2 \xi-1, \omega)
$$

$\mathrm{Za} \xi>1$ funkcija prvog integrala $I_{1}(\xi)$ je jedinični polinom nultog stupnja.

Pomoću izraza (5.23) mogu se izračunati integrali funkcije $\operatorname{Eup}(\xi, \omega)$ od lijevog ruba nosača do karakterističnih točaka tipa $\xi_{k}=\left(-1+k / 2^{m}\right), k=1, \ldots, 2^{m+1}$.

Na primjer, za $m=1$ slijedi

$$
\begin{aligned}
I_{1}\left(-\frac{1}{2}\right) & =\frac{1}{\omega} y_{\omega}\left(-\frac{1}{2}\right)-\frac{a}{2 \omega} \cdot I_{1}(0) \\
I_{1}(0) & =\frac{1}{\omega} y_{\omega}(0)-\frac{a}{2 \omega} \cdot I_{1}(1) ; \quad I_{1}(\xi \geq 1)=1 \\
I_{1}\left(\frac{1}{2}\right) & =\frac{1}{\omega} y_{\omega}\left(\frac{1}{2}\right)+\frac{b}{2 \omega} \cdot I_{1}(0)
\end{aligned}
$$

Iz (5.24) vidi se da je vrijednost integrala od lijevog ruba nosača do točke $\xi=0$ jedina određena i iznosi

$$
I_{1}(0)=\frac{\lambda_{0} \cdot e^{\omega}-\lambda_{0}-\omega}{\omega \cdot\left(e^{\omega}-1\right)}=\frac{\lambda_{0}}{\omega}-\frac{1}{e^{\omega}-1}
$$

te da su integrali $I_{1}(-1 / 2)$ i $I_{1}(1 / 2)$ funkcija integrala $I_{1}(0)$. Integrali do karakterističnih točaka za $m=2$, tj. $\xi_{k}=(-1+k / 4), k=1, \ldots, 8$ su funkcije prethodno izračunatih integrala za $m=1 \mathrm{tj}$., funkcije integrala $I_{1}(-1 / 2), I_{1}(1 / 2)$ i $I_{1}(0)$. Dakle, poopćavanjem izraza (5.23) dolazi se do rekurzivne formule za općenito područje integracije:

$$
I_{1}\left(-1+\frac{k}{2^{m}}\right)=\frac{1}{\omega} y_{\omega}\left(-1+\frac{k}{2^{m}}\right)-\frac{\mathrm{a}}{2 \omega} \cdot I_{1}\left(-1+\frac{k}{2^{m-1}}\right)+\frac{\mathrm{b}}{2 \omega} \cdot I_{1}\left(-3+\frac{k}{2^{m-1}}\right)
$$

Dakle, integral funkcije $\operatorname{Eup}(\xi, \omega)$ bilo kojeg reda u granicama od $-\infty$ do $\xi \in(-\infty, 1]$ odgovara funkciji $\operatorname{Eup}(\xi, \omega)$ koja je po osi apscise rastegnuta na $2^{m}$ puta veću duljinu i koja je pomaknuta tako da je prva točka nosača u točki $\xi=-1$.

Za pojedine posebne slučajeve iz (5.26) se izvodi:

- za $\xi=0$ vrijedi:

$$
I_{1}(0)=\frac{1}{\omega} y_{\omega}(0)-\frac{a}{2 \omega}
$$

- za područje $-1<\xi<0$, tj. $k=1, \ldots, 2^{m}-1$ vrijedi: 


$$
I_{1}\left(-1+\frac{k}{2^{m}}\right)=\frac{1}{\omega} \cdot y_{\omega}\left(-1+\frac{k}{2^{m}}\right)-\frac{a}{2 \omega} \cdot I_{1}\left(-1+\frac{k}{2^{m-1}}\right)
$$

- za područje $0<\xi<1$, tj. $k=2^{m}+1, \ldots, 2^{m+1}-1$ vrijedi:

$$
I_{1}\left(-1+\frac{k}{2^{m}}\right)=\frac{1}{\omega} y_{\omega}\left(-1+\frac{k}{2^{m}}\right)-\frac{a}{2 \omega}+\frac{b}{2 \omega} \cdot I_{1}\left(-3+\frac{k}{2^{m-1}}\right)
$$

- za dio realne osi izvan područja integracije vrijedi:

$$
\begin{array}{ccc}
I_{1}(\xi)=0 & \text { za } & \xi \in(-\infty,-1] \\
I_{1}(\xi)=1 & \text { za } & \xi \in[1,+\infty)
\end{array}
$$
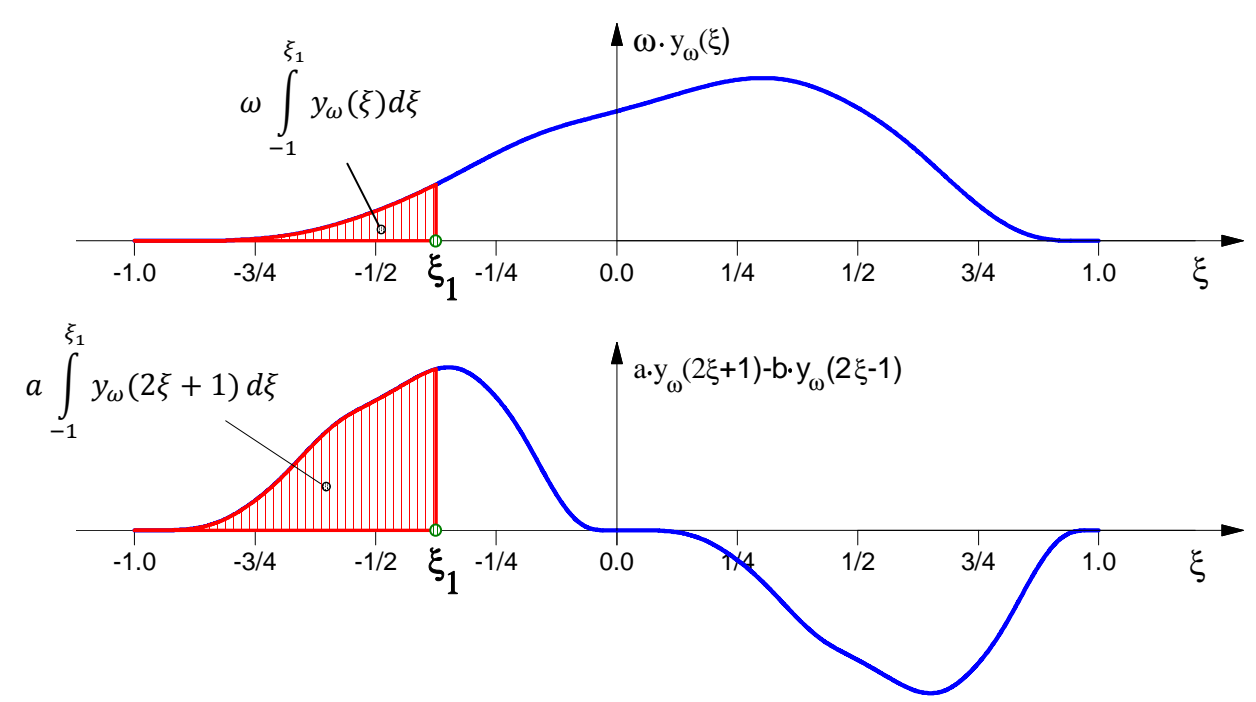

Crtež 5.5 Dvije komponente integrala funkcije $\operatorname{Eup}(\xi, \omega)$ do proizvoljne točke $\xi_{1} \in[-1,0]$

\subsection{Veza baznih funkcija $\operatorname{Eup}(\xi, \omega)$ i eksponencijalnih polinoma $\mathrm{e}^{2 \mathrm{~m} \omega} \xi$}

Uzastopnim pomicanjem samo jedne finitne bazne funkcije $\operatorname{Eup}(\xi, \omega)$ po realnoj osi formira se baza vektorskog prostora $E U P_{n}$. Proizvoljna funkcija $\varphi(\xi)$ može se prikazati kao linearna kombinacija funkcija iz vektorskog prostora $E U P_{n}$ u sljedećem obliku

$$
\varphi(\xi)=\sum_{k=-\infty}^{\infty} C_{n}^{(m)}(k) \cdot \operatorname{Eup}\left(\xi-k \cdot 2^{-n}, \omega\right), \quad k \in Z, \quad n \in N
$$

gdje su $C_{n}^{(m)}(k)$ nepoznati koeficijenti linearne kombinacije, a $k / 2^{n}$ karakteristični pomak bazne funkcije po osi apscise. 
Slično algebarskim ABF (vidi točku 3.8), da bi linearna kombinacija (5.31) predstavljala eksponencijalni monom $\varphi(\xi)=A_{n}^{(m)} \cdot e^{2^{m} \omega \xi}$, potrebno je i dovoljno da se za zadani $n \in N$ djelovanjem diferencijalnog operatora

$$
L_{n}=\prod_{j=1}^{n+1}\left(d / d \xi-2^{j-1} \omega\right)
$$

na izraz (5.31) poništi linearna kombinacija na desnoj strani. Iz toga, prema jednadžbi (5.17), slijedi da koeficijenti $C_{n}^{(m)}(k)$ na odsječku $\left[k \cdot 2^{-n},(k+1) \cdot 2^{-n}\right]$ moraju zadovoljiti sljedeću jednadžbu

$$
\sum_{k=1}^{2^{n+1}} D_{k}^{(n)} C_{n}^{(m)}(k)=0, \quad n \in N
$$

gdje su koeficijenti $D_{k}^{(n)}$ određeni izrazima (5.18) i (5.19). Slično vektorskom prostoru $U P_{n}$, $m=0,1, \ldots, n$ je stupanj eksponencijalnog monoma, a $n$ najviši stupanj eksponencijalnog monoma sadržan u odabranom vektorskom prostoru $E U P_{n}$.

Na crtežima 5.6 i 5.7 ilustrirani su izrazi (5.31) i (5.32) za $n=0$ i $n=1 \mathrm{tj}$., za razvoj eksponencijalne funkcije $A_{0}^{(m)} \cdot e^{2^{0} \omega \xi}$ na karakterističnom odsječku $\Delta \xi_{0}=1 \quad$ i eksponencijalne funkcije $A_{1}^{(m)} \cdot e^{2^{1} \omega \xi}$ na karakterističnom odsječku upola manje duljine $\Delta \xi_{1}=1 / 2$.

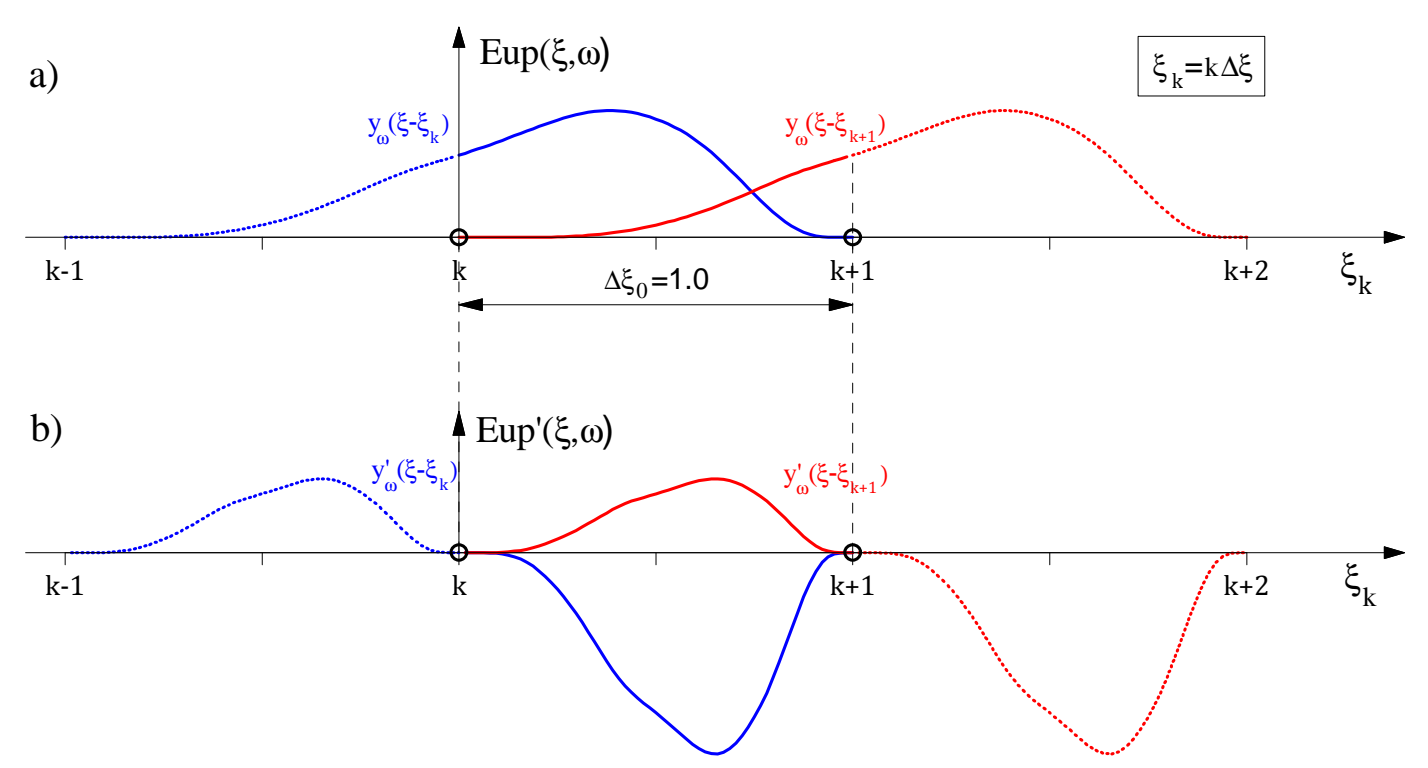

Crtež 5.6 $\varphi(\xi)=A_{0}^{(m)} \cdot e^{2^{0} \omega \xi}$ kao linearna kombinacija baznih funkcija $\operatorname{Eup}(\xi, \omega)$ 


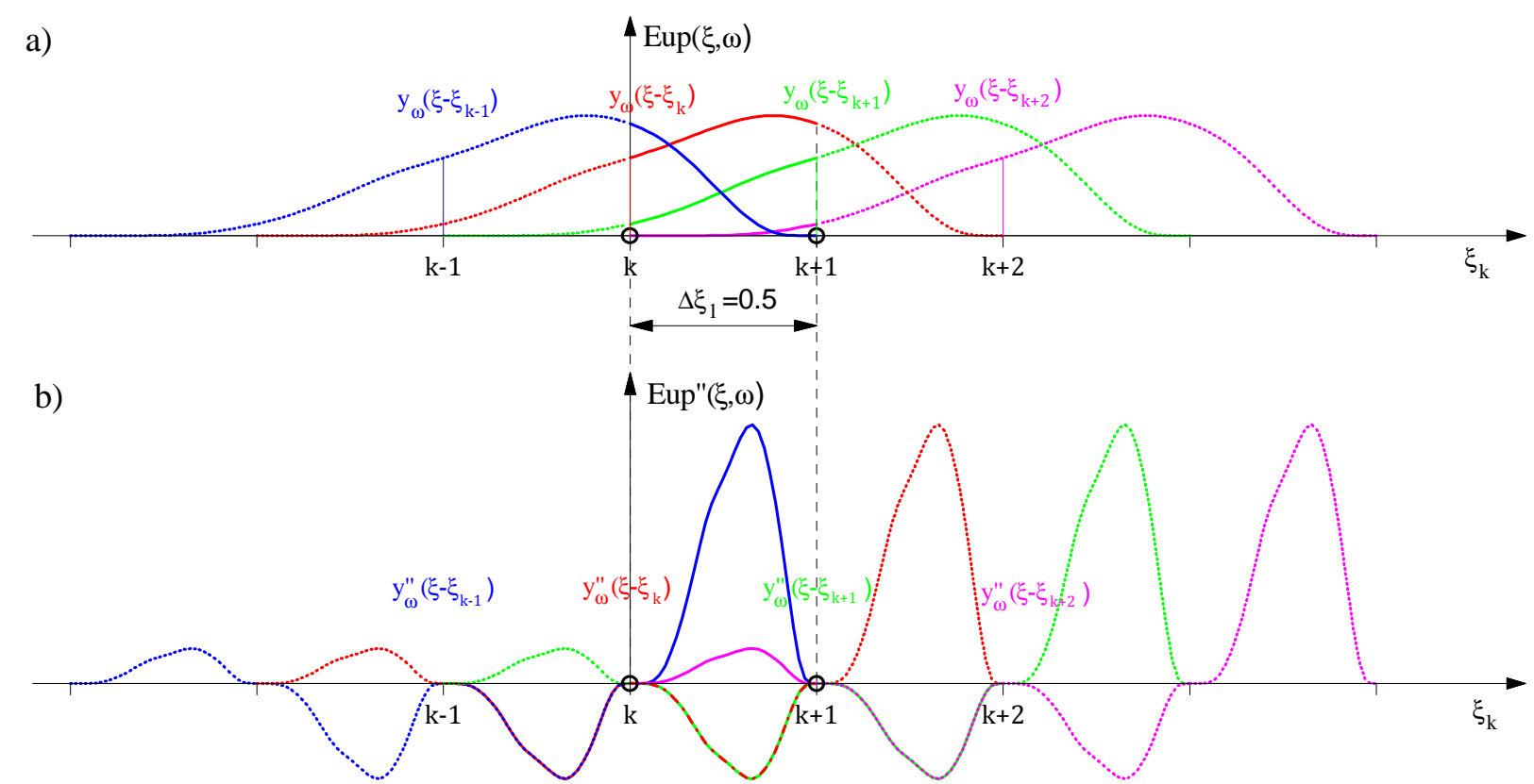

Crtež $5.7 \varphi(\xi)$ kao linearna kombinacija baznih funkcija $\operatorname{Eup}(\xi, \omega)$ za $n=1$

Koeficijenti linearne kombinacije $C_{n}^{(m)}(k)$ iz (5.31), analogno algebarskim ABF, predstavljaju korijene karakteristične jednadžbe linearne rekurzije (5.32).

Na primjer, za $n=0(m=0)$ (crtež 5.6 i crtež 5.8 a)) prema izrazu (5.32) dobije se slijedeća rekurzija

$$
a \cdot C_{0}^{(0)}(k)-a \cdot e^{\omega} \cdot C_{0}^{(0)}(k-1)=0
$$

odnosno

$$
C_{0}^{(0)}(k)-e^{\omega} \cdot C_{0}^{(0)}(k-1)=0
$$

Uvođenjem zamjene

$$
C_{0}^{(0)}(k)=\lambda^{k}
$$

u izraz (5.33) dobije se karakteristična jednadžba u obliku $\lambda^{k}-e^{\omega} \cdot \lambda^{k-1}=0$ iz koje slijedi

$$
\lambda=e^{\omega}
$$

Uvrštavanjem (5.35) u (5.34) dobiju se koeficijenti za točan razvoj eksponencijalnog monoma $e^{2^{0} \omega \xi}$

$$
C_{0}^{(0)}(k)=e^{\omega k}
$$

koji se sada može napisati u obliku 


$$
e^{2^{0} \omega \xi}=\frac{1}{A_{0}^{(0)}} \sum_{k=-\infty}^{\infty} e^{\omega k} \cdot \operatorname{Eup}(\xi-k, \omega), \quad k \in Z
$$

ili

$$
e^{2^{0} \omega \xi}=\frac{1}{A_{0}^{(0)}} \sum_{k=-\infty}^{\infty} e^{2^{0} \omega k / 2^{0}} \cdot \operatorname{Eup}\left(\xi-k / 2^{0}, 2^{0} \cdot \omega \cdot \frac{1}{2^{0}}\right), \quad k \in Z
$$

$\mathrm{Za} \xi \in(0,1]$ iz $(5.37)$ dobiva se

$$
e^{2^{0} \omega \xi}=\frac{1}{A_{0}^{(0)}} \cdot\left[e^{\omega \cdot 0} \cdot \operatorname{Eup}(\xi, \omega)+e^{\omega \cdot 1} \cdot \operatorname{Eup}(\xi-1, \omega)\right]
$$

$\mathrm{tj}:$ :

$$
\operatorname{Eup}(\xi, \omega)=A_{0}^{(0)} \cdot e^{\omega \xi}-e^{\omega} \cdot \operatorname{Eup}(\xi-1, \omega)
$$

Iz izraza (5.39) slijedi da je dovoljno poznavati vrijednosti funkcije $\operatorname{Eup}(\xi, \omega)$ za $\xi \in$ $[-1,0]$ i konstantu $A_{0}^{(0)}$ da bi se mogle izračunati vrijednosti funkcije $\operatorname{Eup}(\xi, \omega)$ na drugoj polovici nosača tj. za $\xi \in[0,1]$. Uvrštavajući koordinatu $\xi=0$ u (5.39) dobiva se koeficijent $A_{0}^{(0)}$ :

$$
A_{0}^{(0)}=\operatorname{Eup}(0, \omega)=\lambda_{0}(\omega)
$$

Analogno, za $n=1(m=0,1)$, (crtež 5.7 i crtež 5.8 b)), prema (5.32) dobije se linearna rekurzija oblika

$$
e^{2 \omega} \cdot C_{1}^{(m)}(k-1)-e^{\omega} \cdot C_{1}^{(m)}(k)-e^{\omega} \cdot C_{1}^{(m)}(k+1)+C_{1}^{(m)}(k+2)=0
$$

Uvođenjem zamjene $C_{1}^{(m)}(k)=\lambda^{k}$ karakteristična jednadžba za $n=1$ je

$$
e^{2 \omega} \cdot \lambda^{k-1}-e^{\omega} \cdot \lambda^{k}-e^{\omega} \cdot \lambda^{k+1}+\lambda^{k+2}=0
$$

čiji su korijeni

$$
\lambda_{0}=\mathrm{e}^{\omega / 2} ; \lambda_{1}=\mathrm{e}^{\omega}
$$

pa su koeficijenti za točan razvoj eksponencijalnih monoma nultog i prvog stupnja

$$
C_{1}^{(0)}(k)=e^{(\omega / 2) k} ; \quad C_{1}^{(1)}(k)=e^{\omega k}
$$

Spomenuti monomi sada se mogu napisati u obliku linearne kombinacije baznih funkcija iz vektorskog prostora $E U P_{1}$ sa crteža 5.8 b) na način:

$$
e^{2^{0} \omega \xi}=\sum_{k=-\infty}^{\infty} \frac{e^{(\omega / 2) k}}{A_{1}^{(0)}} \cdot \operatorname{Eup}(\xi-k / 2, \omega), \quad k \in Z
$$




$$
e^{2^{1} \omega \xi}=\sum_{k=-\infty}^{\infty} \frac{e^{\omega k}}{A_{1}^{(1)}} \cdot \operatorname{Eup}(\xi-k / 2, \omega), \quad k \in Z
$$

ili

$$
\begin{array}{ll}
e^{2^{0} \omega \xi}=\sum_{k=-\infty}^{\infty} \frac{e^{2^{0} \omega k / 2^{1}}}{A_{1}^{(0)}} \cdot \operatorname{Eup}\left(\xi-k / 2^{1}, 2^{1} \cdot \omega \cdot \frac{1}{2^{1}}\right), \quad k \in Z \\
e^{2^{1} \omega \xi}=\sum_{k=-\infty}^{\infty} \frac{e^{2^{1} \omega k / 2^{1}}}{A_{1}^{(1)}} \cdot \operatorname{Eup}\left(\xi-k / 2^{1}, 2^{1} \cdot \omega \cdot \frac{1}{2^{1}}\right), \quad k \in Z
\end{array}
$$

gdje su

$$
\begin{gathered}
A_{1}^{(0)}=e^{-\omega / 2} \cdot \operatorname{Eup}(1 / 2, \omega)+\operatorname{Eup}(0, \omega)+e^{\omega / 2} \cdot \operatorname{Eup}(-1 / 2, \omega) \\
A_{1}^{(1)}=e^{-\omega} \cdot \operatorname{Eup}(1 / 2, \omega)+\operatorname{Eup}(0, \omega)+e^{\omega} \cdot \operatorname{Eup}(-1 / 2, \omega)
\end{gathered}
$$

Za $n=2(m=0,1,2)$, crtež $5.8 \mathrm{c})$, iz (5.32) dobije se slijedeća rekurzija

$$
\begin{aligned}
& -e^{3 \omega} \cdot C_{1}^{(m)}(k-3)+e^{2 \omega} \cdot C_{1}^{(m)}(k-2)+e^{2 \omega} \cdot C_{1}^{(m)}(k-1)-e^{\omega} \cdot C_{1}^{(m)}(k)+ \\
& +e^{2 \omega} \cdot C_{1}^{(m)}(k+1)-e^{\omega} \cdot C_{1}^{(m)}(k+2)-e^{\omega} \cdot C_{1}^{(m)}(k+3)+C_{1}^{(m)}(k+4)=0
\end{aligned}
$$

te koeficijenti za točan razvoj eksponencijalnih monoma do uključivo drugog stupnja

$$
C_{2}^{(0)}(k)=e^{(\omega / 4) k}, \quad C_{2}^{(1)}(k)=e^{(\omega / 2) k}, \quad C_{2}^{(2)}(k)=e^{\omega k}
$$

i tako redom.

Općenito vrijedi da se eksponencijalna funkcija $e^{2^{m} \omega \xi}, m=0,1, \ldots, n ; n \in N$ na odsječku duljine $\Delta \xi_{n}=2^{-n}$ može točno prikazati pomoću linearne kombinacije $2^{n+1}$ baznih funkcija $\operatorname{Eup}(\xi, \omega)$ međusobno pomaknutih za $2^{-n}$ u obliku

$$
e^{2^{m} \omega \xi}=\sum_{k=-\infty}^{\infty} \frac{e^{2^{m} \cdot \omega \cdot k \cdot 2^{-n}}}{A_{n}^{(m)}} \cdot \operatorname{Eup}\left(\xi-\frac{k}{2^{n}}, 2^{n} \cdot \omega \cdot \frac{1}{2^{n}}\right) ; m=0,1, \ldots, n
$$

gdje se koeficijenti $A_{n}^{(m)}$ izračunavaju iz (5.46) za $\xi=0$

$$
A_{n}^{(m)}=\sum_{i=-\left(2^{n}-1\right)}^{2^{n}-1} e^{2^{m} \cdot \omega \cdot i \cdot 2^{-n}} \cdot \operatorname{Eup}\left(-\frac{i}{2^{n}}, 2^{n} \cdot \omega \cdot \frac{1}{2^{n}}\right)
$$

ili u realnom području koordinate $x$ : 


$$
e^{2^{m} \omega x}=\sum_{k=-\infty}^{\infty} \frac{e^{2^{m} \cdot \omega \cdot k \cdot \Delta x_{n}}}{A_{n, x}^{(m)}} \cdot \operatorname{Eup}\left(x-k \cdot \Delta x_{n}, 2^{n} \cdot \omega \cdot \Delta x_{n}\right) ; m=0,1, \ldots, n
$$

gdje je

$$
A_{n, x}^{(m)}=\sum_{i=-\left(2^{n}-1\right)}^{2^{n}-1} e^{2^{m} \cdot \omega \cdot i \cdot \Delta x_{n}} \cdot \operatorname{Eup}\left(i \cdot \Delta x_{n}, 2^{n} \cdot \omega \cdot \Delta x_{n}\right)
$$

Dakle, binarnim povećavanjem broja baznih funkcija u linearnoj kombinaciji na intervalu duljine $\Delta x_{n}$ omogućava se razvoj eksponencijalnog monoma stupnja $m=0,1, \ldots, n$, kao i eksponencijalnog polinoma nastalog njihovom kombinacijom.
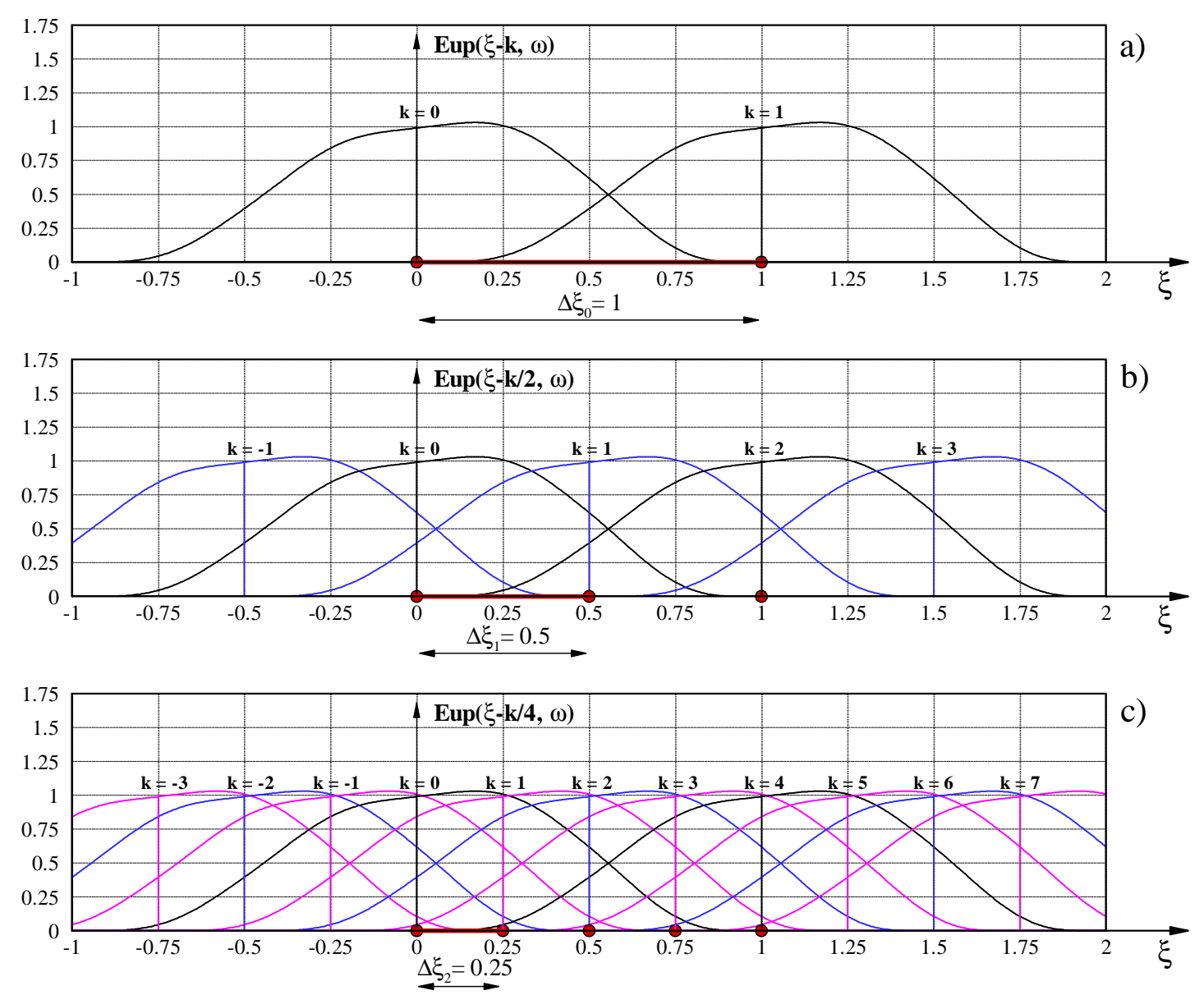

Crtež 5.8 Razvoj eksponencijalnih monoma stupnja 0,1 i 2 pomoću $\operatorname{Eup}\left(\xi-k 2^{-n}, \omega\right)$ funkcija 


\subsubsection{Primjer aproksimacije funkcije eksponencijalnog polinoma}

Zadana funkcija je eksponencijalni polinom drugog stupnja s frekvencijom 0.6 :

$$
f(x)=-230 \cdot e^{2^{0} \cdot 0.6 \cdot x}+304 \cdot e^{2^{1} \cdot 0.6 \cdot x}-65 \cdot e^{2^{2} \cdot 0.6 \cdot x}, x \in[0,1]
$$

Aproksimacija funkcije traži se u obliku linearne kombinacije baznih funkcija prikazanih na crtežu 5.8 a), b) i c), respektivno.

a) Koristeći metodu kolokacije na jednom odsječku duljine $\Delta x_{a}=\Delta x_{0}=1$ i pripadajuću frekvenciju $\omega_{a}=0.6$, za raspored baznih funkcija prema crtežu 5.8a), dobiva se sustav jednadžbi i koeficijenti $\mathrm{C}_{i}=1, i=0,1$ :

$$
\begin{aligned}
& {\left[\begin{array}{cc}
y\left(0, \omega_{a}\right) & 0 \\
0 & y\left(0, \omega_{a}\right)
\end{array}\right] \cdot\left[\begin{array}{l}
C_{0} \\
C_{1}
\end{array}\right]=\left[\begin{array}{l}
f(0) \\
f(1)
\end{array}\right]} \\
& \rightarrow\left[\begin{array}{l}
C_{0} \\
C_{1}
\end{array}\right]=\frac{1}{y\left(0, \omega_{a}\right)} \cdot\left[\begin{array}{l}
f(0) \\
f(1)
\end{array}\right]=\frac{1}{y\left(0, \omega_{a}\right)}\left[\begin{array}{c}
9 \\
-126.278
\end{array}\right]
\end{aligned}
$$

Aproksimacija zadane funkcije $f(x)$ u obliku $\widetilde{f}_{a}(x)=C_{0} \cdot \operatorname{Eup}\left(x, \omega_{a}\right)+C_{1}$. $\operatorname{Eup}\left(x-1, \omega_{a}\right)$ prikazana je na crtežu 5.9.

b) Linearnom kombinacijom ABF eksponencijalnog tipa raspoređenih prema crtežu 5.8b) može se točno opisati eksponencijalni monom nultog i prvog stupnja ili eksponencijalni polinom nastao njihovom kombinacijom. Zadano područje podjeljeno je na dva karakteristična odsječka $\Delta x_{b}=\Delta x_{1}$, a pripadajuća frekvencija baznih funkcija je $\omega_{b}=2$. $\omega_{a}=2 \cdot 0.6=1.2$. U tri kolokacijske točke postavljen je uvjet da linearna kombinacija baznih funkcija iz vektorskog prostora $E U P_{1}$ razvija zadani polinom (5.49). Potrebno je napisati još dvije uvjetne jednadžbe za bazne funkcije s tjemenima izvan zadanog područja (po jedna na svakom rubu). S obzirom da bazne funkcije iz vektorskog prostora $E U P_{n}$ točno opisuju eksponencijalne polinome do uključivo $n$-tog stupnja, logično je da se na rubovima područja zadana funkcija prirodno proširuje upravo eksponencijalnim polinomom. Bazne funkcije sa crteža 5.8b) na karakterističnom odsječku zadovoljavaju rekurziju (5.41) pa je matrični sustav jednadžbi sljedeći

$$
\left[\begin{array}{ccccc}
e^{2 \omega_{b}} & -e^{\omega_{b}} & -e^{\omega_{b}} & 1 & \\
y\left(0.5, \omega_{b}\right) & y\left(0, \omega_{b}\right) & y\left(-0.5, \omega_{b}\right) & & \\
& y\left(0.5, \omega_{b}\right) & y\left(0, \omega_{b}\right) & y\left(-0.5, \omega_{b}\right) & \\
& y\left(0.5, \omega_{b}\right) & y\left(0, \omega_{b}\right) & y\left(-0.5, \omega_{b}\right)
\end{array}\right]\left[\begin{array}{c}
C_{-1} \\
C_{0} \\
C_{1} \\
C_{2} \\
C_{3}
\end{array}\right]=\left[\begin{array}{c}
0 \\
f(0) \\
f(0.5) \\
f(1) \\
0
\end{array}\right]
$$

Traženi koeficijenti $C_{i}$ su

$$
C_{-1}=-39.8432 ; C_{0}=102.6557 ; C_{1}=-104.1104 ; C_{2} 129.6335 ; C_{3}=-294.3229
$$


a dobivena aproksimacija $\widetilde{f_{b}}(x)$ prikazana je na crtežu 5.9.

c) Linearnom kombinacijom ABF eksponencijalnog tipa raspoređenih prema crtežu 5.8c) može se točno opisati eksponencijalni monom nultog, prvog i drugog stupnja ili eksponencijalni polinom nastao njihovom kombinacijom. Zadano područje podjeljeno je na šest karakterističnih odsječaka $\Delta x_{c}=\Delta x_{2}$, a pripadajuća frekvencija baznih funkcija je $\omega_{c}=2^{1} \cdot \omega_{b}=2^{2} \cdot \omega_{a}$. U sedam kolokacijskih točaka postavljen je uvjet da linearna kombinacija baznih funkcija razvija zadani polinom (5.49). Dodatne uvjetne jednadžbe za bazne funkcije iz vektorskog prostora $E U P_{2}$ s tjemenima izvan zadanog područja (tri na desnom i tri na lijevom rubu) određene su izrazom (5.45), a predstavljaju prirodno proširenje funkcije eksponencijalnim polinomom.

Linearna kombinacija baznih funkcija prikazanih na crtežu 5.8c) opisuje točno zadanu funkciju $f(x)$ kao što je vidljivo na crtežu 5.9 što potvrđuje da se za $\Delta x_{2}$ i frekvenciju $\omega_{c}=2.4$ mogu točno prikazati eksponencijalni monomi $e^{(2.4 / 4) \cdot x}, e^{(2.4 / 2) \cdot x}, e^{2.4 \cdot x}$ te bilo koja njihova linearna kombinacija.

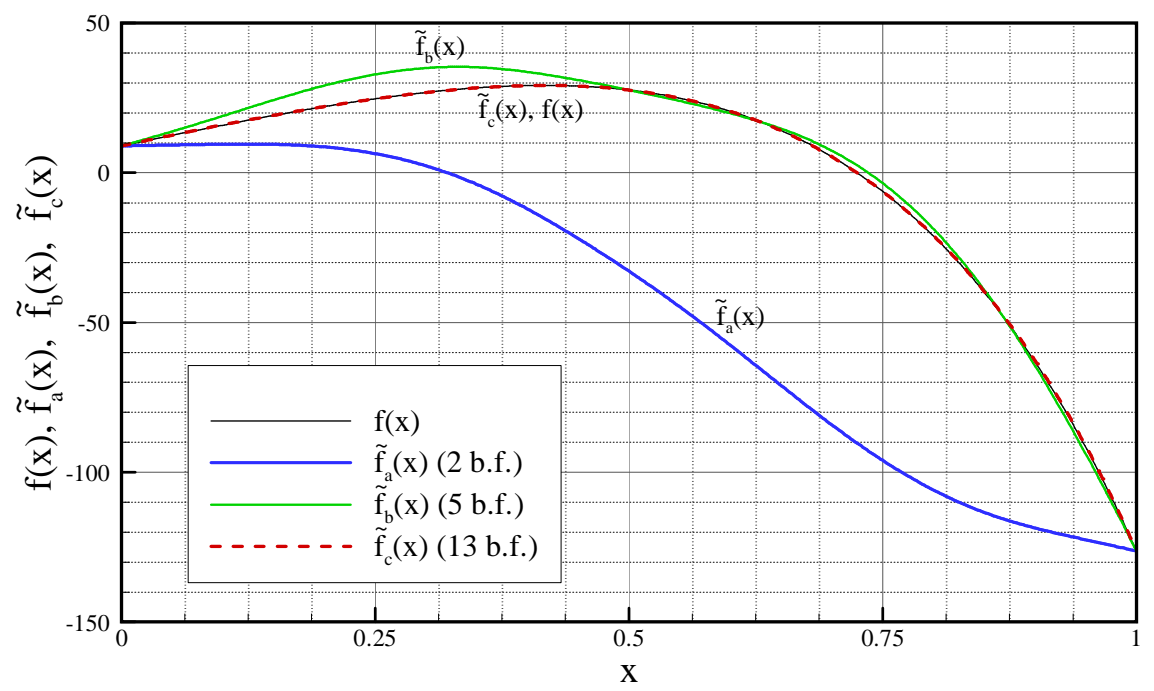

Crtež 5.9 Funkcija $f(x)$ i aproksimacije funkcije $\tilde{f}_{a}(x), \tilde{f}_{b}(x), \tilde{f}_{c}(x)$

\subsection{Vrijednost funkcije $\operatorname{Eup}(\xi, \omega)$ u točki $\xi=0$}

Iz funkcionalno diferencijalne jednadžbe (5.11) za $\xi \in(-1,0]$ slijedi

$$
y_{\omega}{ }^{\prime}(\xi)-\omega \cdot y_{\omega}(\xi)=a \cdot y_{\omega}(2 \xi+1)
$$

Da bi se odredile vrijednosti funkcije $\operatorname{Eup}(\xi, \omega)$ potrebno je integrirati izraz (5.52). Međutim, zbog općeg oblika funkcije $\operatorname{Eup}(\xi, \omega)$ na izraz (5.52) se djeluje na svaki član integralnim operatorom oblika $e^{\omega \xi} \int_{-1}^{\xi} e^{-\omega t}(\bullet) d t$ iz čega se dobije 


$$
e^{\omega \xi} \int_{-1}^{\xi} e^{-\omega t} \cdot\left[y_{\omega}{ }^{\prime}(t)-\omega \cdot y_{\omega}(t)\right] d t=e^{\omega \xi} \int_{-1}^{\xi} e^{-\omega t} \cdot\left[a \cdot y_{\omega}(2 t+1)\right] d t
$$

No, kako je:

$$
\int_{-1}^{\xi} e^{-\omega t} \cdot y_{\omega}{ }^{\prime}(t) d t=\left.y_{\omega}(t) \cdot e^{-\omega t}\right|_{-1} ^{\xi}+\omega \int_{-1}^{\xi} e^{-\omega t} \cdot y_{\omega}(t) d t
$$

izraz (5.53) postaje

$$
y_{\omega}(\xi)=e^{\omega \xi} \int_{-1}^{\xi} e^{-\omega t} \cdot\left[a \cdot y_{\omega}(2 t+1)\right] d t
$$

Uvođenjem supstitucije $u=2 t+1$ u (5.54) slijedi:

$$
y_{\omega}(\xi)=\frac{e^{\omega \xi} \cdot a \cdot e^{\omega / 2}}{2} \cdot \int_{-1}^{2 \xi+1} y_{\omega}(u) \cdot e^{-\omega \cdot u / 2} d u
$$

Integral u (5.55) nema rješenje u zatvorenom obliku, ali se zato može izračunati njegova vrijednost za $\xi=0$, u otvorenom obliku

$$
\begin{aligned}
y_{\omega}(0)=\frac{a \cdot e^{\omega / 2}}{2} & \int_{-\infty}^{\infty} e^{-\omega \cdot u / 2} \cdot y_{\omega}(u) d u \\
& =\frac{a \cdot e^{\omega / 2}}{2} \cdot \prod_{j=1}^{\infty} \frac{\omega}{2 \cdot \operatorname{sh}(\omega / 2)} \cdot \frac{\operatorname{sh}\left(\omega / 2 \cdot\left(1-2^{-j}\right)\right)}{\omega / 2 \cdot\left(1-2^{-j}\right)}
\end{aligned}
$$

Uspoređivanjem prethodnog izraza s (5.5) očigledno je da član neizmjernog produkta odgovara Fourierovoj transformaciji i to za konkretnu vrijednost varijable $t=i \omega / 2$, tj.

$$
F(i \omega / 2)=\prod_{j=1}^{\infty} \frac{\omega}{2 \cdot \operatorname{sh}(\omega / 2)} \cdot \frac{\operatorname{sh}\left(\omega / 2 \cdot\left(1-2^{-j}\right)\right)}{\omega / 2 \cdot\left(1-2^{-j}\right)}
$$

Dakle, vrijednost funkcije $\operatorname{Eup}(\xi, \omega) \mathrm{u}$ ishodištu je

$$
y_{\omega}(0)=\frac{\omega}{2 \cdot \operatorname{sh}(\omega / 2)} \cdot F(i \omega / 2)=\lambda_{0}(\omega)
$$




\subsection{Vrijednost funkcije $\operatorname{Eup}(\xi, \omega)$ u binarno racionalnim točkama $\xi_{b r}$}

U literaturi [43] izveden je izraz za izračunavanje vrijednosti funkcije $\operatorname{Eup}(\xi, \omega)$ u binarno racionalnim točkama $\xi_{b r}=\left(-1+k / 2^{m}\right)$ sljedećeg oblika

$$
\begin{gathered}
y_{\omega}\left(\xi_{b r}\right)=2^{(m+1)(m+2) / 2} \sum_{p=0}^{m} \alpha_{p} \cdot F\left(\frac{i \cdot \omega}{2^{m+1-p}}\right) \cdot \sum_{r=1}^{k} D_{r}^{(m)} \cdot e^{\omega(2 k+1-2 r) / 2^{m+1-p}} \\
m=0,1, \ldots, N \quad ; \quad p=0, \ldots, m ; \quad k=1,2,3 \ldots, 2^{m+1}
\end{gathered}
$$

Koeficijenti $D_{r}^{(m)}$ određeni su izrazima (5.18) i (5.19), a integralni operator $\alpha_{p}$, izveden u [6] ,[43], određen je formulom:

$$
\alpha_{p}=\frac{\omega^{-m}}{\prod_{j=0, p \neq j}^{m}\left(2^{p}-2^{j}\right)} ; \quad z a \quad m=0 \rightarrow \alpha_{0}=1
$$

Član $F\left(\frac{i \cdot \omega}{2^{m+1-p}}\right)$ u (5.58) predstavlja Fourierove transformacije za karakteristične vrijednosti varijable $t$. Koristeći vezu Fourierovih transformacija $F(t)$ i $F(t / 2)$ iz (5.7), tj.

$$
F(t / 2)=\left(\frac{\omega}{2 \cdot \operatorname{sh}(\omega / 2)} \cdot \frac{\operatorname{sh}(\omega / 2+i t / 2)}{\omega / 2+i t / 2}\right)^{-1} \cdot F(t)
$$

uzastopnim supstitucijama $t=i \cdot \omega \cdot 2^{-j} \mathrm{u}(5.60)$, gdje je $j=1,2,3 \ldots$ slijedi veza

$$
F\left(\frac{i \omega}{2^{j+1}}\right)=\prod_{k=1}^{j}\left(\frac{\omega}{2 \cdot \operatorname{sh}(\omega / 2)} \cdot \frac{\operatorname{sh}\left(\omega / 2-\omega / 2^{k+1}\right)}{\omega / 2-\omega / 2^{k+1}}\right)^{-1} \cdot F\left(\frac{i \omega}{2}\right)
$$

gdje $F(i \omega / 2)$ predstavlja Fourierovu transformaciju za vrijednost varijable $t=i \omega / 2$ i određena je s (5.56), a prema (5.57) se može izraziti u obliku

$$
F\left(\frac{i \omega}{2}\right)=\frac{2 \cdot \operatorname{sh}(\omega / 2)}{\omega} \cdot \lambda_{0}(\omega)
$$

gdje je $\lambda_{0}(\omega)$ vrijednost funkcije $\operatorname{Eup}(\xi, \omega)$ u ishodištu. Dakle, pomoću (5.61) i (5.62) član $F\left(\frac{i \cdot \omega}{2^{m+1-p}}\right)$ se nakon sređivanja može napisati u obliku:

$$
\begin{gathered}
F\left(\frac{i \omega}{2^{m+1-p}}\right)=\frac{e^{\omega}-1}{\omega \cdot e^{\omega / 2}} \cdot \lambda_{0}(\omega) \cdot \prod_{j=1}^{m-p} \frac{\left(1-e^{\omega}\right) \cdot\left(2^{j}-1\right) \cdot e^{\omega / 2}{ }^{j+1}}{2^{k}\left(e^{\omega / 2}-e^{\omega}\right)} \quad \text { za } \quad p=0,1, \ldots, m-1 \\
F\left(\frac{i \omega}{2^{m+1-p}}\right)=\frac{e^{\omega}-1}{\omega \cdot e^{\omega / 2}} \cdot \lambda_{0}(\omega) \quad \text { za } \quad p=m
\end{gathered}
$$

Na taj način, sa (5.58) i (5.63), mogu se odrediti vrijednosti funkcije $\operatorname{Eup}(\xi, \omega)$ u binarno racionalnim točkama $\xi_{b r}=\left(-1+k / 2^{m}\right)$ tako da ovise samo o vrijednosti funkcije $\operatorname{Eup}(\xi, \omega)$ u točki $\xi=0$, izvedenoj u točki 5.7.

Na primjer, vrijednosti funkcije $\operatorname{Eup}(\xi, \omega)$ u binarno racionalnim točkama za $m=2$ su: 
$y_{\omega}\left(-\frac{3}{4}\right)=\frac{e^{-\frac{3 \omega}{4}} \cdot\left(e^{\frac{3 \omega}{4}}+3 \cdot e^{\frac{\omega}{2}}+3 \cdot e^{\frac{\omega}{4}}+3\right)}{3 \cdot\left(e^{\frac{\omega}{4}}+1\right)^{2} \cdot\left(e^{\frac{\omega}{2}}+1\right)^{2} \cdot\left(e^{\frac{\omega}{2}}+e^{\frac{\omega}{4}}+1\right)} \cdot \lambda_{0}(\omega)$

$y_{\omega}\left(-\frac{1}{2}\right)=\frac{e^{-\omega / 2}}{e^{\omega / 2}+1} \cdot \lambda_{0}(\omega)$

$y_{\omega}\left(-\frac{1}{4}\right)=\frac{e^{-\omega / 4} \cdot\left(6 \cdot e^{7 \omega / 4}+15 \cdot e^{3 \omega / 2}+26 \cdot e^{5 \omega / 4}+30 \cdot e^{\omega}+27 \cdot e^{3 \omega / 4}+18 \cdot e^{\omega / 2}+9 \cdot e^{\omega / 4}+3\right)}{3 \cdot\left(e^{\omega / 4}+1\right)^{2} \cdot\left(e^{\omega / 2}+1\right)^{2} \cdot\left(e^{\omega / 2}+e^{\omega / 4}+1\right)} \cdot \lambda_{0}(\omega)$

$y_{\omega}(0)=\lambda_{0}(\omega)$

$y_{\omega}\left(\frac{1}{4}\right)=\frac{e^{\omega / 2} \cdot\left(3 \cdot e^{7 \omega / 4}+9 \cdot e^{3 \omega / 2}+18 \cdot e^{5 \omega / 4}+27 \cdot e^{\omega}+30 \cdot e^{3 \omega / 4}+26 \cdot e^{\omega / 2}+15 \cdot e^{\omega / 4}+6\right)}{3 \cdot\left(e^{\omega / 4}+1\right)^{2} \cdot\left(e^{\omega / 2}+1\right)^{2} \cdot\left(e^{\omega / 2}+e^{\omega / 4}+1\right)} \cdot \lambda_{0}(\omega)$

$y_{\omega}\left(\frac{1}{2}\right)=\frac{e^{\omega}}{e^{\omega / 2}+1} \cdot \lambda_{0}(\omega)$

$y_{\omega}\left(\frac{3}{4}\right)=\frac{e^{2 \omega} \cdot\left(3 \cdot e^{3 \omega / 4}+3 \cdot e^{\omega / 2}+3 \cdot e^{\omega / 4}+1\right)}{3 \cdot\left(e^{\omega / 4}+1\right)^{2} \cdot\left(e^{\omega / 2}+1\right)^{2} \cdot\left(e^{\omega / 2}+e^{\omega / 4}+1\right)} \cdot \lambda_{0}(\omega)$

Međutim, s formulama (5.58) i (5.63) vrijednosti se mogu precizno odrediti samo za relativno male vrijednosti parametra $\omega$, te indeksa $m$. Za veće vrijednosti primjena formule je ograničena mogućnostima elektroničkog računala. Na primjer, za $\omega=10, m=10, k=$ $2^{m+1}, p=10, r=1$ slijedi

$$
\mathrm{e}^{\omega(2(\mathrm{k}-\mathrm{r})+1) / 2^{\mathrm{m}+1-\mathrm{p}}}=\mathrm{e}^{10\left(2\left(2^{11}-1\right)+1\right) / 2^{10+1-10}}=\mathrm{e}^{20465} \approx 10^{9000}>>\mathrm{Q}-\text { preciznosti }
$$

Navedeni "bezizgledni" problem ipak se može uspješno riješiti na sljedeći način:

Za $k=1$ iz jednadžbe (5.58) za zadane podatke slijedi:

$$
e^{\omega(2(k-r)+1) / 2^{m+1-p}}=e^{10(2(1-1)+1) / 2^{10+1-10}}=e^{5}=148.4
$$

Također, i ostale vrijednosti se pouzdano određuju. Dakle, izraz (5.58) za $k=1$ postaje:

$$
y_{\omega}\left(-1+2^{-m}\right)=\sum_{p=0}^{m} \alpha_{p} \cdot F\left(\frac{i \cdot \omega}{2^{m+1-p}}\right) \cdot D_{1}^{(m)} \cdot e^{\omega / 2^{m+1-p}}
$$

Za određivanje vrijednosti funkcije u ostalim točkama $\xi_{b r}=-1+k \cdot 2^{-m}, k=$ $2, \ldots, 2^{m+1}$ treba iskoristiti vezu baznih funkcija $\operatorname{Eup}(\xi, \omega)$ s eksponencijalnim polinomima.

U točki 5.6 je pokazano da je dovoljno odrediti vrijednosti funkcije $\operatorname{Eup}(\xi, \omega)$ za $\xi \in$ $(-1,0]$ da bi se mogle izračunati vrijednosti funkcije za $\xi \in(0,1]$. Na sličan način vrijedi da se za poznate vrijednosti funkcije $\operatorname{Eup}(\xi, \omega)$ za $\xi \in(-1,-1 / 2]$ mogu izračunati vrijednosti bazne funkcije na odsječku $\xi \in[-1 / 2,0]$, slično kao kod algebarske materinske bazne funkcije $u p(\xi)$ (vidi točku 3.7).

Eksponencijalni polinom $e^{2^{1} \omega \xi}$ može se napisati u obliku linearne kombinacije atomskih baznih funkcija $\operatorname{Eup}(\xi, \omega)$, međusobno pomaknutih za karakteristični odsječak $\Delta \xi_{1}=0.5$ (vidi točku 5.6). Na primjer, na intervalu $\xi \in[-1 / 2,0]$ vrijedi 


$$
e^{2 \omega \xi}=C_{1}^{(1)}(-2) \cdot y_{\omega}(\xi+1)+C_{1}^{(1)}(-1) \cdot y_{\omega}(\xi+1 / 2)+C_{1}^{(1)}(0) \cdot y_{\omega}(\xi)+C_{1}^{(1)}(1) \cdot y_{\omega}(\xi-1 / 2)
$$

gdje je $y_{\omega}(\xi-1 / 2)$ poznata funkcija za $\xi \in[-1 / 2,0]$, a funkcije $y_{\omega}(\xi+1)$ i $y_{\omega}(\xi+1 / 2)$ se prema (5.39) i (5.40) izraze u obliku

$$
\begin{gathered}
y_{\omega}(\xi+1)=\lambda_{0}(\omega) \cdot \mathrm{e}^{\omega(\xi+1)}-\mathrm{e}^{\omega} \cdot y_{\omega}(\xi) \\
y_{\omega}(\xi+1 / 2)=\lambda_{0}(\omega) \cdot \mathrm{e}^{\omega(\xi+1 / 2)}-\mathrm{e}^{\omega} \cdot y_{\omega}(\xi-1 / 2)
\end{gathered}
$$

Uvrštavanjem (5.67) u (5.66) dobiva se

$$
y_{\omega}(\xi)=\frac{e^{2 \cdot \omega \cdot \xi}-\lambda_{0}(\omega) \cdot e^{\omega(\xi+1)} \cdot\left(C_{1}^{(1)}(-2)+C_{1}^{(1)}(-1) \cdot e^{-\omega / 2}\right)+C_{1}^{(1)}(-1) \cdot y_{\omega}(\xi-1 / 2) \cdot\left(e^{\omega}-1\right)}{C_{1}^{(1)}(0)-C_{1}^{(1)}(-2) \cdot e^{\omega}}
$$

gdje su koeficijenti $C_{1}^{(1)}(k), k=-2, \ldots, 1$ određeni sa (5.44).

Također se za poznate vrijednosti za $\xi \in[-1,-3 / 4]$ mogu izračunati vrijednosti bazne funkcije na odsječku $\xi \in[-3 / 4,-1 / 2]$ itd. Dakle, inicijalno je dovoljno izračunati vrijednost bazne funkcije u samo jednoj točki prema (5.63) i (5.65).

U Tablici 5.1 dane su vrijednosti nulte i prve dvije derivacije funkcije $\operatorname{Eup}(\xi, \omega) \mathrm{u}$ karakterističnim točkama $\xi_{b r}=\left(-1+k / 2^{4}\right)$.

\subsection{Vrijednost funkcije $\operatorname{Eup}(\xi, \omega)$ u proizvoljnoj točki}

Postupak za određivanje vrijednosti funkcije $\operatorname{Eup}(\xi, \omega)$ u proizvoljnoj točki sličan je onome za funkciju $u p(\xi)$ iz točke 3.7. Neka je zadana eksponencijalna funkcija $\varphi_{n}(\xi)$ oblika

$$
\varphi_{n}(\xi)=\operatorname{Eup}(\xi, \omega)+e^{\omega} \cdot \operatorname{Eup}\left(\xi-2^{-n}, \omega\right)
$$

za koju na odsječku $\left[-1+2^{-n},-1+2^{-n+1}\right]$ prema izrazu (5.17) vrijedi da je $L_{n+1}\left[\varphi_{n}(\xi)\right] \equiv 0$. Na tom odsječku razvoj funkcije $\varphi_{n}(\xi)$ u Taylor-ov red u točki $\xi=-1+$ $2^{-n}$ je slijedeći

$$
\varphi_{n}(\xi)=\sum_{l=0}^{\infty} \frac{\varphi_{n}^{(l)}\left(-1+2^{-n}\right)}{l !} \cdot\left(\xi-\left(-1+2^{-n}\right)\right)^{l}
$$

gdje je prema (5.68)

$$
\begin{aligned}
\varphi_{n}^{(l)}\left(-1+2^{-n}\right) & =\operatorname{Eup}^{(l)}\left(-1+2^{-n}, \omega\right)+e^{\omega} \cdot \operatorname{Eup}^{(l)}(-1, \omega) \\
& =\operatorname{Eup}^{(l)}\left(-1+2^{-n}, \omega\right)
\end{aligned}
$$

Uvrštavajući (5.70) u (5.69) pa potom u (5.68), slijedi da je na odsječku $\left[-1+2^{-n},-1+\right.$ $\left.2^{-n+1}\right]$ vrijednost funkcije $\operatorname{Eup}(\xi, \omega)$ jednaka 
Tablica 5.1 Vrijednosti funkcije $\operatorname{Eup}(\xi, \omega)$ i prve dvije derivacije za $\omega=1$

\begin{tabular}{|c|c|c|c|}
\hline $\begin{array}{c}\xi_{b r}=\left(-1+k / 2^{4}\right) \\
k=0, \ldots, 32\end{array}$ & $y_{\omega}\left(\xi_{b r}\right)$ & $y_{\omega}^{\prime}\left(\xi_{b r}\right)$ & $y_{\omega}^{\prime \prime}\left(\xi_{b r}\right)$ \\
\hline-1.0000 & 0.0000000000 & 0.0000000000 & 0.0000000000 \\
\hline-0.9375 & 0.0000034178 & 0.0003968262 & 0.0381361174 \\
\hline-0.8750 & 0.0003379933 & 0.0162116846 & 0.6038400194 \\
\hline-0.8125 & 0.0032804203 & 0.0917738722 & 1.9125401829 \\
\hline-0.7500 & 0.0136377376 & 0.2524277724 & 3.1575416837 \\
\hline-0.6875 & 0.0363917531 & 0.4890363841 & 4.4108935594 \\
\hline-0.6250 & 0.0760283452 & 0.7821474164 & 4.6856711472 \\
\hline-0.5625 & 0.1334841638 & 1.0438956144 & 3.5355520071 \\
\hline-0.5000 & 0.2051542888 & 1.2479511108 & 3.3335447548 \\
\hline-0.4375 & 0.2899684801 & 1.4705426907 & 3.7312438728 \\
\hline-0.3750 & 0.3888855221 & 1.6847139795 & 2.7653298028 \\
\hline-0.3125 & 0.4979535545 & 1.7746638354 & -0.1401712943 \\
\hline-0.2500 & 0.6066557844 & 1.6768384734 & -2.7815172781 \\
\hline-0.1875 & 0.7043563105 & 1.4221415823 & -5.3421696168 \\
\hline-0.1250 & 0.7821717260 & 1.0703419756 & -5.1253338699 \\
\hline-0.0625 & 0.8413258212 & 0.8681104516 & -0.9018347776 \\
\hline 0.0000 & 0.8959094150 & 0.8959094150 & 0.8959094150 \\
\hline 0.0625 & 0.9536813175 & 0.9526119224 & 0.8500258930 \\
\hline 0.1250 & 0.1014279607 & 0.9711304402 & -0.6262089844 \\
\hline 0.1875 & 1.0717559302 & 0.8312057879 & -4.1181501883 \\
\hline 0.2500 & 1.1132992456 & 0.4642006332 & -7.4327177214 \\
\hline 0.3125 & 1.1256399392 & -0.1047757361 & -1.0765488830 \\
\hline 0.3750 & 1.0968740379 & -0.8225566020 & -1.1433434227 \\
\hline 0.4375 & 1.0247640699 & -1.449990833 & -8.2230151278 \\
\hline 0.5000 & 0.9194377339 & -1.9151779182 & -7.5844092223 \\
\hline 0.5625 & 0.7841539409 & -2.4249794832 & -8.5702024259 \\
\hline 0.6250 & 0.6166786946 & -2.9057482539 & -5.8431666098 \\
\hline 0.6875 & 0.4281505243 & -3.0423078324 & 2.1627537053 \\
\hline 0.7500 & 0.2475788517 & -2.6614793051 & 9.4575881192 \\
\hline 0.8125 & 0.1043240732 & -1.8468185878 & 16.5404856268 \\
\hline 0.8750 & 0.0230117719 & -0.7603161812 & 16.0812768847 \\
\hline 0.9375 & 0.0008241461 & -0.0719840281 & 4.7392259259 \\
\hline 1.0000 & 0.0000000000 & 0.0000000000 & 0.0000000000 \\
\hline
\end{tabular}




$$
\operatorname{Eup}(\xi, \omega)=\sum_{l=0}^{\infty} \frac{\operatorname{Eup}^{(l)}\left(-1+2^{-n}\right)}{l !} \cdot\left(\xi+1-2^{-n}\right)^{l}-e^{\omega} \cdot \operatorname{Eup}\left(\xi-2^{-n}, \omega\right)
$$

Dakle, za izračunavanje vrijednosti funkcije $\operatorname{Eup}(\xi, \omega)$ u točkama $\xi \in\left[-1+2^{-n},-1+\right.$ $\left.2^{-n+1}\right]$ potrebno je poznavati njezine vrijednosti u točkama $\xi \in\left[-1,-1+2^{-n}\right]$.

Također, ako se odsječak $\left[-1,-1+2^{-n}\right]$ raspolovi na odsječke $\left[-1,-1+2^{-n-1}\right] \mathrm{i}$ $\left[-1+2^{-n-1},-1+2^{-n}\right]$, tada se izračunavanje vrijednosti funkcije $\operatorname{Eup}(\xi, \omega)$ na odsječku $\left[-1+2^{-n-1},-1+2^{-n}\right]$ svodi na određivanje njezinih vrijednosti na odsječku $[-1,-1+$ $\left.2^{-n-1}\right]$. Nastavljanjem postupka dobiva se mogućnost konstruiranja reda za izračunavanje vrijednosti funkcije $\operatorname{Eup}(\xi, \omega)$ u bilo kojoj točki nosača na analogan način kao i za funkciju $u p(\xi)$ u točki 3.7.

Međutim, za razliku od funkcije $u p(\xi)$ koja u točki $\xi=-1+2^{-n}$ ima konačan razvoj u Taylorov red tj. $u p^{(n+1)}\left(-1+2^{-n}\right) \equiv 0$, za funkciju $\operatorname{Eup}(\xi, \omega)$ vrijedi $\operatorname{Eup}^{(l)}\left(-1+2^{-n}\right) \neq$ $0, l \in N$ pa je suma u (5.71) beskonačna. No korištenjem poznatog reda $e^{\omega \xi}=\sum_{k=0}^{\infty} \frac{(\omega \xi)^{k}}{k !} \mathrm{iz}$ [2] suma u (5.71) može se svesti na konačan oblik kako se pokazuje u nastavku. Na primjer, za $n=1$

$$
\begin{aligned}
\sum_{l=0}^{\infty} \frac{\operatorname{Eup}^{(l)}\left(-1+2^{-1}\right)}{l !} \cdot\left(\xi+1-2^{-1}\right)^{l}= \\
=y_{\omega}\left(-\frac{1}{2}\right)+y_{\omega}{ }^{\prime}\left(-\frac{1}{2}\right) \cdot\left(\xi+\frac{1}{2}\right)+\frac{1}{2 !} \cdot y_{\omega}^{\prime \prime}\left(-\frac{1}{2}\right) \cdot\left(\xi+\frac{1}{2}\right)^{2}+\frac{1}{3 !} \cdot y_{\omega}^{\prime \prime \prime}\left(-\frac{1}{2}\right)\left(\xi+\frac{1}{2}\right)^{3}+\cdots \\
\left.=\quad \quad \quad a \cdot y_{\omega}(0)\right] \cdot\left(\xi+\frac{1}{2}\right)^{+} \\
\quad+\quad\left[\omega \cdot y_{\omega}\left(-\frac{1}{2}\right)+\right. \\
+\frac{1}{2 !} \cdot\left[\omega^{2} \cdot y_{\omega}\left(-\frac{1}{2}\right)+3 \cdot \omega \cdot a \cdot y_{\omega}(0)\right] \cdot\left(\xi+\frac{1}{2}\right)^{2}+ \\
+\frac{1}{3 !} \cdot\left[\omega^{3} \cdot y_{\omega}\left(-\frac{1}{2}\right)+7 \cdot \omega^{2} \cdot a \cdot y_{\omega}(0)\right] \cdot\left(\xi+\frac{1}{2}\right)^{3}+\cdots \\
=y_{\omega}\left(-\frac{1}{2}\right) \cdot\left[1+\omega \cdot\left(\xi+\frac{1}{2}\right)+\omega^{2} \cdot \frac{1}{2 !} \cdot\left(\xi+\frac{1}{2}\right)^{2}+\cdot \omega^{3} \cdot \frac{1}{3 !}\left(\xi+\frac{1}{2}\right)^{3}+\cdots\right]+ \\
+\frac{a}{\omega} \cdot y_{\omega}(0) \cdot\left[\omega \cdot\left(\xi+\frac{1}{2}\right)+3 \cdot \omega^{2} \cdot \frac{1}{2 !} \cdot\left(\xi+\frac{1}{2}\right)^{2}+7 \cdot \omega^{3} \cdot \frac{1}{3 !} \cdot\left(\xi+\frac{1}{2}\right)^{3}+\cdots\right] \\
=y_{\omega}\left(-\frac{1}{2}\right) \cdot \sum_{k=0}^{\infty} \omega \omega^{k} \cdot \frac{1}{k !} \cdot\left(\xi+\frac{1}{2}\right)^{k}+\frac{a}{\omega} \cdot y_{\omega}(0) \cdot \sum_{k=1}^{\infty}\left(2^{k}-1\right) \omega^{k} \cdot \frac{1}{k !} \cdot\left(\xi+\frac{1}{2}\right)^{k} \\
=y_{\omega}\left(-\frac{1}{2}\right) \cdot e^{\omega \cdot(\xi+1 / 2)}+\frac{a}{\omega} \cdot y_{\omega}(0) \cdot e^{\omega \cdot(\xi+1 / 2)} \cdot\left(e^{\omega \cdot(\xi+1 / 2)}-1\right)
\end{aligned}
$$


Analogno se dobije za $n=2$ :

$$
\begin{aligned}
& y_{\omega}\left(-\frac{3}{4}\right) \cdot e^{\omega \cdot(\xi+3 / 4)}+ \\
& +\quad \frac{a}{\omega} \cdot y_{\omega}\left(-\frac{1}{2}\right) \cdot e^{\omega \cdot(\xi+3 / 4)} \cdot\left(e^{\omega \cdot(\xi+3 / 4)}-1\right)+ \\
& +\frac{1}{3} \cdot\left(\frac{a}{\omega}\right)^{2} \cdot y_{\omega}(0) \cdot e^{\omega \cdot(\xi+3 / 4)} \cdot\left(e^{\omega \cdot(\xi+3 / 4)}-1\right)^{2} \cdot\left(e^{\omega \cdot(\xi+3 / 4)}+2\right) \\
& \text { odnosno za } n=3:
\end{aligned}
$$

$$
\begin{aligned}
& y_{\omega}\left(-\frac{7}{8}\right) \cdot e^{\omega \cdot\left(\xi+\frac{7}{8}\right)}+ \\
& +\quad \frac{a}{\omega} \cdot y_{\omega}\left(-\frac{3}{4}\right) \cdot e^{\omega \cdot\left(\xi+\frac{7}{8}\right)} \cdot\left(e^{\omega \cdot\left(\xi+\frac{7}{8}\right)}-1\right)+ \\
& +\frac{1}{3} \cdot\left(\frac{a}{\omega}\right)^{2} \cdot y_{\omega}\left(-\frac{1}{2}\right) \cdot e^{\omega \cdot\left(\xi+\frac{7}{8}\right)} \cdot\left(e^{\omega \cdot\left(\xi+\frac{7}{8}\right)}-1\right)^{2} \cdot\left(e^{\omega \cdot\left(\xi+\frac{7}{8}\right)}+2\right) \\
& +\frac{1}{21} \cdot\left(\frac{a}{\omega}\right)^{3} \cdot y_{\omega}(0) \quad \cdot e^{\omega \cdot\left(\xi+\frac{7}{8}\right)} \cdot\left(e^{\omega \cdot\left(\xi+\frac{7}{8}\right)}-1\right)^{3} \cdot\left(e^{8 \cdot \omega \cdot\left(\xi+\frac{7}{8}\right)}+3 \cdot e^{3 \cdot \omega \cdot\left(\xi+\frac{7}{8}\right)}+6 \cdot e^{2 \cdot \omega \cdot\left(\xi+\frac{7}{8}\right)}+10 \cdot e^{8 \cdot \omega \cdot\left(\xi+\frac{7}{8}\right)}+8\right)
\end{aligned}
$$

Vrijednosti funkcije $\operatorname{Eup}(\xi, \omega)$ u prethodnim izrazima određuju se pomoću (5.65), dok se koeficijenti uz njih mogu napisati u općem obliku:

$$
\begin{aligned}
A_{j k}=\left(\frac{a_{\omega}}{\omega}\right)^{j} & \frac{1}{\prod_{i=0}^{j-1}\left(2^{i+1}-1\right)} \sum_{m=0}^{j}(-1)^{m} \cdot 2^{m \cdot(m-1) / 2} \\
& \cdot \prod_{i=0}^{m-1} \frac{2^{-i}\left(2^{j}-2^{i}\right)}{2^{i+1}-1} \cdot e^{\omega \cdot 2^{j-m} \cdot\left(x+\left(2^{k}-1\right) / 2^{k}\right)}
\end{aligned}
$$

pa je izraz za izračunavanje vrijednosti funkcije $\operatorname{Eup}(\xi, \omega)$ u proizvoljnoj točki slijedeći:

$$
y_{\omega}(\xi)=\sum_{k=0}^{\infty}(-1)^{p_{0}+p_{1}+\ldots+p_{k}+1} \cdot p_{k} \cdot e^{\omega \cdot\left(p_{0}+p_{1}+\ldots+p_{k}-1\right)} \sum_{j=0}^{k} A_{j k} \cdot y_{\omega}\left(-1+\frac{1}{2^{k-j}}\right)
$$

Ako se proizvoljna točka prikaže u binarnom obliku $\xi=p_{0} p_{1} \ldots p_{k}$ gdje su $p_{0}, p_{1}, \ldots, p_{k}$ znamenke 0 ili 1 binarnog razvoja vrijednosti koordinate $\xi$, onda točnost funkcije $\operatorname{Eup}(\xi, \omega)$ u proizvoljnoj točki ovisi o točnosti elektroničkog računala. Za taj nivo točnosti potreban je vrlo mali broj članova reda.

Primjenom izraza (5.17) - (5.19) na (5.74) izveden je izraz za derivaciju $n$-tog reda funkcije $\operatorname{Eup}(\xi, \omega)$ u proizvoljnoj točki oblika:

$$
y_{\omega}^{(n)}(\xi)=\sum_{i=0}^{n} \omega^{n-i} \cdot D_{r}^{(i-1)} \cdot 2^{i \cdot(i-1) / 2} \cdot y_{\omega}\left(2^{i} \cdot \xi-2 \cdot r+2^{i}+1\right) \cdot \prod_{k=0}^{i-1} \frac{\left(2^{n-k}-1\right)}{2^{k+1}-1}
$$

gdje je $n$ red derivacije, $D_{r}^{(-1)}=1$ po definiciji, dok su koeficijenti $D_{r}^{(i)}$ određeni izrazima (5.18) i (5.19), a $r$ je cjelobrojna vrijednost određena sa 


$$
r=\operatorname{INT}\left[(\xi+1) \cdot 2^{i-1}+1\right]
$$

\subsection{Momenti funkcije $\operatorname{Eup}(\xi, \omega)$}

Fourierova transformacija funkcije $\operatorname{Eup}(\xi, \omega)$ određena je izrazom (5.5)

$$
F(t)=\prod_{j=1}^{\infty} \frac{\omega}{2 \operatorname{sh}(\omega / 2)} \frac{\operatorname{sh}\left(\omega / 2+i \cdot t / 2^{j}\right)}{\omega / 2+i \cdot t / 2^{j}}
$$

odnosno

$$
F(t)=\int_{-\infty}^{\infty} e^{i t \xi} \cdot y_{\omega}(\xi) d \xi
$$

Deriviranjem Fourierove transformacije (5.78) po ' $t$ ' dobije se

$$
F^{\prime}(t)=i \cdot \int_{-\infty}^{\infty} \xi \cdot e^{i t \xi} \cdot y_{\omega}(x) d \xi
$$

Za vrijednost FT u točki $t=0$ slijedi

$$
F^{\prime}(0)=i \cdot \underbrace{\int_{-1}^{1} \xi \cdot y_{\omega}(\xi) d \xi}_{a_{1}}
$$

Uzastopnim deriviranjem izraza (5.78) po ' $t$ ', te izračunavajući vrijednost dobivenog izraza u $t=0$, slijedi

$$
F_{0}^{(n)}=i^{n} \int_{-\infty}^{\infty} \xi^{n} \cdot y_{\omega}(\xi) d \xi=i^{n} \cdot a_{n}
$$

Primjenjujući isti postupak na FT u obliku (5.77), dobiva se:

$$
F_{0}^{(n)}=-\frac{i \cdot n}{\omega} \cdot F_{0}^{(n-1)}+\sum_{j=1}^{n} \frac{C_{n}^{j} \cdot F_{0}^{(n-j)} \cdot i^{j}}{2^{n+1} \cdot \operatorname{sh}(\omega / 2)} \cdot\left[e^{\omega / 2}+(-1)^{j+1} e^{-\omega / 2}\right]
$$

Uspoređivanjem izraza (5.79) i (5.80) vidljivo je da su lijeve strane jednadžbi međusobno jednake, pa prema tome moraju biti međusobno jednake i desne strane, iz čega konačno slijedi rekurzivna formula za izračunavanje momenata funkcije $\operatorname{Eup}(\xi, \omega)$

$$
\begin{aligned}
& a_{0}=1 \\
& a_{n}=\frac{n !}{2^{n}-1} \cdot \sum_{j=1}^{n} \frac{a_{n-j}}{(n-j) ! \cdot j ! \operatorname{sh}(\omega / 2)} \cdot\left[\frac{e^{\omega / 2}+(-1)^{j+1} e^{-\omega / 2}}{2}\right]-\frac{n \cdot 2^{n}}{2^{n}-1} \cdot \frac{a_{n-1}}{\omega}
\end{aligned}
$$


Prema (5.81), na primjer, prva tri momenta imaju sljedeće vrijednosti napisane u općem obliku:

$$
\begin{aligned}
a_{1}= & \frac{1}{\omega} \cdot a_{0} \cdot[\omega \cdot \operatorname{cth}(\omega / 2)-2] \\
a_{2}= & \frac{1}{3 \omega^{2}} \cdot\left[2 \cdot \omega \cdot a_{1} \cdot(\omega \cdot \operatorname{cth}(\omega / 2)-2)+a_{0} \cdot\left(\omega^{2}-4 \omega \cdot \operatorname{cth}(\omega / 2)+8\right)\right] \\
a_{3}= & \frac{1}{7 \omega^{3}} \cdot\left[3 \cdot \omega^{2} \cdot a_{2} \cdot(\omega \cdot \operatorname{cth}(\omega / 2)-2)+3 \omega \cdot a_{1} \cdot\left(\omega^{2}-4 \omega \cdot \operatorname{cth}(\omega / 2)+8\right)+\right. \\
\quad & \left.\quad a_{0} \cdot\left(\omega^{3} \cdot \operatorname{cth}(\omega / 2)-6 \omega^{2}+24 \omega \cdot \operatorname{cth}(\omega / 2)-48\right)\right]
\end{aligned}
$$

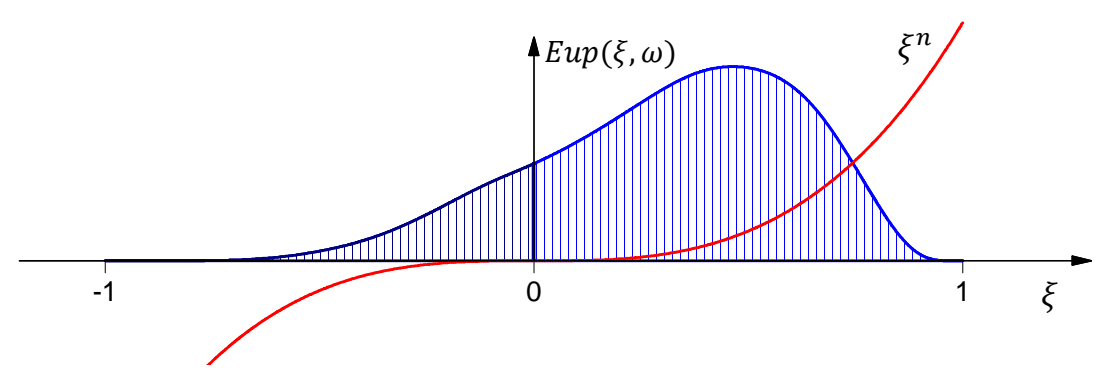

Crtež 5.10 Skalarni produkt funkcije $\operatorname{Eup}(\xi, \omega)$ i algebarskog monoma $\xi^{n}$

Međutim, po formuli (5.81) nije moguće izračunati pomoćne momente funkcije $\operatorname{Eup}(\xi, \omega)$, odnosno skalarne produkte funkcije $\operatorname{Eup}(\xi, \omega)$ i algebarskog monoma $\xi^{n}$ na samo pozitivnom, odnosno negativnom dijelu realne osi. U tu svrhu potrebno je FT funkcije $\operatorname{Eup}(\xi, \omega)$ napisati u obliku prema $(5.7), \mathrm{tj} .:$

$$
F(t)=\frac{\omega}{2 \operatorname{sh}(\omega / 2)} \cdot \frac{e^{(\omega+i t) / 2}-e^{-(\omega+i t) / 2}}{\omega+i \cdot t} F(t / 2)
$$

Ukoliko se desnoj strani jednadžbe (5.82) doda i oduzme izraz $\lambda_{0}(\omega) /(\omega+i t)$, Fourierova transformacija se može napisati u obliku:

$$
F(t)= \pm \frac{\lambda_{0}(\omega)}{\omega+i \cdot t} \mp \frac{\omega}{2 \operatorname{sh}(\omega / 2)} \cdot \frac{e^{\mp(\omega+i t) / 2}}{\omega+i \cdot t} \cdot F(t / 2)
$$

gdje je $\lambda_{0}(\omega)$ vrijednost funkcije $\operatorname{Eup}(\xi, \omega)$ u ishodištu definirana izrazom (5.57). Koristeći (5.79) i (5.83) pomoćni moment se može napisati u obliku:

$$
a_{n}^{\mp}=\frac{1}{i^{n}} \cdot \underbrace{\left.\frac{d^{n}}{d t^{n}}\left\{ \pm \frac{\lambda_{0}(\omega)}{\omega+i \cdot t} \mp \frac{\omega}{2 s h(\omega / 2)} \cdot \frac{e^{\mp(\omega+i t) / 2}}{\omega+i \cdot t} \cdot F(t / 2)\right\}\right|_{t=0}}_{F_{0}^{(n)}}
$$

Za $n=0$ iz (5.84) dobiva se izravno:

$$
a_{0}^{\mp}= \pm \frac{\lambda_{0}(\omega)}{\omega} \mp \frac{e^{\mp \omega / 2}}{2 \operatorname{sh}(\omega / 2)}
$$


ili odvojeno na pozitivnom i negativnom dijelu koordinatne osi:

$$
\begin{array}{ll}
a_{0}^{-}=\frac{\lambda_{0}(\omega)}{\omega}-\frac{e^{-\omega / 2}}{2 \operatorname{sh}(\omega / 2)} & \text { na odsječku }[-1,0] \\
a_{0}^{+}=-\frac{\lambda_{0}(\omega)}{\omega}+\frac{e^{\omega / 2}}{2 \operatorname{sh}(\omega / 2)} \quad \text { na odsječku }[0,1]
\end{array}
$$

Također, za na primjer $n=1$, slijedi

$$
\begin{aligned}
a_{1}^{\mp} & =\frac{1}{i} \cdot \frac{d}{d t}\left\{ \pm \frac{\lambda_{0}(\omega)}{\omega+i \cdot t} \mp \frac{\omega}{2 \operatorname{sh}(\omega / 2)} \cdot \frac{e^{\mp(\omega+i t) / 2}}{\omega+i \cdot t} \cdot F(t / 2)\right\}=\cdots= \\
& =\mp \frac{\omega}{2 \operatorname{sh}(\omega / 2)} \cdot\left[\mp \frac{\omega-2}{2 \omega^{2}} \cdot e^{\mp \omega / 2} \cdot a_{0}+\frac{e^{\mp \omega / 2}}{2 \omega} \cdot a_{1}\right]
\end{aligned}
$$

ili odvojeno na pozitivnom i negativnom dijelu koordinatne osi:

$$
\begin{aligned}
& a_{1}^{-}=\frac{a_{1} \omega-a_{0}(\omega+2)}{2 \omega\left(1-e^{\omega}\right)} \quad \text { na lijevoj polovici nosača }[-1,0] \\
& a_{1}^{+}=\frac{a_{1} \omega+a_{0}(\omega-2)}{2 \omega\left(1-e^{\omega}\right)} \quad \text { na desnoj polovici nosača }[0,1]
\end{aligned}
$$

Prvi pribrojnik u vitičastim zagradama iz (5.84) uzastopnim deriviranjem po ' $t$ ', te uvrštavajući $t=0$ može se napisati u obliku:

$$
\pm(-1)^{n} \cdot \frac{n ! \lambda_{0}(\omega)}{\omega^{n+1}}
$$

$\mathrm{Na}$ isti način dobije se i opći oblik drugog pribrojnika u vitičastim zagradama:

$$
\frac{n !}{2^{n}\left(1-e^{ \pm \omega}\right)} \cdot \sum_{j=0}^{n}(\mp 1)^{j} \frac{a_{n-j}}{\omega^{j}(n-j) !} \cdot \sum_{k=0}^{j} \frac{(\mp 1)^{k} \cdot 2^{k} \cdot \omega^{j-k}}{(j-k) !}
$$

tako da konačni oblik formule za izračunavanje pomoćnih momenata funkcije $\operatorname{Eup}(\xi, \omega)$ ima sljedeći oblik:

$$
\begin{gathered}
a_{n}^{\mp}= \pm(-1)^{n} \frac{n ! \lambda}{\omega^{n+1}}+\frac{n !}{2^{n}\left(1-e^{ \pm \omega}\right) !} \cdot \sum_{j=0}^{n}(\mp 1)^{j} \frac{a_{n-j}}{\omega^{j}(n-j) !} \cdot \sum_{k=0}^{j} \frac{(\mp)^{k} 2^{k} \cdot \omega^{j-k}}{(j-k) !} \\
a_{n}=a_{n}^{-}+a_{n}^{+}
\end{gathered}
$$

gdje $a_{n}^{-}$predstavlja pomoćni moment na negativnom dijelu nosača funkcije tj. na $[-1,0] \mathrm{i}$ uzima gornji predznak iz (5.87), dok $a_{n}^{+}$predstavlja pomoćni moment na pozitivnom dijelu nosača funkcije tj. na $[0,1]$ i uzima donji predznak.

U Tablici 5.2 prikazani su nulti i prva četiri momenta funkcije $\operatorname{Eup}(\xi, \omega)$ za $\omega=1$. 
Tablica 5.2 Nulti i prva četiri momenta funkcije $\operatorname{Eup}(\xi, \omega)$ za $\omega=1$

\begin{tabular}{|c|c|c|c|}
\hline $\mathrm{n}$ & $a_{n}$ & $a_{n}^{-}$ & $a_{n}^{+}$ \\
\hline 0 & 1.0000000000 & 0.3139324065 & 0.6860675935 \\
\hline 1 & 0.1639534138 & -0.0706525869 & 0.2346060007 \\
\hline 2 & 0.1326492626 & 0.02421983577 & 0.1084294272 \\
\hline 3 & 0.0476245466 & -0.0102088235 & 0.0578333693 \\
\hline 4 & 0.0386202666 & 0.0048980515 & 0.0337222177 \\
\hline
\end{tabular}

\subsection{Derivacije funkcije $\operatorname{Eup}(\xi, \omega)$ u karakterističnim točkama po parametru $\omega$}

U pojedinim numeričkim metodama javlja se potreba izračunavanja derivacija bazne funkcije $\operatorname{Eup}(\xi, \omega)$ po parametru $\omega$.

Vrijednosti funkcije $\operatorname{Eup}(\xi, \omega)$ izražavaju se u obliku umnoška pripadajuće eksponencijalne funkcije $f_{\xi}(\omega)$ i vrijednosti bazne funkcije u ishodištu $\lambda_{0}(\omega)$ (kao što se vidi u izrazu (5.64) u točkama $\left.\xi_{k}=k / 4, k=-3, \ldots, 3\right)$ te se općenito može napisati:

$$
\operatorname{Eup}(\xi, \omega)=f_{\xi}(\omega) \cdot \lambda_{0}(\omega)
$$

Prva derivacija funkcije $\operatorname{Eup}(\xi, \omega)$ po parametru $\omega$ izražene prema (5.88) određuje se jednostavno pomoću pravila za derivaciju umnoška funkcija, tj.

$$
\frac{\partial \operatorname{Eup}(\xi, \omega)}{\partial \omega}=\frac{\partial f_{\xi}(\omega)}{\partial \omega} \cdot \lambda_{0}(\omega)+f_{\xi}(\omega) \cdot \frac{\partial \lambda_{0}(\omega)}{\partial \omega}
$$

Druga derivacija funkcije $\operatorname{Eup}(\xi, \omega)$ po parametru $\omega$ dobije se deriviranjem izraza (5.89)

$$
\frac{\partial^{2} \operatorname{Eup}(\xi, \omega)}{\partial^{2} \omega}=\frac{\partial^{2} f_{\xi}(\omega)}{\partial^{2} \omega} \cdot \lambda_{0}(\omega)+2 \cdot \frac{\partial f_{\xi}(\omega)}{\partial \omega} \cdot \frac{\partial \lambda_{0}(\omega)}{\partial \omega}+f_{\xi}(\omega) \cdot \frac{\partial^{2} \lambda_{0}(\omega)}{\partial^{2} \omega}
$$

i tako redom.

Derivacije $\partial^{m} f_{\xi}(\omega) / \partial^{m} \omega, m=1,2, \ldots$ lako se određuju uz korištenje nekog od programskih paketa npr. Derive ili Mathematica, dok se derivacije vrijednosti $\lambda_{0}(\omega)$ po parametru $\omega$ izračunavaju kako slijedi.

Vrijednost $\lambda_{0}(\omega)$ je jedina vrijednost izražena u obliku otvorenog produkta (5.57) i (5.56) i jedina vrijednost koju se mora prethodno numerički izračunati. Ako se izrazi u obliku eksponencijalne funkcije tada ona ima sljedeći oblik: 


$$
\lambda_{0}(\omega)=\frac{\omega \cdot e^{\omega / 2}}{e^{\omega}-1} \prod_{j=1}^{\infty} \frac{2^{j} \cdot e^{-\omega \cdot 2^{-j-1}} \cdot\left(e^{\omega \cdot 2^{-j}}-e^{\omega}\right)}{\left(1-e^{\omega}\right) \cdot\left(2^{j}-1\right)}
$$

Derivacije vrijednosti $\lambda_{0}(\omega)$ po parametru $\omega$ također se određuju pomoću pravila za derivaciju umnoška funkcija. Ako se pojedini faktor u produktu (5.91) zbog preglednosti označi sa $f_{j}(\omega)$

$$
\lambda_{0}(\omega)=\frac{\omega \cdot e^{\omega / 2}}{e^{\omega}-1} \cdot \prod_{j=1}^{\infty} f_{j}(\omega)
$$

onda je prva derivacija produkta kako slijedi:

$$
\begin{aligned}
& \left(\frac{\partial f_{1}}{\partial \omega}\right) \cdot\left(f_{2}\right) \cdot\left(f_{3}\right) \cdots+\left(f_{1}\right) \cdot\left(\frac{\partial f_{2}}{\partial \omega}\right) \cdot\left(f_{3}\right) \cdot \cdots+\left(f_{1}\right) \cdot\left(f_{2}\right) \cdot\left(\frac{\partial f_{3}}{\partial \omega}\right) \cdots+\cdots \\
& =\left(f_{1}\right) \cdot\left(f_{2}\right) \cdot\left(f_{3}\right) \cdot \cdots \cdot\left[\frac{\left(\frac{\partial f_{1}}{\partial \omega}\right)}{\left(f_{1}\right)}+\frac{\left(\frac{\partial f_{2}}{\partial \omega}\right)}{\left(f_{2}\right)}+\frac{\left(\frac{\partial f_{3}}{\partial \omega}\right)}{\left(f_{3}\right)}+\cdots\right] \\
& =\left(\prod_{j=1}^{\infty} f_{j}\right) \cdot\left(\sum_{j=1}^{\infty} \frac{\partial f_{j}}{\frac{\partial \omega}{f_{j}}}\right)
\end{aligned}
$$

Nakon sređivanja konačan izraz za prvu derivaciju vrijednosti $\lambda_{0}(\omega)$ po parametru $\omega$ je:

$$
\frac{\partial \lambda_{0}(\omega)}{\partial \omega}=\left[\varphi_{1}(\omega)+\varphi_{2}(\omega)\right] \cdot \lambda_{0}(\omega)
$$

gdje je

$$
\begin{aligned}
& \varphi_{1}(\omega)=\frac{e^{\omega} \cdot(\omega-2)+\omega+2}{2 \cdot \omega \cdot\left(1-e^{\omega}\right)} \\
& \varphi_{2}(\omega)=\sum_{j=1}^{\infty} \frac{2^{-j-1} \cdot\left(e^{\omega \cdot 2^{-j}} \cdot\left(2^{j+1} \cdot e^{\omega}-e^{\omega}+1\right)-2^{j+1} \cdot e^{\omega}-e^{2 \omega}+e^{\omega}\right)}{\left(1-e^{\omega}\right) \cdot\left(e^{\omega \cdot 2^{-j}}-e^{\omega}\right)}
\end{aligned}
$$

Izraz za drugu derivaciju vrijednosti $\lambda_{0}(\omega)$ po parametru $\omega$ određuje se na analogan način:

$$
\frac{\partial^{2} \lambda_{0}(\omega)}{\partial^{2} \omega}=\left\{\psi_{1}(\omega)+\psi_{2}(\omega)+\left[\psi_{3}(\omega)+\psi_{4}(\omega)\right]^{2}\right\} \cdot \lambda_{0}(\omega)
$$

gdje je

$$
\begin{aligned}
& \psi_{1}(\omega)=-\frac{e^{2 \cdot \omega}-e^{\omega} \cdot\left(\omega^{2}+2\right)+1}{\omega^{2} \cdot\left(e^{\omega}-1\right)^{2}} \\
& \psi_{2}(\omega)=\sum_{j=1}^{\infty} \frac{2^{-2 j} e^{\omega}\left(2^{2 j} e^{\omega \cdot 2^{1-n}}-e^{\omega \cdot 2^{-n}}\left(2^{2 j}\left(e^{2 \omega}+1\right)-2^{j+1}\left(e^{2 \omega}-2 e^{\omega}+1\right)+e^{2 \omega}-2 e^{\omega}+1\right)+e^{\omega}+2^{2 j} e^{2 \omega}\right)}{\left(e^{\omega \cdot 2^{-n}}-e^{\omega}\right)^{2} \cdot\left(e^{\omega}-1\right)^{2}} \\
& \psi_{3}(\omega)=\varphi_{1}(\omega) \\
& \psi_{4}(\omega)=\varphi_{2}(\omega)
\end{aligned}
$$


Analogno se određuje i ostali red derivacije.

$\mathrm{Na}$ crtežu 5.11 dana je grafička interpretacija ovisnosti vrijednosti $\lambda_{0}(\omega)$ kao i njenih prvih dviju derivacija o parametru $\omega$.

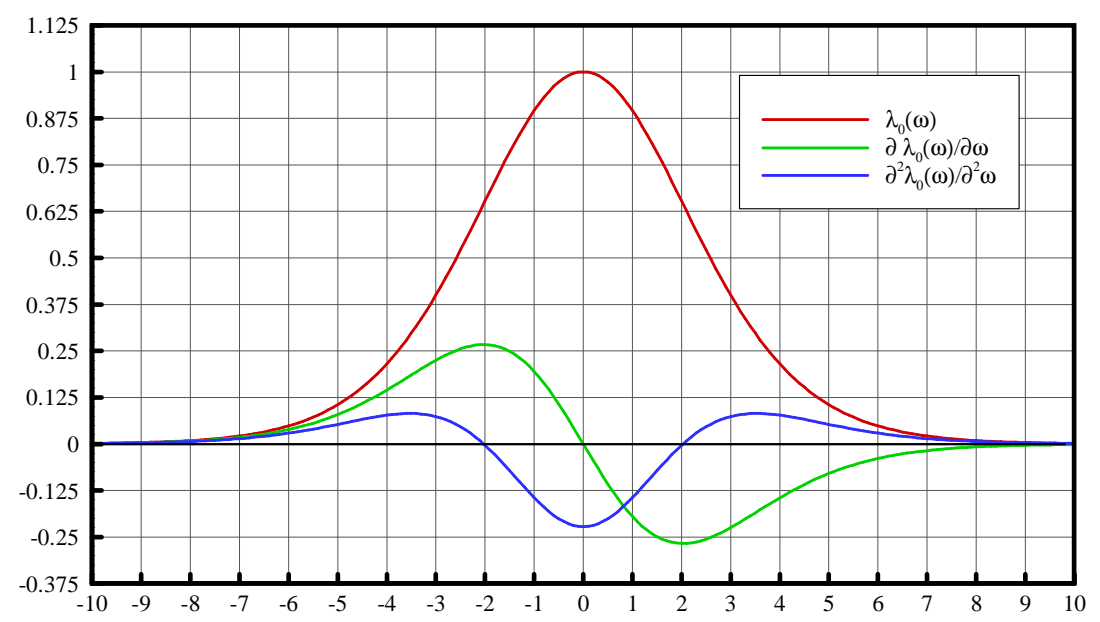

$\omega$

Crtež 5.11 Ovisnost vrijednosti $\lambda_{0}(\omega)$ i njenih prvih dviju derivacija o parametru $\omega$

U realnom području koordinate $x$ prva i druga derivacija funkcije $\operatorname{Eup}(x, \omega)$ po parametru $\omega \mathrm{su}$

$$
\begin{aligned}
\frac{\partial \operatorname{Eup}\left(x, \omega \cdot \Delta x_{0}\right)}{\partial \omega}= & {\left[\frac{1}{\Delta x_{0}} \cdot \frac{\partial f_{\xi}\left(\omega \cdot \Delta x_{0}\right)}{\partial \omega} \cdot \lambda_{0}\left(\omega \cdot \Delta x_{0}\right)+\frac{1}{\Delta x_{0}} \cdot f_{\xi}\left(\omega \cdot \Delta x_{0}\right) \cdot \frac{\partial \lambda_{0}\left(\omega \cdot \Delta x_{0}\right)}{\partial \omega}\right] \cdot \Delta x_{0} } \\
\frac{\partial^{2} \operatorname{Eup}\left(x, \omega \cdot \Delta x_{0}\right)}{\partial^{2} \omega}= & {\left[\frac{1}{\Delta x_{0}} \cdot \frac{\partial^{2} f_{\xi}\left(\omega \cdot \Delta x_{0}\right)}{\partial^{2} \omega} \cdot \lambda_{0}\left(\omega \cdot \Delta x_{0}\right)+\right.} \\
& \left.+2 \cdot \frac{1}{\Delta x_{0}} \cdot \frac{\partial f_{\xi}\left(\omega \cdot \Delta x_{0}\right)}{\partial \omega} \cdot \frac{\partial \lambda_{0}\left(\omega \cdot \Delta x_{0}\right)}{\partial \omega}+\frac{1}{\Delta x_{0}} \cdot f_{\xi}\left(\omega \cdot \Delta x_{0}\right) \cdot \frac{\partial^{2} \lambda_{0}\left(\omega \cdot \Delta x_{0}\right)}{\partial^{2} \omega}\right] \cdot \Delta x_{0}{ }^{2}
\end{aligned}
$$

gdje je

$$
\begin{aligned}
& \frac{\partial \lambda_{0}\left(\omega \cdot \Delta x_{0}\right)}{\partial \omega}=\left[\varphi_{1}\left(\omega \cdot \Delta x_{0}\right)+\varphi_{2}\left(\omega \cdot \Delta x_{0}\right)\right] \cdot \lambda_{0}\left(\omega \cdot \Delta x_{0}\right) \\
& \frac{\partial^{2} \lambda_{0}\left(\omega \cdot \Delta x_{0}\right)}{\partial^{2} \omega}=\left\{\psi_{1}\left(\omega \cdot \Delta x_{0}\right)+\psi_{2}\left(\omega \cdot \Delta x_{0}\right)+\left[\psi_{3}\left(\omega \cdot \Delta x_{0}\right)+\psi_{4}\left(\omega \cdot \Delta x_{0}\right)\right]^{2}\right\} \cdot \lambda_{0}\left(\omega \cdot \Delta x_{0}\right)
\end{aligned}
$$

Primjer. Izračunati vrijednosti prve i druge derivacije funkcije $\operatorname{Eup}(\xi, \omega)$ po parametru $\omega$ $\mathrm{u}$ točki $\xi=1 / 2 \mathrm{u}$ realnom području koordinate $x$ ako je $\omega=4.7$ i $\Delta x_{0}=0.25$.

Vrijednost funkcije u točki $\xi=1 / 2$ izrazi se u obliku umnoška eksponencijalne funkcije i vrijednosti $\lambda_{0}(\omega)$ kao u izrazu (5.88)

$$
f_{1 / 2}\left(\omega \cdot \Delta x_{0}\right)=\frac{e^{\omega \cdot \Delta x_{0}}}{e^{\omega \cdot \Delta x_{0} / 2}+1}=1.15669275288743
$$

gdje su potrebne derivacije 


$$
\begin{aligned}
& \frac{\partial f_{1 / 2}\left(\omega \cdot \Delta x_{0}\right)}{\partial \omega}=\frac{e^{\omega \cdot \Delta x_{0}} \cdot\left(e^{\omega \cdot \Delta x_{0} / 2}+2\right)}{2 \cdot\left(e^{\omega \cdot \Delta x_{0} / 2}+1\right)^{2}}=0.784936719703322 \\
& \frac{\partial^{2} f_{1 / 2}\left(\omega \cdot \Delta x_{0}\right)}{\partial^{2} \omega}=\frac{e^{\omega \cdot \Delta x_{0}} \cdot\left(e^{\omega \cdot \Delta x_{0}}+3 e^{\omega \cdot \Delta x_{0} / 2}+4\right)}{4 \cdot\left(e^{\omega \cdot \Delta x_{0} / 2}+1\right)^{3}}=0.466264222792068
\end{aligned}
$$

te

$$
\begin{aligned}
& \frac{\partial \lambda_{0}\left(\omega \cdot \Delta x_{0}\right)}{\partial \omega}=-0.217942978567028 \\
& \frac{\partial^{2} \lambda_{0}\left(\omega \cdot \Delta x_{0}\right)}{\partial^{2} \omega}=-0.119506056043847
\end{aligned}
$$

Uvrštavanjem izračunatih vrijednosti u (5.98) dobije se

$$
\begin{aligned}
& \frac{\partial \operatorname{Eup}\left(\xi, \omega \cdot \Delta x_{0}\right)}{\partial \omega}=0.422738441825604 \\
& \frac{\partial^{2} \operatorname{Eup}\left(\xi, \omega \cdot \Delta x_{0}\right)}{\partial^{2} \omega}=-0.019878653362734
\end{aligned}
$$

U Tablici 5.3 dani su koeficijenti za vrijednosti nulte i prve dvije derivacije po parametru $\omega$ funkcije $\operatorname{Eup}(\xi, \omega)$ za $\omega=0$ u realnom području koordinate $x$ u točkama $x=-1+$ $k / 4, k=1, \ldots, 7$.

Tablica 5.3 Koeficijenti za izračun nulte i prve dvije derivacije funkcije $\operatorname{Eup}(x, \omega)$ po parametru $\omega$ za $\omega=0$

\begin{tabular}{|c||c|c|c|}
\hline & $y_{\mathbf{0}}(\boldsymbol{x})=\boldsymbol{C}_{\mathbf{0}} /\left(\Delta \boldsymbol{x}_{\mathbf{0}} \cdot \mathbf{7 2}\right)$ & $\partial y_{\mathbf{0}}(\boldsymbol{x}) / \partial \omega=\boldsymbol{C}_{\mathbf{1}} / \mathbf{2 8 8}$ & $\partial^{2} y_{\mathbf{0}}(\boldsymbol{x}) / \partial^{2} \omega=C_{\mathbf{2}} \cdot \Delta \boldsymbol{x}_{\mathbf{0}} / \mathbf{2 0 7 3 6}$ \\
\hline $\boldsymbol{x}$ & $\boldsymbol{C}_{\mathbf{0}}$ & $\boldsymbol{C}_{\mathbf{1}}$ & $\boldsymbol{C}_{\mathbf{2}}$ \\
\hline $\mathbf{- 3 / 4}$ & 5 & -29 & 2509 \\
\hline $\mathbf{- 1 / 2}$ & 36 & -108 & -3085 \\
\hline $\mathbf{- 1 / 4}$ & 67 & -81 & -4608 \\
\hline $\mathbf{0}$ & 72 & 0 & -3085 \\
\hline $\mathbf{1 / 4}$ & 67 & 81 & 2880 \\
\hline $\mathbf{1} / \mathbf{2}$ & 36 & 108 & 2509 \\
\hline $\mathbf{3 / 4}$ & 5 & 29 & \\
\hline
\end{tabular}




\subsection{Primjena ABF $\operatorname{Eup}(x, \omega)$}

\subsubsection{Raspored baznih funkcija}

ABF eksponencijalnog tipa u odnosu na bazne funkcije algebarskog tipa sadrže i parametar $\omega$, ili analogno trigonometrijskim funkcijama, frekvenciju.

Vektorski prostor $E U P_{n}$ kojega tvore $\mathrm{ABF} \operatorname{Eup}(x, \omega)$ s kompaktnim nosačem $\operatorname{supp} \operatorname{Eup}(x, \omega)=\left[-\Delta x_{0}, \Delta x_{0}\right]$ ima stanovite sličnosti sa vektorskim prostorom trigonometrijskih funkcija. Razvoj jedinice u oba prostora moguć je samo u slučaju $\omega_{0}=0$, pri čemu je općenito

$$
\omega \in\left\{\omega_{k}\right\}, \quad k \in Z
$$

Funkcija $\sinh (\omega, \mathrm{x})=\left(e^{\omega \mathrm{x}}-e^{-\omega \mathrm{x}}\right) / 2$ sastavljena je od eksponencijalne funkcije $\mathrm{s}$ pozitivnom i negativnom frekvencijom. Dakle, i vektorski prostor koji sadrži funkciju $\sinh (\omega, \mathrm{x})$ mora također sadržavati bazne funkcije s pozitivnom i negativnom frekvencijom, crtež 5.12b).

Negativnim vrijednostima frekvencija pridružuju se neparni indeksi, a pozitivnim frekvencijama parni. Približenje zadanoj funkciji $f(x), x \in[A, B]$, pri čemu je područje $\mathrm{AB}$ podijeljeno na $n$ odsječaka duljine $\Delta x_{0}$, može se opisati pomoću linearne kombinacije baznih funkcija $\operatorname{Eup}\left(x /\left(2^{k} \Delta x_{k}\right)-i / 2^{k}, \omega_{k}\right)$ međusobno pomaknutih za $\Delta x_{k}=\Delta x_{0} / 2^{k}$ u obliku:

$$
f(x)=\sum_{i=1-2^{k}}^{n * 2^{k+1}-1} C_{i}^{(k)} \cdot \operatorname{Eup}\left(\frac{x}{2^{\mathrm{k}} \Delta \mathrm{x}_{\mathrm{k}}}-\frac{\mathrm{i}}{2^{\mathrm{k}}}, \omega_{\mathrm{k}}\right), \quad \mathrm{k}=0,1,2, \ldots
$$

Ukoliko je $k$ konačan, tada se funkcija $f(x)$ aproksimira tako da se iz odabrane inicijalne vrijednosti $\Delta x$ odredi duljina odsječaka $\Delta x_{k}$ i uključi pripadajuća frekvencija $\omega_{k}$.

Obzirom da frekvencije $\omega_{k}, k=0,1,2, \ldots$ unaprijed nisu poznate, potrebno je odabrati kriterij i konstruirati postupak za izbor najbolje frekvencije.

Postignuta točnost aproksimacije $\varepsilon$ (razlika zadane funkcije $f(x)$ i približenja $\tilde{f}(x)$ ) uspoređuje se sa zadanom točnosti $\varepsilon^{*}$, prema sljedećem izrazu:

$$
\varepsilon=\|\mathrm{f}(\mathrm{x})-\tilde{\mathrm{f}}(\mathrm{x})\| \leq \varepsilon^{*}
$$

Numerički postupak se može realizirati na različite načine. Kod svakog načina se formira globalni sustav jednadžbi prema (5.100). Aproksimacija se može tražiti za odabrani broj baznih funkcija i pripadajuću frekvenciju. Drugi način se svodi na metodu residuua kod koje se rješava parcijalni doprinos pojedine frekvencije ukupnoj aproksimaciji, dakle sukcesivno se 
vrši aproksimacija razlike između zadane funkcije i tekućeg zbroja aproksimacija funkcija residuua.

$\mathrm{Na}$ crtežu 5.12b) prikazan je raspored baznih funkcija $\operatorname{Eup}\left(\frac{x}{2 \cdot \Delta x}-\frac{i}{2}, \pm \omega_{1}\right), i=-1$, $0,1,2,3$ za frekvenciju $\omega_{1}=\mp 0.4$ i duljinu karakterističnog odsječka $\Delta x_{1}=L / 2$.

Bazne funkcije su nagnute udesno ili ulijevo ovisno o predznaku frekvencije $\omega_{1}$. Ukoliko iznos frekvencije teži nuli, tada bazne funkcije postaju parne te odgovaraju ABF algebarskog tipa $u p\left(\frac{x}{2 \cdot \Delta x}-i / 2\right), i=-1,0,1,2,3$ prema crtežu 5.12a).
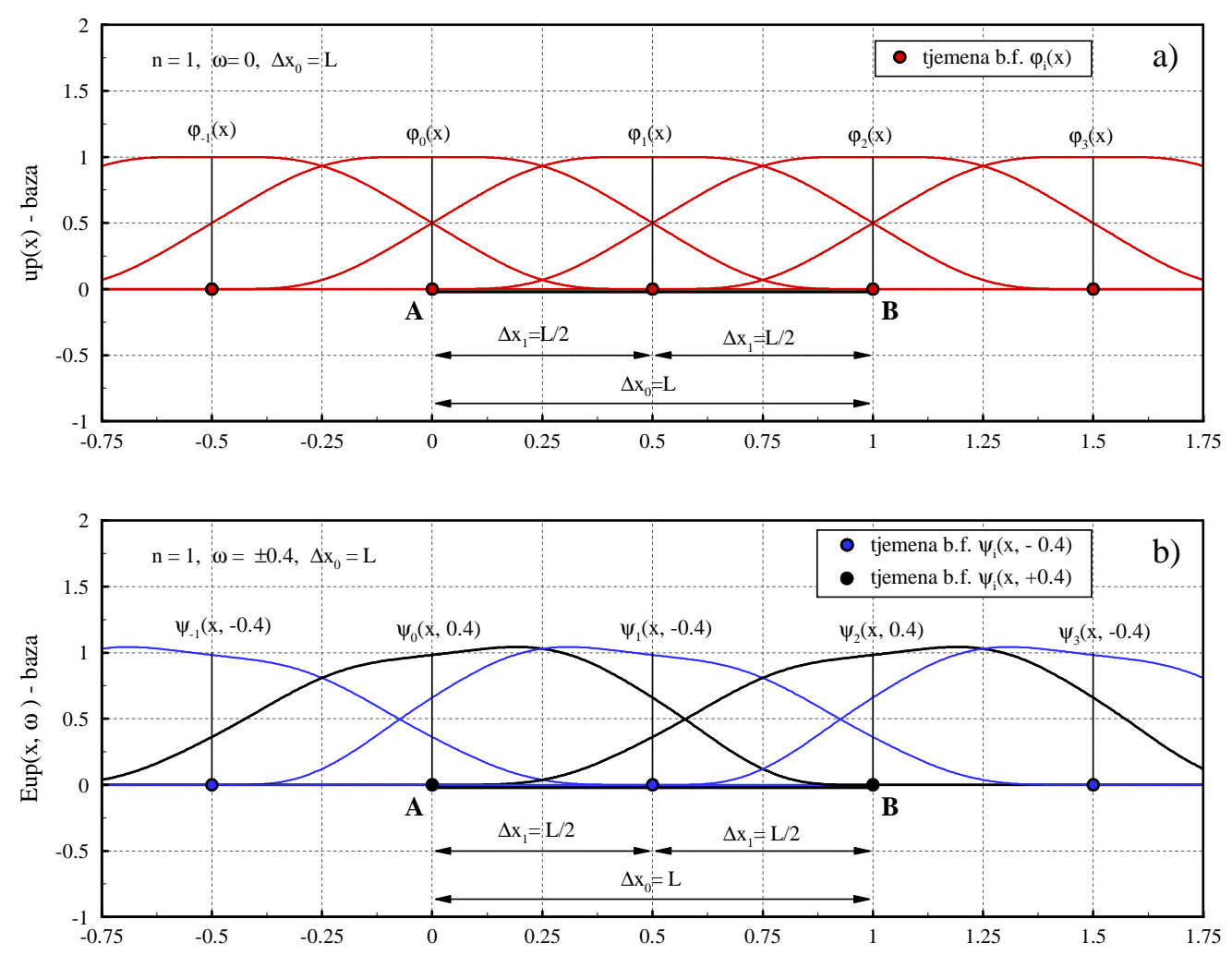

Crtež 5.12 Raspored baznih funkcija a) up $(x)$ i b) $\operatorname{Eup}\left(x, \omega_{1}\right)$

\subsubsection{Aproksimacija zadane eksponencijalne funkcije $e^{\omega x}$}

Neka je na odsječku $\overline{A B}$ zadana funkcija u obliku $f(x)=e^{10(x-1)}, x \in[0,1]$. Koristeći dva karakteristična odsječka $\Delta x$ i raspored baznih funkcija prema crtežu 5.12b) traže se pripadajuće aproksimacije. Iz zadane funkcije vidljivo je da ona ima eksponencijalni karakter i da frekvencija $\omega$ ima vrijednost 10 (samo pozitivne vrijednosti frekvencija).

Koristeći metodu kolokacije, izračunati su koeficijenti $C_{i}, i=-1,0,1,2,3$ linearnih kombinacija funkcija $u p\left(\frac{x}{2 \cdot \Delta x}-i / 2\right)$ i $\operatorname{Eup}\left(\frac{x}{2 \cdot \Delta x}-\frac{i}{2}, \omega=10\right)$ i prikazani su u sljedećoj tablici. 
Tablica $\quad 5.4 \quad$ Koeficijenti linearnih kombinacija baznih funkcija

\begin{tabular}{|l|l|l|l|l|l|}
\hline$C_{i} i$ & -1 & 0 & 1 & 2 & 3 \\
\hline \hline$C_{i}-$ Alg. & 0.2433 & 0.0 & -0.2433 & 0.5 & 1.2433 \\
\hline$C_{i}-$ Exp. & $\mathbf{0 . 0}$ & 0.0291 & $\mathbf{0 . 0}$ & 640.7983 & $\mathbf{0 . 0}$ \\
\hline
\end{tabular}

Na crtežu 5.13 vidljivo je preklapanje aproksimacije dobivene linearnom kombinacijom eksponencijalnih baznih funkcija sa zadanom funkcijom.

Vrijednosti koeficijenata $C_{i} \mathrm{~s}$ neparnim indeksima su nula (vidi Tablicu 5.4), jer pripadajuće bazne funkcije ne sudjeluju u aproksimaciji. Zadana funkcija ima samo pozitivnu frekvenciju, pa bazne funkcije s negativnom frekvencijom moraju ostati neutralne kako ne bi kvarile aproksimaciju. Aproksimacija algebarskim baznim funkcijama ima poznati oscilirajući karakter dok aproksimacija eksponencijalnim baznim funkcijama točno odgovara zadanoj funkciji.

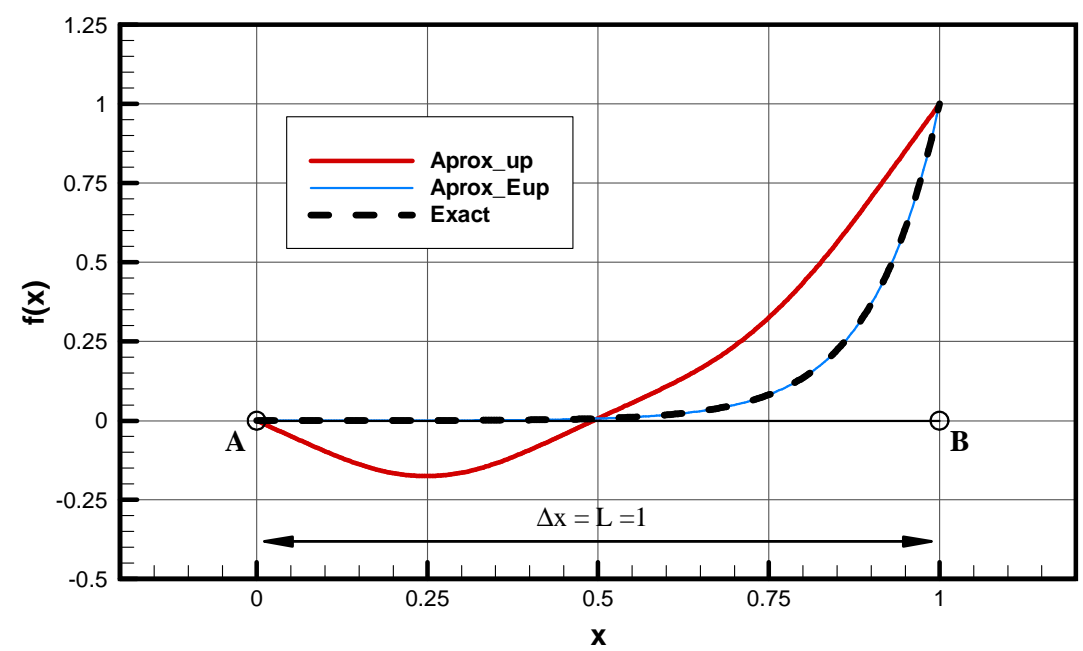

Crtež 5.13

Usporedba aproksimacija sa zadanom funkcijom koristeći algebraske i eksponencijalne bazne funckije s frekvencijom $\omega=10$.

Općenito, zadana funkcija koju treba aproksimirati može sadržavati frekvenciju koja unaprijed nije poznata po predznaku a niti po vrijednosti. Stoga je potrebno konstruirati postupak za određivanje frekvencije bazne funkcije $\operatorname{Eup}(\mathrm{x}, \omega)$ koja daje najbolju aproksimaciju.

\subsubsection{Određivanje najbolje frekvencije}

Aproksimacija zadane funkcije $f(x)$ traži se kolokacijskom metodom u obliku linearne kombinacije eksponencijalnih baznih funkcija koje sadrže nepoznatu frekvenciju $\omega$. 
Za određivanje najbolje frekvencije $\omega$ potrebno je izračunati svojstvene vrijednosti $\omega_{i}, i=1,2, \ldots, n$ matrice sustava. Na primjer, za zadanu funkciju $f(x)=-\operatorname{tgh}((x-3 / 4) / 0.02), x \in[0,4]$, za odabrani $\Delta x$ dobiva se pet jednadžbi, a svojstvene vrijednosti pripadajuće matrice koeficijenata su prikazane na crtežu 5.14.

Dakle, za određivanje frekvencije $\omega$ za koju se dobiva najbolja aproksimacija $\mathrm{u}$ određenom smislu mora se odabrati dodatni odgovarajući kriterij u fizikalnom ili nekom drugom smislu.

Ovdje je odabran kriterij metode najmanjih kvadrata odstupanja između zadane funkcije i njezine aproksimacije na svakom karakterističnom odsječku duljine $\Delta x$.

$$
\sum_{k=0}^{n-1} \int[f(x)-\tilde{f}(x)]^{2} d x=\min
$$

pri čemu je $f(x)$ zadana funkcija, $\tilde{f}(x)$ aproksimacija zadane funkcije, $n$ broj karakterističnih odsječaka $\Delta x$ na području $\overline{A B}$.

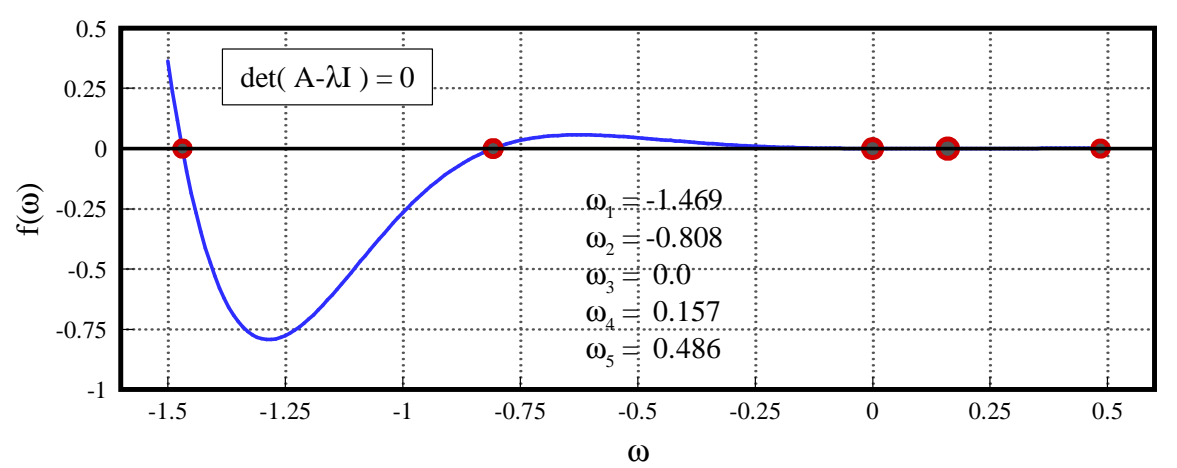

Crtež 5.14 Korijeni frekventne funkcije $\omega_{i}, i=1, \ldots, 5$

Korištenjem (5.101) provjeravaju se frekvencije $\omega_{i}, i=1, \ldots, 5$ i odabire se ona koja će dati najmanji kvadrat odstupanja.

U ovom radu odabran je manje ekonomičan, ali jednostavniji postupak. Općenito, kada zadana funkcija nije niti algebarski polinom niti eksponencijalna funkcija, tada se odabire korak frekvencije $\Delta \omega$ i počinjući od nule izračunava prema (5.101) vrijednost kvadrata odstupanja aproksimacije u odnosu na zadanu funkciju.

$\mathrm{Na}$ crtežu 5.15 vidljiv je oblik ovisnosti odstupanja o frekvenciji baznih funkcija. Prikazana zakonitost slična je u aproksimacijama različitih funkcija. Dakle, počinjući od nule odstupanje naglo počinje rasti i naglo opadati pri čemu se postižu lokalni minimumi.

Apsolutni minimum, ukoliko nije registriran kod $\omega=0$, javlja se u području veoma blage promjene kvadrata odstupanja ovisnog o frekvenciji $\omega$, kao što je prikazano na crtežu 5.14. 
Linearna kombinacija baznih funkcija $\operatorname{Eup}(\mathrm{x}, \omega)$ sa ovako izračunatom frekvencijom $\omega>0 \mathrm{u}$ pravilu daje bolju aproksimaciju od analognih atomskih funkcija algebarskog tipa.

Ukoliko je zadana funkcija $f(x)$ polinom $P_{1}(x)$, algoritam za određivanje najbolje frekvencije pronalazi vrijednost $\omega=0$, jer je tada kvadrat odstupanja $S N K \equiv 0$, što odgovara apsolutnom minimumu.

Također, za eksponencijalne polinome na primjer $f(x)=e^{10(x-1)}$ korištenim algoritmom dobiva se najbolja frekvencija $\omega=10$, jer je za nju $S N K \equiv 0$ što određuje apsolutni minimum kvadrata odstupanja aproksimacije $\tilde{f}(x)$ od zadane funkcije $f(x)$.

\subsubsection{Aproksimacija na jednolikom (uniformnom) gridu}

Analizira se funkcija $f(x)=\operatorname{TANGH}((x-4 / 3) / 0.02), x \in[0,4]$. Potrebno je naći aproksimaciju linearnom kombinacijom ABF algebarskog tipa u obliku:

$$
\tilde{f}(x)_{a l g}=\sum_{i=-1}^{2 n+1} C_{i} \cdot u p\left(\frac{x}{2 \cdot \Delta x}-\frac{i}{2}\right)
$$

te $\mathrm{ABF}$ eksponencijalnog tipa u obliku:

$$
\tilde{f}(x)_{\exp }=\sum_{i=-1}^{2 n+1} C_{i} \cdot \operatorname{Eup}\left(\frac{x}{2 \cdot \Delta x}-\frac{i}{2}, \omega_{n}\right)
$$

pri čemu je $n$ broj karakterističnih odsječaka na duljini područja $L=4.0$, indeks $i$ je brojač baznih funkcija i kolokacijskih točaka osim rubnih koje su dvostruke kolokacijske točke.

Numerički eksperiment je proveden za pet različitih duljina odsječaka $\Delta x=L / n$ gdje je $n=16,32,64,128,256$.

$\mathrm{Na}$ crtežu 5.15 u stupcu a1) - a5) uspoređena je zadana funkcija s pripadajućim aproksimacijama (5.102). U prve četiri varijante oscilacije aproksimacijske funkcije su iznimno izražene, a prisutne su čak i kod pete varijante za $\Delta x=L / 256$. Oscilacije se javljaju kod korištenja bilo kojih baznih funkcija algebarskog tipa.

Upravo taj negativni efekt se pokušava otkloniti korištenjem baznih funkcija eksponencijalnog tipa. U stupcu b1) - b5) na crtežu 5.15 prikazana je aproksimacija prema (5.103) za iste rezolucije kao i u stupcu a1) - a5). Vidljiva je neusporedivo bolja aproksimacija, međutim za svaku varijantu trebalo je prethodno odrediti najprikladniju frekvenciju $\omega$. Frekvencija $\omega$ je ista za sve bazne funkcije u linearnoj kombinaciji za odabrani broj odsječaka $n$ prema (5.103). 

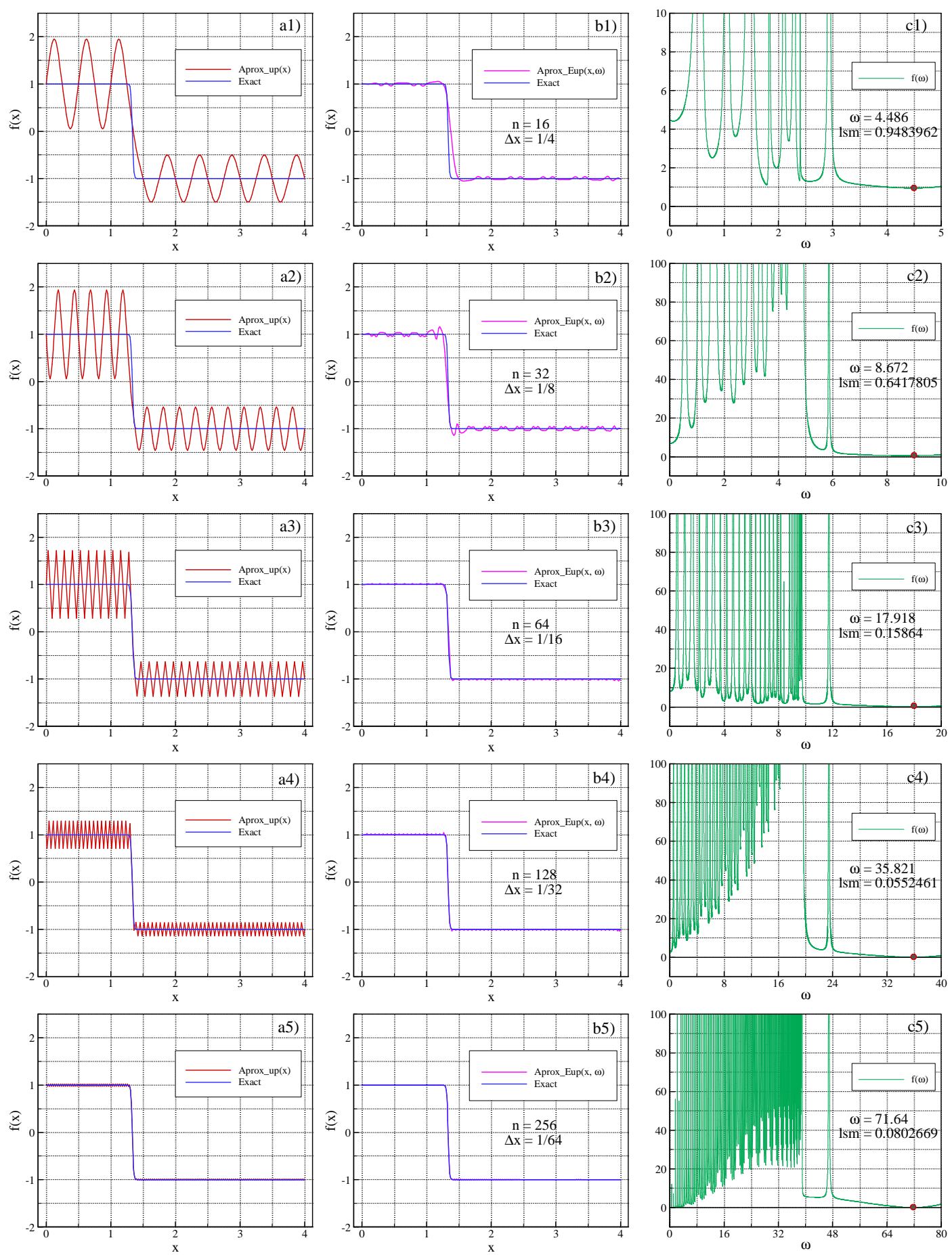

Crtež 5.15 Aproksimacija zadane funkcije $f(x)$ ABF algebarskog tipa: a1) - a5), eksponencijalnog tipa: b1) - b5), te iznalaženje minimuma kvadrata odstupanja ovisno o frekvenciji $\omega: \mathrm{c} 1)-\mathrm{c} 5)$

Po odabranom kriteriju kvadrata najmanjeg odstupanja između aproksimacije i zadane funkcije u stupcu c1) - c5) prikazana je ovisnost kvadrata odstupanja o frekvenciji. 
Algoritam za traženje najbolje frekvencije podešen je samo na nenegativne vrijednosti frekvencije. Ukoliko je vrijednost frekvencije negativna, tada se regulira preko koeficijenata linearne kombinacije.

Efekt utjecaja frekvencije eksponencijalnih baznih funkcija na aproksimaciju vidljiv je već kod $n=8$ na crtežu 5.15b1) u odnosu na a1). Frekvencija je izravno vezana s duljinom odsječka $\Delta x$, i u svim izrazima pojavljuje se u produktu $\Delta x \cdot \omega$.

Vrijednost tog produkta ostaje stalan u svim varijantama c1) - c5) i iznosi oko 2.243. Drugim riječima, dovoljno je precizno izračunati frekvenciju za najveći $\Delta x$, a za manje vrijednosti $\Delta x$, vrijednost frekvencije je $\omega_{k+1}=\frac{\Delta x_{k}}{\Delta x_{k+1}} \cdot \omega_{k}$, ili u slučaju diadičkog povećavanja rezolucije:

$$
\omega_{k+1}=2^{k} \cdot \omega_{1}, \quad k=0,1, \ldots
$$

\subsubsection{Aproksimacija po nivoima (MultiLevel aproksimacija)}

Drugi pristup za dobivanje aproksimacije zadane funkcije je multilevel pristup. Razmatra se zadana funkcija iz prethodne točke.

U nultom koraku, od zadane funkcije $f(x)=f_{0}(x)$ oduzima se njezina aproksimacija $\widetilde{f}_{0}(x)$ i dobiva nova funkcija $f_{1}(x)$. Na crtežu 5.16 b) uspoređuje se funkcija $f_{1}(x) \mathrm{s}$ propisanom točnosti, na primjer $\varepsilon= \pm 0.02$. Ukoliko točnost nije zadovoljena traži se aproksimacija $\widetilde{f}_{1}(x)$ funkcije $f_{1}(x)$ (vidi crtež 5.16 b)). Nakon toga slijedi usporedba razlike $f_{1}(x)-\widetilde{f_{1}}(x)$ s $\varepsilon$ i postupak se ponavlja sve dok se ne postigne zadana točnost, crtež $5.16 \mathrm{f}$ ).

Konačna aproksimacija zadane funkcije $f(x)$ dobiva se kao zbroj pojedinih aproksimacija na svakom nivou

$$
\tilde{f}(x)=\sum_{k=0}^{m} \widetilde{f_{k}}(x), \quad m \in N
$$

pri čemu je pojedina aproksimacija u stvari linearna kombinacija baznih funkcija $\mathrm{s}$ pripadajućom frekvencijom $\omega_{k}$ određenoj prema postupku opisanom u točki 5.7.5:

$$
\widetilde{f}_{k}(x)=\sum_{i=-1}^{2 n_{k}+1} C_{i} \cdot \operatorname{Eup}\left(\frac{x}{2 \cdot \Delta x}-\frac{i}{2}, \omega_{k}\right)
$$

Početni grid $n_{0}$ se bira po volji, a sljedeći je dvostruko gušći tj. $n_{1}=2 \cdot n_{0}$ ili općenito

$$
n_{k}=2^{k} \cdot n_{0} ; \quad k=0,1,2, \ldots
$$



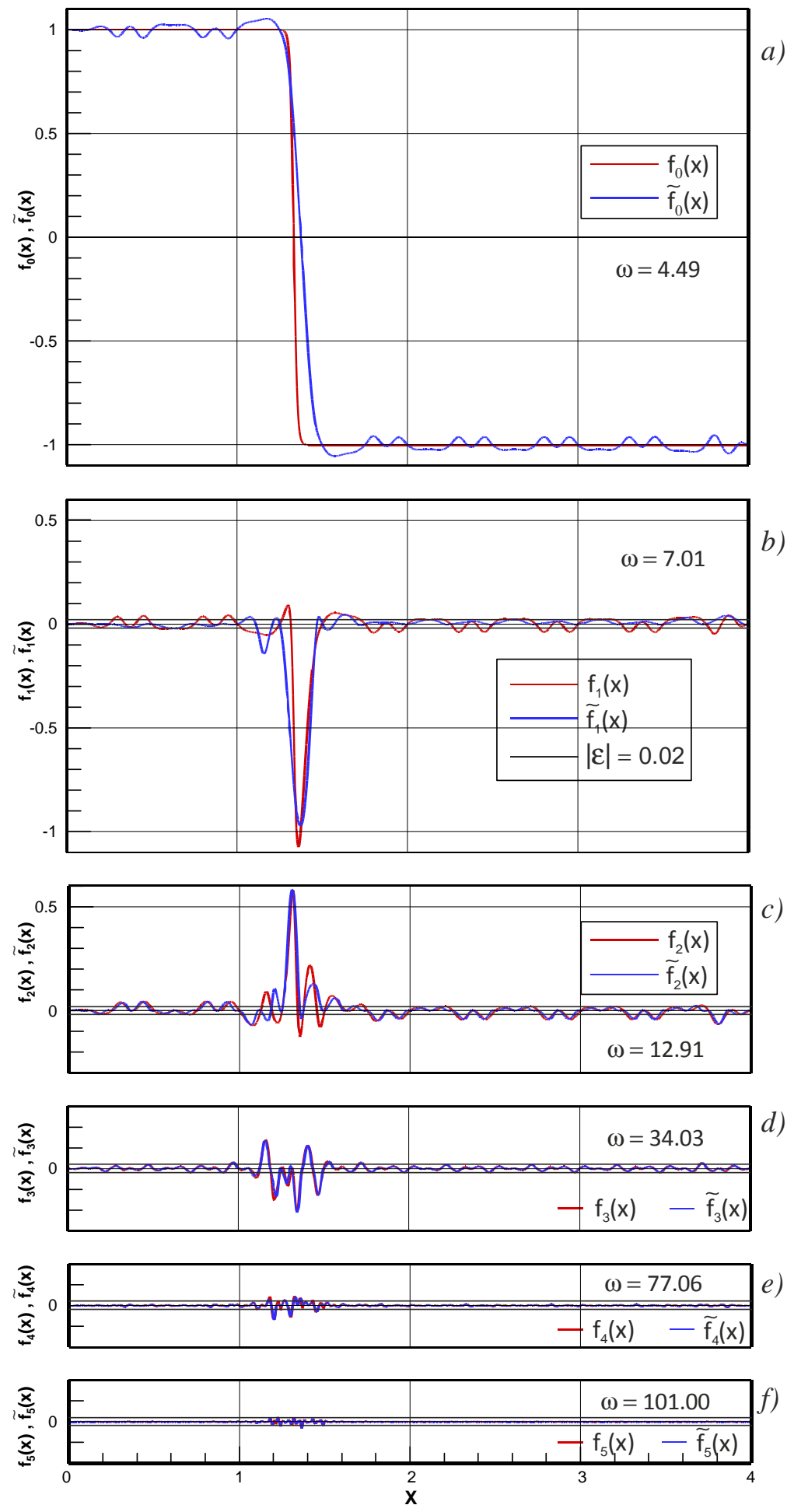

Crtež 5.16 Funkcija $f(x)$, njezina aproksimacija $\tilde{f}(x)$, te residuu $f(x)-\tilde{f}(x)$ po nivoima $\mathrm{a})-\mathrm{f}$ ) 
Za primjer na crtežu 5.16 korišten je inicijalni grid $n_{0}=16$ i izračunata pripadajuća frekvencija $\omega_{0}=4.486$.

U ovom postupku multilevel aproksimacije potrebno je približno 2 puta veći broj baznih funkcija nego u postupku koji koristi uniformni grid opisanom u točki 5.7.4 za istu točnost aproksimacije.

Međutim, ovaj multilevel postupak je analogan postupku koji se koristi kod adaptivne Fup kolokacijske metode [14], [15], [19]. Naime, na višim nivoima promatraju se samo kolokacijske točke u kojima je rezidu veći od propisane točnosti, dok se ostale točke ne moraju uzeti u obzir. Iz crteža 5.16 se vidi da takav kriterij vodi ka adaptacijskom postupku koji štedi CPU vrijeme i drastično smanjiva broj kolokacijskih točaka na višim nivoima. Razvoj takvog adaptivnog postupka za prikazane Eup bazne funkcije ostavljamo za buduća istraživanja kod razvoja novih nestacionarnih algoritama. Dakle, u ovoj točki svaki nivo je promatran sa svim kolokacijskim točkama u obliku neadaptivnog algoritma. 


\section{EKSPONENCIJALNE ATOMSKE BAZNE FUNKCIJE EFUP}

\subsection{Bazna funkcija $\operatorname{EFup}_{n}(\xi, \omega)$}

Primjena pomaknutih $\operatorname{Eup}(\xi, \omega)$ funkcija u numeričkim metodama za rješavanje praktičnih inženjerskih zadataka ograničena je potrebnim brojem baznih funkcija rješenja. Naime, potreban broj baznih funkcija brzo raste za približno rješenje višeg stupnja glatkosti.

Za točan razvoj eksponencijalnog polinoma $e^{2^{n} \cdot \omega \cdot \xi}$ na odsječku duljine $\Delta \xi_{n}=2^{-n}$ potrebno je $2^{n+1}$ baznih funkcija dobivenih pomicanjem funkcije $\operatorname{Eup}(\xi, \omega)$. Ova činjenica, analogno algebarskim ABF, dovela je do potrebe traženja baznih funkcija koje bi zadržale dobra svojstva funkcija $\operatorname{Eup}(\xi, \omega)$ a istovremeno bi ih za razvoj neke funkcije zadane glatkosti trebao manji broj nego baznih funkcija dobivenih pomicanjem funkcije $\operatorname{Eup}(\xi, \omega)$.

Funkcije $\operatorname{EFup}_{n}(\xi, \omega)$ su finitne funkcije iz klase $C^{\infty}$ s kompaktnim nosačem, a elementi su linearnog vektorskog prostora $E U P_{n}[6],[43]$, te zadržavaju sva svojstva 'svoje' materinske bazne funkcije $\operatorname{Eup}(\xi, \omega)$. Indeks ' $n$ ' označava najveći stupanj eksponencijalnog polinoma koji se može prikazati točno u obliku linearne kombinacije međusobno pomaknutih funkcija $\operatorname{EFup}_{n}(\xi, \omega)$ na odsječku duljine $\Delta \xi_{n}=2^{-n}$.

Analogno algebarskim $\mathrm{ABF} F u p_{n}(\xi)$ najpovoljnija mogućnost konstruiranja $\operatorname{EFup}_{n}(\xi, \omega)$ funkcija je u obliku linearne kombinacije pomaknutih $\operatorname{Eup}(\xi, \omega)$ funkcija kao što ce biti pokazano u nastavku. 


\subsection{Generiranje Fourierove transformacije funkcije $\operatorname{EFup}_{n}(\xi, \omega)$}

Fourierova transformacija atomskih baznih funkcija $\operatorname{EFup}_{n}(\xi, \omega)$ konstruira se sličnim postupkom primijenjenim za funkciju $\mathrm{Fup}_{n}(\xi)$ u točki 4.2, tzv. postupkom drobljenja FT.

Analogno izrazu (4.2), vrijedi da je prva iz klase $\mathrm{ABF}$ eksponencijalnog tipa $\operatorname{EFup}_{n}(\xi, \omega)$ za $n=0$ upravo materinska bazna funkcija $\operatorname{Eup}(\xi, \omega), \mathrm{tj} .:$

$$
\operatorname{EFup}_{0}(\xi, \omega)=\operatorname{Eup}(\xi, \omega)
$$

pa je prema (6.1) Fourierova transformacija funkcije $\operatorname{EFup}_{0}(\xi, \omega)$ određena izrazom (5.5) tj.:

$$
F_{0}(t)=\prod_{j=1}^{\infty} \frac{\omega}{2 \operatorname{sh}(\omega / 2)} \frac{\operatorname{sh}\left(\omega / 2+i \cdot t / 2^{j}\right)}{\omega / 2+i \cdot t / 2^{j}}
$$

ili u proširenom obliku

$$
\begin{aligned}
F_{0}(t)=\frac{\omega}{2 \operatorname{sh}(\omega / 2)} \frac{\operatorname{sh}(\omega / 2+i \cdot t / 2)}{\omega / 2+i \cdot t / 2} & \\
& \quad \frac{\omega}{2 \operatorname{sh}(\omega / 2)} \frac{\operatorname{sh}(\omega / 2+i \cdot t / 4)}{\omega / 2+i \cdot t / 4} \prod_{j=3}^{\infty} \frac{\omega}{2 \operatorname{sh}(\omega / 2)} \frac{\operatorname{sh}\left(\omega / 2+i \cdot t / 2^{j}\right)}{\omega / 2+i \cdot t / 2^{j}}
\end{aligned}
$$

Primjenom osnovne trigonometrijske relacije $\operatorname{sh}(\alpha)=2 \cdot[\operatorname{sh}(\alpha / 2) \cdot \operatorname{ch}(\alpha / 2)]$ na prvi faktor produkta $\mathrm{u}(6.3)$, te izostavljanjem člana $\operatorname{ch}(\alpha / 2)$, nakon sređivanja dobiva se Fourierova transformacija finitne funkcije $\operatorname{EFup}_{1}(\xi, \omega)$ oblika

$$
\begin{gathered}
F_{1}(t)=\frac{\omega}{2 \operatorname{sh}(\omega / 2)} \frac{\operatorname{sh}(\omega / 2+i \cdot t / 4)}{\omega / 2+i \cdot t / 4} \frac{\omega}{4 \operatorname{sh}(\omega / 4)} \frac{\operatorname{sh}(\omega / 4+i \cdot t / 4)}{\omega / 4+i \cdot t / 4} \\
\cdot \prod_{j=3}^{\infty} \frac{\omega}{2 \operatorname{sh}(\omega / 2)} \frac{\operatorname{sh}\left(\omega / 2+i \cdot t / 2^{j}\right)}{\omega / 2+i \cdot t / 2^{j}}
\end{gathered}
$$

Nastavljanjem postupka provedenim u (6.4) na jednadžbu (6.3), te poopćavanjem prikazanog postupka dobiva se klasa Fourierovih transformacija eksponencijalnih funkcija $\operatorname{EFup}_{n}(\xi, \omega)$ u obliku

$$
F_{n}(t)=\prod_{j=1}^{n+1} \frac{\omega}{2^{j} \operatorname{sh}\left(\omega / 2^{j}\right)} \cdot \frac{\operatorname{sh}\left(\omega / 2^{j}+i \cdot t / 2^{n+1}\right)}{\omega / 2^{j}+i \cdot t / 2^{n+1}} \cdot \prod_{k=n+2}^{\infty} \frac{\omega}{2 \operatorname{sh}(\omega / 2)} \cdot \frac{\operatorname{sh}\left(\omega / 2+i \cdot t / 2^{k}\right)}{\omega / 2+i \cdot t / 2^{k}}
$$

Kada parametar $\omega$ teži nuli eksponencijalne ABF prelaze u algebarske ABF, pa izraz (6.5) prelazi u (4.7). 
Analogno $\mathrm{ABF} \operatorname{Fup}_{n}(\xi)$, a što je vidljivo i u (6.5), Fourierova transformacija funkcije $\operatorname{EFup}_{n}(\xi, \omega)$ jednaka je umnošku $(n+1)$ FT eksponencijalnih splineova nultog stupnja $\varphi_{0}^{j}(\xi, \omega)$ normiranih na duljinu nosača $h_{0}=2^{-n}$ :

$$
\begin{gathered}
\varphi_{0}^{j}(\xi, \omega)=\frac{2^{j-1} \cdot \omega}{\operatorname{sh}\left(\omega / 2^{n-j+1}\right)} e^{2^{j} \omega \xi}, \quad j=0, \ldots, n \\
\operatorname{supp} \varphi_{0}^{j}(\xi, \omega)=\left[-2^{-(n+1)}, 2^{-(n+1)}\right]
\end{gathered}
$$

i FT materinske funkcije $\operatorname{Eup}(\xi, \omega)$ također sažete na duljinu nosača $\operatorname{supp} \operatorname{Eup}(\xi, \omega)=$ $\left[-2^{-(n+1)}, 2^{-(n+1)}\right]$.

Dakle, funkcija $\operatorname{EFup}_{n}(\xi, \omega)$ može se napisati pomoću teorema konvolucije u sljedećem obliku:

$$
\operatorname{EFup}_{n}(\xi, \omega)=\varphi_{0}^{0}(\xi, \omega) * \ldots * \varphi_{0}^{n}(\xi, \omega) * 2^{n+1} \operatorname{Eup}\left(2^{n+1} \cdot \xi, \omega\right)
$$

Na primjer, funkcija $\operatorname{EFup}_{2}(\xi, \omega)$ predstavlja konvoluciju četiri funkcije normirane na duljinu nosača $\left[-\frac{1}{8}, \frac{1}{8}\right]: 3$ eksponencijalna splinea nultog stupnja i sažete funkcije $\operatorname{Eup}(\xi, \omega)$ :

$$
\operatorname{EFup}_{2}(\xi, \omega)=\frac{\omega \cdot e^{\omega \xi}}{2 \cdot \operatorname{sh}(\omega / 8)} * \frac{\omega \cdot e^{2 \omega \xi}}{\operatorname{sh}(\omega / 4)} * \frac{2 \cdot \omega \cdot e^{4 \omega \xi}}{\operatorname{sh}(\omega / 2)} * 8 y_{\omega}(8 \xi)
$$

U izrazu (6.7) konvolucija $(n+1)-$ og splinea nultog stupnja normiranog na duljinu nosača $h_{0}=2^{-n}$ predstavlja novu opću eksponencijalnu funkciju $f_{n}(\xi, \omega)$ čiji je nosač jednak zbroju svih duljina nosača članova konvolucije tj. $h_{n}=(n+1) 2^{-n}$

$$
f_{n}(\xi, \omega)=\underbrace{\varphi_{0}^{0}(\xi, \omega)}_{\text {supp }=\left[-2^{-(n+1)}, 2^{-(n+1)}\right]} * \ldots * \underbrace{\varphi_{0}^{j}(\xi, \omega)}_{\text {supp }=\left[-2^{-(n+1)}, 2^{-(n+1)}\right]} * \ldots * \underbrace{\varphi_{0}^{n}(\xi, \omega)}_{\text {supp }=\left[-2^{-(n+1)}, 2^{-(n+1)}\right]}
$$

tako se izraz (6.7) može napisati i u sljedećem obliku:

$$
\operatorname{EFup}_{n}(\xi, \omega)=f_{n}(\xi, \omega) * 2^{n+1} \operatorname{Eup}\left(2^{n+1} \xi, \omega\right)
$$

Funkcija $f_{n}(\xi, \omega)$ kada $\omega \rightarrow 0$, postaje sažeti B-spline $n$ - tog stupnja iz izraza (2.4).

$\mathrm{Na}$ crtežu 6.1 dana je grafička interpretacija postupka generiranja funkcije $\operatorname{EFup}_{n}(\xi, \omega), n=0,1,2$ pomoću teorema konvolucije. 
a)

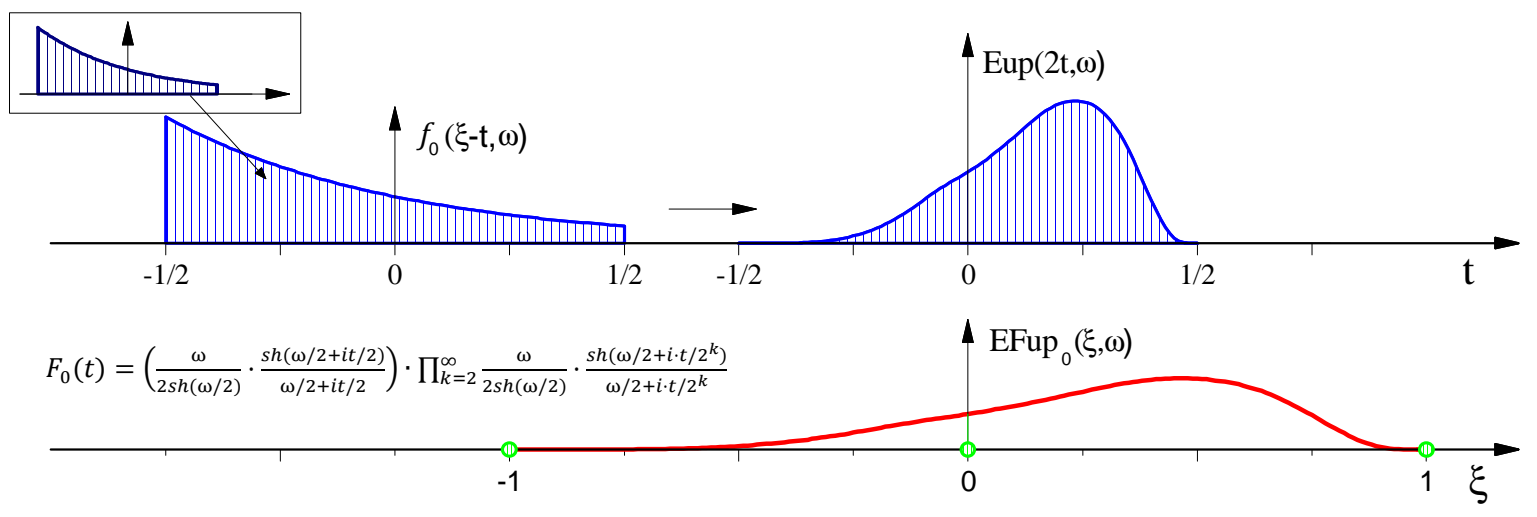

b)
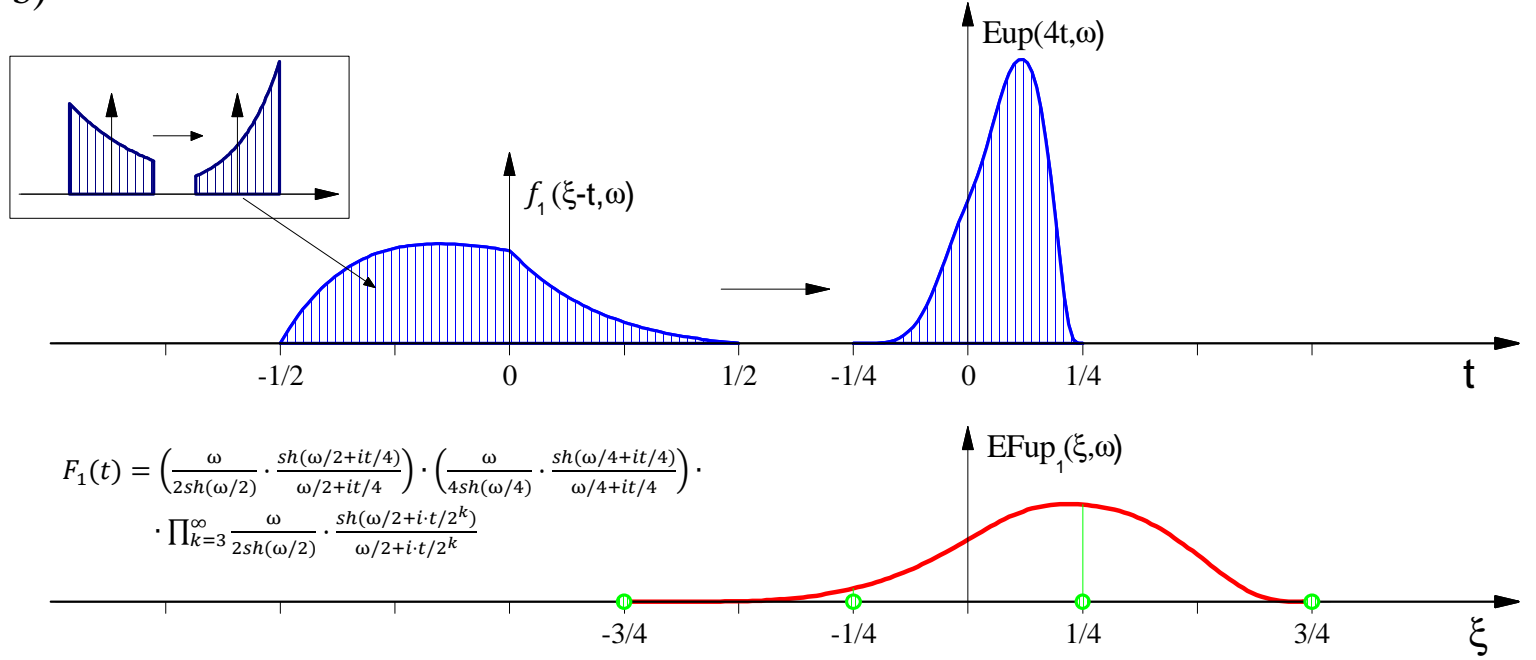

c)

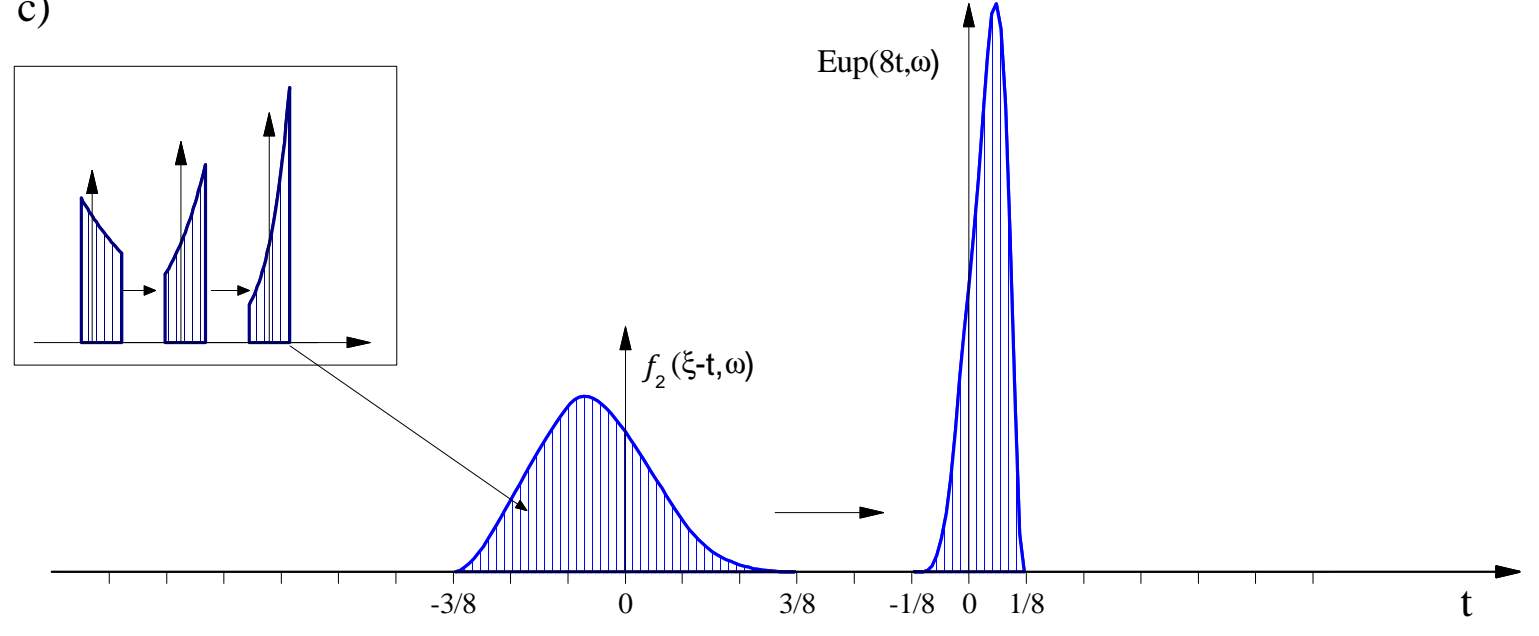

$\begin{aligned} F_{2}(t)= & \left(\frac{\omega}{2 \operatorname{sh}(\omega / 2)} \cdot \frac{\operatorname{sh}(\omega / 2+i t / 8)}{\omega / 2+i t / 8}\right) \cdot\left(\frac{\omega}{4 s h(\omega / 4)} \cdot \frac{\operatorname{sh}(\omega / 4+i t / 8)}{\omega / 4+i t / 8}\right) \cdot \\ & \cdot\left(\frac{\omega}{8 \operatorname{sh}(\omega / 8)} \cdot \frac{\operatorname{sh}(\omega / 8+8+t / 8)}{\omega / 8+i t / 8}\right) \cdot \prod_{k=4}^{\infty} \frac{\omega}{2 \operatorname{sh}(\omega / 2)} \cdot \frac{\operatorname{sh}\left(\omega / 2+i \cdot t / 2^{k}\right)}{\omega / 2+i \cdot t / 2^{k}}\end{aligned}$

Crtež 6.1 Generiranje eksponencijalnih funkcija $\operatorname{EFup}_{n}(\xi, \omega), n=0,1,2$ 
Nosač funkcije $\operatorname{EFup}_{n}(\xi, \omega)$ je prema (6.7) odsječak sastavljen od $(n+2)$ podintervala duljine $2^{-n}$. Karakteristične točke su rubne točke podintervala.

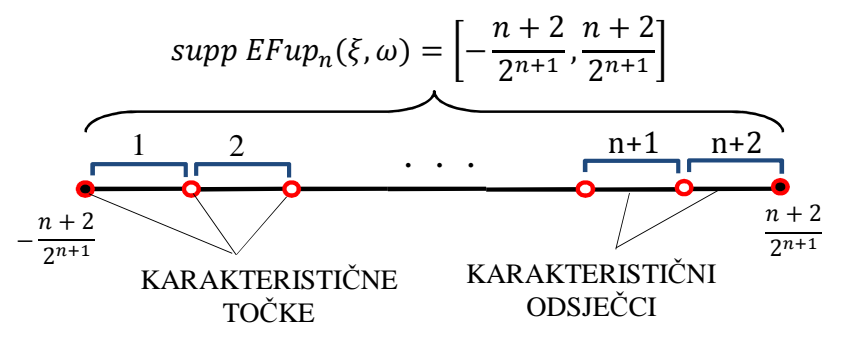

$\mathrm{Na}$ crtežu 6.3 su prikazane bazne funkcije $\operatorname{EFup}_{n}(\xi, \omega), n=0, \ldots, 4$ u lokalnom koordinatnom sustavu za vrijednost parametra $\omega=-4$.

Inverzna Fourierova transformacija, odnosno funkcija $\operatorname{EFup}_{n}(\xi, \omega)$, uz zadovoljenje PaleyWienerovog normirnog uvjeta može se izraziti u obliku:

$$
\operatorname{EFup}_{n}(\xi, \omega)=\frac{1}{2 \pi} \int_{-\infty}^{\infty} e^{-i t \xi} F_{n}(t) d t
$$

Razvojem izraza (6.11) u Fourierov red može se odrediti "original" funkcije $\operatorname{EFup}_{n}(\xi, \omega)$ u proizvoljnim točkama. Međutim, kao i u prethodnim poglavljima, tražiti će se točno rješenje u binarno racionalnim točkama.

Na crtežu 6.2 prikazana je funkcija $\operatorname{EFup}_{2}(\xi, \omega)$ za različite vrijednosti parametra $\omega$. Slično materinskoj funkciji $\operatorname{Eup}(\xi, \omega)$, funkcija je nagnuta u lijevo za negativne vrijednosti parametra $\omega<0$, dok je za pozitivne nagnuta u desno. U graničnom slučaju kada $\omega \rightarrow 0$ eksponencijalna funkcija $\operatorname{EFup}_{2}(\xi, \omega)$ je identički jednaka algebarskoj funkciji $F u p_{2}(\xi)$.

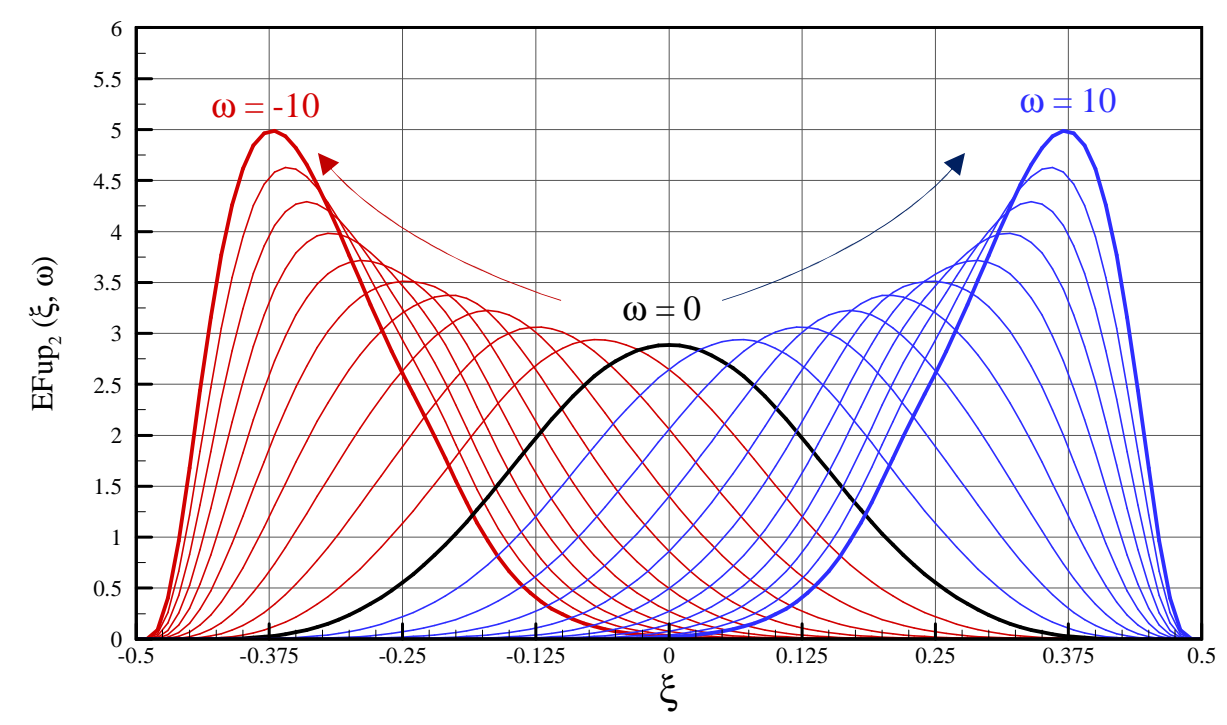

Crtež 6.2 Funkcija $\operatorname{EFup}_{2}(\xi, \omega)$ za različite vrijednosti parametra $-10 \leq \omega \leq 10$ 

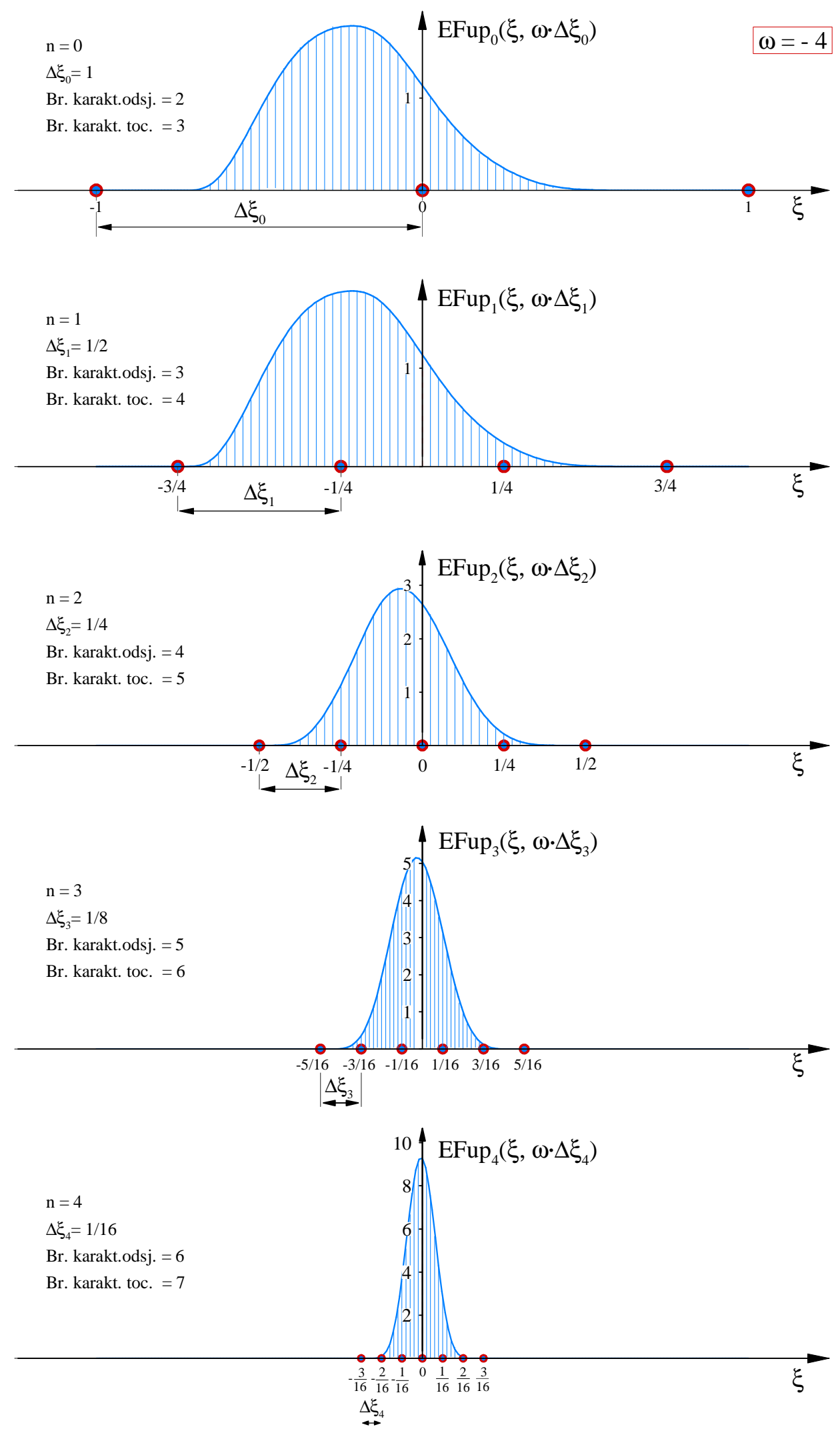

Crtež 6.3 Funkcije $\operatorname{EFup}_{n}(\xi, \omega), n=0, \ldots, 4$ za vrijednost parametra $\omega=-4$ 


\subsection{Izvod funkcionalno diferencijalne jednadžbe funkcije $\operatorname{EFup}_{\mathbf{n}}(\xi, \omega)$}

Analogno algebarskim $\mathrm{ABF} F u p_{n}(\xi)$, funkcionalno diferencijalna jednadžba funkcija $\operatorname{EFup}_{n}(\xi, \omega)$ određuje se iz Fourierove transformacije (6.5) koja se može napisati u obliku:

$$
F_{n}(t)=\frac{\omega}{2^{n+1} \operatorname{sh}\left(\omega / 2^{n+1}\right)} \cdot \frac{\operatorname{sh}\left(\omega / 2^{n+1}+i \cdot t / 2^{n+1}\right)}{\omega / 2^{n+1}+i \cdot t / 2^{n+1}} \cdot \prod_{k=2}^{n+1} \frac{\operatorname{ch}\left(\omega / 2^{k}+i \cdot t / 2^{n+2}\right)}{\operatorname{ch}\left(\omega / 2^{k}\right)} \cdot F_{n}\left(\frac{t}{2}\right)
$$

Na primjer, za baznu funkciju $\operatorname{EFup}_{2}(\xi, \omega)$ prema (6.12) dobije se

$$
F_{2}(t)=\frac{\omega}{8 \cdot \operatorname{sh}(\omega / 8)} \cdot \frac{\operatorname{sh}(\omega / 8+i \cdot t / 8)}{\omega / 8+i \cdot t / 8} \cdot \frac{\operatorname{ch}\left(\frac{\omega}{4}+\frac{i t}{16}\right)}{\operatorname{ch}(\omega / 4)} \cdot \frac{\operatorname{ch}\left(\frac{\omega}{8}+\frac{i t}{16}\right)}{\operatorname{ch}(\omega / 8)} \cdot F_{2}\left(\frac{t}{2}\right)
$$

odnosno

$$
F_{2}(t)=\frac{\omega}{2 \cdot \operatorname{sh}(\omega / 2)} \cdot \frac{\operatorname{sh}(\omega / 8+i \cdot t / 8)}{\omega / 8+i \cdot t / 8} \cdot \operatorname{ch}\left(\frac{\omega}{4}+\frac{i t}{16}\right) \cdot \operatorname{ch}\left(\frac{\omega}{8}+\frac{i t}{16}\right) \cdot F_{2}\left(\frac{t}{2}\right)
$$

Ako se (6.14) napiše u obliku eksponencijalnih funkcija, te pomnoži sa $(\omega+i t)$ nakon sređivanja slijedi:

$$
\begin{gathered}
\omega \cdot F_{2}(t)+i t \cdot F_{2}(t)=\frac{\omega}{2 \cdot \operatorname{sh}(\omega / 2)} \cdot\left[e^{\omega / 2} \cdot e^{\frac{i t}{4}}+\left(1+e^{\omega / 4}\right) \cdot e^{i t / 8}+\left(e^{-\omega / 4}+e^{\omega / 4}\right)\right. \\
\left.-\left(1+e^{-\omega / 4}\right) \cdot e^{-i t / 8}-e^{-\omega / 2} \cdot e^{-i t / 4}\right] \cdot F_{2}(t / 2)
\end{gathered}
$$

Inverzna Fourierova transformacija od (6.15) je

$$
\begin{aligned}
& \omega \frac{1}{2 \pi} \int_{-\infty}^{\infty} e^{-i t \xi} F_{2}(t) d \xi+i t \frac{1}{2 \pi} \int_{-\infty}^{\infty} e^{-i t \xi} F_{2}(t) d \xi= \\
& =\frac{\omega}{2 \cdot \operatorname{sh}(\omega / 2)} \cdot\left[e^{\omega / 2} \frac{1}{2 \pi} \int_{-\infty}^{\infty} e^{-i t(\xi-1 / 4)} F_{2}\left(\frac{t}{2}\right) d \xi+\left(1+e^{\omega / 4}\right) \frac{1}{2 \pi} \int_{-\infty}^{\infty} e^{-i t(\xi-1 / 8)} F_{2}\left(\frac{t}{2}\right) d \xi+\right. \\
& \quad+\left(e^{-\omega / 4}-e^{\omega / 4}\right) \frac{1}{2 \pi} \int_{-\infty}^{\infty} e^{-i t \xi} F_{2}\left(\frac{t}{2}\right) d \xi-\left(1+e^{-\omega / 4}\right) \cdot \frac{1}{2 \pi} \int_{-\infty}^{\infty} e^{-i t(\xi+1 / 8)} F_{2}(t) d \xi- \\
& \left.-e^{-\omega / 2} \cdot \frac{1}{2 \pi} \int_{-\infty}^{\infty} e^{-i t(\xi+1 / 4)} F_{2}(t) d \xi\right] \cdot F_{2}(t / 2)
\end{aligned}
$$

Prvi član lijeve strane prema izrazu (6.11) predstavlja samu funkciju $\operatorname{EFup}_{2}(\xi, \omega)$ pomnoženu s parametrom $\omega$, dok drugi član predstavlja prvu derivaciju funkcije $\operatorname{EFup}_{2}(\xi, \omega)$. Nadalje, prvi integral desne strane može se izraziti kao:

$$
\begin{aligned}
\frac{1}{2 \pi} \int_{-\infty}^{\infty} e^{-i t \cdot(\xi-1 / 4)} \cdot F_{2}(t / 2) d t=\left|\begin{array}{rr}
u=t / 2 & d u=d t / 2 \\
t=2 u & d t=2 d u
\end{array}\right| & =2 \cdot \frac{1}{2 \pi} \int_{-\infty}^{\infty} e^{-i u \cdot(2 \xi-1 / 2)} \cdot F_{2}(u) d u \\
& =2 \cdot \operatorname{EFup}_{2}(2 \xi-1 / 2)
\end{aligned}
$$


Sređivanjem na isti način i ostalih članova desne strane izraza (6.16) dobije se funkcionalno diferencijalna jednadžba funkcije $\operatorname{EFup}_{2}(\xi, \omega)$ u obliku:

$$
\begin{gathered}
y_{2}{ }^{\prime}(\xi)-\omega \cdot y_{2}(\xi)=A_{1} \cdot y_{2}(2 \xi+1 / 2)+A_{2} \cdot y_{2}(2 \xi+1 / 4)+A_{3} \cdot y_{2}(2 \xi)+ \\
+A_{4} \cdot y_{2}(2 \xi-1 / 4)+A_{5} \cdot y_{2}(2 \xi-1 / 2)
\end{gathered}
$$

gdje su koeficijenti $A_{i}$

$$
\begin{gathered}
A_{1}=\frac{2 \cdot \omega}{e^{\omega}-1} \quad ; \quad A_{2}=\frac{2 \cdot \omega \cdot e^{\omega / 4} \cdot\left(e^{\omega / 4}+1\right)}{e^{\omega}-1} \quad ; \quad A_{3}=\frac{2 \cdot \omega \cdot e^{\omega / 4} \cdot\left(e^{\omega / 2}-1\right)}{e^{\omega}-1} \\
A_{4}=-\frac{2 \cdot \omega \cdot e^{\omega / 2} \cdot\left(e^{\omega / 4}+1\right)}{e^{\omega}-1} \quad ; \quad A_{5}=-\frac{2 \cdot \omega \cdot e^{\omega}}{e^{\omega}-1}
\end{gathered}
$$

Posebno, za vrijednost parametra $\omega=0$, dobiva se

$$
A_{1}=2 ; A_{2}=4 ; A_{3}=-4 ; A_{4}=-4 ; A_{5}=-2
$$

tako da je u tom slučaju jednadžba (6.18) ekvivalentna jednadžbi (4.14).
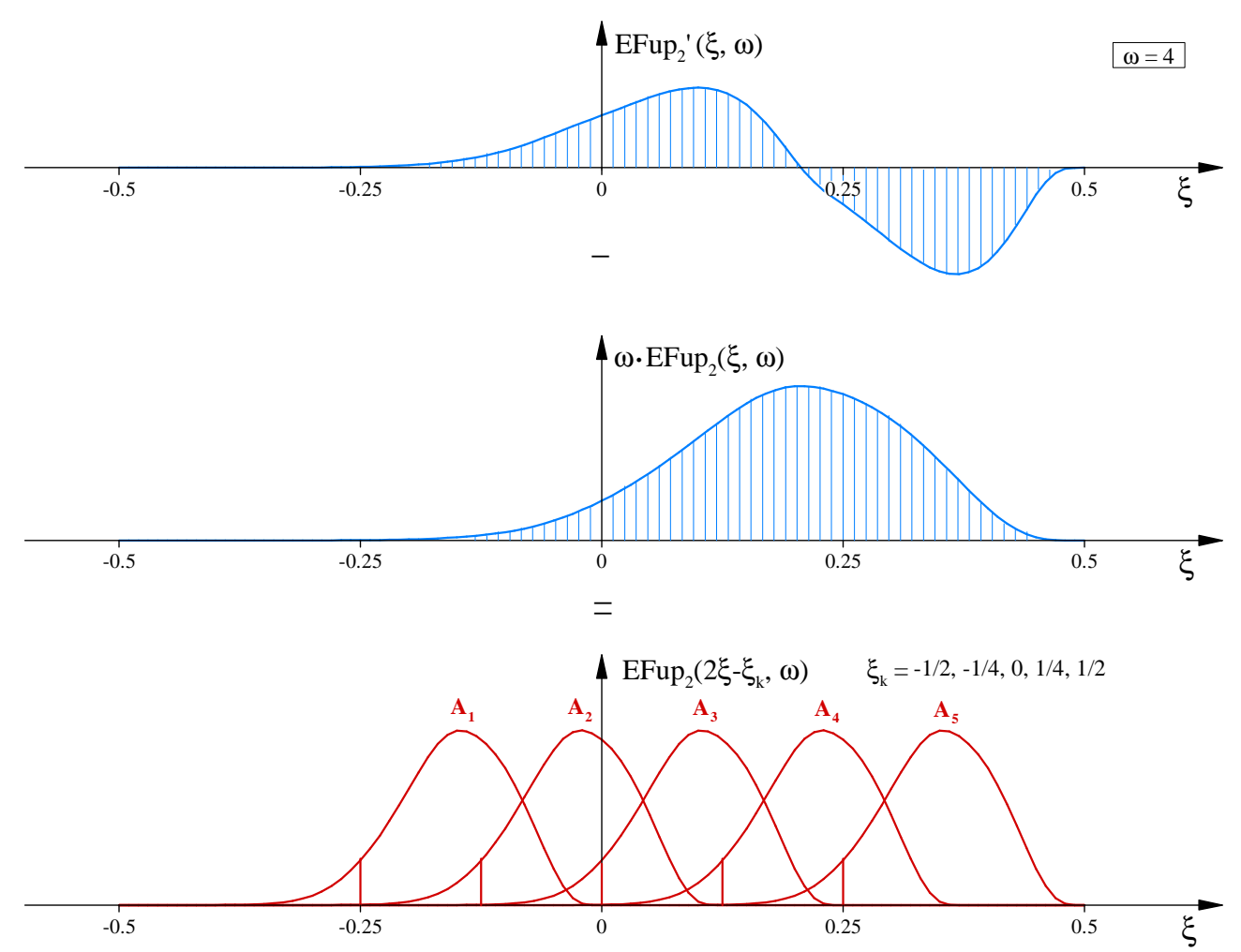

Crtež 6.4 Članovi funkcionalno diferencijalne jednadžbe bazne funkcije $\operatorname{EFup}_{2}(\xi, \omega)$

Analognim postupkom izvodi se funkcionalno diferencijalna jednadžba za bazne funkcije $\operatorname{EFup}_{n}(\xi, \omega)$ bilo kojeg reda $n$ koja u općem obliku glasi [46]:

$$
\operatorname{EFup}_{n}{ }^{\prime}(\xi, \omega)-\omega \cdot \operatorname{EFup}_{n}(\xi, \omega)=\sum_{i=1}^{2^{n+1}} \alpha_{i} \cdot \operatorname{EFup}_{n}\left(2 \xi+\beta_{i}, \omega\right)
$$

gdje su koeficijenti 


$$
\beta_{i}= \pm\left\{\begin{array}{ll}
j \cdot 2^{-2 s} & \text { za } n=2 s \\
(2 j+1) \cdot 2^{-2 s} & \text { za } n=2 s-1
\end{array} \quad ; \quad j=1,2, \ldots, 2 s\right.
$$

i

$$
\alpha_{i}=\frac{2 \omega}{e^{\omega}-1}\left[A_{i}^{n}(\omega)-A_{n+2-i}^{n}(-\omega)\right]
$$

gdje je

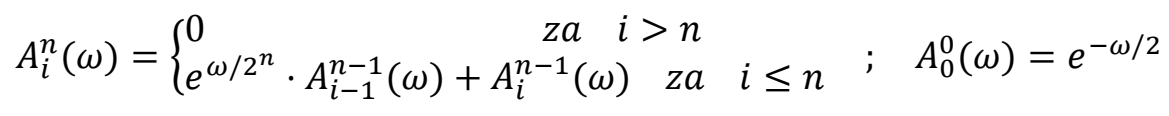

\subsection{Vrijednosti funkcija $\operatorname{EFup}_{\mathbf{n}}(\xi, \omega)$ u karakterističnim točkama}

Vrijednosti funkcija $\operatorname{EFup}_{n}(\xi, \omega)$ u proizvoljnim diskretnim točkama $\xi$ mogu se odrediti pomoću teorema konvolucije prema (6.10) kao rješenje sljedećeg integrala:

$$
\operatorname{EFup}_{n}(\xi, \omega)=2^{n+1} \int_{-\infty}^{\infty} f_{n}(\xi-t) \cdot \operatorname{Eup}\left(2^{n+1} t, \omega\right) d t
$$

gdje je $f_{n}(\xi)$ eksponencijalna funkcija definirana izrazom (6.9).

Međutim, izračunavanje integrala (6.24) u proizvoljnim točkama $\xi$ nije jednostavan niti numerički povoljan postupak, te se stoga rješavanjem integrala (6.24) određuju samo vrijednosti baznih funkcija $\operatorname{EFup}_{n}\left(\xi_{k}, \omega\right)$ u karakterističnim točkama $\xi_{k}$, crtež 6.5.

$\mathrm{Na}$ crtežu 6.5 dana je grafička interpretacija integrala (6.24) za baznu funkciju $\operatorname{EFup}_{2}(\xi, \omega)$ u karakterističnim točkama $\xi_{k}=-\frac{1}{4}, 0, \frac{1}{4}$.

Na primjer, vrijednost funkcije $\operatorname{EFup}_{2}(\xi, \omega)$ u točki $\xi_{k}=-1 / 4$ prema (6.24) odgovara rješenju sljedećeg integrala

$$
\operatorname{EFup}_{2}\left(\xi_{k}, \omega\right)=8 \cdot \int_{-1 / 8}^{\xi_{k}+3 / 8} f_{2}\left(\xi_{k}-t\right) \cdot \operatorname{Eup}(8 t, \omega) d t
$$

Eksponencijalna funkcija $f_{2}\left(\xi_{k}-t\right)$ može se na intervalu $\left[-\frac{1}{8}, \frac{1}{8}\right]$ napisati u sljedećem obliku pogodnom za rješavanje integrala (6.25)

$$
f_{2}\left(-\frac{1}{4}-t\right)=\frac{N_{1}}{B} \cdot e^{-\omega \cdot t}+\frac{N_{2}}{B} \cdot e^{-2 \omega \cdot t}+\frac{N_{3}}{B} \cdot e^{-4 \omega \cdot t} ; \quad t \in\left[-\frac{1}{8}, \frac{1}{8}\right]
$$

gdje je 


$$
\begin{gathered}
N_{1}=8 \cdot \omega \cdot e^{\omega / 8} ; N_{2}=-12 \cdot \omega \cdot e^{\omega / 4} ; N_{3}=4 \cdot \omega \cdot e^{\omega / 2} \\
B=3 \cdot\left(e^{\omega / 4}-1\right)^{3} \cdot\left(e^{\omega / 4}+1\right)^{2} \cdot\left(e^{\omega / 2}+1\right)
\end{gathered}
$$

pa se uvrštavanjem (6.26) u (6.25) dobije

$$
\begin{aligned}
& \operatorname{EFup}_{2}\left(-\frac{1}{4}, \omega\right)= \\
& \frac{8}{B} \cdot\left[N_{1} \int_{-1 / 8}^{1 / 8} e^{-\omega \cdot t} y_{\omega}(8 t) d t+N_{2} \int_{-1 / 8}^{1 / 8} e^{-2 \omega \cdot t} y_{\omega}(8 t) d t+N_{3} \int_{-1 / 8}^{1 / 8} e^{-4 \omega \cdot t} y_{\omega}(8 t) d t\right]
\end{aligned}
$$

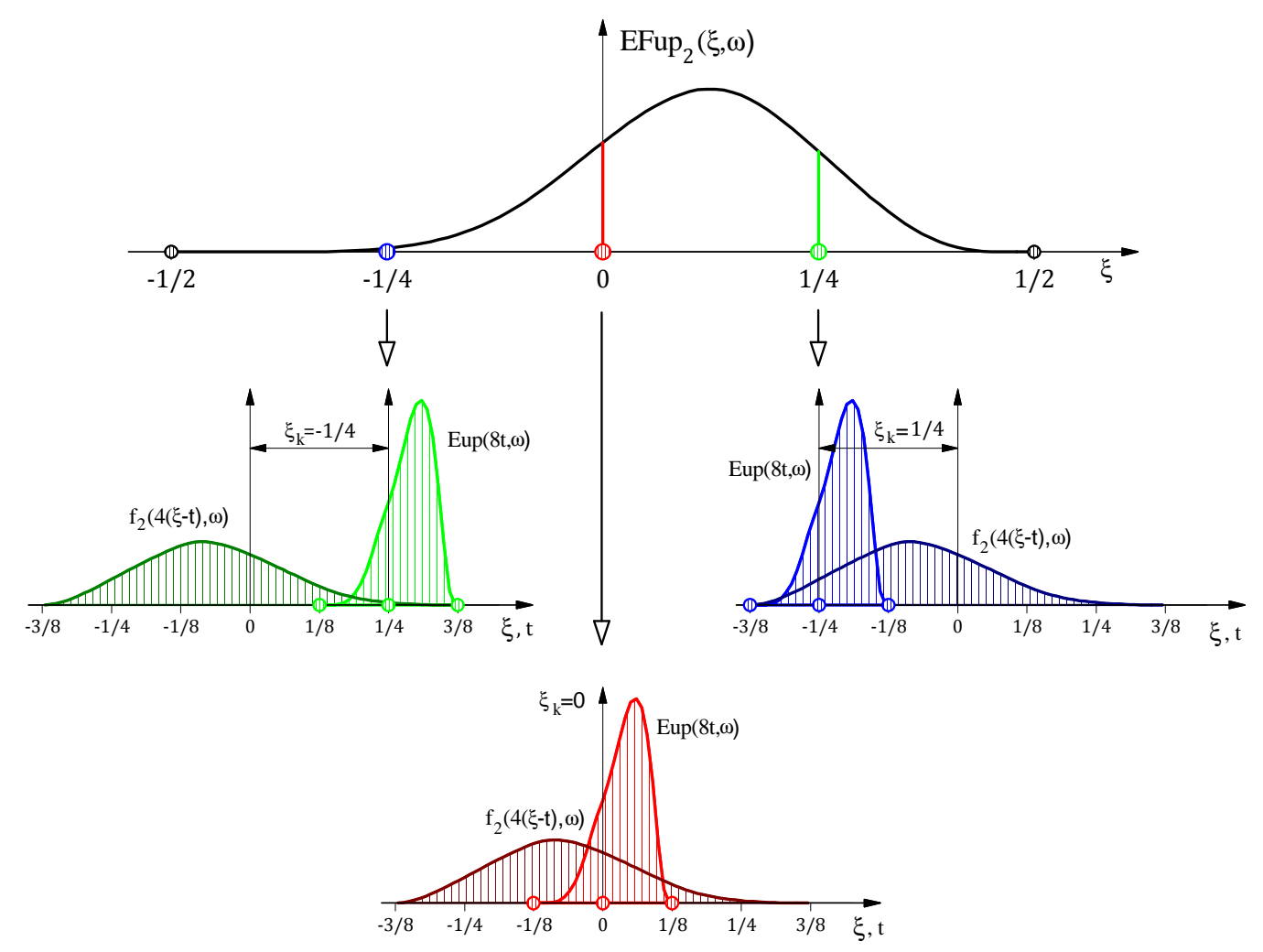

Crtež 6.5 Vrijednosti funkcije $\operatorname{EFup}_{2}(\xi, \omega)$ u karakterističnim točkama $\xi_{k}$ pomoću teorema konvolucije

Sređivanjem integrala desne strane $u(6.28)$ na način

$$
\begin{aligned}
& \int_{-1 / 8}^{1 / 8} e^{-\omega \cdot t} \cdot y_{\omega}(8 \cdot t) d t=\left|\begin{array}{ll}
u=8 \cdot t & \rightarrow t=u / 8 \\
d u=8 \cdot d t & \rightarrow d t=d u / 8 \\
z a t=-1 / 8 & \rightarrow u=-1 \\
z a t=1 / 8 & \rightarrow u=1
\end{array}\right|=\frac{1}{8} \int_{-1}^{1} e^{-\omega \cdot u / 8} \cdot y_{\omega}(u) d u=\frac{1}{8} F\left(\frac{i \omega}{8}\right) \\
& \int_{-1 / 8}^{1 / 8} e^{-2 \omega \cdot t} \cdot y_{\omega}(8 \cdot t) d t=\cdots=\frac{1}{8} F\left(\frac{i \omega}{4}\right) \\
& \int_{-1 / 8}^{1 / 8} e^{-4 \omega \cdot t} \cdot y_{\omega}(8 \cdot t) d t=\cdots=\frac{1}{8} F\left(\frac{i \omega}{2}\right)
\end{aligned}
$$


integral (6.25) postaje

$$
\operatorname{EFup}_{2}\left(-\frac{1}{4}\right)=\frac{N_{1}}{B} \cdot F\left(\frac{i \omega}{8}\right)+\frac{N_{2}}{B} \cdot F\left(\frac{i \omega}{4}\right)+\frac{N_{3}}{B} \cdot F\left(\frac{i \omega}{2}\right)
$$

Izrazi $F\left(\frac{i \cdot \omega}{2^{j+1}}\right), j=0,1,2 \mathrm{u}$ (6.30) predstavljaju Fourierove transformacije (5.5) za vrijednosti varijable $t=\frac{i \cdot \omega}{2^{j+1}}$ koje se sređivanjem mogu izraziti preko vrijednosti $\lambda_{0}(\omega)$ iz izraza (5.57):

$$
F\left(\frac{i \cdot \omega}{2^{n+1}}\right)=\frac{2^{-n \cdot(n+1) / 2} \cdot e^{-\omega \cdot 2^{-n-1}} \cdot\left(1-e^{\omega}\right)^{n+1}}{\omega \cdot \prod_{k=1}^{n} \frac{e^{\omega \cdot 2^{-k}}-e^{\omega}}{2^{k}-1}} \cdot \lambda_{0}(\omega)
$$

Konačno, uvrštavanjem (6.31) za $j=0,1,2 \mathrm{u}$ izraz (6.30) dobije se vrijednost bazne funkcije $\operatorname{EFup}_{2}(\xi, \omega)$ u karakterističnoj točki $\xi_{k}=-1 / 4$ oblika

$$
\operatorname{EFup}_{2}\left(-\frac{1}{4}\right)=\frac{e^{-3 \omega / 4} \cdot\left(e^{3 \omega / 4}+3 \cdot e^{\omega / 2}+3 \cdot e^{\omega / 4}+3\right)}{3 \cdot\left(e^{\omega / 4}+1\right) \cdot\left(e^{\omega / 2}+e^{\omega / 4}+1\right)} \cdot \lambda_{0}(\omega)
$$

Analognim postupkom određuju se vrijednosti i u ostalim karakterističnim točkama

$$
\begin{gathered}
\operatorname{EFup}_{2}(0)=\frac{e^{-\omega / 4} \cdot\left(3 \cdot e^{\omega}+6 \cdot e^{3 \cdot \omega / 4}+8 \cdot e^{\omega / 2}+6 \cdot e^{\omega / 4}+3\right)}{3 \cdot\left(e^{\omega / 2}+e^{\omega / 4}+1\right)} \cdot \lambda_{0}(\omega) \\
\operatorname{EFup}_{2}\left(\frac{1}{4}\right)=\frac{e^{3 \cdot \omega / 4} \cdot\left(3 \cdot e^{3 \cdot \omega / 4}+3 \cdot e^{\omega / 2}+3 \cdot e^{\omega / 4}+1\right)}{3 \cdot\left(e^{\omega / 4}+1\right) \cdot\left(e^{\omega / 2}+e^{\omega / 4}+1\right)} \cdot \lambda_{0}(\omega)
\end{gathered}
$$

odnosno vrijednosti baznih funkcija $\operatorname{EFup}_{n}(\xi, \omega)$ u karakterističnim točkama, općenito.

Kao što se vidi u izrazima (6.32) i (6.33), vrijednosti funkcija $\operatorname{EFup}_{n}(\xi, \omega) \mathrm{u}$ karakterističnim točkama $\xi_{k}$ imaju 'konačan' zapis u obliku umnoška određene eksponencijalne funkcije i vrijednosti funkcije $\operatorname{Eup}(\xi, \omega)$ u točki $\xi=0$ tj., $\lambda_{0}(\omega)$ određene izrazom (5.57).

\subsection{Veza baznih funkcija $\operatorname{EFup}_{n}(\xi, \omega)$ i $\operatorname{EFup}_{n-1}(\xi, \omega)$}

Slično kao kod ABF algebarskog tipa $F u p_{n}(\xi)$, veza baznih funkcija $\operatorname{EFup}_{n}(\xi, \omega)$ i $\operatorname{EFup}_{n-1}(\xi, \omega)$ proizlazi iz odnosa njihovih Fourierovih transformacija $F_{n}(t)$ i $F_{n-1}(t)$ određenih izrazom (6.5).

Na primjer, za bazne funkcije $\operatorname{EFup}_{0}(\xi, \omega)$ i $\operatorname{EFup}_{1}(\xi, \omega)$ prema (6.3) i (6.4) vrijedi sljedeći odnos

$$
F_{0}(t)=\frac{\operatorname{ch}(\omega / 4+i \cdot t / 4)}{\operatorname{ch}(\omega / 4)} \cdot F_{1}(t)
$$


Uvrštavanjem (6.34) u original funkcije $\operatorname{EFup}_{0}(\xi, \omega)=\operatorname{Eup}(\xi, \omega)$ određen izrazom (5.6) dobije se

$$
\operatorname{Eup}(\xi, \omega)=\frac{1}{2 \pi} \int_{-\infty}^{\infty} \frac{\operatorname{ch}(\omega / 4+i \cdot t / 4)}{\operatorname{ch}(\omega / 4)} \cdot F_{1}(t) \cdot e^{-i t \xi} d t
$$

ili u eksponencijalnom obliku

$$
\operatorname{Eup}(\xi, \omega)=\frac{1}{2 \operatorname{ch}\left(\frac{\omega}{4}\right)}\left[e^{-\omega / 4} \cdot \frac{1}{2 \pi} \int_{-\infty}^{\infty} e^{-i t\left(\xi+\frac{1}{4}\right)} \cdot F_{1}(t) d t+e^{\frac{\omega}{4}} \cdot \frac{1}{2 \pi} \int_{-\infty}^{\infty} e^{-i t\left(\xi-\frac{1}{4}\right)} \cdot F_{1}(t) d t\right]
$$

odakle slijedi

$$
\operatorname{Eup}(\xi, \omega)=\frac{\operatorname{EFup}_{1}(\xi+1 / 4, \omega)}{e^{\omega / 2}+1}+\frac{\operatorname{EFup}_{1}(\xi-1 / 4, \omega)}{e^{-\omega / 2}+1}
$$

Izraz (6.37) predstavlja atomsku baznu funkciju $\operatorname{Eup}(\xi, \omega)$ prikazanu u obliku linearne kombinacije pomaknutih baznih funkcija $\operatorname{EFup}_{1}(\xi, \omega)$, a grafički je prikazan na crtežu 6.6a.
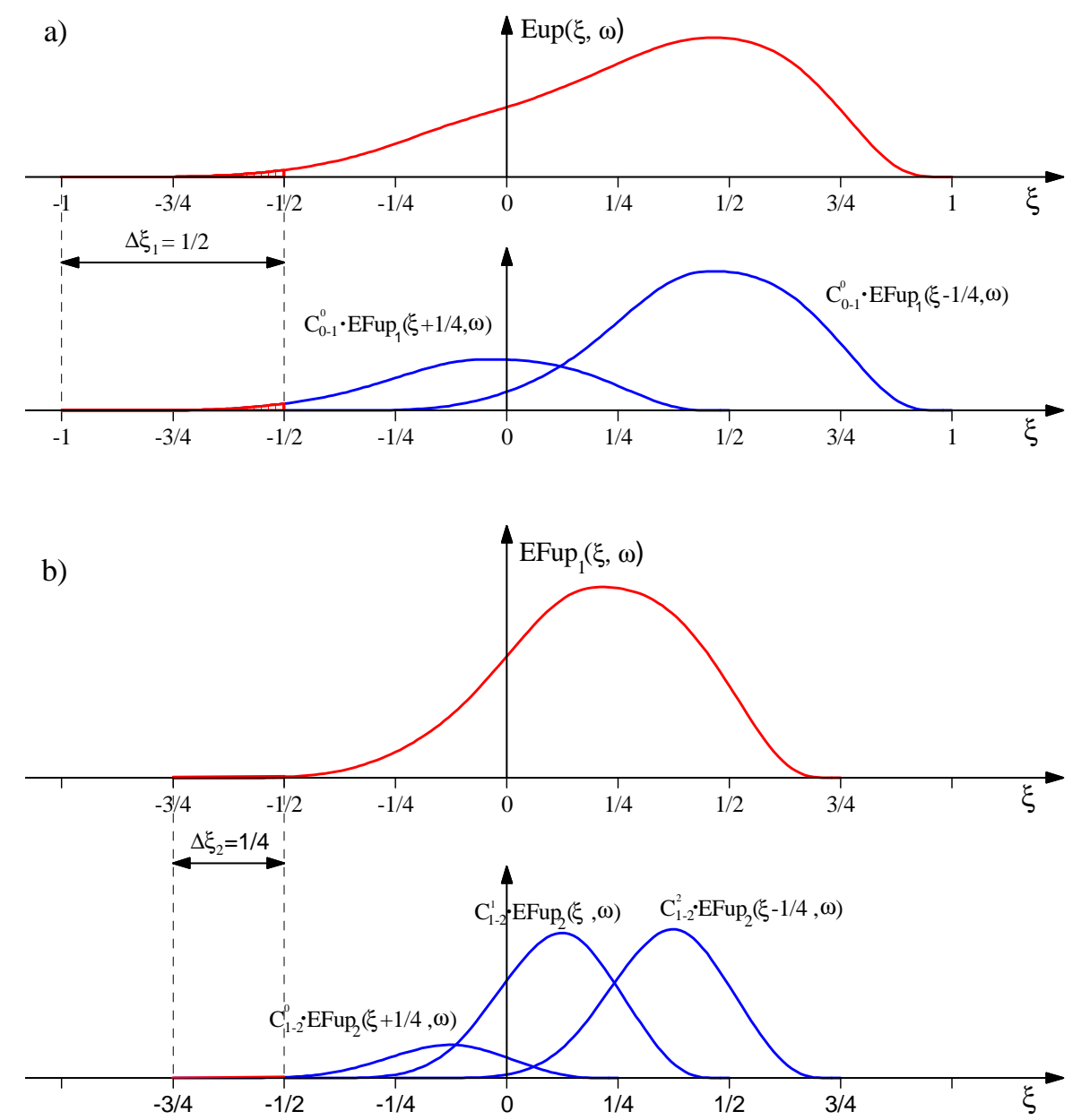

Crtež 6.6 a) Funkcija $\operatorname{Eup}(\xi, \omega)$ u obliku linearne kombinacije $E F u p_{1}(\xi, \omega)$ baznih funkcija b) Funkcija $\operatorname{EFup}_{1}(\xi, \omega)$ u obliku linearne kombinacije $\operatorname{EFup}_{2}(\xi, \omega)$ baznih funkcija 
$\mathrm{Na}$ crtežu se vidi da je funkcija $\operatorname{Eup}(\xi, \omega)$ proporcionalna s funkcijom $\operatorname{EFup}_{1}(\xi+$ $1 / 4, \omega)$ na odsječku $[-1,-1 / 2]$, koji upravo predstavlja prvi karakteristični odsječak bazne funkcije $\operatorname{EFup}_{1}(\xi, \omega)$, te je koeficijent proporcionalnosti prema (6.37) jednak

$$
C_{0-1}^{0}=1 /\left(e^{\omega / 2}+1\right)
$$

$\mathrm{Na}$ analogan način se bazna funkcija $\operatorname{EFup}_{1}(\xi, \omega)$ može prikazati u obliku linearne kombinacije pomaknutih baznih funkcija $\operatorname{EFup}_{2}(\xi, \omega)$ :

$\operatorname{EFup}_{1}(\xi, \omega)=\frac{\operatorname{EFup}_{2}\left(\xi+\frac{1}{4}, \omega\right)}{\left(e^{\omega / 4}+1\right) \cdot\left(e^{\omega / 2}+1\right)}+\frac{e^{\omega / 4} \cdot \operatorname{EFup}_{2}(\xi, \omega)}{\left(e^{\omega / 2}+1\right)}+\frac{e^{3 \omega / 4} \cdot \operatorname{EFup}_{2}\left(\xi-\frac{1}{4}, \omega\right)}{\left(e^{\omega / 4}+1\right) \cdot\left(e^{\omega / 2}+1\right)}$

U izrazu (6.39) vidi se da su i atomske bazne funkcije $\operatorname{EFup}_{1}(\xi, \omega)$ i $\operatorname{EFup}_{2}(\xi+1 / 4, \omega)$ također međusobno proporcionalne na odsječku $[-3 / 4,-1 / 2]$ koji predstavlja prvi karakteristični odsječak bazne funkcije $\operatorname{EFup}_{2}(\xi, \omega)$, crtež $6.6 \mathrm{~b}$, te da je koeficijent proporcionalnosti:

$$
C_{1-2}^{0}=1 /\left[\left(e^{\omega / 4}+1\right) \cdot\left(e^{\omega / 2}+1\right)\right]
$$

Uvrštavanjem izraza (6.39) u (6.26) dobije se da su i bazne funkcije $\operatorname{Eup}(\xi, \omega)$ i $\operatorname{EFup}_{2}(\xi, \omega)$ međusobno proporcionalne na prvom karakterističnom odsječku funkcije $\operatorname{EFup}_{2}(\xi, \omega)$ s koeficijentom proporcionalnosti:

$$
C_{0-2}^{0}=1 /\left[\left(e^{\omega / 4}+1\right) \cdot\left(e^{\omega / 2}+1\right)^{2}\right]
$$

Iz navedenog slijedi da se atomske bazne funkcije $\operatorname{EFup}_{n}(\xi, \omega)$ na prvom karakterističnom odsječku $\left[-\frac{n+2}{2^{n+1}},-\frac{n}{2^{n+1}}\right]$ mogu prikazati pomoću bazne funkcije $\operatorname{Eup}(\xi, \omega)$ definirane na odsječku $\left[-1,-1+2^{-n}\right]$ i pomnožene koeficijentom proporcionalnosti općeg oblika

$$
C_{0}(n)=\prod_{i=1}^{n}\left(e^{\omega / 2^{n-i+1}}+1\right)^{i}
$$

\section{6 $\operatorname{EFup}_{\mathbf{n}}(\xi)$ kao linearna kombinacija pomaknutih funkcija $\operatorname{Eup}(\xi, \omega)$}

Vrijednosti baznih funkcija $\operatorname{EFup}_{n}(\xi, \omega)$ u proizvoljnim diskretnim točkama mogu se, između ostalog, odrediti i razvojem izraza (6.11) u Fourierov red. Međutim, analogno algebarskim $\mathrm{ABF}$, praktično najpovoljnija mogućnost konstruiranja funkcija $\operatorname{EFup}_{n}(\xi, \omega)$ je u obliku linearne kombinacije međusobno pomaknutih $\operatorname{Eup}(\xi, \omega)$ baznih funkcija 


$$
\operatorname{EFup}_{n}(\xi, \omega)=\sum_{k=0}^{\infty} C_{k}(n) \cdot \operatorname{Eup}\left(\xi-1-\frac{k}{2^{n}}+\frac{n+2}{2^{n+1}}, \omega\right)
$$

gdje su $C_{k}(n)$ koeficijenti linearne kombinacije.

„Nulti“ koeficijenti $C_{0}(n)$ određeni su izrazom (6.42), a ostali koeficijenti linearne kombinacije $C_{k}(n), k=1, \ldots, n+1$ su nepoznati i određuju se kako slijedi.

Na primjer, za baznu funkciju $\operatorname{EFup}_{2}(\xi, \omega)$ linearna kombinacija (6.43) ima sljedeći oblik

$$
\operatorname{EFup}_{2}(\xi, \omega)=C_{0}(2) \cdot y_{\omega}\left(\xi-\frac{1}{2}\right)+C_{1}(2) \cdot y_{\omega}\left(\xi-\frac{3}{4}\right)+C_{2}(2) \cdot y_{\omega}(\xi-1)+C_{3}(2) \cdot y_{\omega}\left(\xi-\frac{5}{4}\right)
$$

ili napisana u karakterističnim točkama:

$$
\begin{aligned}
& \operatorname{EFup}_{2}\left(-\frac{1}{4}\right)=C_{0}(2) \cdot y_{\omega}\left(-\frac{3}{4}\right) \\
& \operatorname{EFup}_{2}(0)=C_{0}(2) \cdot y_{\omega}\left(-\frac{1}{2}\right)+C_{1}(2) \cdot y_{\omega}\left(-\frac{3}{4}\right) \\
& \operatorname{EFup}_{2}\left(\frac{1}{4}\right)=C_{0}(2) \cdot y_{\omega}\left(-\frac{1}{4}\right)+C_{1}(2) \cdot y_{\omega}\left(-\frac{1}{2}\right)+C_{2}(2) \cdot y_{\omega}\left(-\frac{3}{4}\right) \\
& \operatorname{EFup}_{2}\left(\frac{1}{2}\right)=C_{0}(2) \cdot y_{\omega}(0)+C_{1}(2) \cdot y_{\omega}\left(-\frac{1}{4}\right)+C_{2}(2) \cdot y_{\omega}\left(-\frac{1}{2}\right)+C_{3}(2) \cdot y_{\omega}\left(-\frac{3}{4}\right)
\end{aligned}
$$

gdje su vrijednosti bazne funkcije $\operatorname{EFup}_{2}(\xi, \omega)$ u karakterističnim točkama poznate i računaju se kako je pokazano u točki 6.4 .

Iz prve jednadžbe u (6.45) izravno slijedi izraz za „,nulti“ koeficijent u obliku

$$
C_{0}(2)=\frac{\operatorname{EFup}_{2}(-1 / 4)}{y_{\omega}(-3 / 4)}
$$

Uvrštavanjem vrijednosti $y_{\omega}(-3 / 4)$ iz (5.64) i (6.32) u (6.46) dobije se

$$
C_{0}(2)=\left(e^{\omega / 4}+1\right) \cdot\left(e^{\omega / 2}+1\right)^{2}
$$

što odgovara izrazu (6.42) za $n=2$.

Iz druge jednadžbe u (6.45) slijedi ,,prvi“ koeficijent linearne kombinacije (6.44) oblika

$$
C_{1}(2)=\frac{\operatorname{EFup}_{2}(0)-C_{0}(2) \cdot y_{\omega}(-1 / 2)}{y_{\omega}(-3 / 4)}
$$

Uvrštavanjem koeficijenta $C_{0}(2)$ i ostalih potrebnih vrijednosti dobije se

$$
C_{1}(2)=-e^{\omega / 4} \cdot\left(e^{\omega / 4}+1\right) \cdot\left(e^{\omega / 2}+1\right)
$$

Iz treće jednadžbe u (6.45) slijedi izraz za „treći“ koeficijent, itd. Poopćavanjem prikazanog postupka dolazi se do općeg izraza za koeficijente $C_{k}(n)$ u obliku rekurzivne formule: 


$$
C_{k}(n)=\frac{\operatorname{EFup}_{n}\left(-\frac{n+2}{2^{n+1}}+\frac{k+1}{2^{n}}, \omega\right)-\sum_{i=1}^{k} C_{i-1}(n) \cdot \operatorname{Eup}\left(-1+\frac{k+2-i}{2^{n}}, \omega\right)}{\operatorname{Eup}\left(-1+2^{-n}, \omega\right)}
$$

gdje su koeficijenti $C_{0}(n)$ određeni sa (6.42).

Dakle, za određivanje koeficijenata $C_{k}(n), k=0, \ldots, n+1$ linearne kombinacije (6.43) potrebno je poznavati „nulti“ koeficijent $C_{0}(n)$ te vrijednosti funkcija $\operatorname{Eup}(\xi, \omega)$ i $\operatorname{EFup}_{n}(\xi, \omega)$ u karakterističnim točkama $\xi_{k}$.

$\mathrm{Na}$ crtežu 6.7 prikazana je funkcija $\operatorname{EFup}_{2}(\xi, \omega)$ u obliku linearne kombinacije međusobno pomaknutih $\operatorname{Eup}(\xi, \omega)$ baznih funkcija.

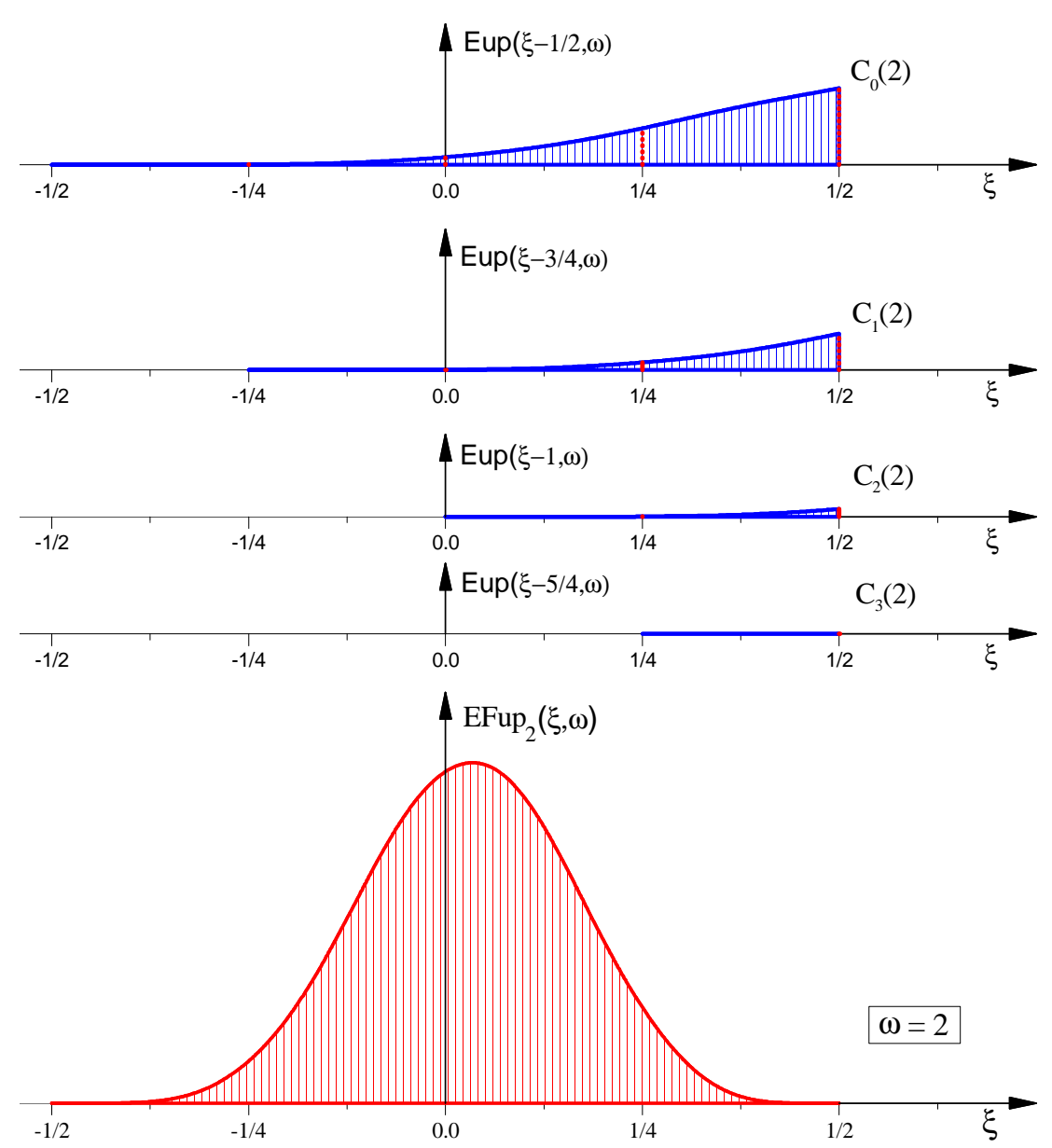

Crtež 6.7 Funkcija $\operatorname{EFup}_{2}(\xi, \omega)$ kao linearna kombinacija pomaknutih $\operatorname{Eup}(\xi, \omega)$ funkcija

Koeficijenti linearne kombinacije za razvoj baznih funkcija $\operatorname{EFup}_{n}(\xi, \omega), n=1, \ldots, 4$ mogu se napisati i u obliku

$$
C_{k}(n)=C_{0}(n) \cdot C_{k}{ }^{\prime}(n), \quad k=0, \ldots, n+1
$$

gdje su $C_{0}(n)$ određeni izrazom $(6.42)$, a pomoćni koeficijenti $C_{k}{ }^{\prime}(n), n=0, \ldots, 4$ su slijedeći izrazi: 


$$
\begin{aligned}
& C_{0}{ }^{\prime}(0)=1 \\
& C_{0}{ }^{\prime}(1)=1 \\
& C_{1}{ }^{\prime}(1)=-e^{\omega / 2} \\
& C_{2}{ }^{\prime}(1)=e^{\omega} \\
& C_{0}{ }^{\prime}(2)=1 \\
& C_{1}{ }^{\prime}(2)=-e^{\omega / 4} \cdot\left(e^{\omega / 4}+1\right) \\
& C_{2}{ }^{\prime}(2)=e^{3 \omega / 4} \cdot\left(e^{\omega / 4}+1\right) \\
& C_{3}{ }^{\prime}(2)=-e^{5 \omega / 4} \cdot\left(e^{\omega / 4}+1\right) \\
& C_{0}{ }^{\prime}(3)=1 \\
& C_{1}^{\prime}(3)=-\mathrm{e}^{\omega / 8} \cdot\left(\mathrm{e}^{3 \omega / 8}+\mathrm{e}^{\omega / 8}+1\right) \\
& C_{2}{ }^{\prime}(3)=\mathrm{e}^{3 \omega / 8} \cdot\left(\mathrm{e}^{5 \omega / 8}+\mathrm{e}^{3 \omega / 8}+\mathrm{e}^{\omega / 4}+1\right) \\
& C_{3}^{\prime}(3)=-\mathrm{e}^{7 \omega / 8} \cdot\left(\mathrm{e}^{5 \omega / 8}+\mathrm{e}^{3 \omega / 8}+\mathrm{e}^{\omega / 4}+1\right) \\
& C_{4}^{\prime}(3)=\mathrm{e}^{\omega} \cdot\left(\mathrm{e}^{\omega}+\mathrm{e}^{3 \omega / 4}+\mathrm{e}^{5 \omega / 8}+\mathrm{e}^{3 \omega / 8}+1\right) \\
& C_{0}{ }^{\prime}(4)=1 \\
& C_{1}{ }^{\prime}(4)=-e^{\frac{\omega}{16}} \cdot\left(e^{\frac{7 \omega}{16}}+e^{\frac{3 \omega}{16}}+e^{\frac{\omega}{16}}+1\right) \\
& C_{2}{ }^{\prime}(4)=e^{\frac{3 \omega}{16}} \cdot\left(e^{\frac{13 \omega}{16}}+e^{\frac{9 \omega}{16}}+e^{\frac{7 \omega}{16}}+e^{\frac{3 \omega}{8}}+e^{\frac{3 \omega}{16}}+e^{\frac{\omega}{8}}+1\right) \\
& C_{3}{ }^{\prime}(4)=-e^{\frac{7 \omega}{16}} \cdot\left(e^{\frac{17 \omega}{16}}+e^{\frac{13 \omega}{16}}+e^{\frac{11 \omega}{16}}+e^{\frac{5 \omega}{8}}+e^{\frac{7 \omega}{16}}+e^{\frac{3 \omega}{8}}+e^{\frac{\omega}{4}}+1\right) \\
& C_{4}{ }^{\prime}(4)=e^{\frac{15 \omega}{16}} \cdot\left(e^{\frac{17 \omega}{16}}+e^{\frac{13 \omega}{16}}+e^{\frac{11 \omega}{16}}+e^{\frac{5 \omega}{8}}+e^{\frac{7 \omega}{16}}+e^{\frac{3 \omega}{8}}+e^{\frac{\omega}{4}}+e^{\frac{\omega}{16}}+1\right) \\
& C_{5}{ }^{\prime}(4)=-e^{\frac{17 \omega}{16}} \cdot\left(e^{\frac{23 \omega}{16}}+e^{\frac{19 \omega}{16}}+e^{\frac{17 \omega}{16}}+e^{\omega}+e^{\frac{13 \omega}{16}}+e^{\frac{3 \omega}{4}}+e^{\frac{5 \omega}{8}}+e^{\frac{7 \omega}{16}}+e^{\frac{3 \omega}{8}}+e^{\frac{3 \omega}{16}}+e^{\frac{\omega}{16}}+1\right)
\end{aligned}
$$

U limesu kada $\omega \rightarrow 0$ koeficijenti $C_{k}{ }^{\prime}(n)$ iz (6.52) za razvoj eksponencijalnih funkcija $\operatorname{EFup}_{n}(\xi, \omega), n=1, \ldots, 4$ prelaze u koeficijente $C_{k}{ }^{\prime}(n)$ iz tablice 4.1 za razvoj algebarskih baznih funkcija $\mathrm{Fup}_{n}(\xi)$ u obliku linearne kombinacije međusobno pomaknutih funkcija $u p(\xi)$. 


\subsection{Derivacije i integrali funkcije $\operatorname{EFup}_{\mathbf{n}}(\xi, \omega)$}

Derivacije funkcije $\operatorname{EFup}_{n}(\xi, \omega)$ dobivaju se linearnom kombinacijom derivacija pomaknutih funkcija $\operatorname{Eup}(\xi, \omega)$ pomoću koeficijenata određenih u prethodnoj točki:

$$
\operatorname{EFup}_{n}^{(m)}(\xi, \omega)=\sum_{k=0}^{\infty} C_{k}(n) \cdot \operatorname{Eup}^{(m)}\left(\xi-1-\frac{k}{2^{n}}+\frac{n+2}{2^{n+1}}, \omega\right)
$$

Na crtežu 6.8 prikazane su komponente derivacija $y_{2}^{*}(\xi, \omega)$ s pripadajućim koeficijentima za izračun do uključivo četvrte derivacije funkcije $\operatorname{EFup}_{2}(\xi, \omega)$. Prikazane komponente derivacija su dobivene linearnom kombinacijom pripadajućih komponenata derivacija bazne funkcije $\operatorname{Eup}(\xi, \omega)$ koje su prikazane na crtežu 5.3.

Kako je to pokazano kod bazne funkcije $\operatorname{Eup}(\xi, \omega)$, koja je samo poseban slučaj funkcije $\operatorname{EFup}_{n}(\xi, \omega)$ za $n=0$, derivacija funkcije $\operatorname{EFup}_{n}(\xi, \omega)$ reda $n$ dobije se linearnom kombinacijom svih derivacija funkcije do reda $(n-1)$ i posljednje komponente koja predstavlja sažete i pomaknute same funkcije $\operatorname{EFup}_{n}(\xi, \omega)$, a što formalno odgovara $n$-toj derivaciji bazne funkcije $\mathrm{Fup}_{n}(\xi)$.

Na crtežu 6.9 prikazana je bazna funkcija $\operatorname{EFup}_{2}(\xi, \omega)$ i njene prve tri derivacije za vrijednost parametra $\omega=2 \mathrm{u}$ konačnom (zbrojenom) obliku.

Na crtežu 6.10 je prikazana bazna funkcija $\operatorname{EFup}_{4}(\xi, \omega)$ i njene prve četiri derivacije za visoku vrijednost parametra $\omega=200$. Kako se vidi na crtežu, nulta derivacija je zbog visoke vrijednosti parametra $\omega$ u potpunosti 'prešla' na pozitivnu stranu osi $\xi$. Upravo fleksibilnost i podatljivost ovih funkcija, koja se jasno vidi na crtežima, opravdava njihova izuzetna svojstva aproksimacije. Vrijednost derivacija raste za dva reda veličine tako da je četvrta derivacija funkcije $\operatorname{EFup}_{4}(\xi, \omega)$ reda veličine $10^{8}$.

Integrali funkcije $\operatorname{EFup}_{n}(\xi, \omega)$ također se dobivaju linearnom kombinacijom integrala pomaknutih $\operatorname{Eup}(\xi, \omega)$ funkcija

$$
\int_{-\infty}^{\xi} \operatorname{EFup}_{n}(\xi, \omega) d \xi=\sum_{k=0}^{\infty} C_{k}(n) \int_{-\infty}^{\xi} \operatorname{Eup}\left(\xi-1-\frac{k}{2^{n}}+\frac{n+2}{2^{n+1}}, \omega\right) d \xi
$$




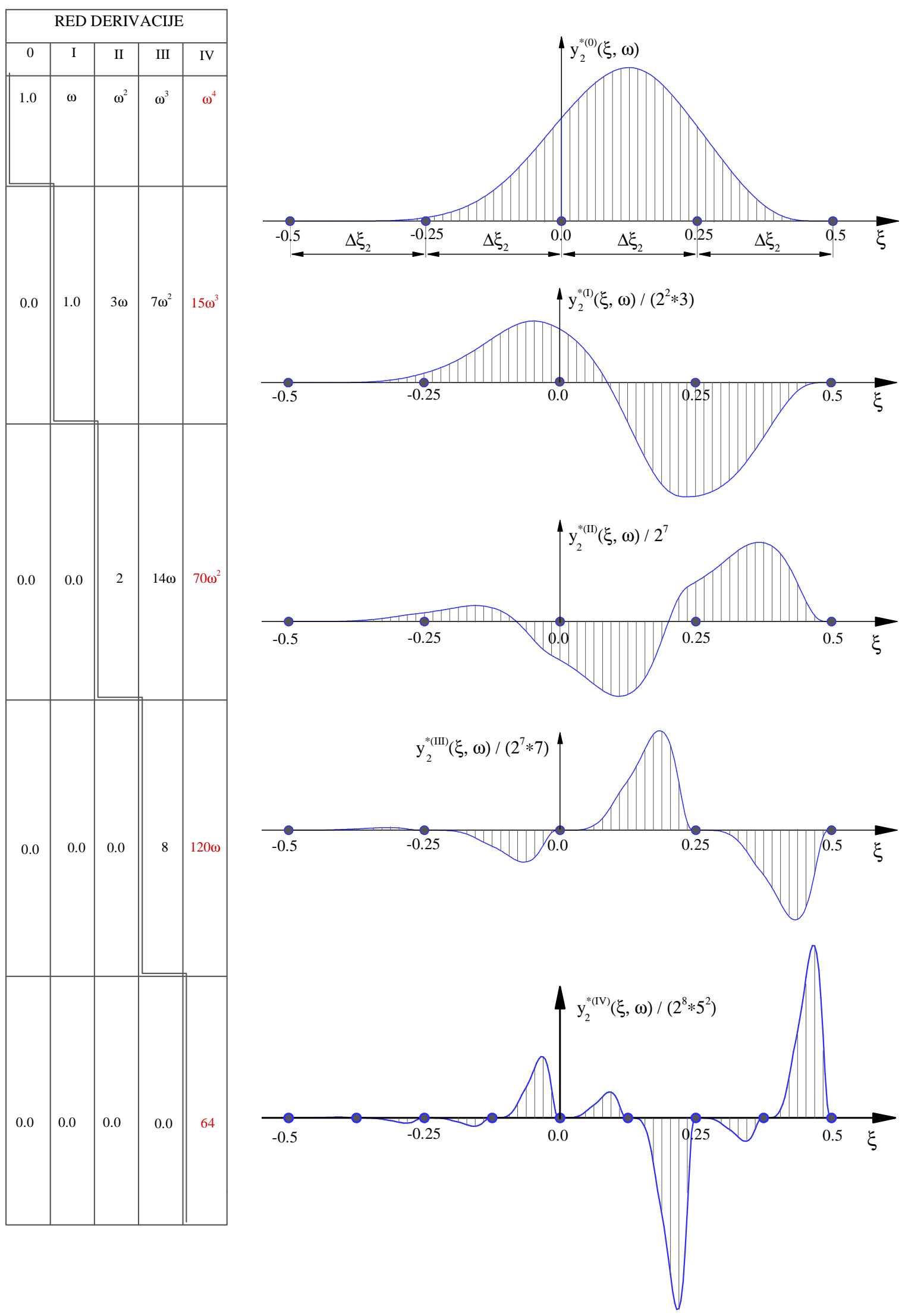

Crtež 6.8 Komponente za izračun do uključivo četvrte derivacije funkcije $\operatorname{EFup}_{2}(\xi, \omega)$ 

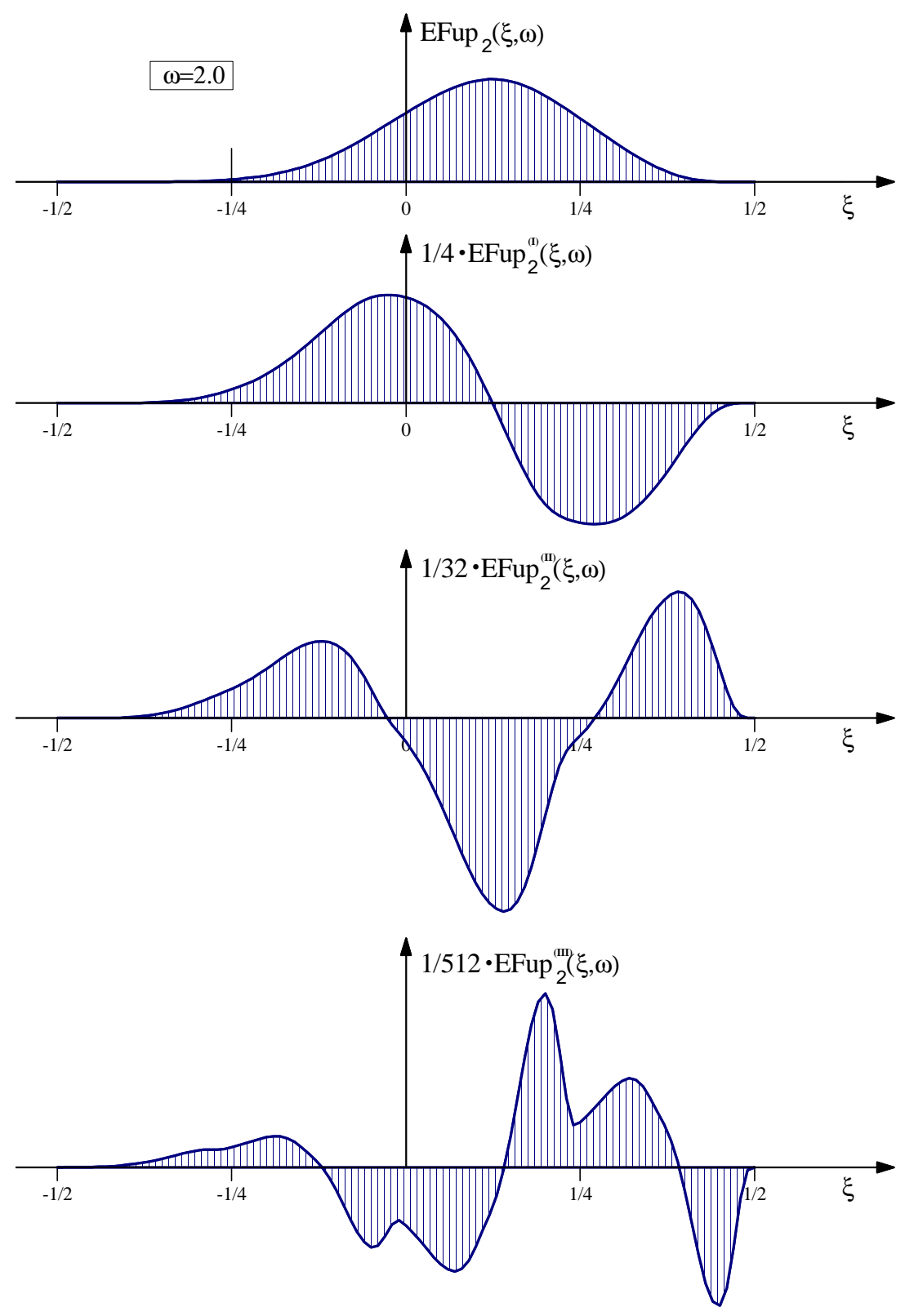

Crtež 6.9 Funkcija $\operatorname{EFup}_{2}(\xi, \omega)$ i prve tri derivacije 

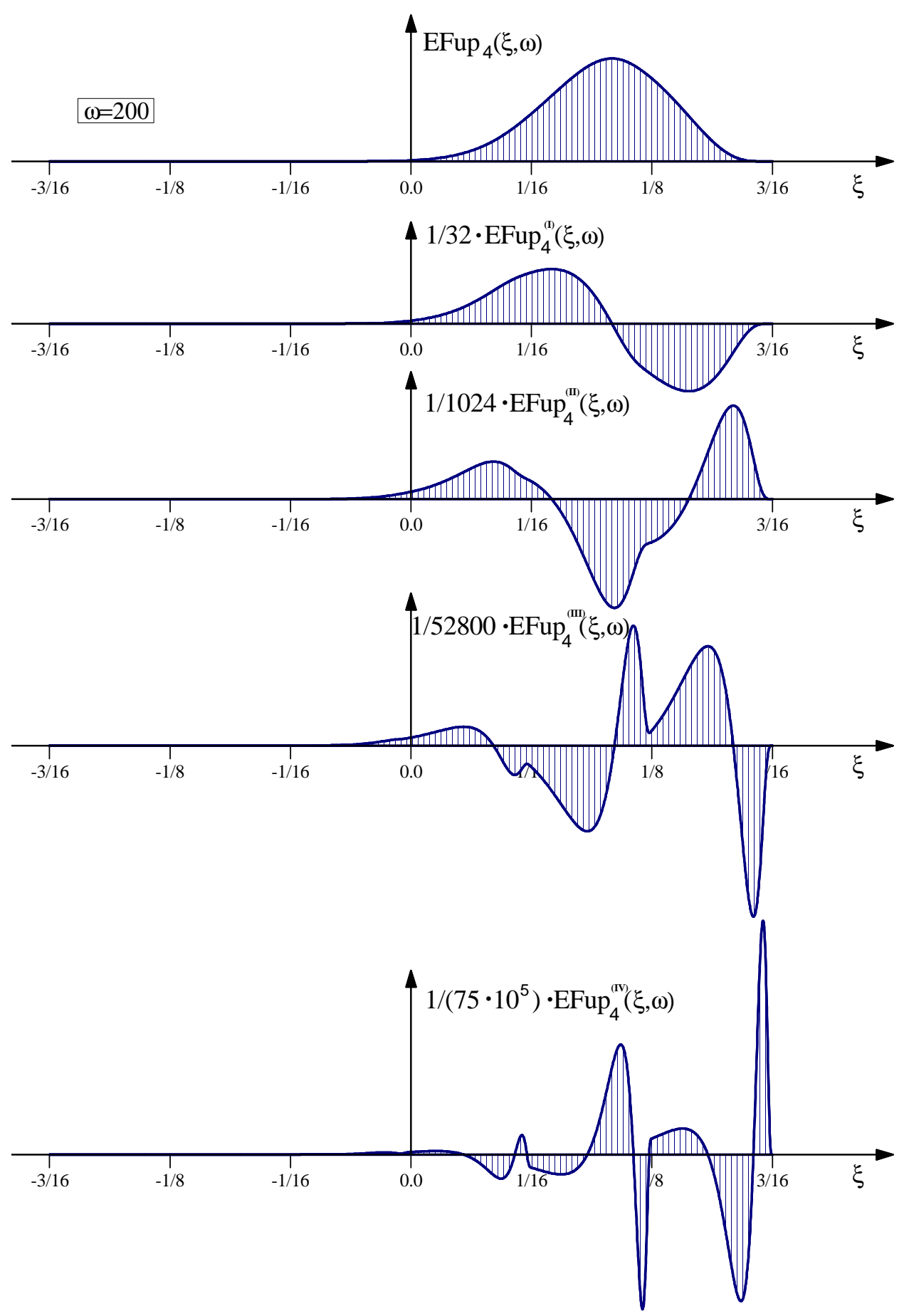

Crtež 6.10 Funkcija $\operatorname{EFup}_{4}(\xi, \omega)$ i prve četiri derivacije 


\subsection{Veza funkcije $\operatorname{EFup}_{\mathbf{n}}(\xi, \omega)$ i eksponencijalnih polinoma}

Slično kao i za funkciju $\operatorname{Eup}(\xi, \omega)$, koja je samo poseban slučaj funkcije $\operatorname{EFup}_{n}(\xi, \omega)$ za $n=0$, može se uspostaviti veza između funkcija $\operatorname{EFup}_{n}(\xi, \omega)$ i eksponencijalnih monoma $A_{m}^{(n)} \cdot e^{2^{n \cdot \omega} \cdot \xi}$. Da bi linearna kombinacija baznih funkcija $\operatorname{EFup}_{n}(\xi, \omega)$ međusobno pomaknutih za karakteristični odsječak $\Delta \xi_{n}=2^{-n}$

$$
\varphi(\xi)=\sum_{k=-\infty}^{\infty} C_{n}^{(m)}(k) \cdot \operatorname{EFup}_{n}\left(\xi-k \cdot 2^{-n}, \omega\right)
$$

bila eksponencijalni polinom stupnja $n$, nužno je i dovoljno da se za zadani $n \in N$ djelovanjem diferencijalnog operatora 5.14 na izraz (6.55) poništi linearna kombinacija na desnoj strani iz čega slijedi da koeficijenti $C_{n}^{(m)}(k)$ na odsječku $\left[k \cdot 2^{-n},(k+1) \cdot 2^{-n}\right]$ moraju zadovoljiti sljedeću jednadžbu

$$
\sum_{k=1}^{l}\left(C_{n}^{(m)}(l-k+1) \cdot \sum_{i=1}^{\left[\frac{k}{2^{n-N F U P}}\right]} C_{i}(n) \cdot D_{k-(i-1) \cdot 2^{n-N F U P}}^{(n)}\right)=0
$$

gdje je $N F U P=n$ red bazne funkcije $\operatorname{EFup}_{n}(\xi, \omega), l=2^{n-N F U P} \cdot(N F U P+2),\left[\frac{k}{2^{n-N F U P}}\right]$ je veća cjelobrojna vrijednost izraza u zagradi, $C_{n}^{(m)}(k)$ su nepoznati koeficijenti linearne kombinacije (6.56), $C_{i}(n)$ su koeficijenti linearne kombinacije baznih funkcija $\operatorname{Eup}(\xi, \omega)$ za razvoj $\operatorname{ABF} \operatorname{EFup}_{n}(\xi, \omega), D_{k}^{(n)}$ su koeficijenti određeni izrazima (6.51) i (6.52), $m=$ $0,1, \ldots, n$ je stupanj eksponencijalnog monoma, a $n$ najviši stupanj eksponencijalnog monoma sadržanog u odabranom vektorskom prostoru $E U P_{n}$.

Na crtežu 6.11a) prikazan je raspored baznih funkcija $\operatorname{EFup}_{2}(\xi, \omega)$ za $n=2$. Takvim rasporedom baznih funkcija točno se razvijaju eksponencijalni monomi do uključivo drugog stupnja kao i eksponencijalni polinom nastao njihovom kombinacijom. Nepoznati koeficijenti $C_{2}^{(m)}(k)$ određuju se na isti način kao i za funkciju $\operatorname{Eup}(\xi, \omega)$ kako slijedi.

Iz (6.56) za $n=2$ dobije se sljedeća rekurzija

$$
a_{1} \cdot C_{2}^{(m)}(k-1)+a_{2} \cdot C_{2}^{(m)}(k)+a_{3} \cdot C_{2}^{(m)}(k+1)+a_{4} \cdot C_{2}^{(m)}(k+2)=0
$$

gdje su 

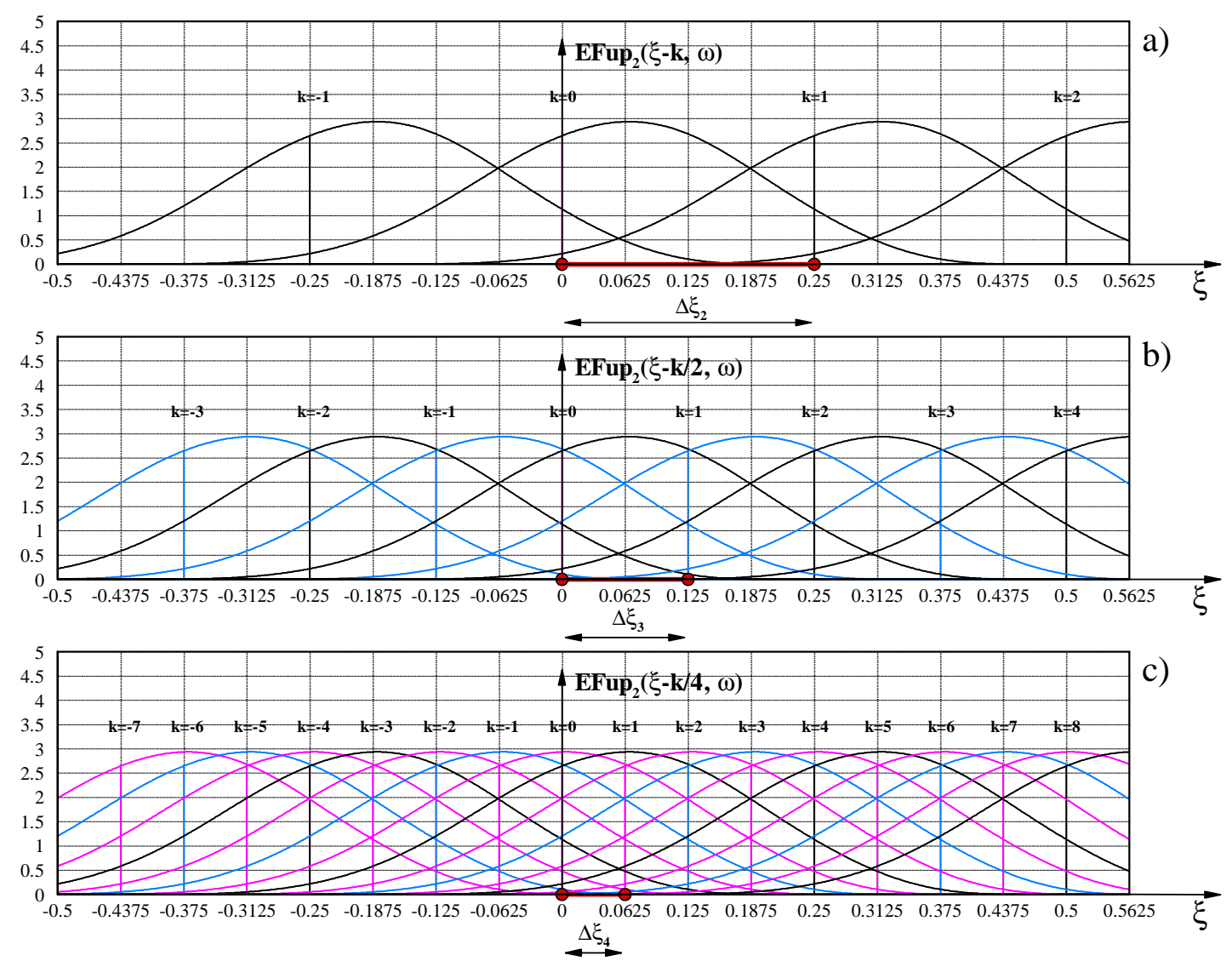

Crtež 6.11 Raspored $\operatorname{EFup}_{2}(\xi, \omega)$ funkcija za linearnu kombinaciju polinoma

$$
\begin{aligned}
& \varphi(x)=e^{\omega \cdot \xi \cdot 2^{m}}, m=2,3,4 \\
& a_{1}=64 \cdot \omega^{3} \cdot e^{7 \cdot \omega / 4} / N \\
& a_{2}=-64 \cdot \omega^{3} \cdot e^{3 \cdot \omega / 4} \cdot\left(e^{3 \cdot \omega / 4}+e^{\omega / 2}+1\right) / N \\
& a_{3}=64 \cdot \omega^{3} \cdot e^{\omega / 4} \cdot\left(e^{3 \cdot \omega / 4}+e^{\omega / 4}+1\right) / N \\
& a_{4}=-64 \cdot \omega^{3} / N \\
& N=\left(e^{\omega / 4}+1\right)^{2} \cdot\left(1-e^{\omega / 4}\right)^{3} \cdot\left(e^{\omega / 2}+1\right)
\end{aligned}
$$

ili nakon sređivanja

$$
\begin{aligned}
& e^{7 \cdot \omega / 4} \cdot C_{2}^{(m)}(k-1)+e^{3 \cdot \omega / 4} \cdot\left(e^{3 \cdot \omega / 4}+e^{\omega / 2}+1\right) \cdot C_{2}^{(m)}(k)+ \\
& +e^{\omega / 4} \cdot\left(e^{3 \cdot \omega / 4}+e^{\omega / 4}+1\right) \cdot C_{2}^{(m)}(k+1)+C_{2}^{(m)}(k+2)=0
\end{aligned}
$$

Uvođenjem zamjene $C_{2}^{(m)}(k)=\lambda^{k}$ u (6.57) dobije se karakteristična jednadžba čiji su korijeni

$$
\lambda_{0}=\mathrm{e}^{\omega / 4} ; \lambda_{1}=\mathrm{e}^{\omega / 2} ; \lambda_{2}=\mathrm{e}^{\omega}
$$

pa su koeficijenti linearne kombinacije (6.55) za $n=2$ sljedeći 


$$
C_{2}^{(0)}(k)=e^{(\omega / 4) k} ; \quad C_{2}^{(1)}(k)=e^{(\omega / 2) k} ; \quad C_{2}^{(2)}(k)=e^{\omega k}
$$

Dakle, eksponencijalni monomi nultog, prvog i drugog stupnja mogu se napisati u obliku linearne kombinacije baznih funkcija $\operatorname{EFup}_{2}(\xi, \omega)$ kako slijedi:

$$
\begin{aligned}
e^{2^{0} \omega \xi} & =\sum_{k=-\infty}^{\infty} \frac{e^{(\omega / 4) k}}{A_{2}^{(0)}} \cdot \operatorname{EFup}_{2}(\xi-\mathrm{k} / 4, \omega) \\
e^{2^{1} \omega \xi} & =\sum_{k=-\infty}^{\infty} \frac{e^{(\omega / 2) k}}{A_{2}^{(1)}} \cdot \operatorname{EFup}_{2}(\xi-\mathrm{k} / 4, \omega), \quad \mathrm{k} \in \mathrm{Z} \\
e^{2^{2} \omega \xi} & =\sum_{k=-\infty}^{\infty} \frac{e^{\omega k}}{A_{2}^{(2)}} \cdot \operatorname{EFup}_{2}(\xi-\mathrm{k} / 4, \omega)
\end{aligned}
$$

ili

$$
\begin{aligned}
e^{2^{0} \omega \xi} & =\sum_{k=-\infty}^{\infty} \frac{e^{2^{0} \omega k / 2^{2}}}{A_{2}^{(0)}} \cdot \operatorname{EFup}_{2}\left(\xi-\mathrm{k} / 2^{2}, 2^{2} \cdot \omega \cdot \frac{1}{2^{2}}\right) \\
e^{2^{1} \omega \xi} & =\sum_{k=-\infty}^{\infty} \frac{e^{2^{1} \omega k / 2^{2}}}{A_{2}^{(1)}} \cdot \operatorname{EFup}_{2}\left(\xi-\mathrm{k} / 2^{2}, 2^{2} \cdot \omega \cdot \frac{1}{2^{2}}\right), \quad \mathrm{k} \in \mathrm{Z} \\
e^{2^{2} \omega \xi} & =\sum_{k=-\infty}^{\infty} \frac{e^{2^{2} \omega k / 2^{2}}}{A_{2}^{(2)}} \cdot \operatorname{EFup}_{2}\left(\xi-\mathrm{k} / 2^{2}, 2^{2} \cdot \omega \cdot \frac{1}{2^{2}}\right)
\end{aligned}
$$

gdje su

$$
\begin{aligned}
& A_{2}^{(0)}=e^{-\omega / 4} \cdot \operatorname{EFup}_{2}(1 / 2, \omega)+\operatorname{EFup}_{2}(0, \omega)+e^{\omega / 4} \cdot \operatorname{EFup}_{2}(-1 / 2, \omega) \\
& A_{2}^{(1)}=e^{-\omega / 2} \cdot \operatorname{EFup}_{2}(1 / 2, \omega)+\operatorname{EFup}_{2}(0, \omega)+e^{\omega / 2} \cdot \operatorname{EFup}_{2}(-1 / 2, \omega) \\
& A_{2}^{(2)}=e^{-\omega} \cdot \operatorname{EFup}_{2}(1 / 2, \omega)+\operatorname{EFup}_{2}(0, \omega)+e^{\omega} \cdot \operatorname{EFup}_{2}(-1 / 2, \omega)
\end{aligned}
$$

Na crtežu 6.11b) prikazan je raspored baznih funkcija $\operatorname{EFup}_{2}(\xi, \omega)$ za $n=3$ za razvoj eksponencijalnih monoma do uključivo trećeg stupnja. Nepoznati koeficijenti $C_{3}^{(m)}(k)$ određuju se iz rekurzije

$$
\begin{aligned}
& a_{1} \cdot C_{3}^{(m)}(k-3)+a_{2} \cdot C_{3}^{(m)}(k-2)+a_{3} \cdot C_{3}^{(m)}(k-1)+a_{4} \cdot C_{3}^{(m)}(k)+ \\
+ & a_{5} \cdot C_{3}^{(m)}(k+1)+a_{6} \cdot C_{3}^{(m)}(k+2)+a_{7} \cdot C_{3}^{(m)}(k+3)+a_{8} \cdot C_{3}^{(m)}(k+4)=0
\end{aligned}
$$

gdje su 


$$
\begin{aligned}
a_{1} & =1024 \cdot \omega^{4} \cdot e^{11 \cdot \omega / 4} / N \\
a_{2} & =-1024 \cdot \omega^{4} \cdot e^{7 \cdot \omega / 4} / N \\
a_{3} & =-1024 \cdot \omega^{4} \cdot e^{7 \cdot \omega / 4} \cdot\left(e^{3 \cdot \omega / 4}+e^{\omega / 2}+1\right) / N \\
a_{4} & =1024 \cdot \omega^{4} \cdot e^{3 \cdot \omega / 4} \cdot\left(e^{3 \cdot \omega / 4}+e^{\omega / 2}+1\right) / N \\
a_{5} & =1024 \cdot \omega^{4} \cdot e^{5 \cdot \omega / 4} \cdot\left(e^{3 \cdot \omega / 4}+e^{\omega / 4}+1\right) / N \\
a_{6} & =-1024 \cdot \omega^{4} \cdot e^{\omega / 4} \cdot\left(e^{3 \cdot \omega / 4}+e^{\omega / 4}+1\right) / N \\
a_{7} & =-1024 \cdot \omega^{4} \cdot e^{\omega} / N \\
a_{8} & =1024 \cdot \omega^{4} / N \\
N & =\left(e^{\omega / 4}+1\right)^{3} \cdot\left(e^{\omega / 4}-1\right)^{4} \cdot\left(e^{\omega / 2}+1\right)^{2}
\end{aligned}
$$

pa su koeficijenti

$$
C_{3}^{(0)}(k)=e^{(\omega / 8) k}, \quad C_{3}^{(1)}(k)=e^{(\omega / 4) k}, \quad C_{3}^{(2)}(k)=e^{(\omega / 2) k}, \quad C_{3}^{(3)}(k)=e^{\omega k}
$$

Općenito vrijedi da se eksponencijalna funkcija $e^{2^{m} \omega \xi}, m=0,1, \ldots, n, n \in N$ na odsječku duljine $2^{-n}$ može točno prikazati pomoću linearne kombinacije $(N F U P+2) \cdot 2^{n}$ baznih funkcija $\operatorname{EFup}_{n}(\xi, \omega)$ međusobno pomaknutih za $2^{-n}$ u obliku

$$
e^{2^{m} \omega \xi}=\sum_{k=-\infty}^{\infty} \frac{e^{2^{m} \cdot \omega \cdot k \cdot 2^{-n}}}{A_{n}^{(m)}} \cdot \operatorname{EFup}_{n}\left(\xi-\frac{k}{2^{n}}, 2^{n} \cdot \omega \cdot \frac{1}{2^{n}}\right) ; m=0,1, \ldots, n
$$

gdje se koeficijenti $A_{n}^{(m)}$ izračunavaju iz (6.60) za $\xi=0$

$$
A_{n}^{(m)}=\sum_{i=-(N F U P+2) \cdot 2^{n-1}}^{(N F U P+2) \cdot 2^{n-1}} e^{2^{m \cdot \omega} \cdot i \cdot 2^{-n}} \cdot \operatorname{EFup}_{n}\left(-\frac{i}{2^{n}}, 2^{n} \cdot \omega \cdot \frac{1}{2^{n}}\right)
$$

ili u realnom području koordinate $x$ :

$$
e^{2^{m} \omega x}=\sum_{k=-\infty}^{\infty} \frac{e^{2^{m} \cdot \omega \cdot k \cdot \Delta x_{n}}}{A_{n, x}^{(m)}} \cdot \operatorname{EFup}_{n}\left(x-k \cdot \Delta x_{n}, 2^{n} \cdot \omega \cdot \Delta x_{n}\right) ; m=0,1, \ldots, n
$$

gdje je

$$
A_{n, x}^{(m)}=\sum_{i=-(N F U P+2) \cdot 2^{n-1}}^{(N F U P+2) \cdot 2^{n-1}} e^{2^{m} \cdot \omega \cdot i \cdot \Delta x_{n}} \cdot \operatorname{EFup}_{n}\left(-\frac{i}{\Delta x_{n}}, 2^{n} \cdot \omega \cdot \Delta x_{n}\right)
$$




\subsection{Praktično korištenje eksponencijalnih ABF}

Na Katedri za tehničku mehaniku na FGAG-u već duže vremena koristi se Module FUP_0_16_Q u programskom jeziku Fortran 90 koji omogućava vrlo jednostavnu primjenu algebarskih atomskih baznih funkcija u numeričkoj analizi. U okviru istraživanja u ovoj disertaciji kreiran je modul efupnM za izračunavanje vrijednosti funkcija $\operatorname{EFup}_{n}(\xi, \omega)$ i njihovih derivacija u proizvoljnim točkama. Korištenje programskih modula svodi se na jednostavno pozivanje funkcije na sličan način kako bi se pozivala npr. trigonometrijska funkcija sinus: $\sin (\omega x+\varphi) \rightarrow$ sinus(omega, xpoint, fi). Oba navedena modula integrirana su u jednu programsku cjelinu, a razlikovanje algebarskih atomskih baznih funkcija se postiže zadavanjem nulte vrijednosti parametra $\omega$.

U nastavku je prikazan ,kostur“ programa koji koristi module efupnM. Na crtežu 6.12 dana je grafička interpretacija varijabli koje je potrebno zadati kod korištenja modula efupnM, a na crtežu 6.13 dijagram toka modula efupnM.

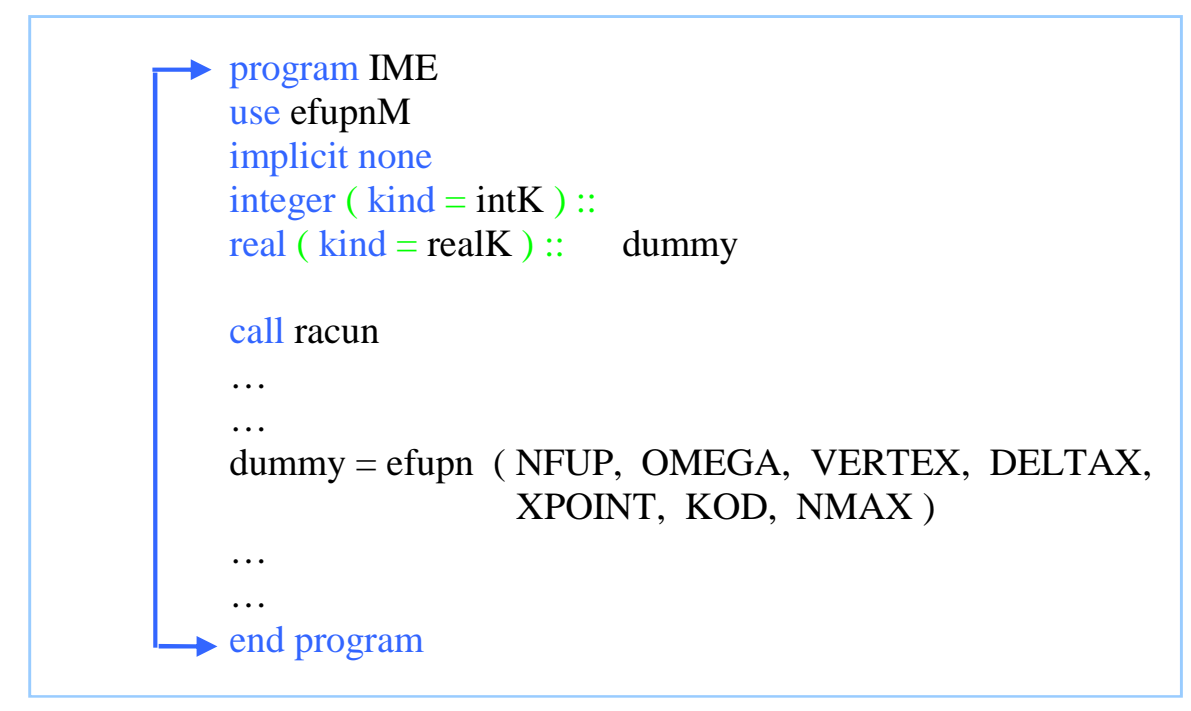

gdje je:

NFUP -

OMEGA -

red funkcije $\operatorname{EFup}_{n}(x, \omega)$

VERTEX -

frekvencija ili parametar napetosti

DELTAX

x-koordinata lokalnog koordinatnog sustava (koji se nalazi u središtu

DELTAX nosača)

XPOINT realna duljina karakterističnog odsječka

KOD realna $\mathrm{x}$-koordinata proizvoljne točke $\mathrm{u}$ kojoj se traži vrijednost funkcije $\operatorname{EFup}_{n}(x, \omega)$

NMAX red derivacije funkcije parametar točnosti (ovisi o karakteristikama računala) 


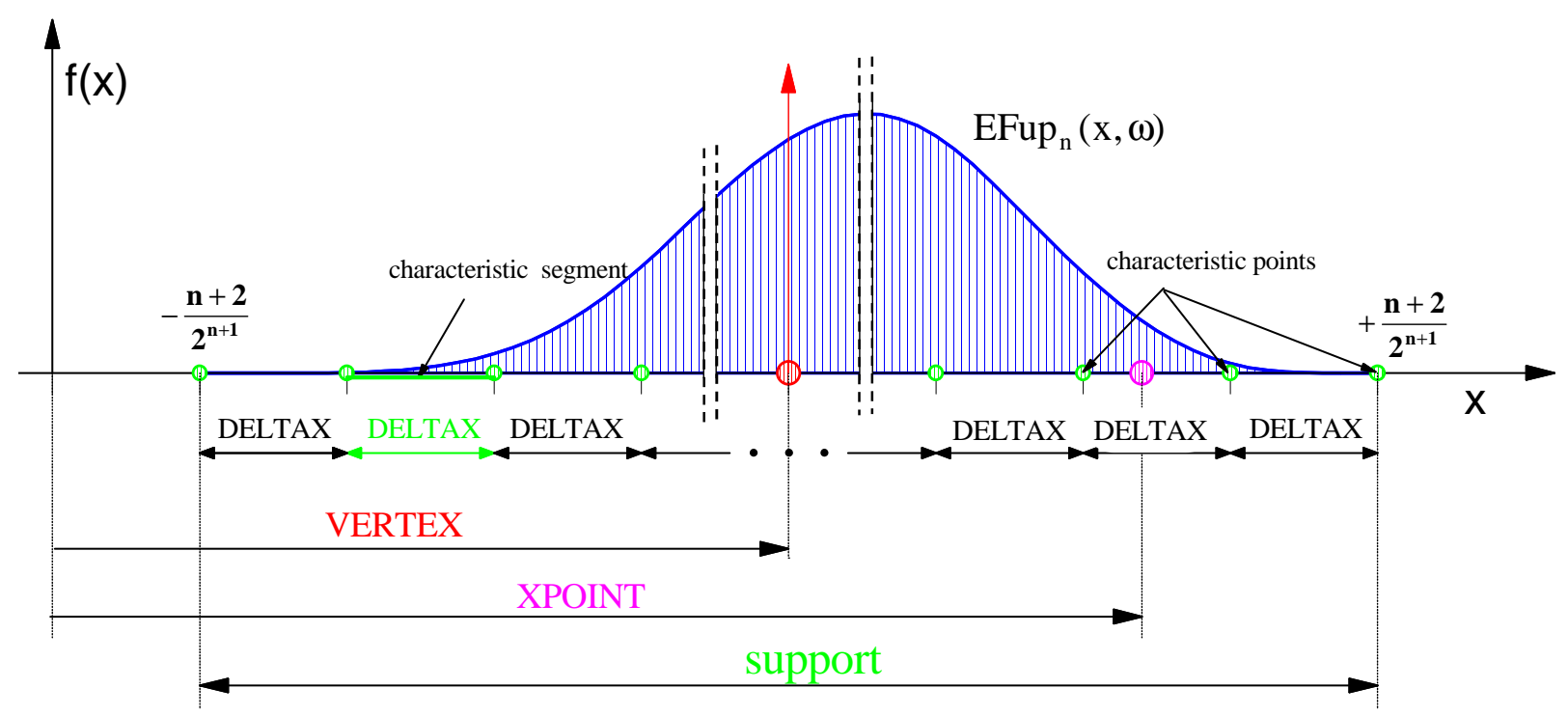

Crtež 6.12 Korištenje programskog modula efupnM za izračunavanje vrijednosti $F u p_{n}(x)$ i $\operatorname{EFup}_{n}(x, \omega)$ baznih funkcija

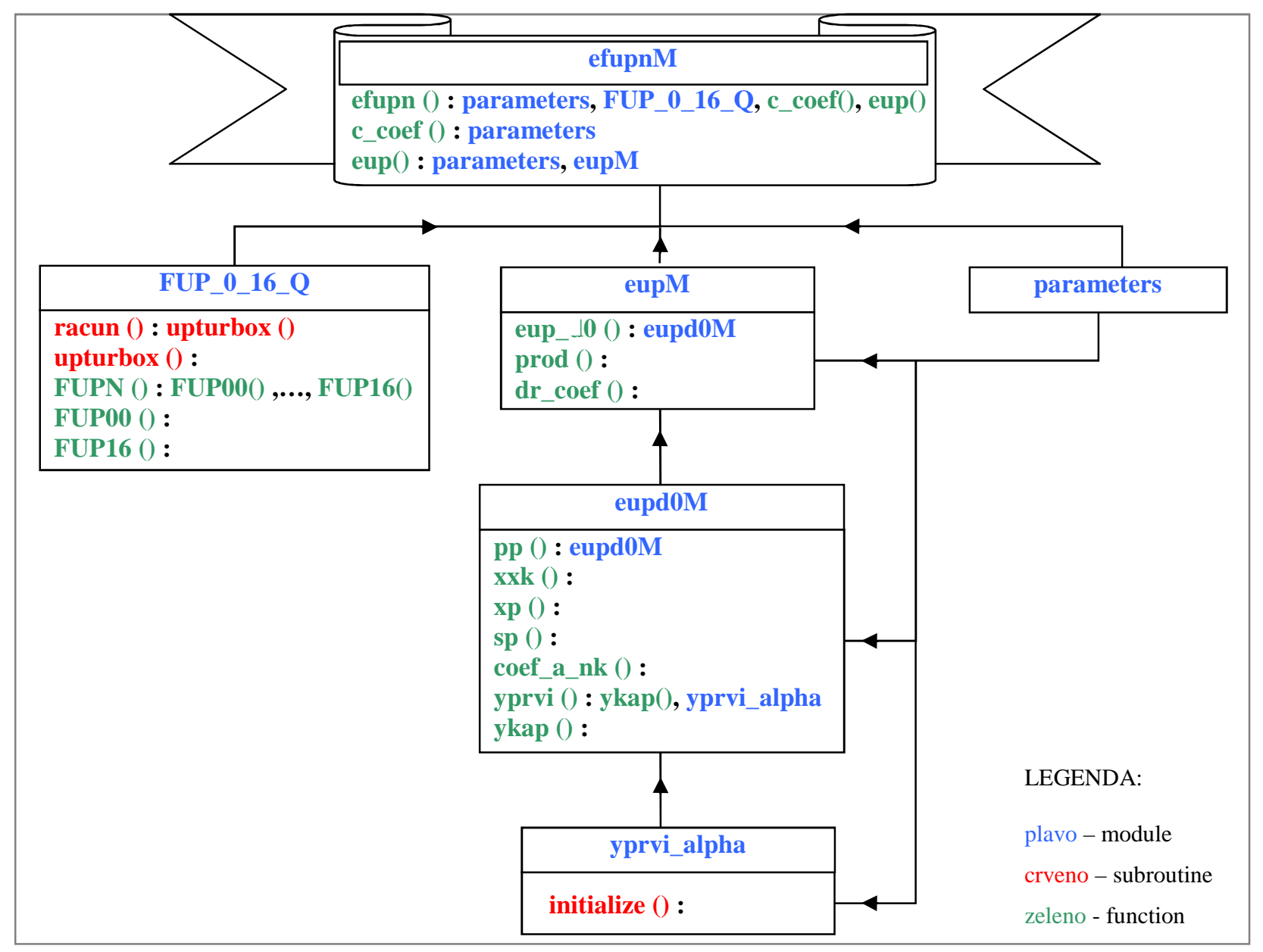

Crtež 6.13 Dijagram toka Modula efupnM 


\section{PRIMJENA EKSPONENCIJALNIH ATOMSKIH BAZNIH FUNKCIJA}

\subsection{Uvod}

Na crtežima 5.2 i 6.2 vidi se da eksponencijalne atomske bazne funkcije mijenjaju oblik obzirom na apsolutnu vrijednost parametra $\omega$, odnosno imaju otklon u lijevu ili desnu stranu ovisno o njegovom predznaku. Upravo ovo svojstvo čini ih ,podatljivima“ i daje im prednost u odnosu na algebarske ABF i to naročito u opisivanju rješenja s velikim gradijentima gdje su općenito algebarske bazne funkcije podložne tzv. Gibsovom efektu.

S obzirom da eksponencijalne atomske bazne funkcije točno opisuju eksponencijalne polinome za koje vrijedi

$$
y^{\prime}=\omega \cdot y \quad \rightarrow \quad \omega=y^{\prime} / y
$$

gdje je $y$ eksponencijalni polinom, jedan od kriterija izbora parametra $\omega$ u određenim primjerima aproksimacije funkcije biti će upravo (7.1), dok u drugim primjerima može pomoći u određivanju intervala vrijednosti parametra. Kada su problemi opisani diferencijalnom jednadžbom parameter $\omega$ određuje se iz fizikalnih karakteristika problema.

U nastavku se pokazuje tzv. trostruka baza koja sadrži bazne funkcije sa pozitivnom i negativnom vrijednosti parametra $\omega$ te sa vrijednosti parametra $\omega=0$ čime se postiže općenitost kako u postupcima aproksimacije funkcije tako i u rješavanju diferencijalnih jednadžbi. Također, pokazana je i primjena multirezolucijskog postupka. 


\subsection{Raspored baznih funkcija u trostrukoj bazi}

ABF eksponencijalnog tipa u odnosu na bazne funkcije algebarskog tipa sadrže i parametar $\omega$, ili analogno trigonometrijskim funkcijama, frekvenciju.

Kako je već rečeno u prethodnim poglavljima, nema općenito gledano jedinstvenog kriterija za izbor parametra $\omega \mathrm{u}$ problemima aproksimacije zadane funkcije i rješavanju diferencijalnih jednadžbi ukoliko on nije zadan unutar same jednadžbe.

Iz tog razloga, formira se baza u vektorskom podprostoru koji sadrži eksponencijalne ABF sa pozitivnom i negativnom vrijednosti parametra $\omega \mathrm{tj}$. bazne funkcije $\operatorname{EFup}_{n}(x,+\omega) \mathrm{i}$ $\operatorname{EFup}_{n}(x,-\omega)$. Time se postiže općenitost u smislu izbora predznaka frekvencije $\omega$ na razini dimenzije odabranog podprostora.

Također, osim eksponencijalnih ABF formirana baza sadrži i algebarske $\operatorname{ABF~Fup~}_{n}(x)$ ili barem $u p(x)$ kako bi se ispunio kriterij ,razvoja jedinice“. Naime, vektorski prostor $E U P_{n}$ kojega tvore $\mathrm{ABF} \operatorname{EFup}_{n}(x, \omega)$ ima stanovite sličnosti sa vektorskim prostorom trigonometrijskih funkcija. Razvoj jedinice u oba prostora moguć je samo u slučaju $\omega=0$. Kao što je i prije rečeno, za vrijednost parametra $\omega=0 \rightarrow \operatorname{EFup}_{n}(x, 0)=\operatorname{Fup}_{n}(x)$.

Tako formirana baza koja uz eksponencijalne $\operatorname{ABF} \operatorname{EFup}_{n}(x,+\omega)$ i $\operatorname{EFup}_{n}(x,-\omega)$ sadrži i algebarske $\mathrm{ABF} \operatorname{Fup}_{n}(x)$ naziva se trostruka baza. Npr. za $n=2$, približno rješenje problema tražiti će se u slijedećem obliku, crtež 7.1:

$\tilde{f}(x)=\sum_{i=-6}^{n+6,4} A_{i} \cdot \operatorname{EFup}_{2}\left(\frac{x}{\Delta x_{2}}-\frac{1}{4}, \omega\right)+\sum_{j=-5}^{n+5,2} B_{j} \cdot \operatorname{EFup}_{2}\left(\frac{x}{2 \cdot \Delta x_{2}}-\frac{j}{4}, 0\right)+\sum_{k=-4}^{n+4,4} C_{k} \cdot \operatorname{EFup}_{2}\left(\frac{x}{\Delta x_{2}}-\frac{k}{4},-\omega\right)$

Izraz (7.2) predstavlja linearnu kombinaciju međusobno pomaknutih baznih funkcija $\operatorname{EFup}_{2}\left(x, \omega^{*}\right), \omega^{*}=+\omega, 0,-\omega$ gdje su istovrsne bazne funkcije međusobno pomaknute za duljinu karakterističnog odsječka $\Delta x_{2}$, pri čemu je duljina karakterističnog odsječka algebarskih, ili točnije eksponencijalnih $\mathrm{ABF}$ za vrijednost parametra $\omega=0$, upola manja od baznih funkcija $\operatorname{EFup}_{n}(x, \pm \omega)$, zbog čega je broj baznih funkcija u bazi dvostruko veći, crtež 7.1. Prostoru koji sadrži pozitivne i negativne frekvencije potrebno je dodati još toliko baznih funkcija kako bi dimenzija $2^{n}$ porasla na $2^{n+1}$. Međusobni razmak tjemena baznih funkcija je prema tome $\Delta x_{V}=\Delta x_{2} / 4$.

U nastavku su dani primjeri aproksimacije zadane funkcije te traženje približnog rješenja zadane diferencijalne jednadžbe s pripadajućim rubnim uvjetima pomoću trostruke baze $\mathrm{u}$ obliku (7.2) metodom kolokacije u točki. 
Jednadžbe za određivanje nepoznatih koeficijenata u linearnoj kombinaciji (7.2) su sljedeće:

- Za bazne funkcije s tjemenima u području i na rubu područja u kolokacijskim točkama zadovoljavaju se vrijednosti zadane funkcije (ili diferencijalna jednadžba).

- Za bazne funkcije čija su tjemena izvan područja dodatne uvjetne jednadžbe na oba ruba su zadovoljavanje vrijednosti prve derivacije zadane funkcije (rubnog uvjeta) na pojedinom rubu, a preostale jednadžbe su rekurzivne formule izvedene u točki 6.8 . 

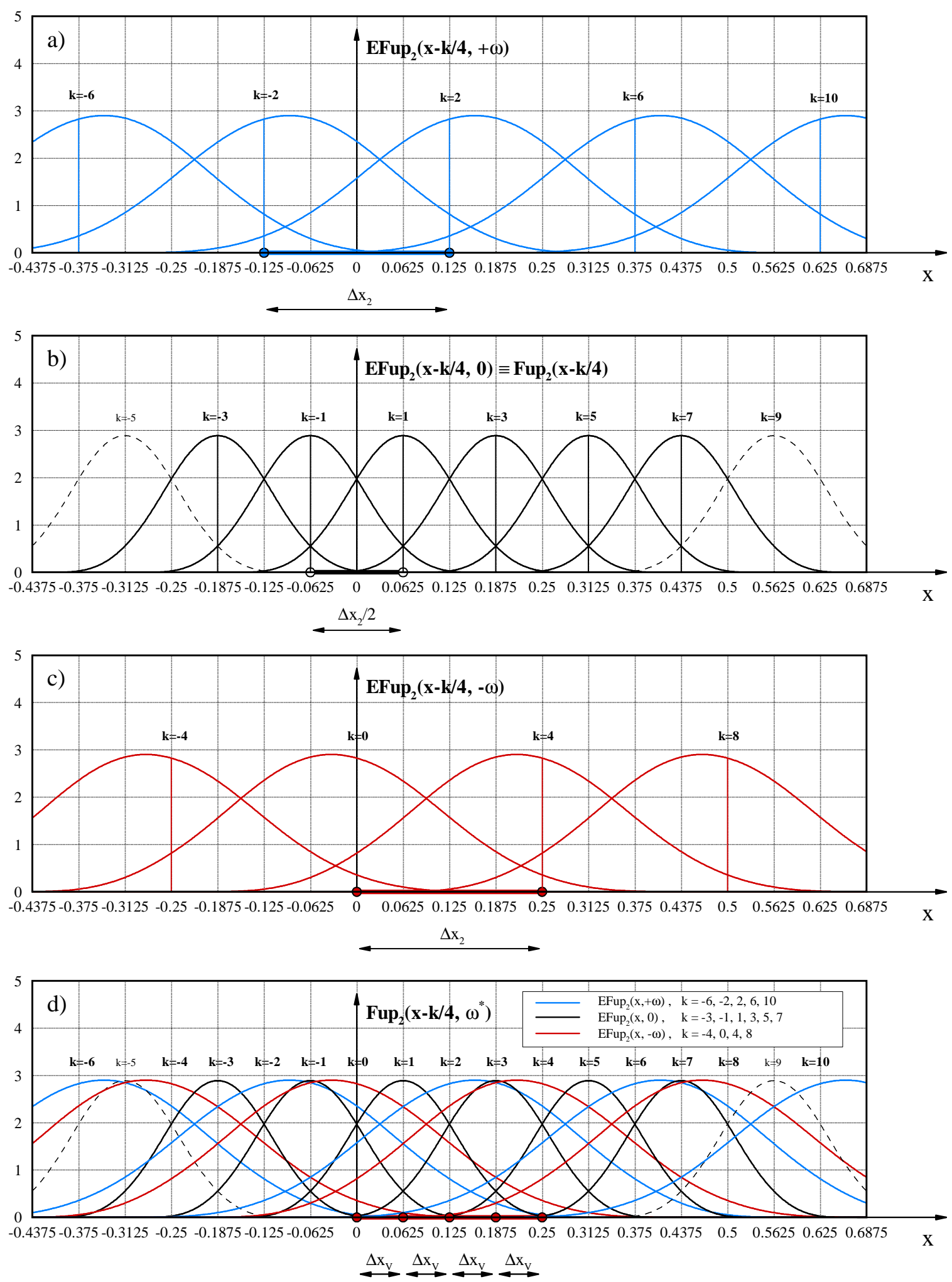

Crtež 7.1 Raspored baznih funkcija $\operatorname{EFup}_{2}\left(x, \omega^{*}\right)$ u trostrukoj bazi:

a) Bazne funkcije s negativnom frekvencijom $\omega<0$

b) Bazne funkcije s neutralnom frekvencijom $\omega=0$

c) Bazne funkcije s pozitivnom frekvencijom $\omega>0$

d) Trostruka baza 


\subsection{Multirezolucijski postupak}

U pojedinim problemima, bilo da se radi o aproksimaciji funkcije ili rješavanju diferencijalne jednadžbe, grafovi rješenja na većem dijelu područja mogu biti jednostavne funkcije (npr. konstanta ili polinom nekog nižeg stupnja) koje bi se mogle točno opisati i sa malim brojem baznih funkcija, dok tek na malom dijelu područja mogu biti složene funkcije s izraženim gradijentima gdje je potreban veliki broj baznih funkcija kako bi se rješenje aproksimiralo sa zahtjevanom točnosti. Takav je i 2. Primjer gdje je na većem dijelu područja zadana funkcija konstanta ili nul funkcija, a na dva manja intervala unutar područja su izraženi skokovi, gotovo prekidi funkcije.

U takvim slučajevima, umjesto povećavanja broja baznih funkcija na cijelom području, što je s aspekta trajanja proračuna skup postupak, pogodne su tzv. multirezolucijske metode.

Kod multirezolucijske metode područje se, ovisno o obliku rješenja, dijeli na određeni broj intervala. Na pojedinom intervalu bira se odgovarajuća podjela područja kao i prikladna vrijednost parametra $\omega$, a u točki "spoja" između dvaju intervala postavlja se uvjet neprekinutosti derivacija.
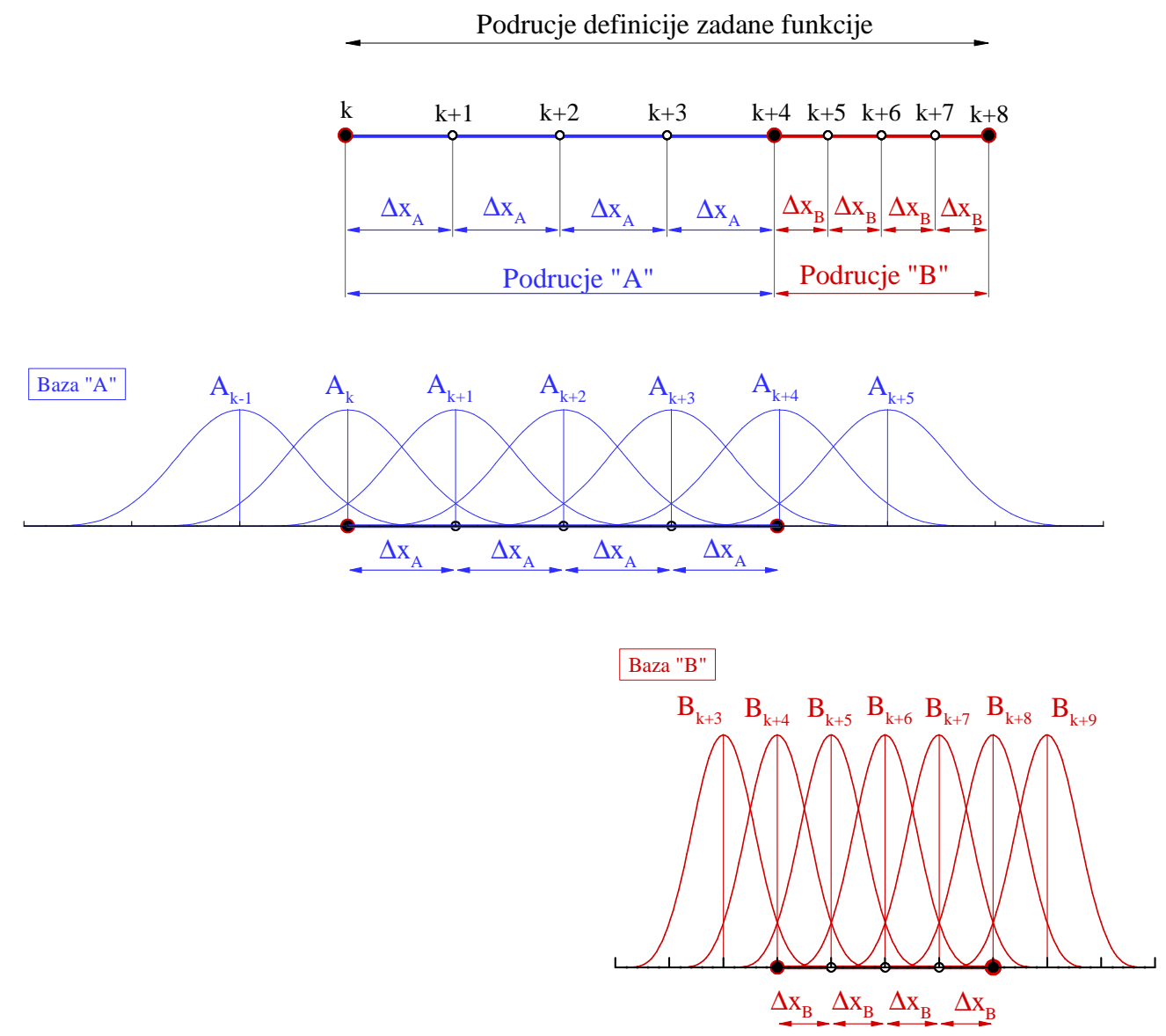

Crtež 7.2 Raspored baznih funkcija $\mathrm{Fup}_{2}(x)$ u multirezolucijskoj metodi 
Na crtežu 7.2 prikazan je raspored baznih funkcija u multirezolucijskom postupku za bazne funkcije $\operatorname{Fup}_{n}(x)$ iz izraza (7.2) (zbog jednostavnijeg prikaza). Područje definicije zadane funkcije podijeljeno je na dva intervala, A i B.

\subsection{Aproksimacija zadane funkcije}

\section{Primjer}

U prvom primjeru pokazano je opisivanje jednom glatkom funkcijom zadanu funkciju sastavljenu od elementarnih funkcija po segmentima. Elementarne funkcije su algebarski ili eksponencijalni polinomi do drugog stupnja:

$$
f(x)= \begin{cases}4 & \text { za } x \in[0,2) \\ 2 x & \text { za } x \in[2,4) \\ 8(x-5)^{2} & \text { za } x \in[4,6) \\ 8 e^{-10 x+60} & \text { za } x \in[6,8) \\ 8 e^{10 x-100} & \text { za } x \in[8,10]\end{cases}
$$

Aproksimacija zadane funkcije (7.3) određuje se pomoću linearne kombinacije (7.2) metodom kolokacije na 160 karakterističnih odsječaka. Iako je na prvi pogled broj baznih funkcija velik, važno je naglasiti da na pojedinom intervalu samo polovica ili trećina koeficijenata ostaje različita od nule.

Na prva tri intervala zadana funkcija je algebarski polinom nultog, prvog i drugog stupnja, respektivno pa je vrijednost frekvencije za točan razvoj navedenih polinoma jednaka nuli. Na četvrtom intervalu funkcija (7.3) je eksponencijalni polinom drugog stupnja sa zadanom frekvencijom $\omega=-2.5 \mathrm{tj} . f(x)=a \cdot e^{2^{2} \omega x}$, dok je na petom intervalu funkcija također eksponencijalni polinom drugog stupnja ali sa frekvencijom $\omega=+2.5$, vidi točke 5.6 i 6.8 . Dakle, vrijednost parametra $\omega$ slijedi iz same funkcije.

S obzirom da bazne funkcije $\operatorname{EFup}_{2}(x, 0)$ iz (7.2) točno opisuju navedene algebarske polinome, koeficijenti ostalih baznih funkcija su jednaki nuli osim na rubovima intervala zbog prekida funkcije. Također na četvrtom intervalu zadana funkcija je eksponencijalni polinom s negativnom frekvencijom $\omega=-2.5$ tako da su različiti od nule samo koeficijenti uz bazne funkcije $\operatorname{EFup}_{2}(x, \omega)$. Analogno vrijedi i na petom intervalu. Na crtežu 7.3 pokazana je usporedba aproksimacije sa zadanom funkcijom te odstupanje u odnosu na zadanu točnost koja je uzeta $\delta=0.2$. 

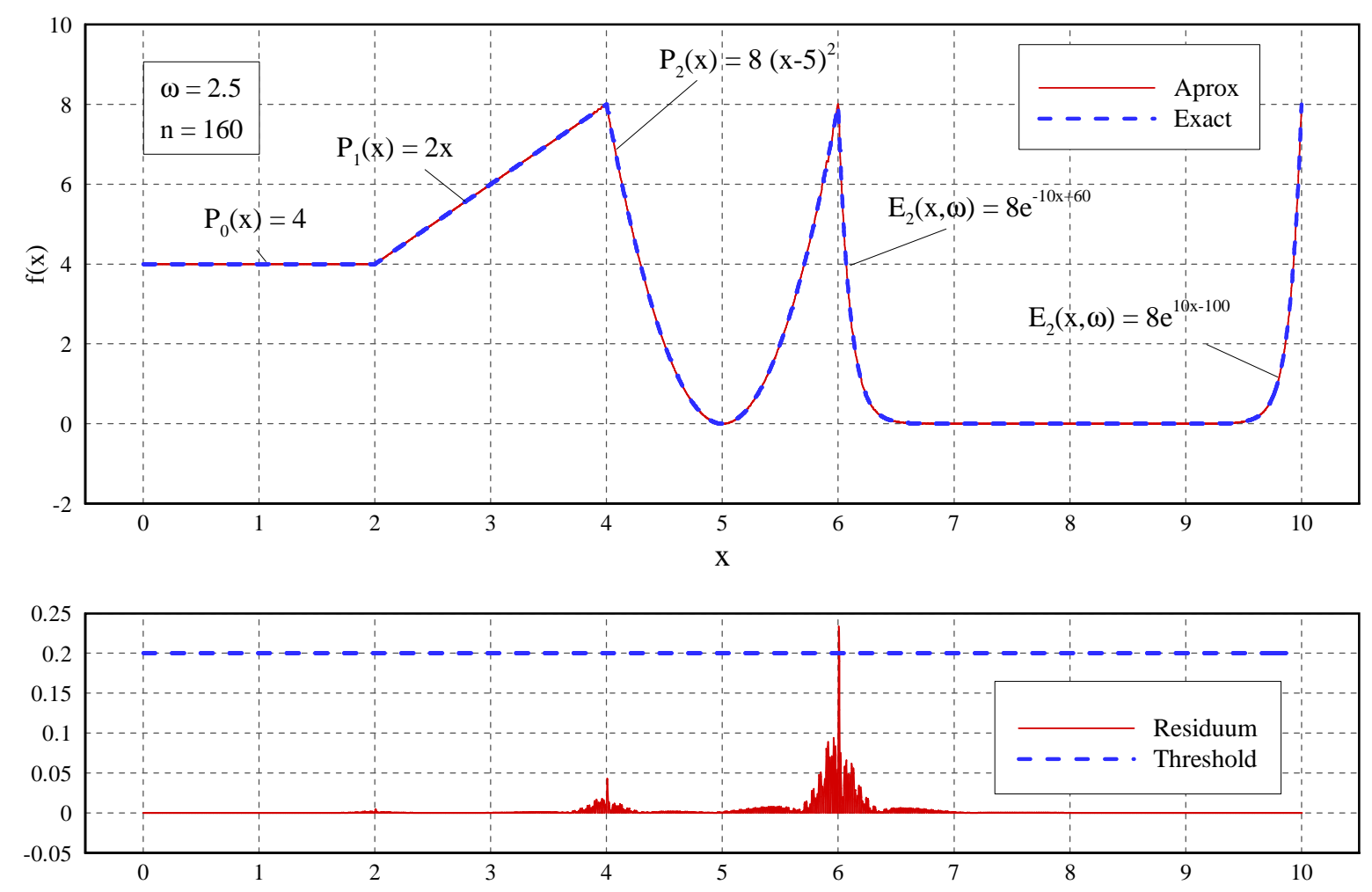

Crtež 7.3 a) Aproksimacija po dijelovima zadane funkcije jednom glatkom funkcijom

b) Odstupanje u odnosu na zadanu točnost

\section{Primjer}

Na temelju svojstava istaknutih u poglavljima 5. i 6., za očekivati je da eksponencijalne ABF daju dobra rješenja kod problema s visokim gradijentima (frontovima). Jedan od takvih problema je npr. osnovni advekcijsko dominantni problem s pomičnim oštrim frontom, tj. advekcijsko disperzijska jednadžba s konstantnom brzinom i velikim Pecletovim brojem.

Za demonstraciju aproksimacijskih svojstava eksponencijalnih ABF-ja razmatra se sljedeća test funkcija (,,front - val“)

$$
f(x)=e^{-4096 \cdot(x-1.5)^{2}}+0.5 \cdot(1-\operatorname{TANH}((x-0.75) / 0.02))
$$

Koja odgovara upravo rješenju jednog takvog problema advekcijsko disperzijske jednadžbe u određenom vremenskom trenutku uz dodatni izraženi skok (front) u obliku putujućeg vala.

Aproksimacija ove funkcije prikazana je u [19] korištenjem adaptivne multirezolucijske Fup kolokacijske transformacije s algebarskim baznim funkcijama $F u p_{4}(x)$, crtež 7.6. Očigledno je da postoje dva osjetljiva područja s oštrim gradijentima koja zahtijevaju gušću raspodjelu kolokacijskih točaka odnosno baznih funkcija. 
Ovdje je aproksimacija funkcije izvršena pomoću trostruke baze (7.2) s dosta visokom granicom točnosti $\delta=0.008$, što znači da odstupanje između ABF aproksimacije i funkcije mora biti manje od zadane vrijednosti $\delta$.

Za razliku od funkcije (7.3) gdje je vrijednost parametra $\omega$ slijedila iz same funkcije, u problemu aproksimacije funkcije (7.4) vrijednost parametra $\omega$ određuje se pomoću veze eksponencijalnih ABF sa eksponencijalnim polinomima, odnosno iz odnosa prve i nulte derivacije (7.1). S obzirom da kvocijent (7.1) za zadanu funkciju (7.4) u pojedinim točkama područja teži ka $\pm \infty$ zbog mogućnosti grafičkog prikaza uvodi se korekcijski parametar $\varepsilon$.

Na crtežu 7.4 prikazan je kvocijent (7.1) za zadanu funkciju (7.4) i različite vrijednosti parametra $\varepsilon$ gdje se uočavaju dva 'osjetljiva' područja sa oštrim gradijentima gdje vrijednost parametra teži ka maksimalnoj vrijednosti, tj. $\pm \infty$. S obzirom da je računska frekvencija baznih funkcija jednaka umnošku frekvencije i duljine karakterističnog odsječka tj. $\omega_{b f}=\omega$. $\Delta x_{2}$, za veći broj odsječaka (što podrazumijeva manju duljinu karakterističnog odsječka) može se uzeti viša vrijednost parametra $\omega$ bez da se prekorači točnost računala.

Aproksimacija zadane funkcije traži se u obliku (7.2) gdje će bazne funkcije algebarskog tipa $\operatorname{Fup}_{2}(x)$ s frekvencijom nula zadovoljiti (dominirati) u dijelu područja gdje je zadana funkcija konstantna, dok će eksponencijalne $\mathrm{ABF} \operatorname{EFup}_{2}(x, \pm \omega)$ i to sa najvišom frekvencijom (a da se ne prekorači točnost računala) zadovoljiti u dijelu gdje su dominantni frontovi.

Na crtežu 7.5 prikazana je aproksimacija zadane funkcije (7.4) kao i njene prve derivacije za broj karakterističnih odsječaka $n=128$ i odabranu vrijednost parametra $\omega=1024$ prema najvećoj vrijednosti iz omjera (7.1). Može se uočiti potpuno približenje zadanoj funkciji, čak i u dijelovima područja s izrazitim gradijentima.

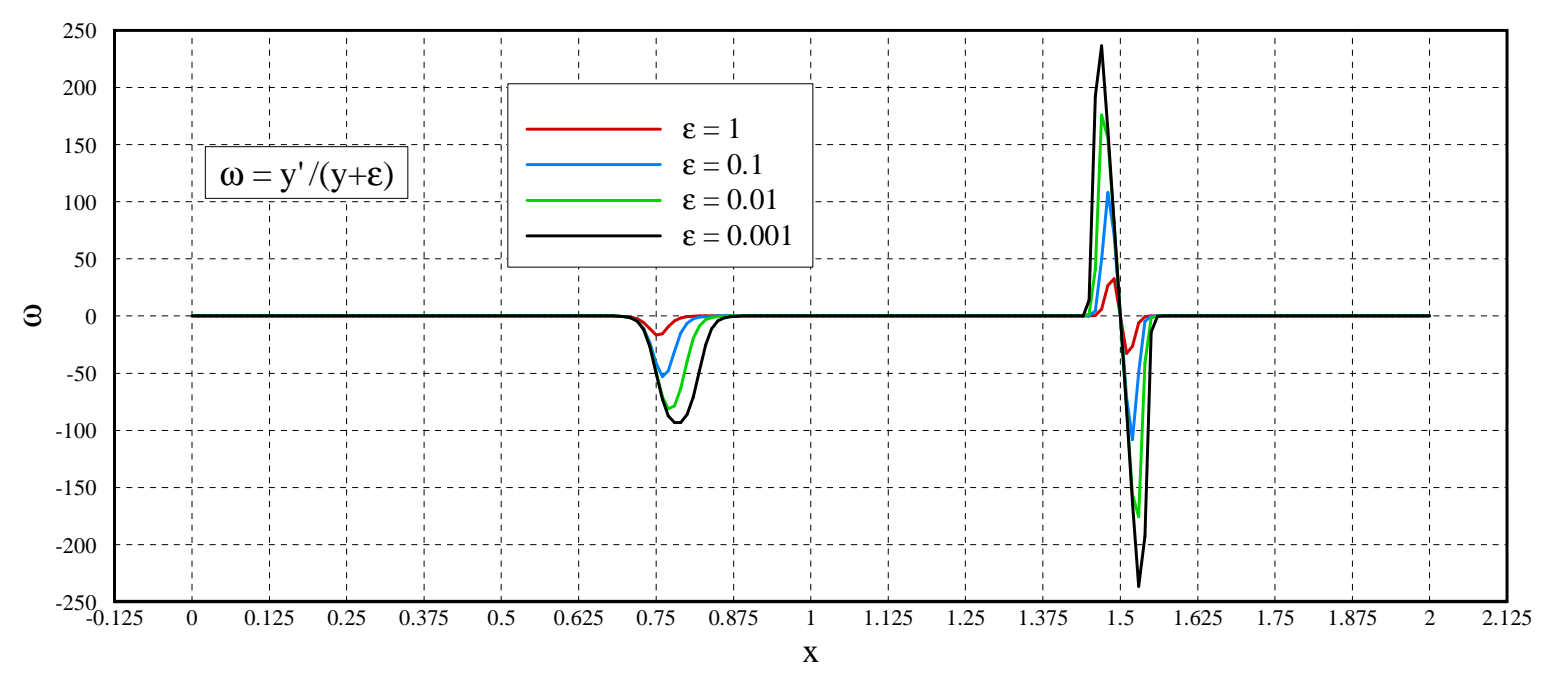

Crtež 7.4 Odnos prve i nulte derivacije zadane funkcije 

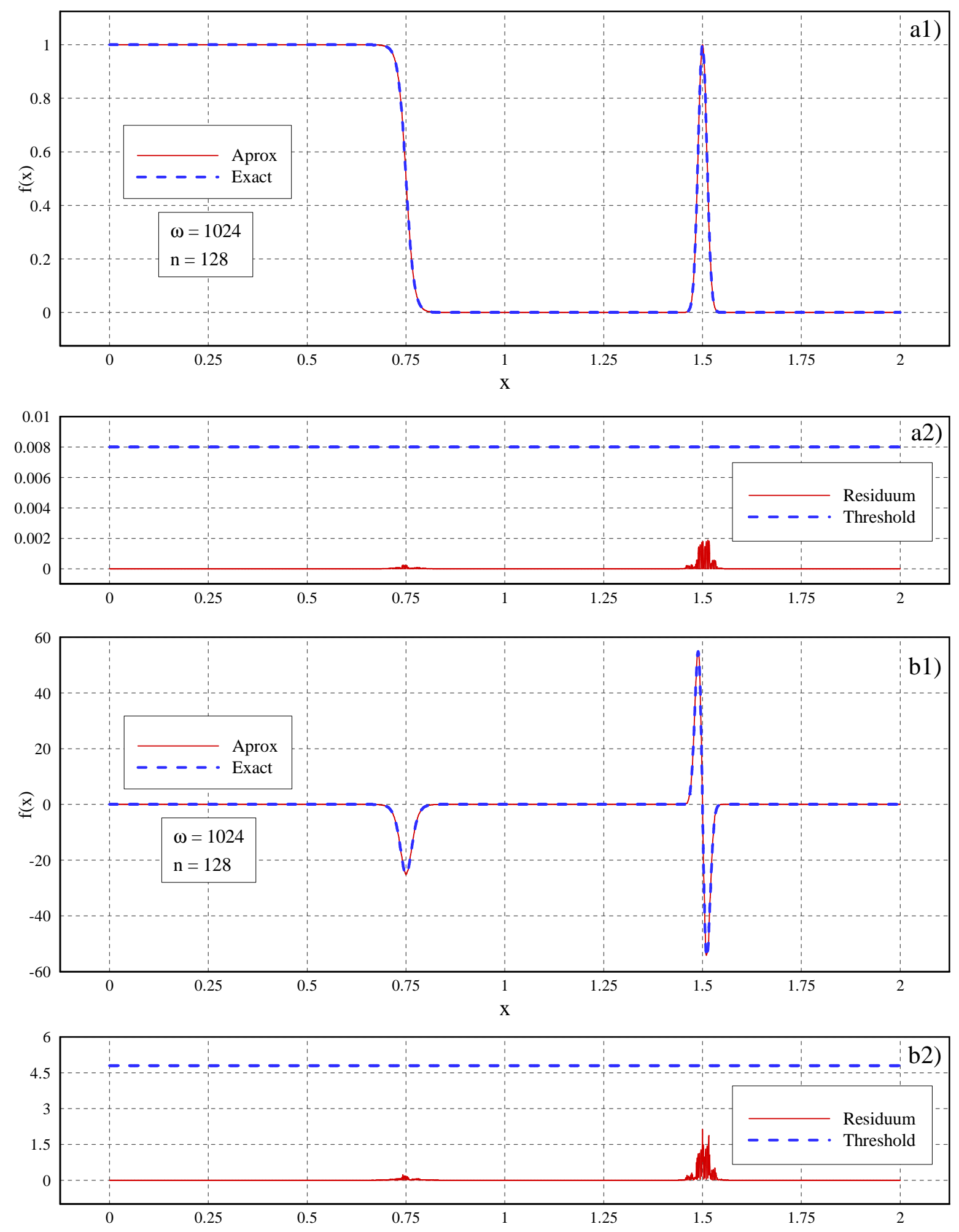

Crtež 7.5 a1) Nulta derivacija, a2) Odstupanje u odnosu na zadanu točnost b1) Prva derivacija, b2) Odstupanje od točne vrijednosti i propisana točnost 

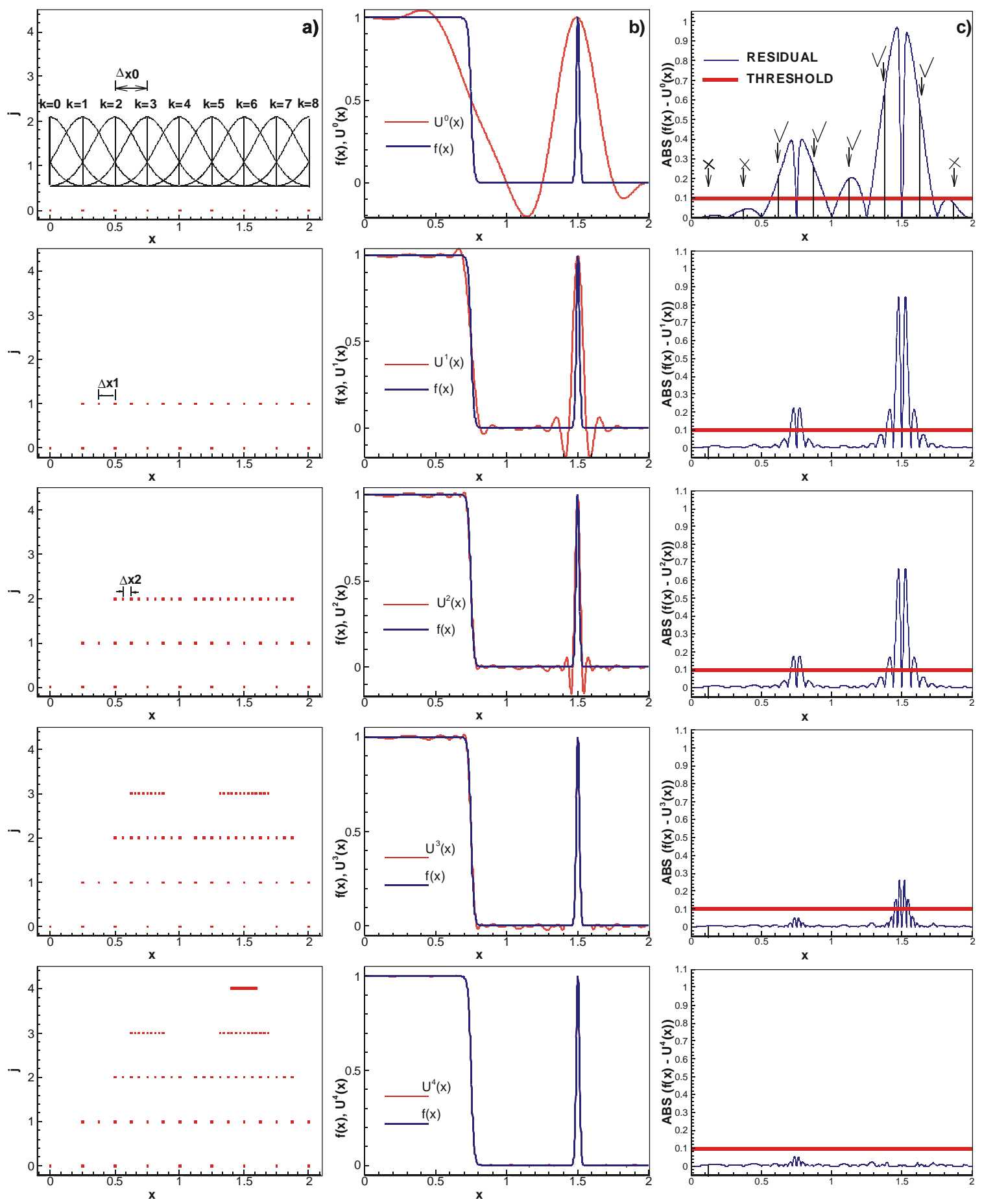

Crtež 7.6 Adaptivna aproksimacija test funkcije korištenjem ABF algebarskog tipa $\operatorname{Fup}_{2}(x)$ iz [19]:

a) Raspored unutarnjih baznih funkcija i adaptivna podjela područja

b) Usporedba test funkcije i FCT aproksimacije

c) A priori adaptivni kriterij za nove kolokacijske točke na temelju odstupanja između test funkcije i FCT aproksimacije 


\section{Primjer}

Aproksimira se algebarski polinom 12.-tog stupnja

$$
f(x)=858 \cdot x^{2} \cdot(1-x)^{10}
$$

Vrijednost parametra $\omega$ kao i u prethodnom primjeru određuje se pomoću veze eksponencijalnih ABF sa eksponencijalnim polinomima tj. iz odnosa (7.1) koji je za zadanu funkciju prikazan na crtežu 7.7 .

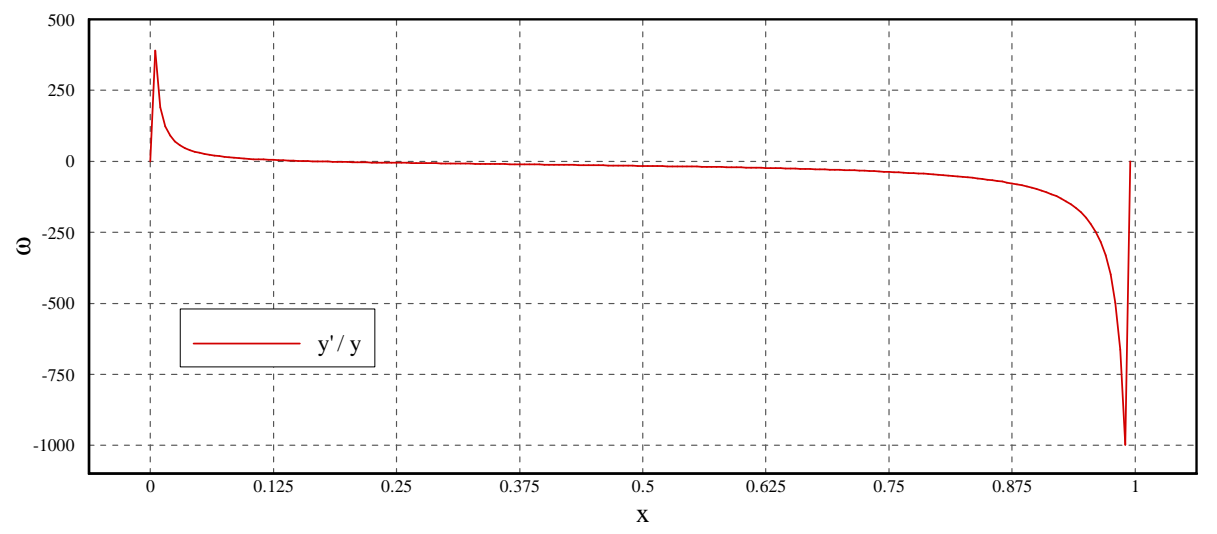

Crtež 7.7 Odnos prve i nulte derivacije zadane funkcije
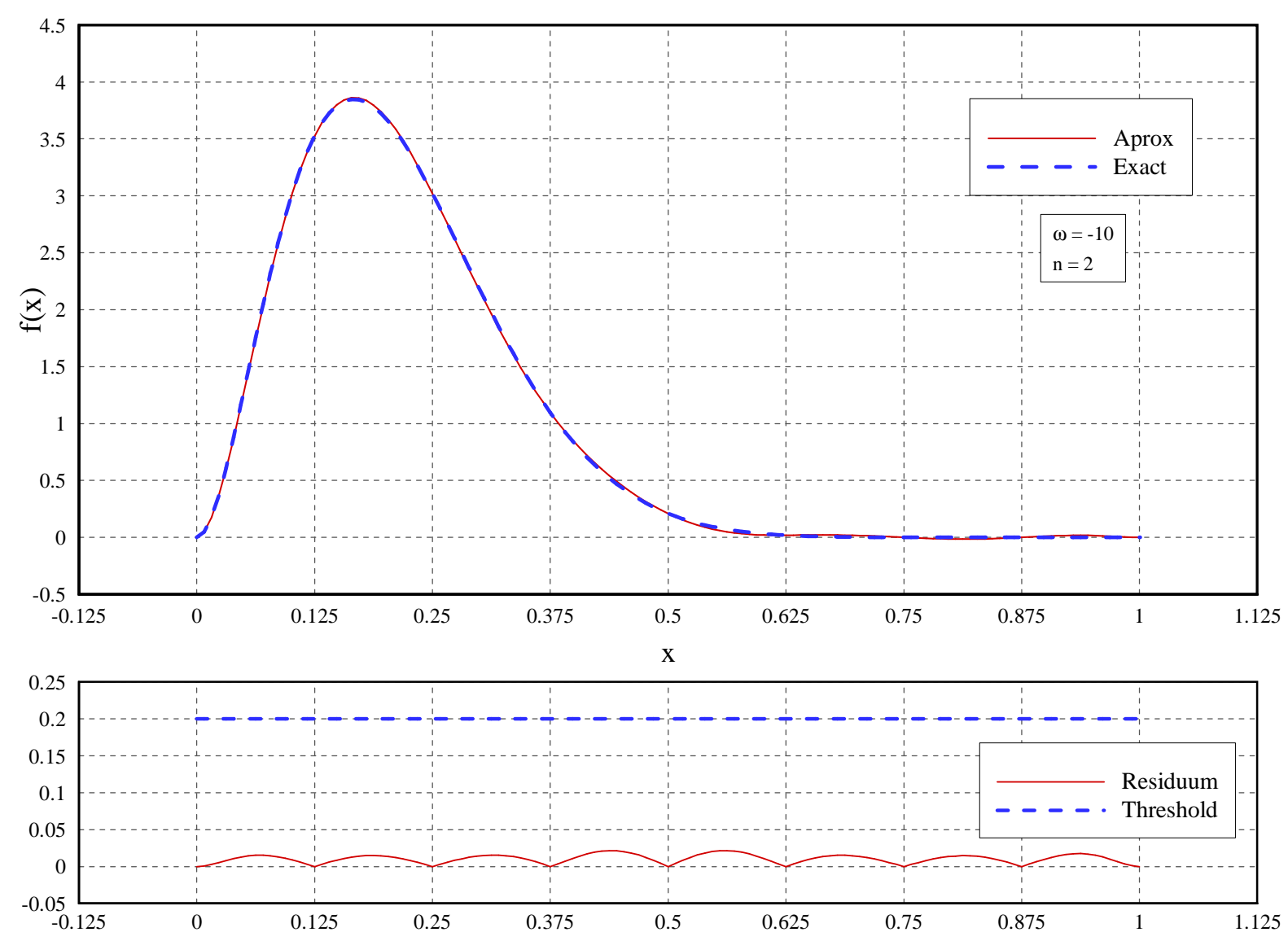

Crtež 7.8 a) Usporedba aproksimacije sa zadanom funkcijom

b) Usporedba odstupanja sa zadanom granicom točnosti 
Područje je podjeljeno na dva karakteristična odsječka a odabrana vrijednost parametra je prosječna vrijednost (7.1) tj. $\omega=-10$. Usporedba aproksimacije i zadane funkcije te residuuma sa zadanom točnošću prikazana je na crtežu 7.8 .

Iz ovog primjera može se zaključiti da eksponencijalne ABF-je dobro aproksimiraju i algebarske polinome visokog stupnja.

U nastavku je na primjerima aproksimacije funkcije primijenjena multirezolucijska metoda.

\section{Primjer}

Ovdje se analizira test funkcija

$$
f(x)=\operatorname{TANH}\left(\frac{x-2 / 3}{0.02}\right)
$$

koja može predstavljati rješenje problema advekcijsko disperzijske jednadžbe u određenom vremenskom trenutku. Ovakav oblik ima npr. funkcija koncentracije s pomičnim oštrim frontom kod procesa miješanja u poroznom mediju.

Funkcija (7.6) je na većem dijelu područja konstantna $( \pm 1)$ a na jednom uskom dijelu područja ima izražen skok. Područje je prema obliku funkcije podijeljeno na tri intervala:

$$
I_{1}=[0,0.5], \quad I_{2}=[0.5,0.8], \quad I_{3}=[0.8,2],
$$

a vrijednost parametra odabire se iz odnosa prve i nulte derivacije (7.1) analogno 2. Primjeru.

Prvi interval $I_{1}$ podjeljen je na četiri karakteristična odsječka a odabrana vrijednost parametra je $\omega=-0.5$, tj. jako mala jer je na tom području funkcija konstantna. Drugi interval $I_{2}$ podjeljen je na 16 karakterističnih odsječaka te je odabrana najviša vrijednost parametra $\omega=-2048$, dok je treći interval $I_{3}$ podjeljen je na 12 karakterističnih odsječaka i analogno prvom odsječku, vrijednost parametra je $\omega=-0.5$.

Usporedbe aproksimacije i zadane funkcije te odstupanja i propisane točnosti prikazane su na crtežu 7.9. 

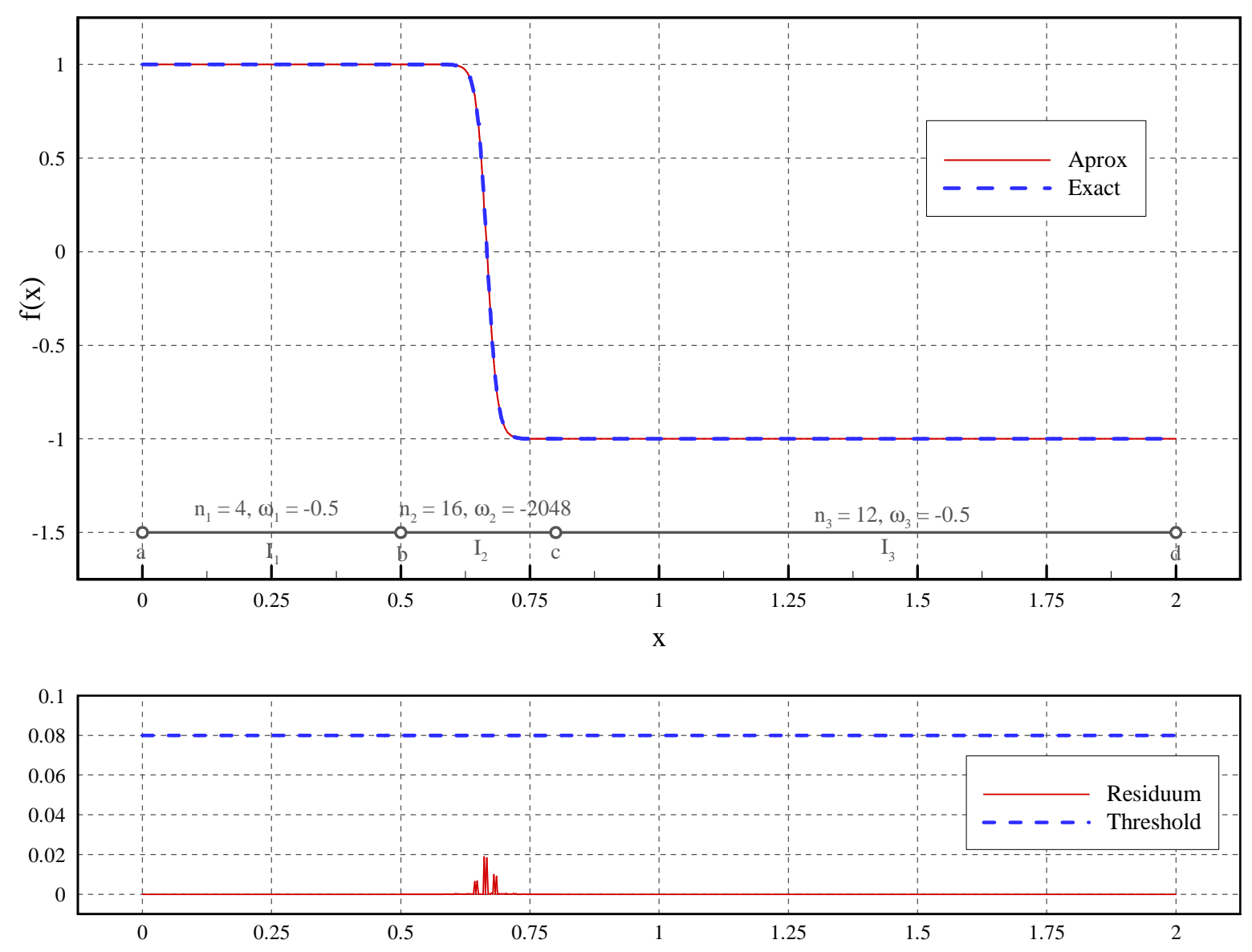

Crtež 7.9 a) Usporedba aproksimacije sa zadanom funkcijom

b) Usporedba odstupanja i propisane točnosti

\section{Primjer}

Zadana je funkcija sastavljena od polinoma prvog stupnja tako da, promatrajući je kao jednu neprekinutu funkciju ima izražen skok, gotovo prekid funkcije, u polovici područja:

$$
f(x)= \begin{cases}(1024 / 1023) x & \text { za } x \in[0,2-1 / 512] \\ 1025-512 x & \text { za } x \in[2-1 / 512,2-1 / 512] \\ (2 / 1023)(512 x-1025) & \text { za } x \in[2-1 / 512,4]\end{cases}
$$

Aproksimacije tipa zadane funkcije (7.7) sklone su Gibbsovom fenomenu ukoliko se koriste klasične bazne funkcije. Na crtežu 7.10 je prikazan razvoj zadane funkcije u Fourierov red sa 32 članova reda te se uočava Gibbsov fenomen.

Aproksimacija zadane funkcije pomoću trostruke baze (7.2) traži se koristeći multirezolucijski postupak. Područje je podijeljeno na tri intervala:

$$
I_{1}=[0,(2-1 / 512)], \quad I_{2}=[(2-1 / 512),(2+1 / 512)], \quad I_{3}=[(2+1 / 512), 4]
$$


Svi su intervali podijeljeni na dva karakteristična odsječka a odabrana vrijednost parametra je mala i iznosi $\omega=0.01$ zbog toga što je zadana funkcija po dijelovima pravac, tj. polinom prvog stupnja.

Usporedbe aproksimacije i zadane funkcije kao i odstupanja sa zadanom točnosti prikazane su na crtežu 7.11 .

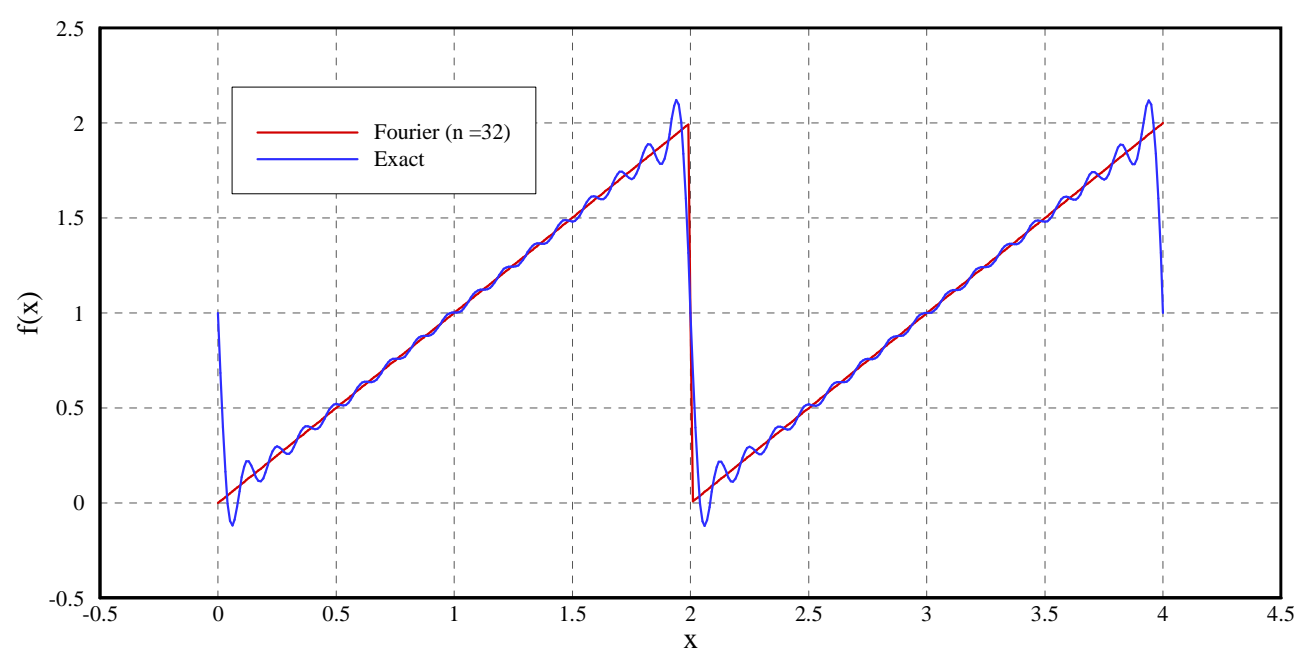

Crtež 7.10 Razvoj zadane funkcije u Fourierov red
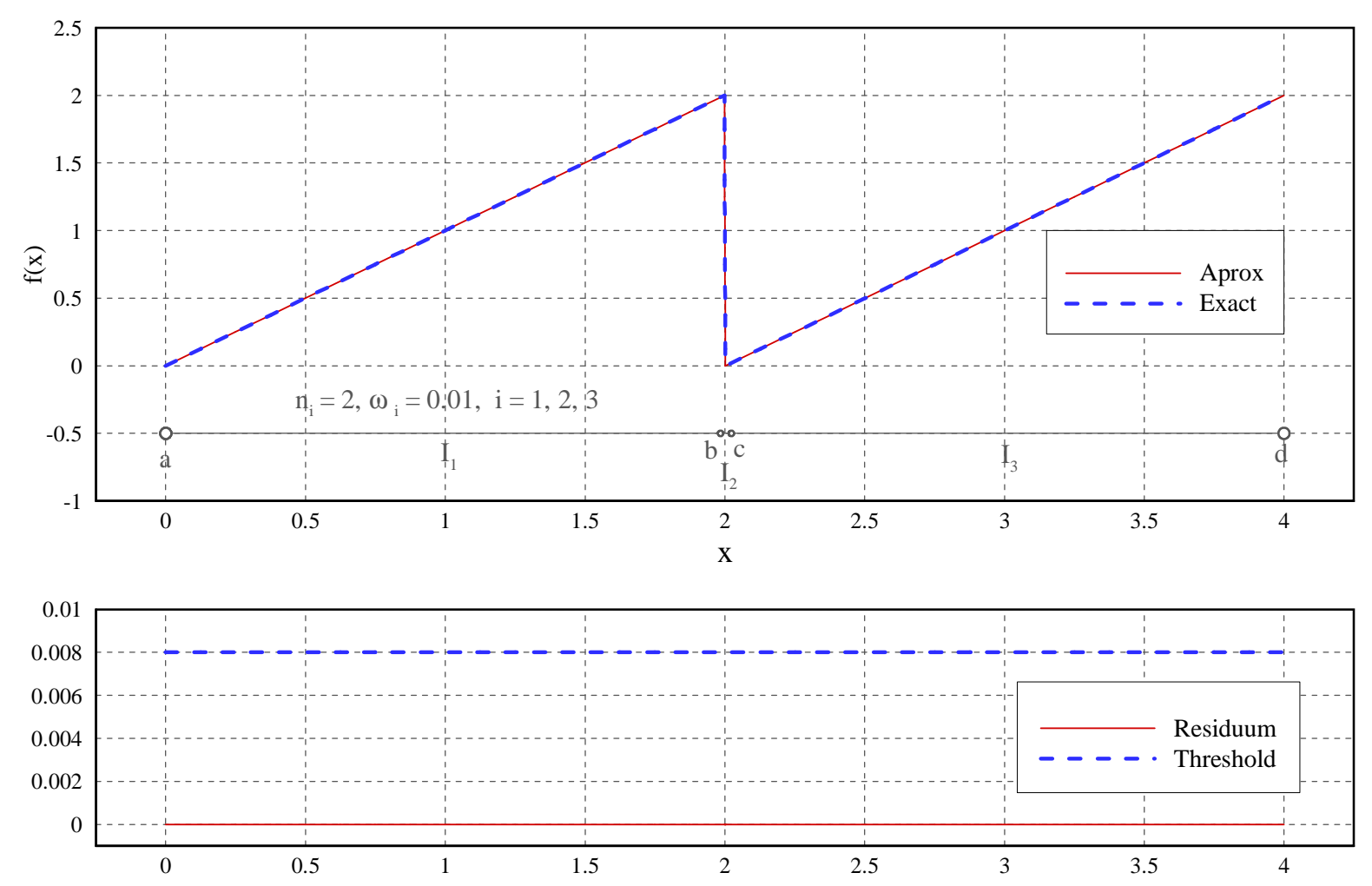

Crtež 7.11 a) Usporedba aproksimacije sa zadanom funkcijom

b) Usporedba odstupanja sa zadanom točnošću 


\section{Primjer}

Zadana test funkcija iz [37] je polovica kružnice proširena obostrano konstantnom funkcijom. Na spojevima kružnice s konstantnim funkcijama prva derivacija ima skok neizmjerne vrijednosti:

$$
f(x)= \begin{cases}1 & \text { za } x \in[0,2] \\ 1+\sqrt{4-(x-4)^{2}} & \text { za } x \in[2,6] \\ 1 & \text { za } x \in[6,8]\end{cases}
$$

Aproksimacija zadane funkcije pomoću trostruke baze (7.2) traži se koristeći multirezolucijski postupak. Područje je podijeljeno prema definiciji same funkcije, tj. $I_{1}=[0,2], I_{2}=[2,6], I_{3}=[6,8]$.

Prvi i treći interval $I_{1}$ i $I_{3}$ podjeljeni su svaki na 2 karakteristična odsječka a odabrane vrijednosti parametara su $\omega_{1}=50 \mathrm{i} \omega_{3}=-50$, dok je drugi interval $I_{2}$ podjeljen na 16 karakterističnih odsječaka a odabrana vrijednost parametra je $\omega=100$.

Usporedbe aproksimacije i zadane funkcije kao i odstupanja sa zadanom točnosti prikazane su na crtežu 7.12 .
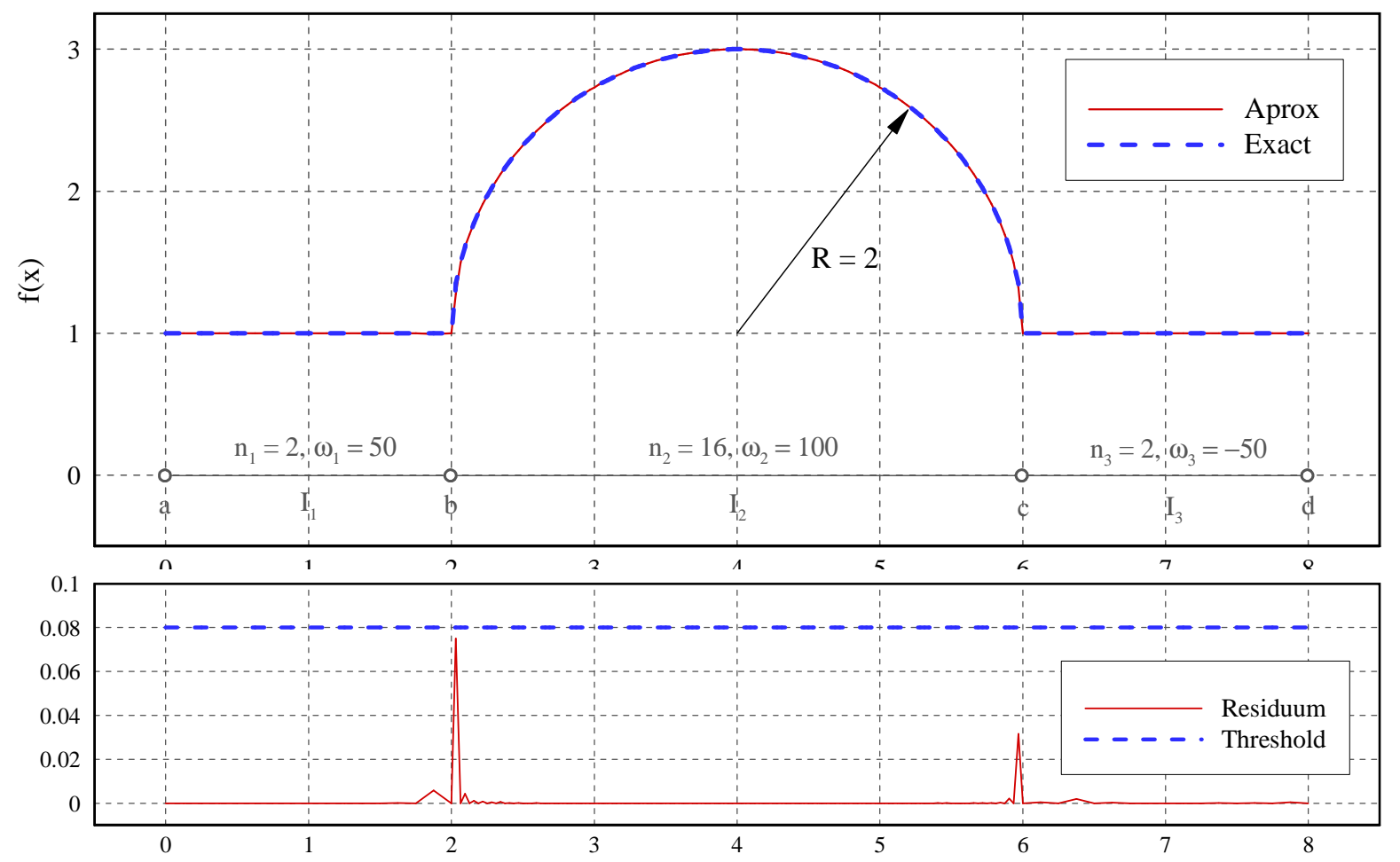

Crtež 7.12 a) Usporedba aproksimacije sa zadanom funkcijom

b) Usporedba odstupanja sa zadanom točnosti

Opet se može uočiti izvrsno podudaranje ABF aproksimacije sa zadanom funkcijom. 


\subsection{Funkcija opisana diferencijalnom jednadžbom i rubnim uvjetima}

\section{Primjer}

Rješava se problem provođenja opisan diferencijalnom jednadžbom drugog reda i rubnim uvjetima

$$
u^{\prime \prime}-\omega \cdot u^{\prime}=0 ; \quad u(0)=1, \quad u(1)=2
$$

s poznatim analitičkim rješenjem

$$
u(x)=\left(e^{\omega \cdot x}-1\right) /\left(e^{\omega}-1\right)+1
$$

Na crtežu 7.13 vidljiva je ovisnost rješenja (7.10) o parametru $\omega$, te kako se za visoke vrijednosti $\omega$ funkcija rješenja pomiče prema desnom rubu.

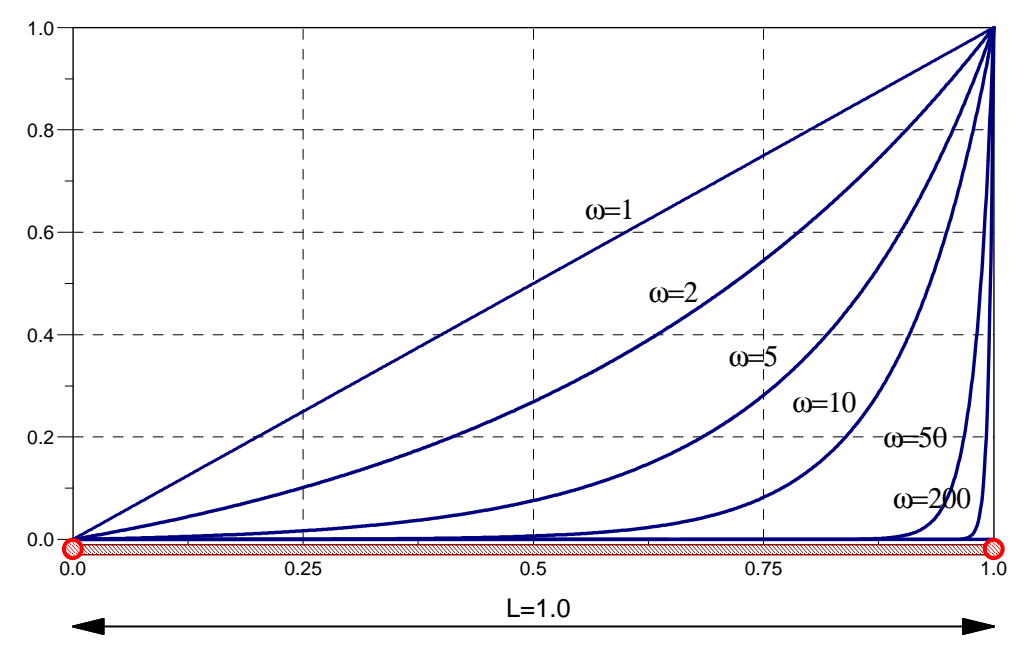

Crtež 7.13 Ovisnost rješenja o frekvenciji $\omega$

$\mathrm{Na}$ crtežu 7.14 dana je usporedba točnog rješenja problema provođenja $\mathrm{s}$ rješenjima dobivenim pomoću baznih funkcija algebarskog tipa $F_{u p}(x)$ metodom kolokacije u točki za broj karakterističnih odsječaka $n=8,16,32,64$.

Aproksimacija pomoću baznih funkcija algebarskog tipa ograničena je Pecletovim brojem $P e=\omega \cdot(L / n)$ jer pri visokim vrijednostima $P e$ dolazi do numeričke pogreške i osciliranja približnog rješenja što se vidi na crtežu 7.14.

Eksponencijalni i algebarski monom sastavni su dio rješenja (7.10) zbog čega numeričko rješenje u obliku linearne kombinacije (7.2) mora odgovarati analitičkom rješenju i to za minimalni broj karakterističnih odsječaka.

Jednadžba (7.9) može se napisati i u slijedećem obliku 


$$
d / d x\left(u^{\prime}-\omega \cdot u\right)=0
$$

gdje izraz u zagradi odgovara lijevoj strani funkcionalno diferencijalne jednadžbe eksponencijalnih $\mathrm{ABF}$ što znači da je vrijednost frekvencije $\omega$ poznata, tj. vidljiva je iz diferencijalne jednadžbe.

Visoke vrijednosti parametra $\omega$ ograničene su točnošću računala. Međutim, računska frekvencija baznih funkcija je $\omega_{b f}=\omega \cdot \Delta x_{2}$ što znači da se za malu duljinu karakterističnog odsječka $\Delta x_{2}$ (što podrazumijeva veći broj odsječaka $n$ ) mogu koristiti izuzetno visoke vrijednosti parametra, odnosno frekvencije $\omega$.

$\mathrm{Na}$ crtežu 7.15 vidljivo je numeričko rješenje odgovara analitičkom za broj karakterističnih odsječaka $n=4$ i vrijednost parametra $\omega=100$.

Vrijednost koeficijenata linearne kombinacije baznih funkcija $\operatorname{EFup}_{2}(x, 0)=\operatorname{Fup}_{2}(x)$ iznosi 0.125 , koeficijenti baznih funkcija $\operatorname{EFup}_{2}(x,-\omega)$ su jednaki nuli, dok koeficijenti baznih funkcija $\operatorname{EFup}_{2}(x,+\omega)$ postupno rastu prema dijelu funkcije s visokim gradijentom.

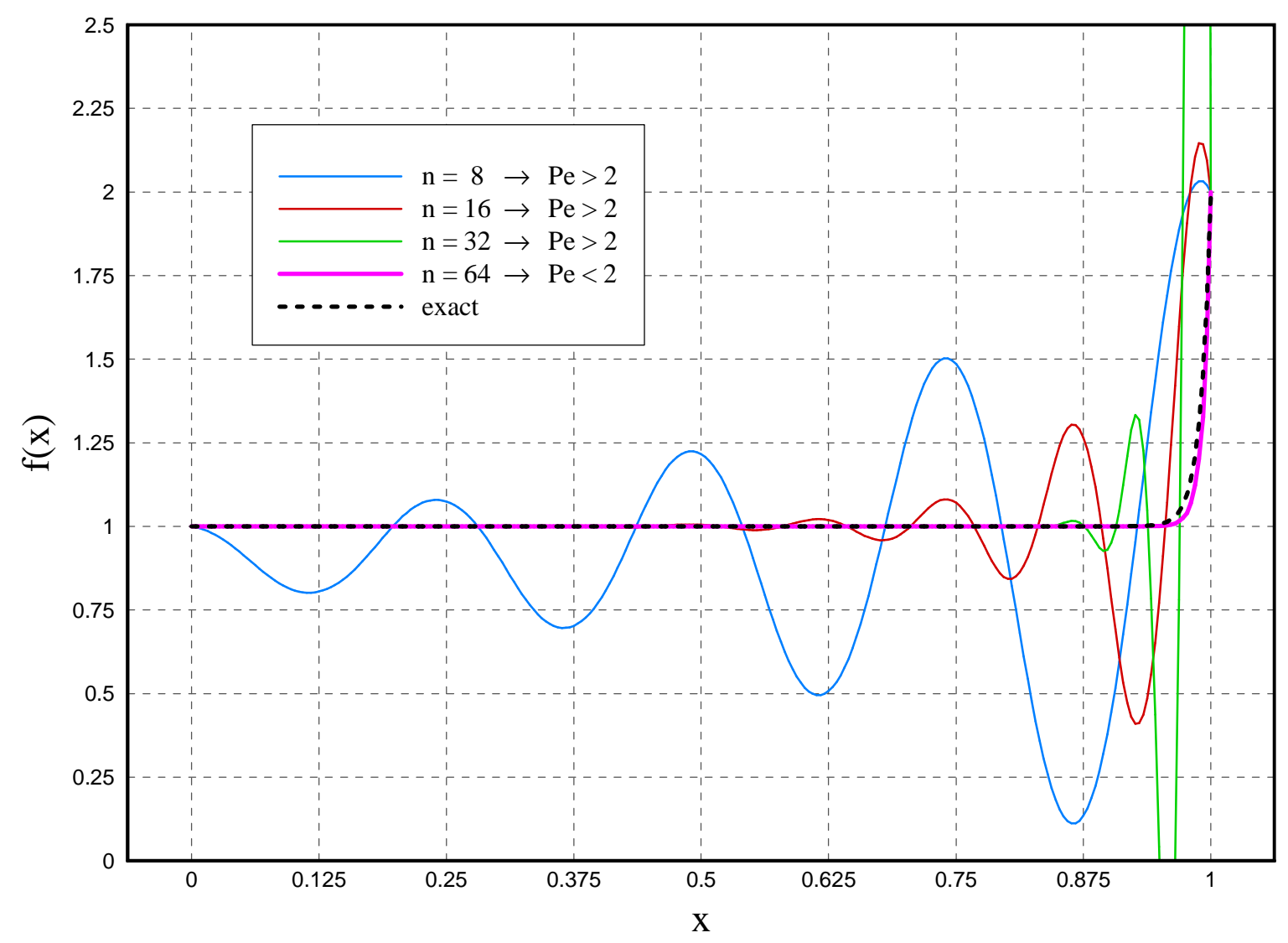

Crtež 7.14 Usporedba točnog rješenja problema provođenja s približnim rješenjima dobivenima pomoću $\mathrm{ABF}$ algebarskog tipa $\operatorname{Fup}_{2}(x)$ za $n=8,16,32,64$ 


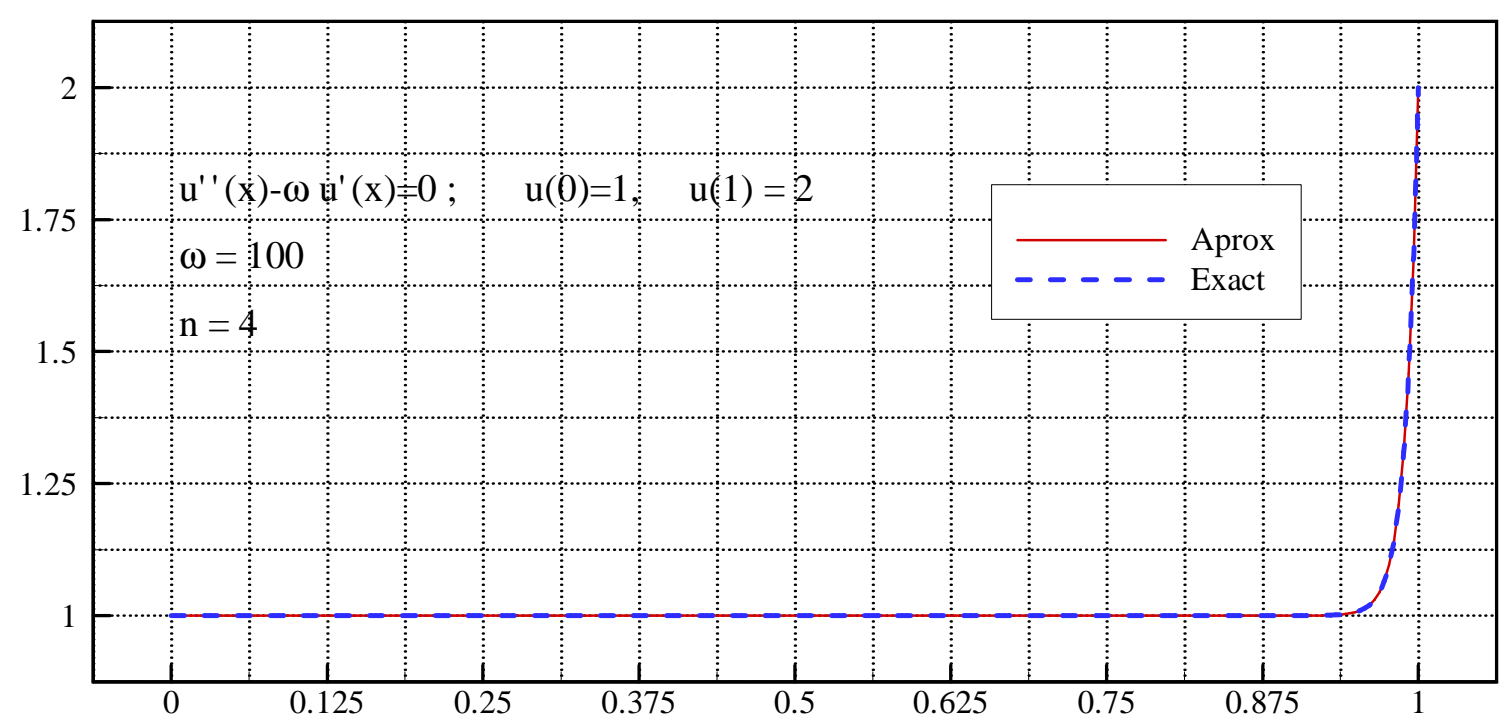

Crtež 7.15 Usporedba približnog dobivenog trostrukom bazom i točnog rješenja problema provođenja

\section{Primjer}

Rješava se diferencijalna jednadžba lančanice na elastičnoj podlozi opterećena kontinuiranim opterećenjem i koncentriranom silom u sredini

$$
\begin{aligned}
& u^{\prime \prime}(x)-\frac{k}{H} \cdot u(x)=\frac{1}{H}[q+F \cdot \delta(x-L / 2)], \quad 0 \leq x \leq L \\
& u(0)=0, \quad u(L)=0
\end{aligned}
$$

Poznato analitičko rješenje ravnotežnog položaja lančanice je:

$$
u(x)=u_{q}(x)+ \begin{cases}u_{F}(x) & \text { za } x \in[0, L / 2] \\ u_{F}(L-x) & \text { za } x \in[L / 2, L]\end{cases}
$$

gdje je

$$
\begin{gathered}
u_{q}(x)=\frac{q}{k}\left(\frac{e^{x \sqrt{k / H}}-e^{-x \sqrt{k / H}}}{e^{L \sqrt{k / H}}+1}+e^{-x \sqrt{k / H}}-1\right) \\
u_{F}(x)=\frac{F \sqrt{k / H}}{2 \cdot k \cdot\left(e^{L \sqrt{k / H}}+1\right)}\left(e^{(L-2 x) \sqrt{k / H} / 2}-e^{(L+2 x) \sqrt{k / H} / 2}\right)
\end{gathered}
$$

Na primjer, zadatak polaganja podmorskog cjevovoda je opisan jednadžbom (7.12).

Neka je zadano

$$
L=10(m), \quad q=10\left(k N / m^{\prime}\right), \quad F=100(k N), \quad k=5\left(k N / m^{\prime} / m^{\prime}\right), \quad H=10(k N)
$$




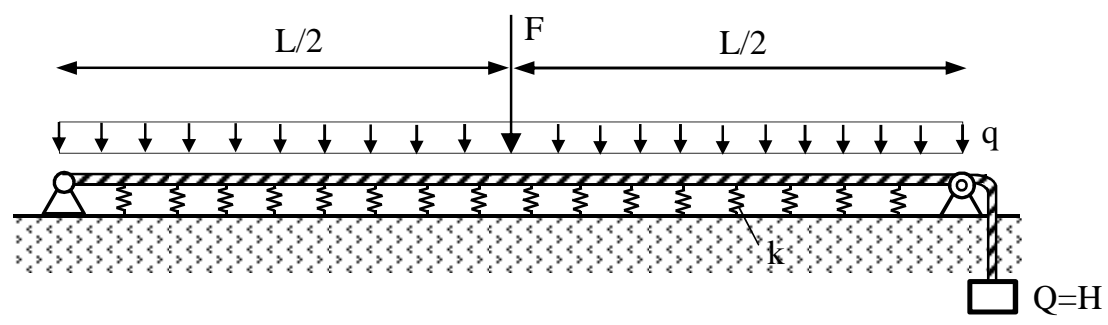

Crtež 7.16 Cijev ili kabel na elastičnoj podlozi

Područje $[0, L]$ podijeljeno je na dva intervala $I_{1}=[0,5]$ i $I_{2}=[5,10]$. Oba intervala podijeljena su na 16 karakterističnih odsječaka te su odabrane vrijednosti parametra $\omega_{1}=$ 14.5 i $\omega_{2}=-14.5$. Aproksimacija je dobivena multirezolucijskim postupkom primjenom trostruke baze.

Usporedba ABF aproksimacije sa analitičkim rješenjem (7.13) prikazana je na crtežu 7.17.
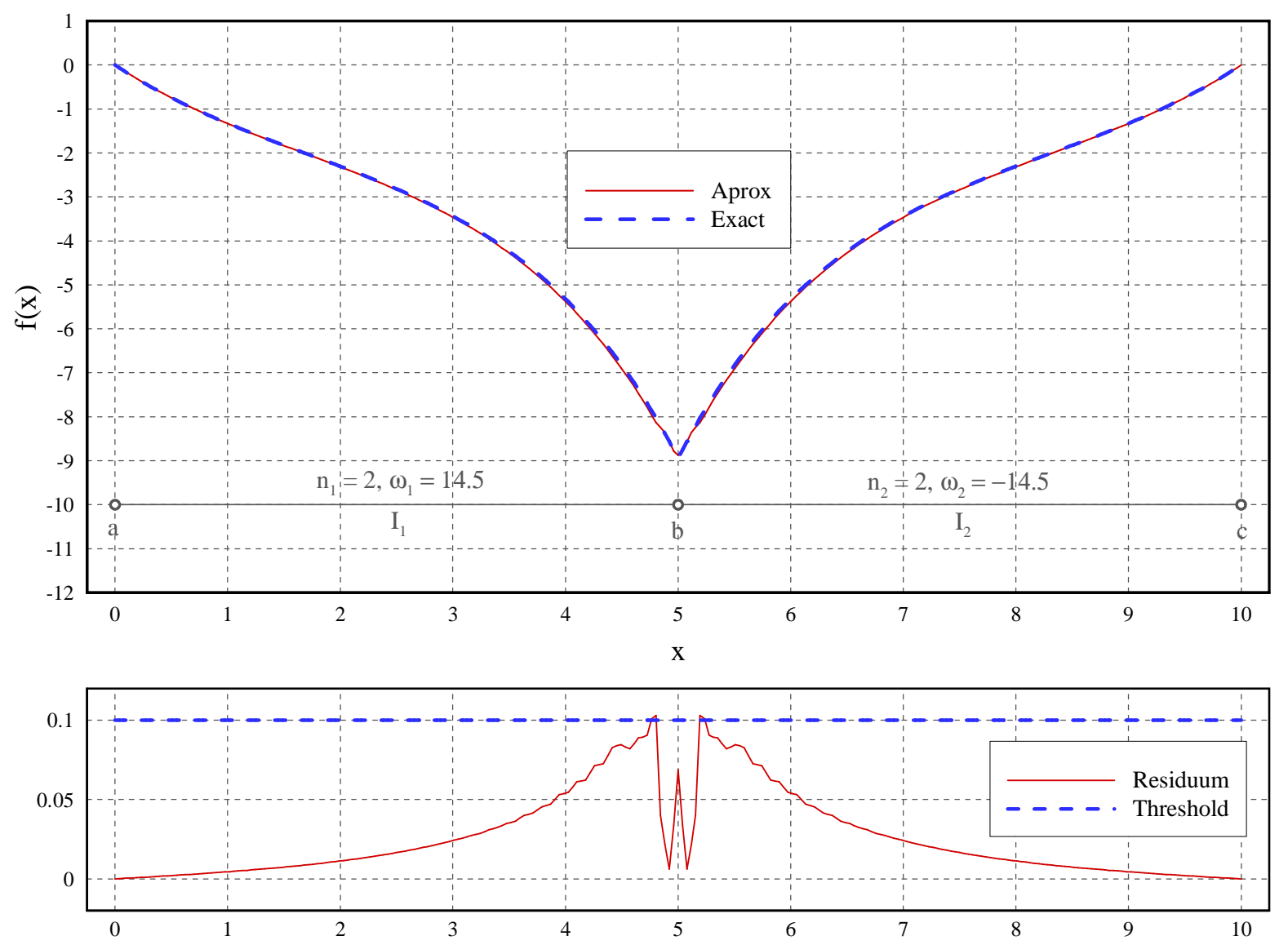

Crtež 7.17 Usporedba približnog i točnog rješenja problema lančanice na el. podlozi

Na crtežu 7.16 može se uočiti da je najveće odstupanje upravo oko mjesta djelovanja koncentrirane sile koja uzrokuje najveće gradijente u funkciji rješenja. No, i to odstupanje nalazi se unutar granice propisane točnosti $\delta=0.1$. 


\section{Primjer}

Primjena eksponencijalnih splineova se često u literaturi pokazuje na primjeru tzv. Singularno Perturbiranog Rubnog Problema (SPRP) (npr. [21], [36], [38], [39]). Taj problem javlja se u mnogim područjima dinamike fluida (prijelaz iz Navier-Stokseove u Eulerovu jednadžbu u modelima tečenja fluida). SPRP je problem konvekcije-difuzije ili reakcijedifuzije sa difuznim koeficijentom vrlo blizu nule što daje visoke gradijente blizu granice područja a u općem obliku glasi:

$$
\begin{aligned}
& \varepsilon \cdot u^{\prime \prime}(x)+b(x) \cdot u^{\prime}(x)+d(x) \cdot u(x)=f(x), \quad 0 \leq x \leq 1 \\
& u(0)=\alpha, \quad u(1)=\beta
\end{aligned}
$$

gdje je koeficijent difuzije $\varepsilon>0$ mala vrijednost, a funkcije $b(x), d(x), f(x)$ su glatke. Mala vrijednost koeficijenta $\varepsilon$ značajno otežava prirodu problema kod diferencijalnih jednadžbi visokog reda.

Neka je zadan jednodimenzionalni SPRP:

$$
\begin{aligned}
& \varepsilon \cdot u^{\prime \prime}(x)+(1+x)^{3} \cdot u^{\prime}(x)=f(x), \quad 0 \leq x \leq 1 \\
& u(0)=2 \\
& u(1)=0.125 \cdot e^{-3.75 / \varepsilon}+e^{-0.5}
\end{aligned}
$$

s poznatim analitičkim rješenjem

$$
u(x)=\frac{1}{(1+x)^{3}} e^{\left(1-(1+x)^{4}\right) /(4 \cdot \varepsilon)}+e^{-x / 2}
$$

Na crtežu 7.18 prikazano je rješenje problema (7.16) iz literature [38] za vrijednost parametra $\varepsilon=10^{-3}$ te korištenjem eksponencijalnih splineova $E_{4}(\xi, \omega)$ iz poglavlja 2 .

Rješenje je dobiveno kombiniranjem dva pristupa za rješavanje SPRP: „fitted“ operatori konačnih razlika i po dijelovima uniformne „fitted“ mreže. Na crtežu 7.18 a) rješenje je dobiveno sa $n=52$ odsječaka te jednim nivoom rezolucije, dok je na crtežu 7.18 b) rješenje dobiveno sa $n=141$ odsječka te dva nivoa rezolucije.

$\mathrm{Na}$ crtežu 7.19. prikazana je usporedba analitičkog rješenja (7.16) i aproksimacije dobivene metodom kolokacije u točki pomoću trostruke baze (7.2) multirezolucijskom metodom.

Područje je podijeljeno na dva intervala $I_{1}=[0,0.0625]$ i $I_{2}=[0.0625,1]$. Prvi interval $I_{1}$ podjeljen je na 4 karakteristična odsječka a odabrana vrijednost parametra je maksimalna a da se ne prekorači točnost računala $\omega=-2048$. Drugi interval $I_{2}$ je također podijeljen na 4 karakteristična odsječka a odabrana vrijednost parametra je $\omega=-32$. 


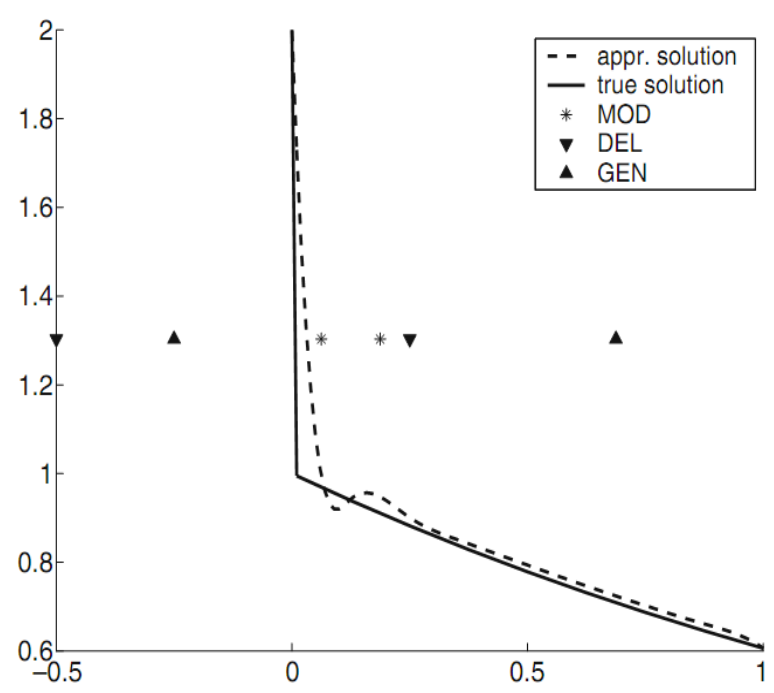

a) $n=52$ odsječaka (jedan nivorezolucije)

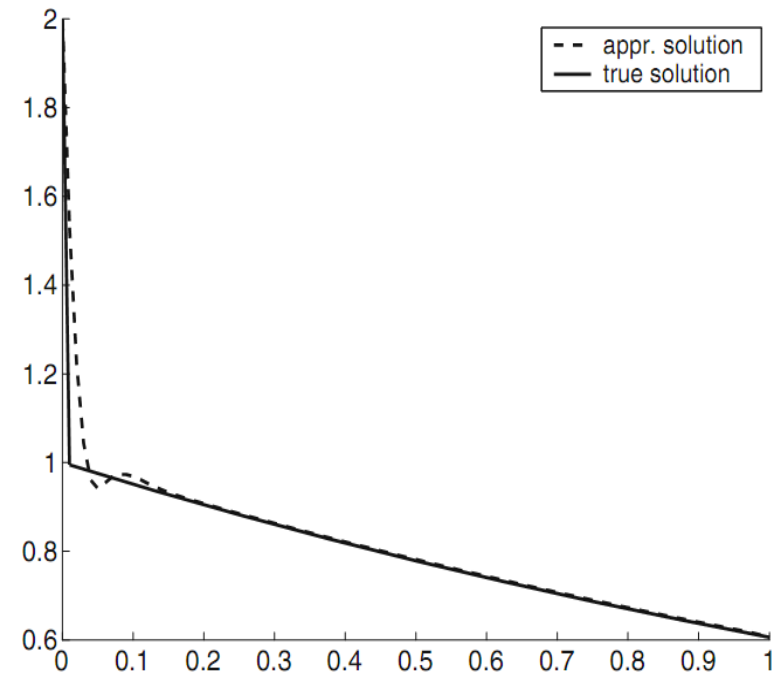

b) $n=141$ odsječka (dva nivoa rezolucije)

Crtež 7.18 Rješenje singularno perturbiranog rubnog problema iz [38]
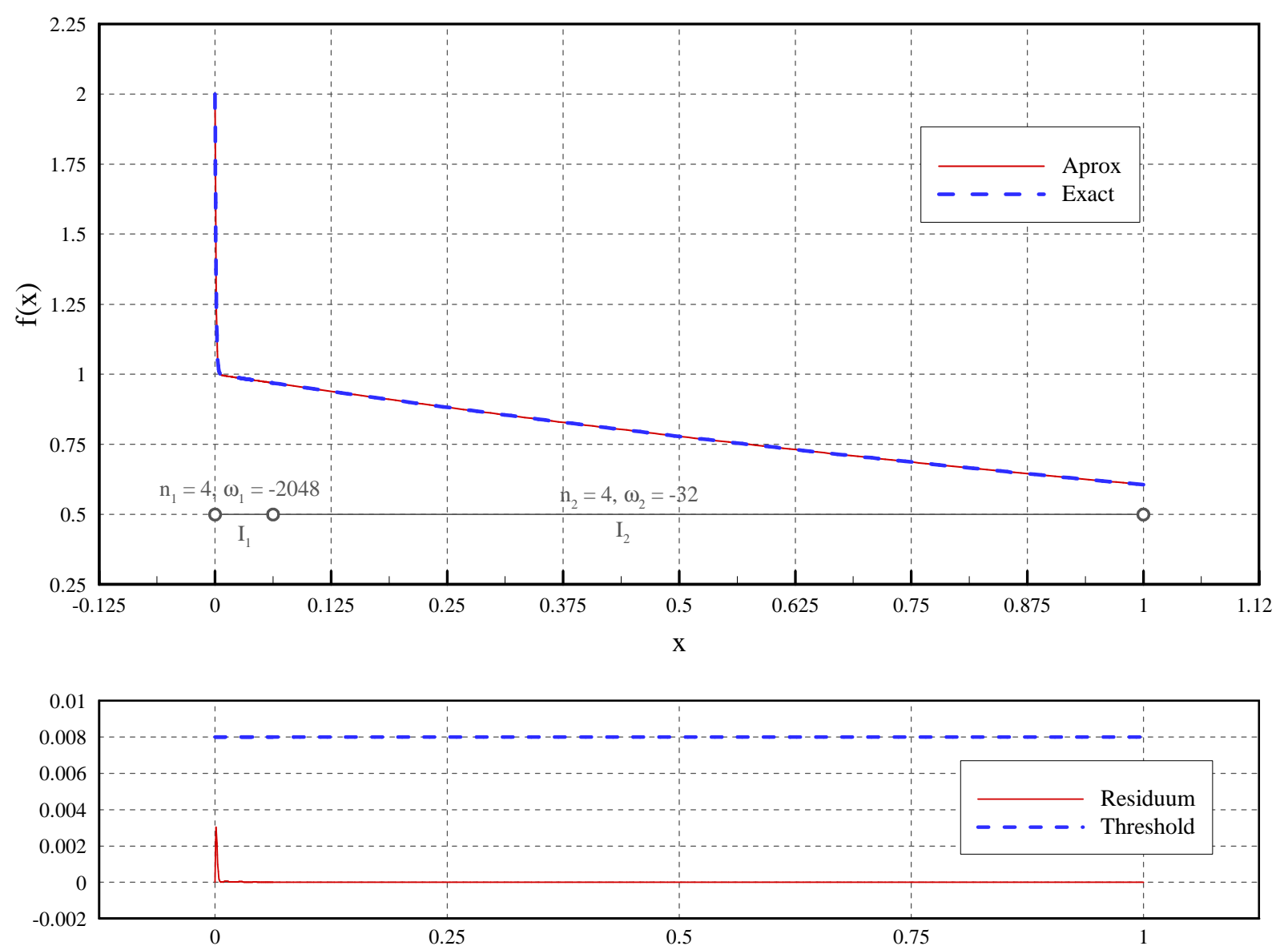

Crtež 7.19 Singularno perturbirani rubni problem

I ovaj primjer pokazuje bolja aproksimacijska svojstva eksponencijalnih ABF u odnosu na eksponencijalne splineove. 


\section{Primjer}

Mnogi važni praktični zadaci uključuju konstrukcije koje su izložene toplinskom opterećenju. Toplinski proces unutar konstrukcije formirajući toplinsko polje dovodi do promjene naprezanja u nosivom elementu. Na primjer, na skici je prikazan zid debljine $L$ koji razdvaja dvije prostorije različitih temperatura, primjerice hladnjaču i prostoriju za rad. Zadana je početna temperatura zida, te temperature unutar prostorija.

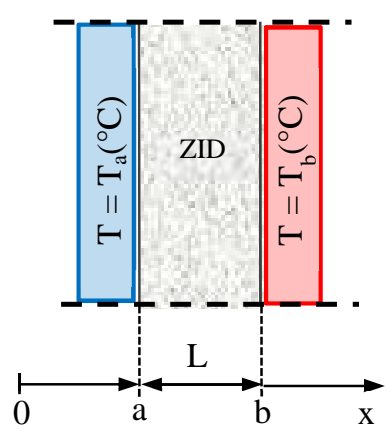

Ovaj se problem može promatrati kao nestacionarni jednodimenzionalni problem provođenja topline koji je opisan parcijalnom diferencijalnom jednadžbom i pripadajućim rubnim uvjetima oblika:

$$
\begin{aligned}
& \frac{\partial T(x, t)}{\partial t}-\alpha \frac{\partial^{2} T(x, t)}{\partial x^{2}}=0 \\
& T(x, 0)=T_{0}, \quad T(0, t)=T_{a}, \quad T(L, t)=T_{b}
\end{aligned}
$$

U toj jednadžbi, paraboličnog tipa, veličina $t$ predstavlja vremensku varijablu, a veličina $x$ prostornu varijablu. Veličina $\alpha$ označava temperaturnu provodnost (toplinsku difuzivnost) krutog tijela, a koja je strukturirana od fizikalnih svojstava $\rho$ (density), c (specific heat), $\lambda$ (thermal conductivity), pa se temperaturna provodnost računa prema jednadžbi:

$$
\alpha=\frac{\lambda}{\rho \cdot c}
$$

Početni uvjet je temperatura zida, dok su rubni uvjeti temperature na stjenkama zida. Za $\alpha=1$ može se naći analitičko rješenje promatranog problema u otvorenom obliku u literaturi [45] i iznosi

$$
T(x, t)=a+(b-a) \frac{x}{L}+\frac{2}{\pi} \sum_{n=1}^{\infty} \frac{b \cdot \cos (n \cdot \pi)-a}{n} \cdot \sin \left(\frac{n \cdot \pi \cdot x}{L}\right) \cdot e^{-\left(\frac{n \cdot \pi}{L}\right)^{2} \cdot t}
$$

Na crtežu 7.20 prikazane su izolinije polja temperature $T(x, t)$ prema analitičkom rješenju (7.19) za slijedeće podatke

$a=0.0, \quad b=1.0, \quad L=1.0, \quad T_{0}=0^{\circ} \mathrm{C}, \quad T_{a}=0^{\circ} \mathrm{C}, \quad T_{b}=1^{\circ} \mathrm{C}$ 
dok su na crtežima 7.21 i 7.22 prikazane linije polja temperature $T\left(x, t_{i}\right), i=1, \ldots, 10 \mathrm{i}$ $T\left(x_{i}, t\right), i=1, \ldots, 12$, respektivno.

Na crtežima 7.24 i 7.23 prikazana je usporedba analitičkog rješenja (7.19) i numeričkog rješenja dobivenog metodom kolokacije $u$ točki pomoću trostruke baze (7.2) polja temperature u karakterističnim presjecima i to $T(x, 0.001)$ i $T(0.99 \cdot L, t)$, respektivno. U oba presjeka numeričko rješenje je dobiveno sa 64 karakteristična odsječka i vrijednosti parametra $\omega=1024$. Naime, radi se o izolinijama s izražajnim gradijentima gdje odgovaraju visoke vrijednosti parametra kao što se vidi i na crtežima 7.24 i 7.23 gdje se uočava preklapanje numeričkog rješenja s analitičkim.

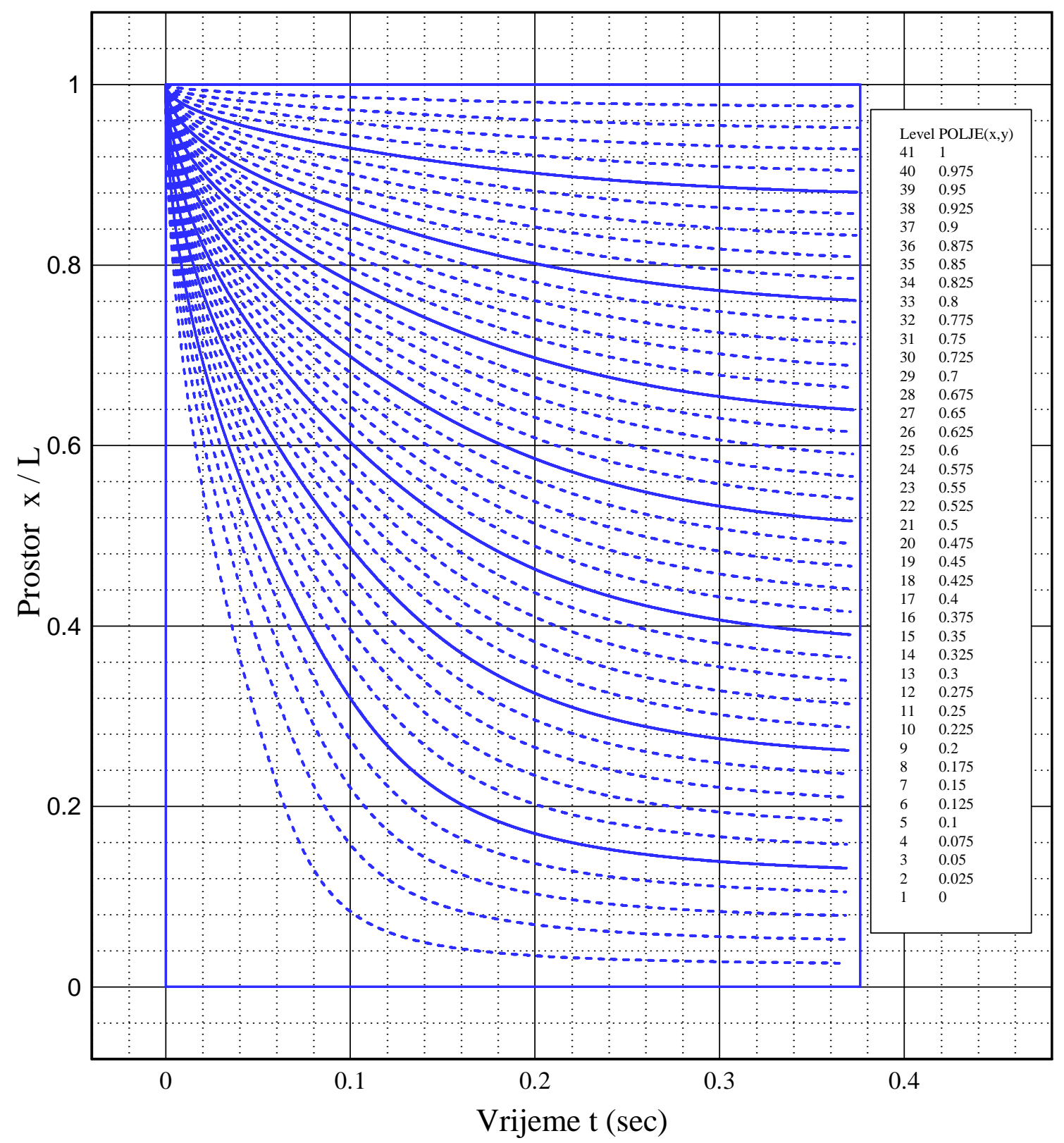

Crtež 7.20 Izolinije polja temperature $T(x, t)$ 


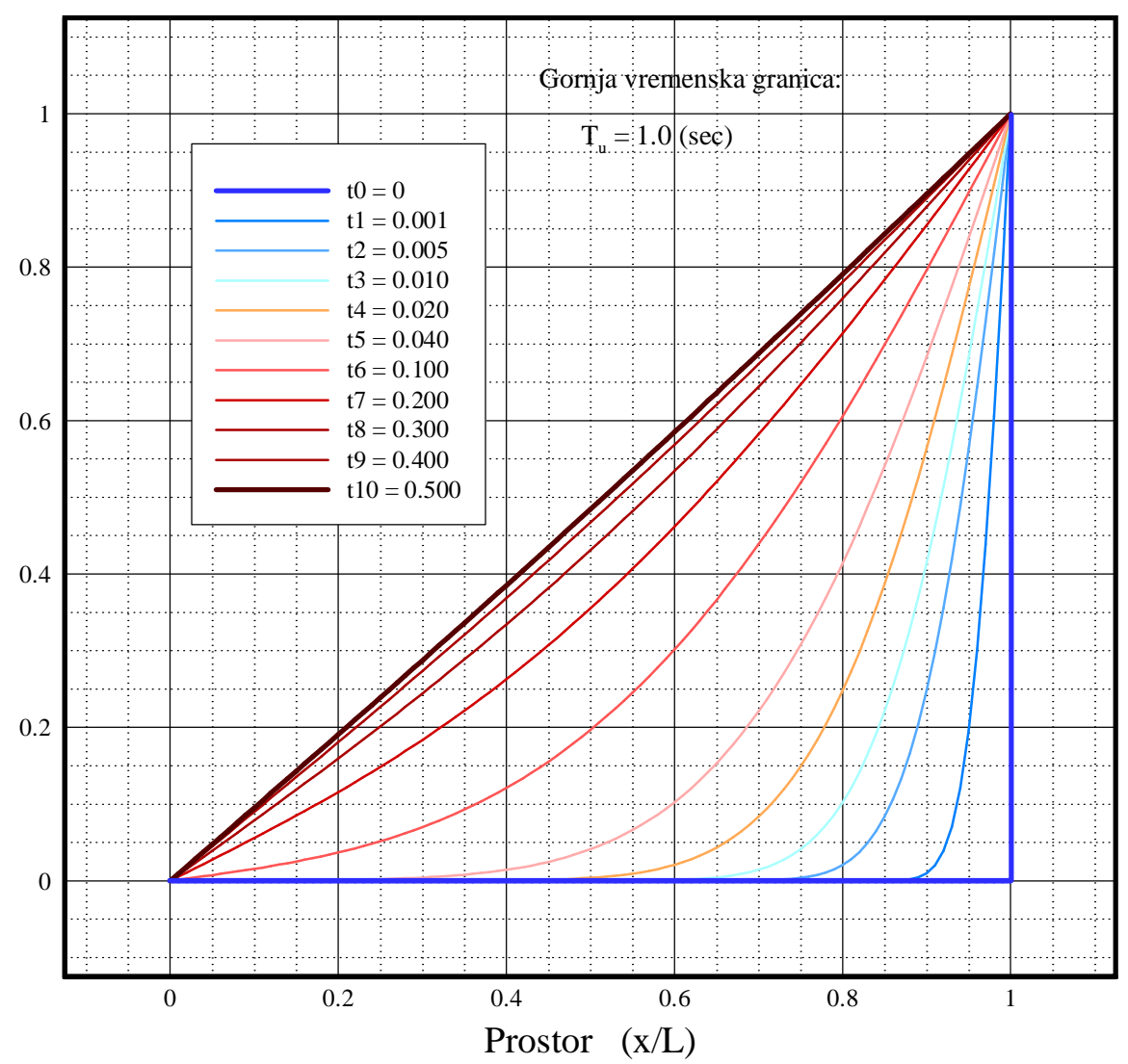

Crtež 7.21 Linije polja temperature $T\left(x, t_{i}\right), i=0, \ldots, 10$

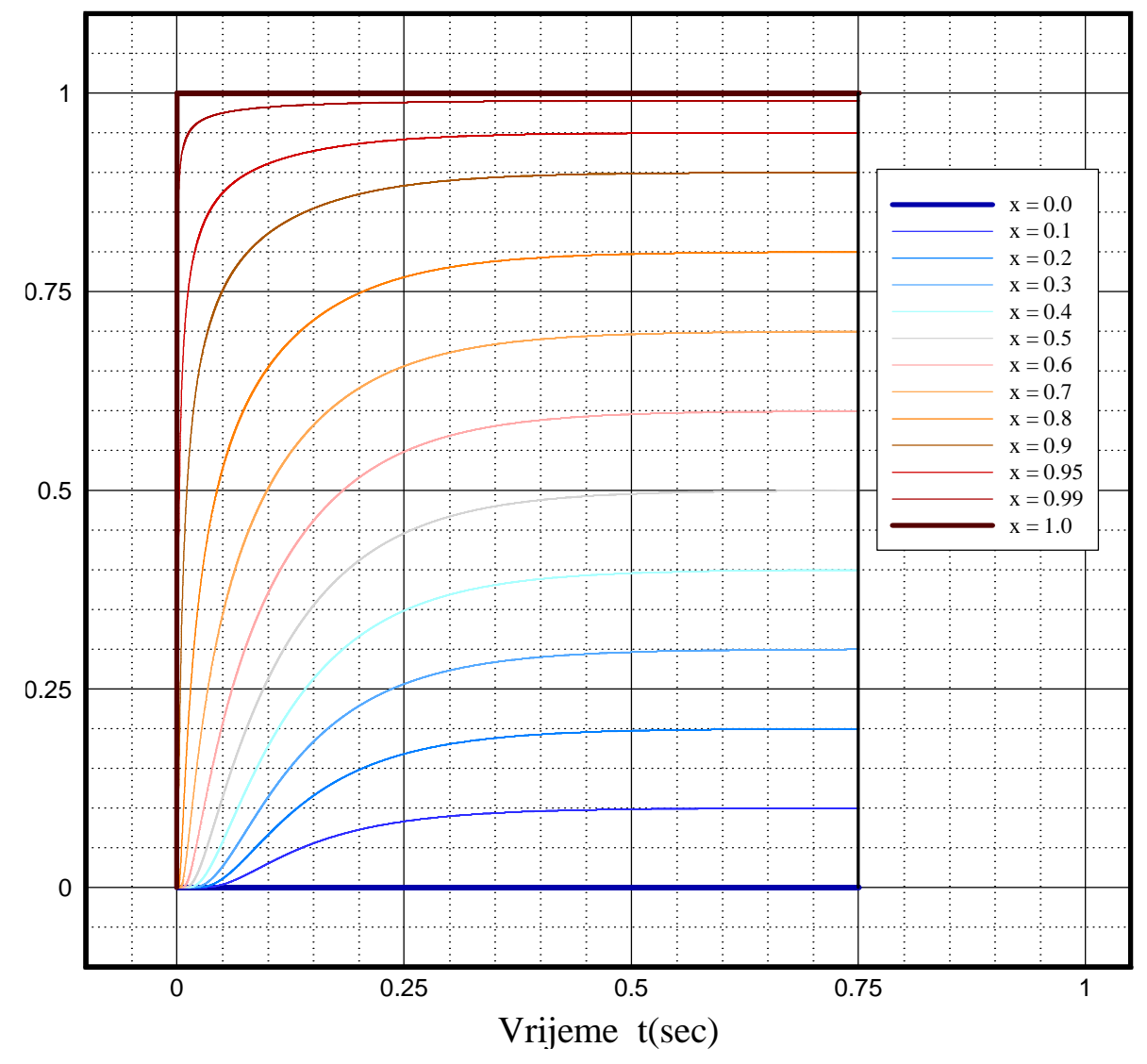

Crtež 7.22 Linije polja temperature $T\left(x_{i}, t\right), i=0, \ldots, 12$ 

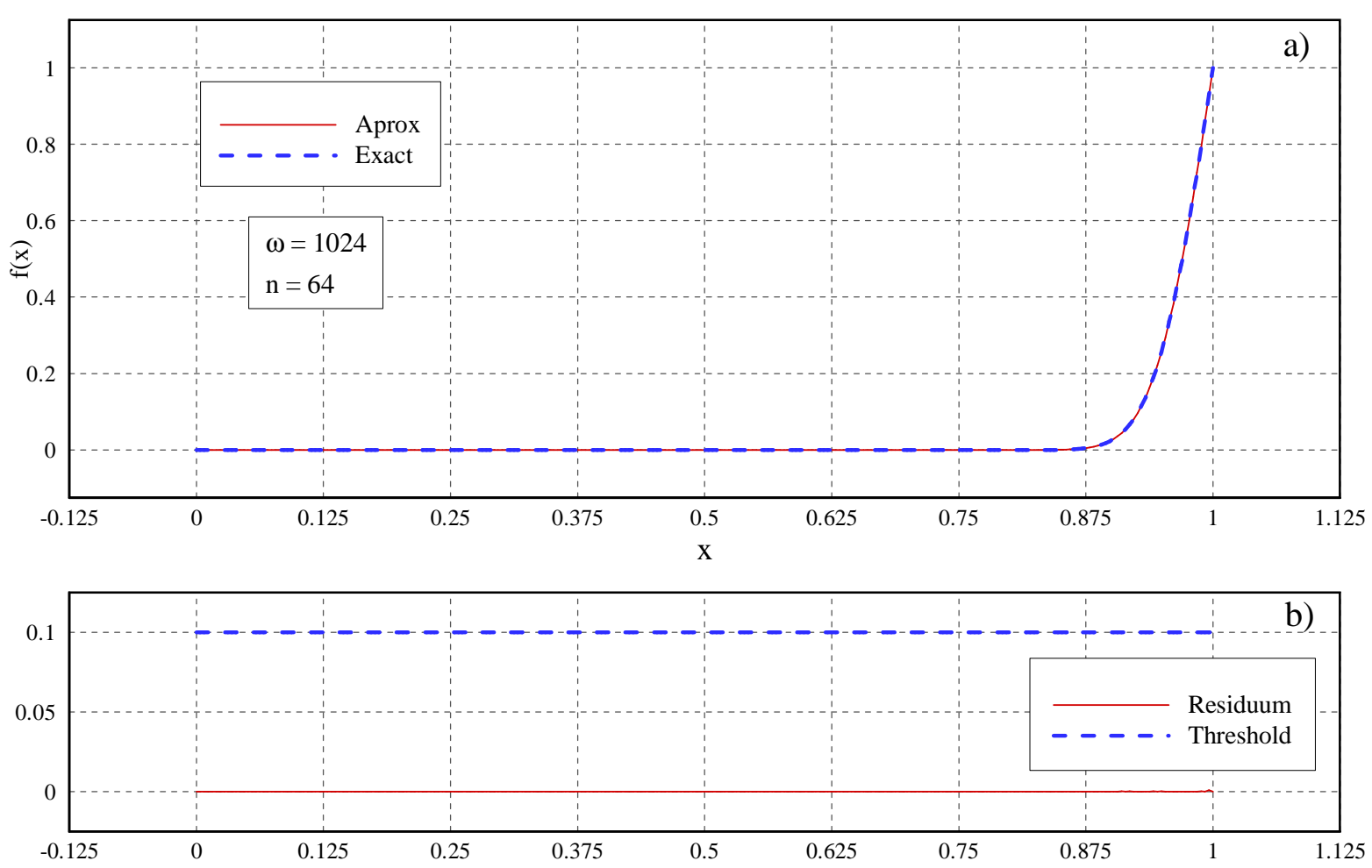

Crtež 7.23 Usporedba aproksimacije i analitičkog rješenja presjeka polja temperature $T(x, 0.001)$
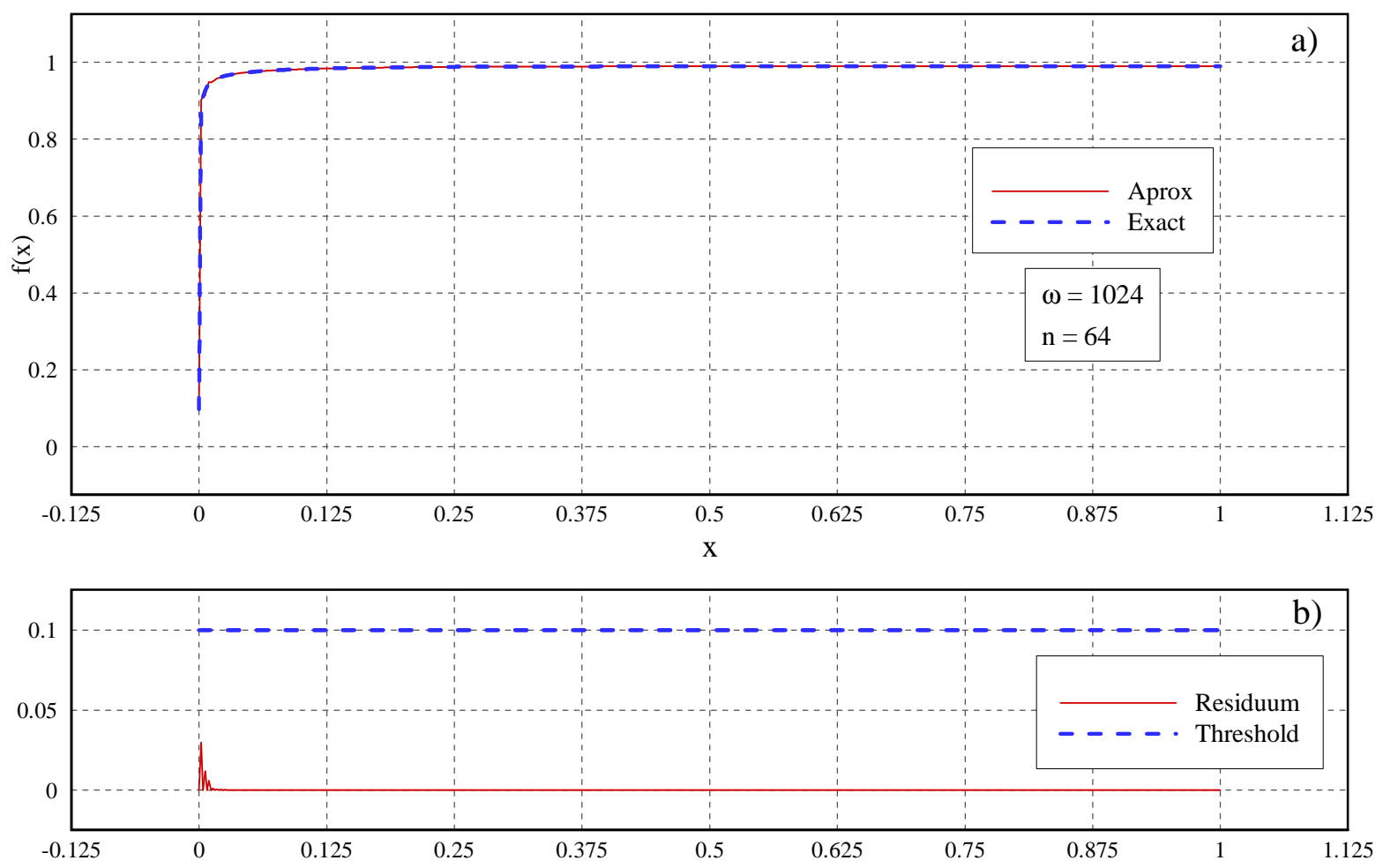

Crtež 7.24

Usporedba aproksimacije i analitičkog rješenja presjeka polja temperature $T(0.99 \cdot L, t)$ 


\section{ZAKLJUČCI I PRAVCI DALJNJIH ISTRAŽIVANJA}

U radu je dan kratak prikaz osnovnih svojstava baznih funkcija koje se koriste $\mathrm{u}$ numeričkim modeliranjima s obzirom da je izbor istih posebno važan zadatak u svim numeričkim metodama. Naglašena je prednost atomskih baznih funkcija algebarskog tipa koja znatno poboljšavaju kvalitetu numeričkih rješenja u odnosu na klasične bazne funkcije te npr. splineove i waveletove, što je potvrđeno nizom radova danih u uvodnom poglavlju. Upravo izvrsna svojstva ABF algebarskog tipa bila su motivacija za razvoj ABF eksponencijalnog tipa koja su širi prostor od algebarskih, štoviše prostor ABF algebarskog tipa je sadržan u prostoru $\mathrm{ABF}$ eksponencijalnog tipa.

Zato su još jednom sintetizirana dosadašnja znanja o algebarskim atomskim baznim funkcijama, i to o materinskoj algebarskoj funkciji $u p(x)$ te funkcijama $\operatorname{EFup}_{n}(x)$, ali na jedan nov i originalan način a to je polazeći od poznate Fourierove transformacije i teorema konvolucije. Opisana su njihova aproksimacijska svojstva, a izrazi za potrebne matematičke operacije su prikazani na jednostavniji, razumljiviji i korisniku prihvatljiviji način. Osim toga, postojećim izrazima pridruženi su i neki novi izrazi potrebni za njihovu primjenu u numeričkim metodama kao npr. skalarni produkti te modificirane rubne bazne funkcije.

O ABF eksponencijalnog tipa znalo se vrlo malo i bile su razvijene tek na osnovnoj razini u [5], [6]. Zadatak ove disertacije bio je detaljno istražiti njihova svojstva koristeći isti pristup kao kod ABF algebarskog tipa, i to materinske algebarske funkcije $\operatorname{Eup}(x, \omega)$ te funkcija $\operatorname{EFup}_{n}(x, \omega)$. Izvedeni su novi izrazi između kojih se posebno izdvaja izraz za izračunavanje vrijednosti funkcije i željenog broja derivacija u proizvoljnoj točki nosača bazne funkcije što je izvoran doprinos ovog rada, i što je osobito važno, pravila (elementi) za njihovo praktično 
korištenje. U sklopu disertacije napravljen je i programski modul EFupnM za praktičnu uporabu ovih funkcija kao i vlastita grafička podrška kako bi se glavni međurezultati neposredno mogli pratiti (Fortran - Winteracter).

Prikazana je trostruka baza te multirezolucijski postupak za rješavanje primjera aproksimacije funkcije te traženje približnog rješenja diferencijalnih jednadžbi i pripadajućih rubnih uvjeta na $1 \mathrm{D}$ primjerima iz različitih područja tehnike.

Numerički rezultati pokazuju izvrsna aproksimacijska svojstva ovih baznih funkcija, posebno u slučaju naglih promjena gradijenata zadane funkcije. Može se zaključiti da eksponencijalne ABF imaju prednost pred ostalim baznim funkcijama upravo u rješavanju problema s velikim gradijentima jer jedino one neće davati izražene oscilacije numeričkog rješenja.

U radu je pokazan izvorni znanstveni pristup u razvoju jedne klase baznih funkcija za primjenu u numeričkim metodama čiji znanstveni doprinos uključuje:

- Originalan pristup poznatim ABF algebarskog tipa uz nadopunu novih izraza potrebnih za njihovu primjenu

- Izvod novih i originalnih izraza za izračunavanje svih svojstava ABF eksponencijalnog tipa potrebnih za njihovu praktičnu primjenu s naglaskom na jednostavnost $\mathrm{i}$ inženjerski pristup

- Razvoj programskog modula te vlastite grafičke podrške kojim se primjena atomskih baznih funkcija eksponencijalnog tipa svodi na razinu korištenja korisničke ili kompajlerske funkcije

- Validacija i primjena novorazvijenih izraza te programskog modula na 1D verifikacijskim primjerima

U radu je usvojen kriterij za izbor parametra $\omega$ (frekvencije) baznih funkcija u izdvojenim 1D verifikacijskim primjerima aproksimacije funkcije te rješavanja diferencijalnih jednadžbi. Međutim, kao i kod eksponencijalnih splineova, ova složena problematika iziskuje još dodatnog istraživanja koje se namjerava provesti u sklopu daljnje primjene $\mathrm{ABF}$ eksponencijalnog tipa, kako u 1D problemima, tako i u višim dimenzijama prostora.

Prirodan slijed razvoja pojedine metode, pa tako i razvoja $i$ primjene ABF eksponencijalnog tipa vodi prema 2D i 3D numeričkim analizama, bilo da se radi o rubnim ili rubno - početnim problemima, gdje obje bazne funkcije u kartezijevom produktu mogu biti eksponencijalnog tipa, ali nisu isključene ni ostale varijante u produktu. Poseban naglasak ostaje na problemima čija rješenja imaju izražene gradijente s obzirom da su i u radu ABF 
eksponencijalnog tipa pokazale prednost u odnosu na bazne funkcije algebarskog tipa. Osim problema iz primijenjene teorije elastičnosti s npr. koncentriranim opterećenjima, područje interesa su i npr. problemi provođenja topline u elementima inženjerskih konstrukcija ili pronosa zagađenja u podzemlju.

Prednost ABF eksponenencijalnog tipa posebno može doći do izražaja u „multiphysics” problemima gdje se nelinearne parcijalne diferencijalne jednadžbe (PDJ) simultano rješavaju u prostornoj i vremenskoj domeni. U tim problemima konvergencija numeričkog rješenja značajno ovisi o početnim uvjetima i tipu PDJ. Općenito, PDJ koje su pretežno hiperboličke teže je numerički rješavati nego paraboličke. Početni uvjeti koji opisuju nagle frontove zahtjevaju više nivoe rezolucije da bi se postigla tražena točnost aproksimacije, što ima za posljedicu gušću mrežu kako bi se mogli opisati ovi diskontinuiteti. Upravo eksponencijalne ABF mogu zadovoljiti traženu točnost na samom početku vremenskog procesa.

ABF eksponencijalnog tipa su pogodne i za primjenu adaptivnih postupaka jer se sažimanjem baznih funkcija istovremeno povećava i frekvencija tako da se konvergencija postupka postiže pomoću dva paralelna kriterija iz čega slijedi da bi se bolja rješenja morala dobiti s daleko manjim brojem baznih funkcija.

$S$ obzirom da je u radu prikazan jedan originalan i inženjerski pristup prema poznatim ABF algebarskog tipa, te eksponencijalnim ABF kao izvornom doprinosu rada, ovaj rad predstavlja i jednu dobru polaznu osnovu za razvoj trigonometrijskih ABF čime bi se zaokružila ,trilogija” o atomskim baznim funkcijama. Naime, elementarna rješenja običnih diferencijalnih jednadžbi s konstantnim koeficijentima su upravo algebarski polinomi te eksponencijalne i trigonometrijske funkcije. 


\section{LITERATURA}

[1] Brajčić Kurbaša, N., Gotovac, B., Kozulić, V. Numerical modeling of the boundary value problems using the R-function method and Atomic basis functions. ECCOMAS Congress CDROM Proceedings. Vienna (2012): 1-14.

[2] Bronštejn, I.N., Demendjajev, K.A. (1964) Matematički priručnik za inženjere i studente. Tehnička knjiga, Zagreb.

[3] Čolak, I. (2000) Numerical modeling of bending thin sheets of the general form. Ph.D. Thesis, Faculty of Civil Engineering, University of Mostar, Mostar (in Croatian)

[4] Dyn, N., Ron, A.: Multiresolution analysis by infinitely differentiable compactly supported Functions. Appl. And Comput. Harmonic Analysis. 2, 15-20 (1992).

[5] Gorshkov, A.S., Kravchenko, V.F., Rvachev, V.L.. Atomic Exponential Functions. Physics - Doclady, vol 39, No 5, 1994, pp. 297-299. Translated from Doklady Akademii Nauk, vol 336, No 3, 1994, pp. 309-311.

[6] Gotovac, B. (1986) Numerical modelling of engineering problems by smooth finite functions. Ph.D. Thesis, Faculty of Civil Engineering, University of Zagreb, Zagreb. (In Croatian)

[7] Gotovac, B.; Kozulić, V. On a selection of basis functions in numerical analyses of engineering problems. International Journal for Engineering Modelling. 12 (1999.), 1-4; 2541.

[8] Gotovac, B.; Kozulić, V. FFCM in elasto-plastic analysis of the torsion of prismatic bars. CD-Rom Proceedings of the VIIIth International Conference Numerical Methods in 
Continuum Mechanics (NMCM 2000). Liptovský Ján, Slovak Republic : University of Žilina, 2000. 16 str.

[9] Gotovac, B., Kozulić, V. Numerical solving of an initial-value problem by Rbf basis functions of algebraic polynomials class. Proceedings of the 3rd International Congress of Croatian Society of Mechanics. Cavtat - Dubrovnik : Croatian Society of Mechanics, 2000. 121-128.

[10] Gotovac, B., Kozulić, V. Analyses of Thin Plate Bending by Fup Fragment Collocation Method. Proceedings of the Euroconference on Computational Mechanics and Engineering. Szczyrk: Wydawnictwo Politechniki Lodzkiej Filii w Bielsku-Bialej, 2001. 156-161.

[11] Gotovac, B., Kozulić, V. Application of FFCM in the analysis of thin plate bending problem. Zbornik seminarja Gradbena informatika. Ljubljana : Univerza v Ljubljani, FAGG, IKPIR, 2001. 111-118.

[12] Gotovac, B., Kozulić, V. Numeričko rješavanje početnih problema pomoću Rbf baznih funkcija. Zbornik 2 Građevinskog fakulteta Sveučilišta u Mostaru. Mostar : Građevinski fakultet Sveučilišta u Mostaru, 2002. 135-160.

[13] Gotovac, B., Kozulić, V. Numerical solving of initial-value problems by Rbf basis functions. Structural engineering and mechanics. 14 (2002), 3; 263-285.

[14] Gotovac, H., Andričević, R., Gotovac, B., Vranješ, M., Radelja, T. Multilevel adaptive modeling of multiphase flow in porous media. Computational Methods in Multiphase Flow III. Southampton, Boston : WIT Press, 2005. 95-111

[15] Gotovac, H., Andričević, R., Gotovac, B. Multi-resolution adaptive modeling of groundwater flow and transport problems. Advances in Water Resources. 30 (2007), 5; 11051126.

[16] Gotovac, H., Gotovac, B. Maximum entropy algorithm with inexact upper entropy bound based on Fup basis functions with compact support. Journal of Computational Physics. 228 (2009), 24; 9079-9091.

[17] Gotovac, H., Kozulić, V., Gotovac, B. Numerical Solving of Boundary-Initial Value Problems using Space-Time Adaptive Fup Collocation Method. Proceedings of the 6th International Congress of Croatian Society of Mechanics. Zagreb: Hrvatsko društvo za mehaniku, 2009. 1-8. 
[18] Gotovac, H., Kozulić, V., Gotovac, B. Modeling of boundary-initial value problems using an adaptive meshless method. CD-Rom Proceedings of the 7th EUROMECH Solid Mechanics Conference. Lisbon : Portuguese Association for Theoretical, Applied and Computational Mechanics, 2009. 1-14.

[19] Gotovac, H., Kozulić, V., Gotovac, B. Space-Time Adaptive Fup Multi-Resolution Approach for Boundary-Initial Value Problems. Computers, materials \& continua. 15 (2010), 3; 173-198.

[20] Hilberg W. Impulse und Impulsfolgen, die durch Integration oder Differentiation in einem veränderten Zeitmaütab reproduziert warden, Arkiv für Elektrizität und Übertragung Technik (AEU), Band 25, Heft 1, 39-48 (1971).

[21] Kadalbajoo, M. K., Aggarwal, V. K.: Fitted mesh B-spline collocation method for solving self-adjoint singularly perturbed boundary value problems. Applied Mathematics and Computation. 161, 973-987 (2005).

[22] Kolodyazhny, V.M., Rvachev, V.A.: Atomic functions: Generalization to the multivariable case and promising applications. Cybernetics and Systems Analysis. 43, 893-911 (2007).

[23] Konovalov, Y.Y., Kravchenko, O.V.: Application of new family of atomic functions cha,n to solution of boundary value problems, Days on Diffraction, IEEE, (2014)

[24] Kozulić, V. (1999) Numerical modeling by the fragment method with Rbf functions, Ph.D. Thesis, Faculty of Civil Engineering, University of Split, Split (in Croatian)

[25] Kozulić, V., Gotovac, B. Numerical analyses of 2D problems using Fup $(\mathrm{x}, \mathrm{y})$ basis functions. International Journal for Engineering Modelling. 13 (2000), 1-2; 7-18.

[26] Kozulić, V., Gotovac, B. Numerical solving of an initial-value problem by Rbf basis functions of trigonometric polynomials class. Proceedings of the 3rd International Congress of Croatian Society of Mechanics. Cavtat - Dubrovnik : Croatian Society of Mechanics, 2000. 113-120.

[27] Kozulić, V., Gotovac, B. Elasto-plastic analysis of the torsion by FFCM. Zbornik seminara Gradbena informatika 2001. Ljubljana : Univerza v Ljubljani, FAGG, IKPIR, 2001. 119-126. 
[28] Kozulić, V., Gotovac, B. Elasto-Plastic Analysis of Structural Problems Using Atomic Basis Functions. Computer modeling in engineering \& sciences. 80 (2011), 3-4; 251-274.

[29] Kozulić, V., Gotovac, B. Multilevel Meshless Model for the Elasto-Plastic Torsion of Prismatic Bars. ECCOMAS 2012 Congress CD-ROM Proceedings. Vienna: Vienna University of Technology, 2012. 1-16

[30] Kozulić, V., Gotovac, B., Čolak, I. Multilevel Mesh Free Method for the Torsion Problem. International Scientific Symposium Modeling of Structures - Proceedings. Mostar : University of Mostar, 2008. 281-304.

[31] Kozulić, V., Gotovac, B., Gotovac, H., Radelja, T. Numerical solving of problems with high gradients using adaptive multiresolution method. Proceedings of the 5th International Congress of Croatian Society of Mechanics. Zagreb:Croatian Society of Mechanics, 2006. 1-8 [32] Kozulić, V., Gotovac, H., Gotovac, B. An Adaptive Multi-resolution Method for Solving PDE's. Computers, materials \& continua. 6 (2007), 2; 51-70.

[33] Kravchenko, V.F., Rvachev, V.A., Rvachev, V.L.: Mathematical methods for signal processing on the basis of atomic functions, Radiotekhnika i Elektronika, 40 (9), 1385 (1995).

[34] Kravchenko, V.F., Basarab, M.A., Perez-Meana, H.: Spectral properties of atomic functions used in digital signal processing. J. Commun. Technol. Electron., vol. 46, pp. 494511. (2001)

[35] Kvasov, B.I.: Algorithms for Shape Preserving Local Approximation with Automatic Selection of Tension Parameters. Computer Aided Geometric Design. 17, 17-37 (2000).

[36] Marušić M., Rogina M.: A Collocation Method for Singularly Perturbed Two-point Boundary Value Problems with Splines in Tension. Advances in Computational Mathematics. 6, 65-76 (1996).

[37] McCartin, B.J. (1981) Theory, computation, and application of exponential splines. Courant Mathematics and Computing Laboratory Research and Development Report,.

[38] Radunović, D.: Multiresolution exponential B-splines and singularly perturbed boundary problem. Numer. Algor. 47, 191-210 (2008).

[39] Rao, S.C.S., Kumar, M.: Exponential B-spline collocation method for self-adjoint singularly perturbed boundary value problems. Applied Numerical Mathematics. 58, 1572$1581(2008)$. 
[40] Rudin W. (1973) Functional Analysis, McGraw-Hill Publishing Co., USA.

[41] Rvachev V. L. and Rvachev V. A., "A certain finite function," Dokl. Akad. Nauk UkrSSR, Ser. A, No. 8, 705-707 (1971).

[42] Rvachev V.L., Rvachev V.A.: Atomic Functions in Mathematical Physics. Mathematization of Knowledge and Scientific and Technological Advance, Naukova Dumka, Kiev pp. 188-199 (1975).

[43] Rvachev, V.L., Rvachev, V.A. (1979) Nonclassical methods of approximation theory in boundary value problems. Kiev: Naukova Dumka.

[44] Rvachev V. A., "Atomic functions and their applications," in: Theory of R-Functions and Topical Problems of Applied Mathematics, Naukova Dumka, Kiev (1986), pp. 45-65.

[45] Rvachev, V. L.; Sheiko, T. I. R-functions in boundary value problems in mechanics. Applied Mechanics Reviews, 1995. 48(4):151-188

[46] Sjerjeda J.U. F. Nekotorije svojstva finitnih rješenii diferencijalnovo uravnerija s ozklonjajušćimsja argumentom, UDK 517.943 